\title{
Exploitation and Optimization of Reservoir Performance in Hunton Formation, Oklahoma
}

\section{FINAL TECHNICAL REPORT}

\author{
Submitted by \\ Dr. Mohan Kelkar \\ Department of Petroleum Engineering \\ The University of Tulsa \\ 600 S. College Avenue \\ Tulsa, Oklahoma 74104-3189
}

Contract Date: March 7, 2000

Completion Date: June 30, 2007

Reporting Period: April 1, 2000 - June 30, 2007

Date Issued: August 27, 2007

DOE Contract No. DE-FC26-00NT15125

\section{Prepared for}

U.S. Department of Energy Assistant Secretary for Fossil Energy

Contracting Officer's Representative:

Mr. Purna Halder

U.S. Department of Energy

National Petroleum Technology Office/DOE

Post Office Box 3628

Tulsa, Oklahoma 74103 


\section{Disclaimer}

This report was prepared as an account of work sponsored by an agency of the United States Government. Neither the United States Government nor any agency thereof, nor any of their employees, makes any warranty, express or implied, or assumes any legal responsibility for the accuracy, completeness, or usefulness of any information, apparatus, product, or process disclosed, or represents that its use would not infringe privately owned rights. Reference herein to any specific commercial product, process, or service by trade name, trademark, manufacturer, or otherwise does not necessarily constitute or imply its endorsement, recommendation, or favoring by the United States Government or any agency thereof. The views and opinions of authors expressed herein do not necessarily state or reflect those of the United States Government or any agency thereof. 


\begin{abstract}
Hunton formation in Oklahoma has been the subject of attention for the last ten years. The new interest started with the drilling of the West Carney field in 1995 in Lincoln County Subsequently, many other operators have expanded the search for oil and gas in Hunton formation in other parts of Oklahoma. These fields exhibit many unique production characteristics, including:

1) decreasing water-oil or water-gas ratio over time;

2) decreasing gas-oil ratio followed by an increase;

3) poor prediction capability of the reserves based on the log data;

4) low geological connectivity but high hydrodynamic connectivity.

The purpose of this investigation is to understand the principal mechanisms affecting the production, and propose methods by which we can optimize the production from fields with similar characteristics.
\end{abstract}




\section{Table of Contents}

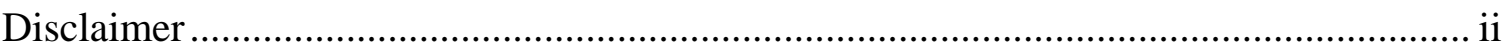

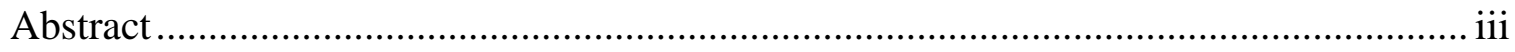

Table of Contents ......................................................................................................... iv

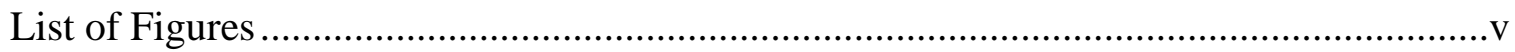

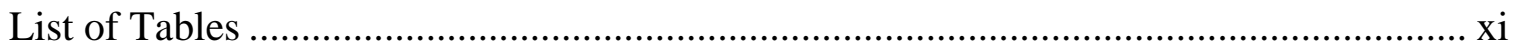

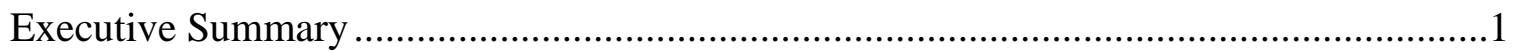

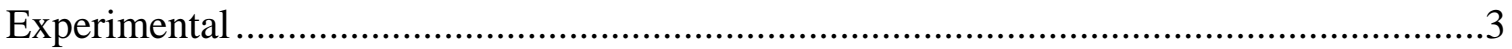

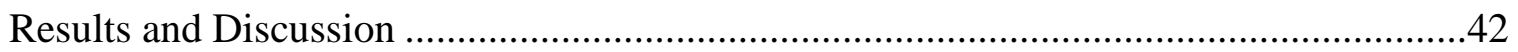

Engineering and Geological Analysis..........................................................................42

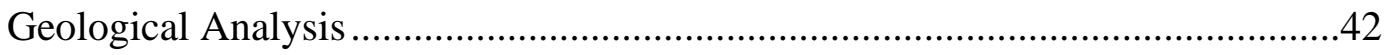

Fluid Properties Analysis..................................................................................66

Petrophysical Properties Analysis.......................................................................71

Material Balance Analysis ................................................................................120

Dynamic Data Analysis ....................................................................................147

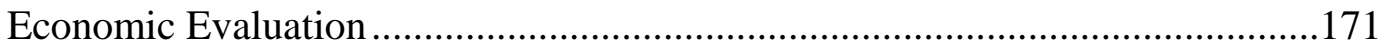

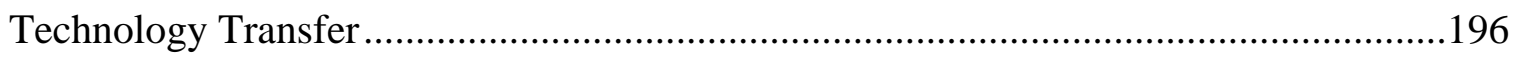

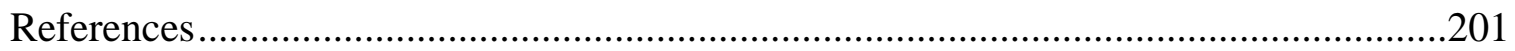

Appendices

Appendix A - Geological Analysis ..................................................................204

Appendix B - Fluid Properties Analysis ...........................................................212

Appendix C - Material Balance Analysis.........................................................216 


\section{List of Figures}

Figure

Description

Page

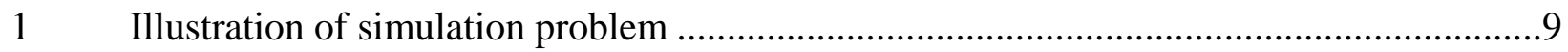

2 Cross-sectional CT scan at 2, 4, and $6 \mathrm{~cm}$ from one side of Core 3 ..............................12

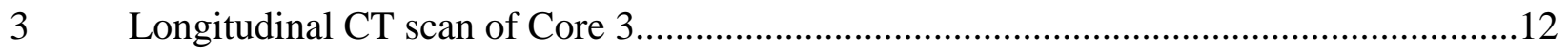

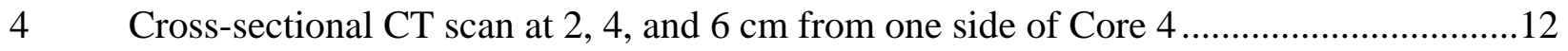

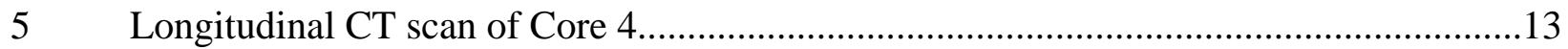

6 Cross-sectional CT scan at 2, 4, and $6 \mathrm{~cm}$ from one side of Core 8.............................13

$7 \quad$ Imbibition relative permeability of Mary Marie 4968.6-7 (Cores 3-4) ............................15

8 Imbibition relative permeability of Wilkerson 4974.9 (Core 5) ...................................15

$9 \quad$ Imbibition relative permeability of Carter 4995.2 (Core 6$)$ )..........................................16

10 Drainage relative permeability of Mary Marie 4968.6-7 (Cores 3-4) ............................16

11 Drainage relative permeability of Wilkerson 4974.9 (Core 5) ....................................17

12 Drainage relative permeability of Carter 4995.2 (Core 6) ............................................17

13a Horizontal thin-section of Mary Marie 4968.6-7 (Cores 3-4) .........................................18

13b Horizontal thin-section of Mary Marie 4968.6-7 (Cores 3-4) .......................................18

14a Horizontal thin-section of Wilkerson 4974.9 (Core 5) ....................................................19

14b Vertical thin-section of Wilkerson 4974.9 (Core 5) ......................................................19

15a Horizontal thin-section of Carter 4995.2 (Core 6) .......................................................20

15b Vertical thin-section of Carter 4995.2 (Core 6) ...........................................................20

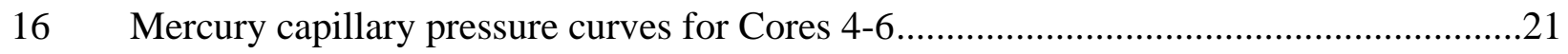

17 Correlation between absolute permeability, porosity and wettability ............................22

18 Correlation between end point water imbibition relative permeability and wettability ....22

19 Contact angle change with time, at large times we get equilibrium contact angle...........23

20 Photograph of the core after treatment with surfactant F, indicating change in wettability of the surface. The drop of brine does not imbibe spontaneously into the rock ...............28

21 Spontaneous imbibition in carbonate cores at room temperature for case of untreated core, core treated with surfactant $\mathrm{D}$ and core treated with surfactant $\mathrm{F}, \mathrm{S}_{\mathrm{wi}}=0 \%$, and $\mathrm{k}=$ $120 \mathrm{mD}$. 
22 Residual permeability of gas for treated and untreated cores at different pressure drops

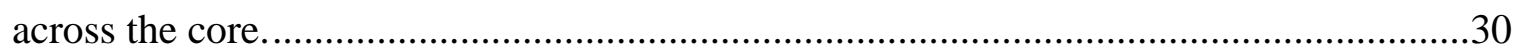

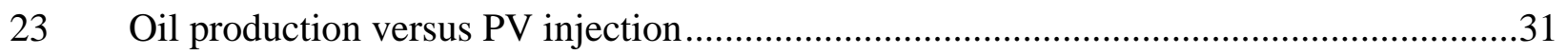

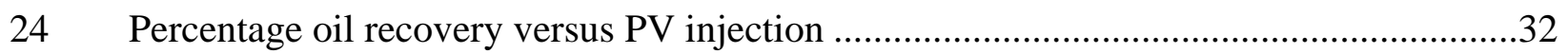

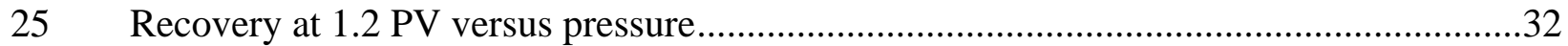

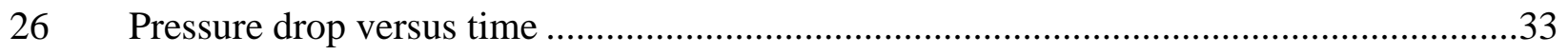

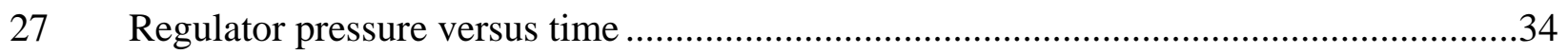

28 Percentage oil recovery versus regulator pressure.............................................................34

$29 \quad$ Percentage oil recovery versus time ……………..............................................................35

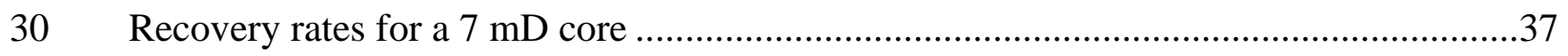

31 Scaling of $0.001 \mathrm{mN} / \mathrm{m}$ IFT reduction and 750 final contact angle curve with

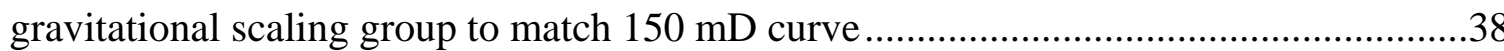

32 Scaling of $0.001 \mathrm{mN} / \mathrm{m}$ IFT reduction and 750 final contact angle curve with capillary scaling group to match $150 \mathrm{mD}$ curve.....

33 Effect of wettability alteration for a surfactant which lowers IFT to $1 \mathrm{mN} / \mathrm{m}$ for $7 \mathrm{mD}$ porous media

34 Effect of wettability alteration for a surfactant which lowers IFT to $0.001 \mathrm{mN} / \mathrm{m}$ for $7 \mathrm{mD}$ porous media......

35 Stratigraphic chart for Hunton Group, comparing Arbuckle Mountain sequence (modified from Stanley, 2001, fig. 2), with the West Carney Hunton Field sequence, labeled local stratigraphy, by Barrick and Derby

$36 \quad 17$ wells in the west, north, and east sides of the fields ...................................................52

3712 wells from the central part of the field, T15N-R2E .................................................53

38 Sea level curve for the Silurian (from Johnson, 1996). Sea level rise \#2 equates to deposition of the Lower Cochrane, \#3 to the Upper Cochrane A, \#4 to the Upper Cochrane B, and \#5 to the Lower Clarita. .55

39 West-East stratigraphic cross-section of West Carney Hunton Field.

40 Comparison of reef platform vs. ramp environments of deposition (figure 4, Stanley, 2001)

41 Facies model for Early Silurian Shores and Shelves of North America and Siberia. B.A. 0 - 6 indicate Benthic Assemblage zones (from M. Johnson, et al., 1997). 
$42 \quad$ Non-regressed phase plot .............................................................................................68

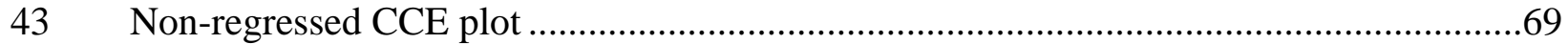

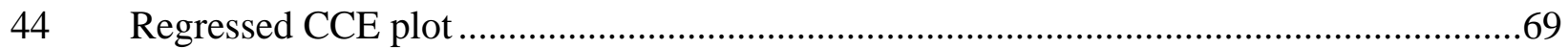

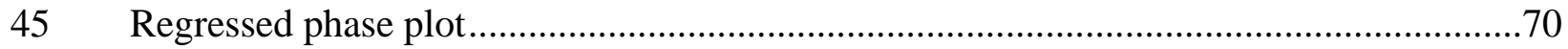

46 Screen plot showing the different principal components and their variance percentage...74

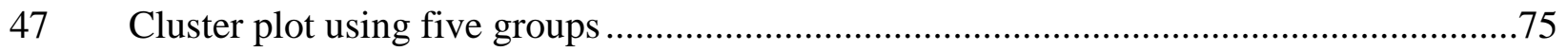

48 Comparison of electrofacies with geological pore types ..................................................76

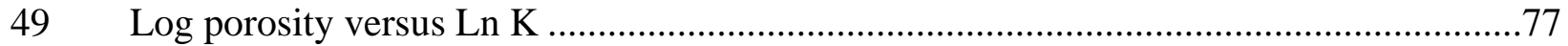

50 Correlation between log porosity and core porosity …………………..........................

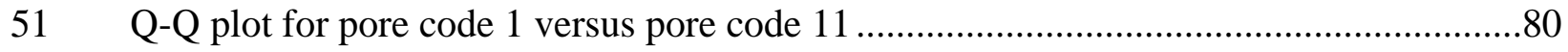

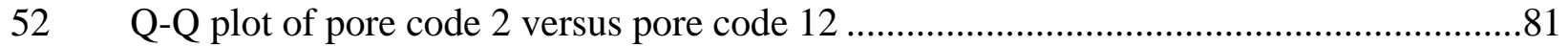

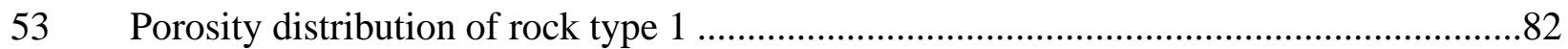

$54 \quad$ Porosity distribution of rock type 2 …………............................................................82

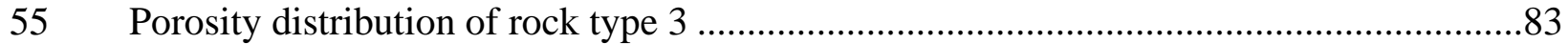

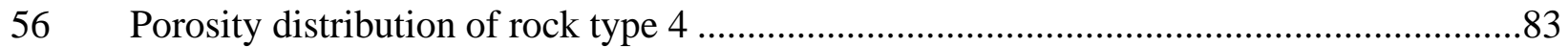

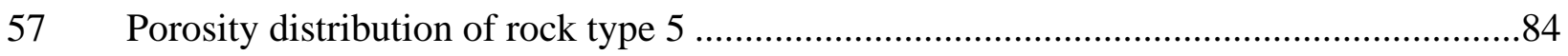

$58 \quad$ Log k versus porosity relationship for rock type 1 ..........................................................85

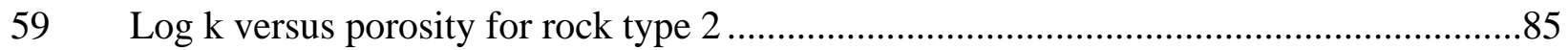

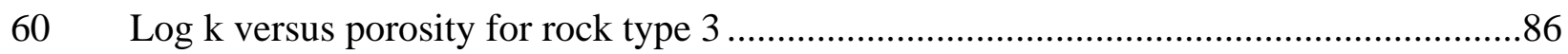

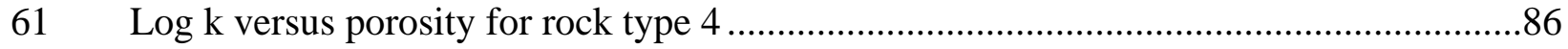

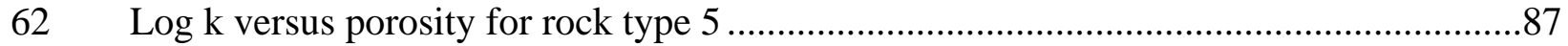

63 Rock type distribution for porosity in the range of 0 to $2 \%$..............................................8

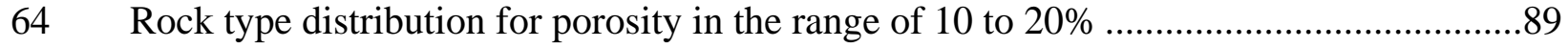

65 A typical Pickett plot .....................................................................................................

66 Pickett plot for the well Danny \#2; legend: ef = electrofacies........................................92

$67 \quad$ Production from well Danny \#2 ......................................................................................

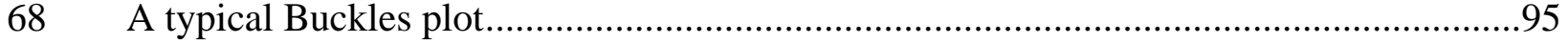

69 Buckles plot for limestone with coarse matrix and vuggy pore types; Legend: $\mathrm{cr}=$ coarse matrix .

70 Buckles plot for limestone with fine matrix and fracture pore types; legend: $f=$ fine matrix and $\mathrm{fr}=$ fracture 
71 Buckles plot for dolomite and partly dolomitized limestone with coarse matrix and vuggy pore types; legend: $\mathrm{cr}=$ coarse matrix

72 Areal map of the areas studied.

73 Average oil saturation versus average porosity .....

74 Average oil saturation versus standard porosity

75 Q-Q plot of porosity for CE versus CW regions........................................................104

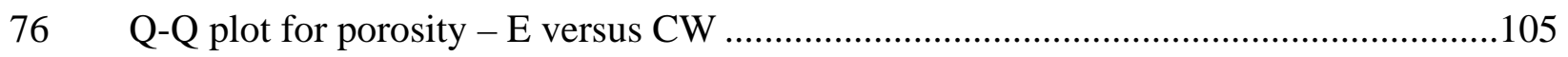

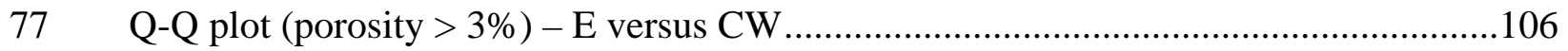

78 Q-Q plot for resistivity (porosity > 3\%) - E versus CW ………………………...............106

79 Oil in place (OIP) for Central West region ......................................................................109

80 Oil in place (OIP) for Central East region ..................................................................110

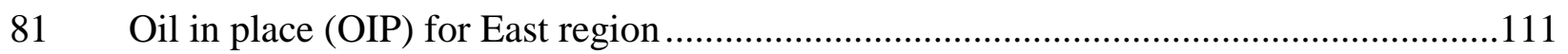

82 Oil in place (OIP) for West region..........................................................................112

83 Oil in place (OIP) for Alabama...........................................................................113

84 Oil in place (OIP) for Chandler ..............................................................................114

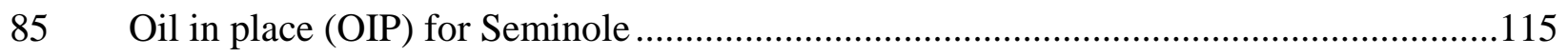

86 Reserves versus gas in place ...............................................................................119

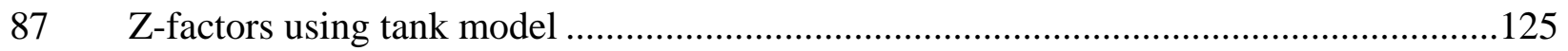

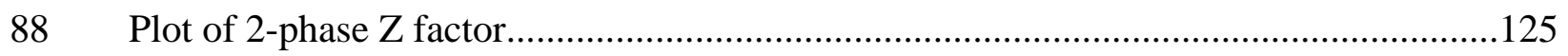

$89 \quad$ Map of West Carney field regions .................................................................................127

90 Material balance West Carney region..........................................................................127

91 Material balance Central West Carney region ................................................................128

92 Material balance Central East Carney region ..................................................................128

93 Material balance East Carney region ..............................................................................129

94 Cumulative production from East Carney field ............................................................138

95 Cumulative water production from West Carney field........................................................139

96 Cumulative water production from Central West Carney ................................................139

97 Cumulative water production from Central East Carney.......................................................140

98 Gas to water relative permeability ratios for East Carney field.........................................142

99 Gas to oil relative permeability ratios for East Carney field ...............................................143

100 Flow diagram for predicting future performance.............................................................144

The University of Tulsa viii DE-FC26-00NT15125 24 August 2007 
101 Comparison of predicted versus observed oil production for East Carney field. .145

102 Cumulative gas production for East Carney - predicted versus observed.........................145

103 Cumulative water production of East Carney - predicted versus observed ......................146

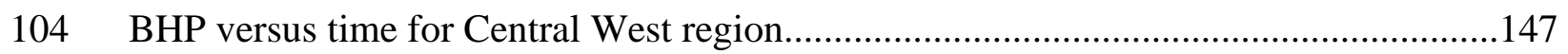

105 Water production versus time for Central East region..........................................................148

106 Gas reserves versus time for Central West region .............................................................149

107 Oil reserves versus time for Central West region .............................................................149

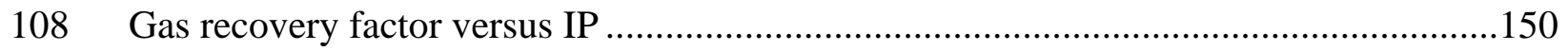

109 Oil recovery factor versus IP ...................................................................................151

110 Equivalent gas reserves versus IP for Central West .......................................................152

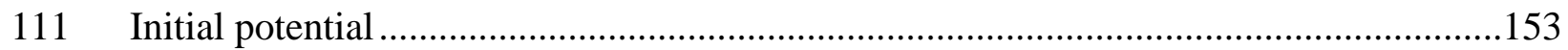

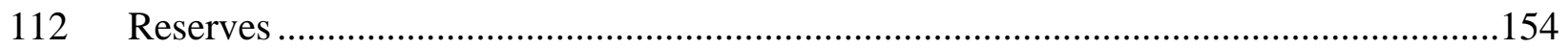

113 Gas recovery versus no. of wells for Central West region .............................................155

114 Oil recovery versus no. of wells for Central West region.................................................156

115 Gas recovery versus no. of wells for Central East region....................................................156

116 Oil recovery versus no. of wells for Central East region .................................................157

117 Gas recovery versus no. of wells for East region...........................................................157

118 Oil recovery versus no. of wells for East region............................................................158

119 Gas recovery versus no. of wells for West region ...........................................................

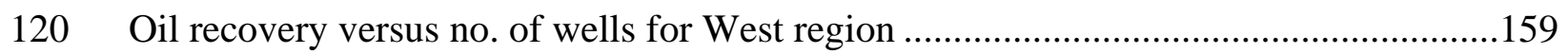

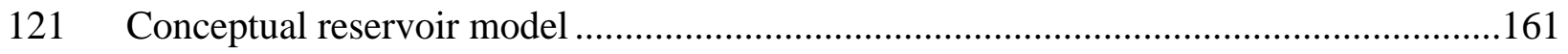

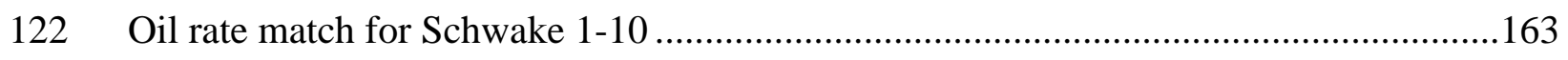

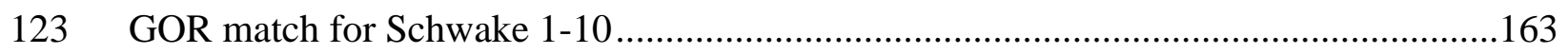

124 GOR match for Schwake (300 days) ...........................................................................164

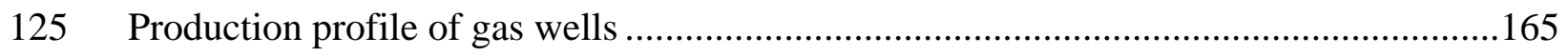

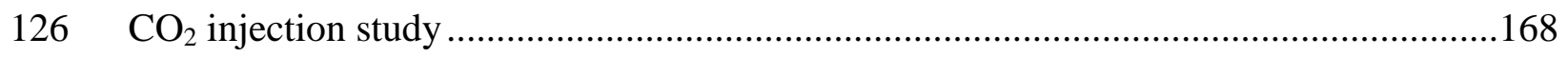

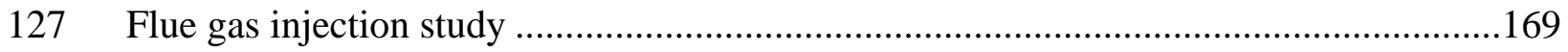

128 Methane injection study .....................................................................................170

129 Average NPV for vertical wells in East Carney ..........................................................174

130 Average NPV (M\$) for Eastern Carney region ...............................................................175

131 Average NPV (M\$) for Central Carney region.................................................................177

The University of Tulsa ix

DE-FC26-00NT15125 24 August 2007 
132 Average NPV (M\$) for West Carney region ........................................................178

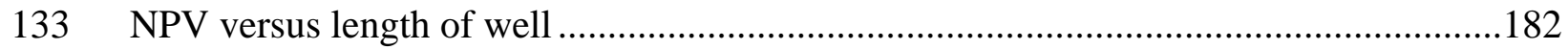

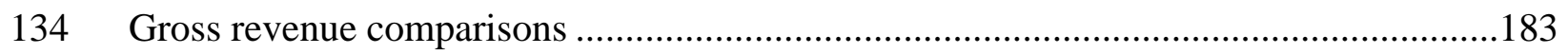

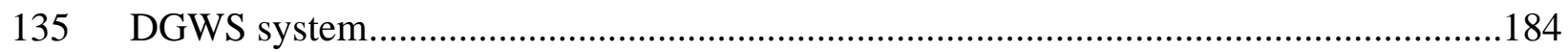

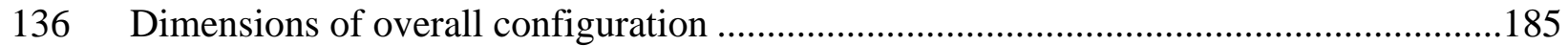

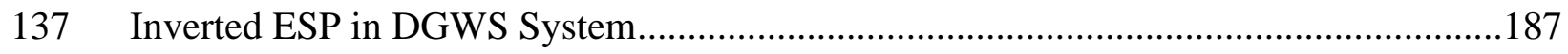

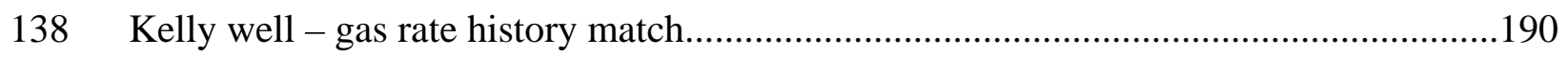

139 Water rate history match - Kelly well .................................................................191

140 Gas/water relative permeability ratio for Wall $1-9$...................................................193

141 Gas/water relative permeability ratio for Sumner 1-13 ............................................194 


\section{List of Tables}

Table

Description

Page

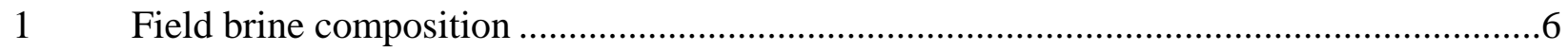

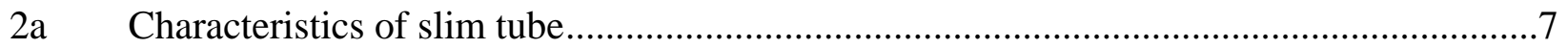

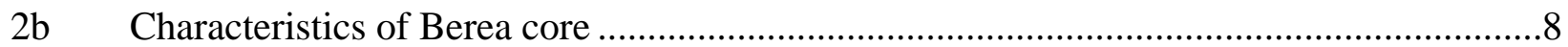

3 Properties of the core used for imbibition......................................................................10

$4 \quad$ List of cores.....................................................................................................

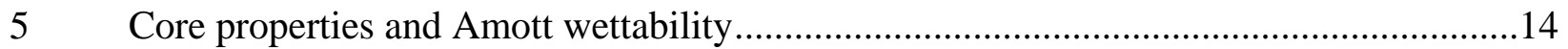

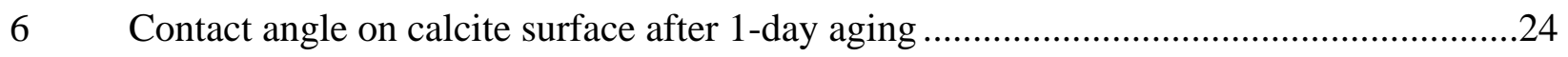

$7 \quad$ Contact angle on silica surface after 1-day aging ...............................................................24

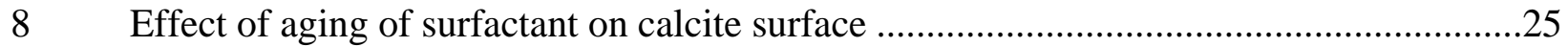

$9 \quad$ Stability of deposited film in field brine calcite surface .................................................25

10 Effect of surfactant concentration on calcite contact angle .................................................26

11 Effect of surfactant concentration on silica contact angle ...............................................26

12 Effect of solvent in surfactant solution preparation on wettability ....................................27

13 Properties of the carbonate cores used for spontaneous imbibition....................................27

14 Cored wells in West Carney Hunton field, alphabetical....................................................44

15 Cored wells in West Carney Hunton field - thickness, core/log adjustment data..............45

16 Explanation of coding of porosity types .........................................................................

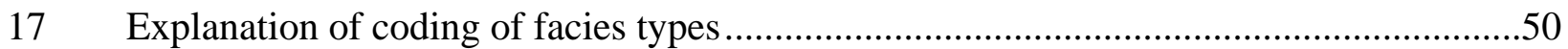

18 Petrophysical, electrofacies and production characteristics of some of the wells ..............94

19 Summary of saturation and porosity data from different regions .....................................102

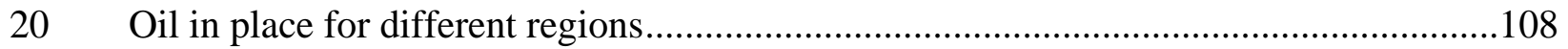

21 Recoverable reserves based on individual wells............................................................116

22 Recoverable reserves in West Carney based on regional decline....................................117

$23 \quad$ Gas and oil recovery factors for different regions ..........................................................118

24 Back-calculated two-phase Z factors ...........................................................................124

25 Comparison of equivalent gas in place values ...............................................................129

26 Comparison of recovery factors..............................................................................130

The University of Tulsa

DE-FC26-00NT15125 24 August 2007 
$27 \quad$ Final oil and water saturation from oil and gas recovery factor ..................................134

28 Final water saturation from prorated water production ............................................135

29 New water production to match final water saturation from gas RF ............................136

30 Optimal parameters for four fields...................................................................141

31 Average oil and gas reserves compared with average IP for different operators ............152

32 Parameter values from history match ....................................................................162

33 Wells studied in East Carney region....................................................................173

$34 \quad$ Wells studied in Central Carney region ..................................................................176

35 Wells studied in Western Carney region ...............................................................179

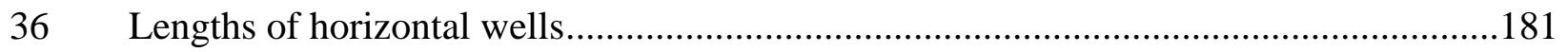

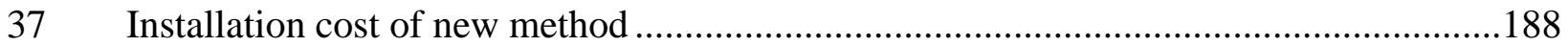

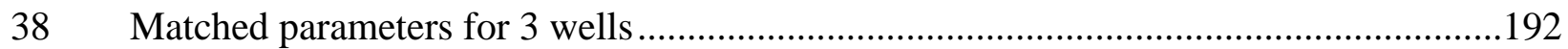

39 Payback period for each well using two methods...................................................194 


\section{Executive Summary}

\section{Primary Mechanism}

Based on our analysis, we have developed a possible reservoir model and the mechanism by which oil and gas are produced. In Hunton formation, the original oil present was displaced by natural water influx in geological times. Some of the oil was displaced and moved to a shallower formation, while some remained trapped in Hunton formation. The amount of trapped oil, which mostly remained in relatively tighter rock, is a function of porosity and homogeneity of the reservoir. The trapped oil was at bubble point and is present in the low porosity areas of the reservoir. Most of the water is present in continuous form and is present in high permeability regions. When a well is put to production, the water present in the high permeability zones of the reservoir is produced first. As a result of this water production, the pressure in the reservoir decreases, as the reservoir is supported by a limited aquifer. Due to water production and pressure depletion, gas is liberated from the oil. Since gas is more mobile than oil, the released gas reaches the production well first and, hence, the initial high gas-oil ratio (GOR). In some cases, where the oil saturation is very low, the oil saturation can never exceed critical oil saturation. As a result, the well never produces oil, only gas. Many wells in the West region, where the oil saturation is very low, only produce gas. At high oil saturations, oil eventually exceeds critical oil saturation and starts moving. As oil is produced, the GOR decreases. As oil and gas reach the producing well, both water-oil ratio (WOR) and water-gas ratio (WGR) decrease over time. As the reservoir pressure depletes, the water rate decreases and so does the oil and gas production. As more and more gas comes out of the solution, the GOR starts increasing as in traditional solution gas drive reservoirs. The recovery factors for oil tend to be lower than conventional solution gas drive reservoirs because part of the gas expansion energy is utilized for producing water rather than oil. Due to the high mobility of gas, we would expect the gas recovery to be higher than oil recovery.

\section{Recovery Processes}

Application of material balance indicates that the recovery of hydrocarbons is inefficient due to the use of gas expansion energy in producing water. One way the overall recovery can be 
improved is by reducing the abandonment pressure. This requires lowering the bottom hole pressure significantly. We compared a new method to reduce the bottom hole pressure; unfortunately, the economics of the new method is not favorable compared to traditional methods of producing water.

We also compared efficacy of using horizontal wells compared to vertical wells to improve the recovery. We observed that as long as vertical wells have good productivity, they will perform as well as horizontal wells. In general, having higher productivity is very critical to produce more gas and oil from a given well. We also noticed that drilling below 160 acre spacing may not be cost effective in these formations.

We examined various enhanced oil recovery processes to improve the performance of the reservoir. $\mathrm{CO}_{2}$ flooding is a viable alternative through the huff-n-puff process; unfortunately, without a source of $\mathrm{CO}_{2}$, it may be difficult to implement. Another possible recovery process is to change the wettability of the rock near the well bore region so that gas becomes more mobile and water becomes less mobile. Experimental data indicated that it is possible to achieve that goal. We are currently investigating the feasibility of injecting surfactant in some wells to see if that would improve the performance of the wells. 


\section{Experimental}

Kishore K. Mohanty, University of Houston

\section{Introduction}

The objective of the first phase of this project was to determine wettability and relative permeability of Hunton formation core plugs. The wettability was determined by the standard Amott technique. The relative permeability was determined by the unsteady state method in the native state. In addition, thin sections and mercury porosimetry were conducted to determine the pore structure.

The objective of the second phase of this project is to study the effect of near well bore treatment on productivity enhancement. In water-wet gas reservoirs, water saturation is high in the near well bore region (or at fracture faces). This leads to low gas relative permeability and low productivity. Treatment of the near-well bore region by a surfactant solution can make the surface less hydrophilic and thus increase the gas-water contact angle. This can lead to a decrease in water saturation and an increase in gas flow. In gas condensate reservoirs, condensates (or oil) accumulate in the near well bore regions (and fracture faces). Making the surface neutral wet to both water and condensate can improve gas productivity. We have evaluated several surfactants for their wettability alteration. Injection of $\mathrm{CO}_{2}$ into the reservoir can remove oil from the near-wellbore region. We have conducted a slimtube study to determine $\mathrm{CO}_{2}$ minimum miscibility pressure (MMP). Natural gas can be injected into reservoirs for storage. Oil and gas mix under high pressure. Withdrawal of the gas can produce some of the oil. We have conducted some laboratory-scale huff-n-puff experiments with methane.

The objective of the third phase of this project is to test the feasibility of improved recovery in the Hunton reservoir. Because the reservoir is fractured and parts of the matrix may be oil-wet, a large amount of oil may be trapped in the matrix. Surfactant solutions can be introduced into the fractures which can diffuse into the matrix and change the wettability to moderately water-wet. ${ }^{1}$ Surfactant water can then displace the oil by gravity drainage. We have conducted this surfactant-aided gravity drainage process in low permeability limestone cores 
with permeability typical of the Hunton reservoir. We have developed a simulator to model this process mechanistically and investigated the sensitivity to interfacial tension reduction and wettability alteration. These results are described in this report.

\section{Methodology}

\section{Phase I: Core Analysis}

Core plugs, as received, were scanned by a CT scanner to detect vugs and fractures. Samples without visible fractures were chosen for core analysis. Dead reservoir crude oil was injected into each core with some back pressure ( 500psig) to remove all gas. The absolute permeability of the core was determined at this stage. The oil pore volume was determined by a tracer test. The tracer used with the reservoir oil was iododecane. The cores were not cleaned at this stage, so as not alter original wettability.

For wettability, a core plug was placed in an Amott imbibition cell filled with brine after determination of initial oil pore volume. The amount of oil expelled from the core was monitored as a function of time. After spontaneous brine imbibition ceased, brine was injected into the core (as a part of the imbibition relative permeability test) and the production of oil was monitored. The brine pore volume was then determined by a tracer method. The tracer used with brine was Sodium iodide. The plug was then placed in an imbibition cell filled with reservoir dead oil. Amount of spontaneous oil imbibition was monitored. After the cessation of oil imbibition, the core was flooded with reservoir dead oil and water production was monitored (as a part of drainage relative permeability test). The amounts of spontaneous and forced imbibitions are used in calculation of Amott wettability index.

For imbibition relative permeability, cores were waterflooded at room temperature and pressure after the spontaneous water imbibition step. Pressure drop and effluent oil cut were monitored. JBN analysis was used to extract the imbibition relative permeability. An oil flood was conducted after the spontaneous oil imbibition step to determine the drainage relative permeability. Pressure drop and effluent oil cut were again monitored. JBN analysis was also used to extract the imbibition relative permeability. 
After the wettability and relative permeability tests, the cores were weighed and then extracted in a Dean-Stark extractor. This extraction gave the brine volume. The brine volume obtained form Dean Stark extraction was checked against that expected, from experiments and tracer tests and a reasonable match was obtained in most of the cases. The core was then vacuum dried. The difference between the dry weight and the saturated weight gave the fluid weight. The oil volume was calculated from the difference between the total fluid volume and the brine volume. Porosity and air permeability of the dry core were measured. A part of this core was then used for thin sectioning and another part was used for mercury porosimetry.

\section{Phase II: Wettability Alteration}

The laboratory studies were conducted in two scales. First, experiments were done at a mineral slab-scale, where carbonate surfaces (Calcite and Marble) and Silica surfaces (Mica and Silica wafer) were treated with surfactant solutions to study their effect on wettability. Second, experiments were done at a core-scale (with limestone cores) to study the effect of surfactants on relative permeability and spontaneous imbibition.

Fluids Used. The surfactants used for this study are five fluorosilanes (A-E). The number of fluoro groups increase from A to E. Field brine of composition given in table 1 is used for studying the effect of field brine on the wettability. Synthetic brine of $0.1 \mathrm{~N} \mathrm{NaCl}$ prepared in distilled water is used as liquid phase for the contact angle measurements. The specific gravity of the brine was 1.01. Temperature of the experiments was at ambient conditions in the lab, which varied from $22^{\circ} \mathrm{C}$ to $24^{\circ} \mathrm{C}$. Air was used as the gas phase and the plates were dried using dry air. 
Table 1. Field brine composition

\begin{tabular}{|l|l|c|c|}
\hline \multicolumn{1}{|c|}{ Salt } & Mol Wt & $\mathbf{~ m M / L}$ & gm/liter \\
\hline CaCl2.2H20 & 147.026 & 20.01 & 2.942 \\
\hline MgCl2.2H20 & 203.33 & 9.992 & 2.032 \\
\hline KCl & 74.567 & 0 & 0 \\
\hline NaCl & 58.448 & 99.492 & 5.815 \\
\hline $\mathbf{F e ( N H 4 ) 2 ( S O 4 ) 2 . 6 H 2 0}$ & 392.158 & 0.018 & 0.007 \\
\hline Na2SO4 & 142.048 & 1.671 & 0.237 \\
\hline
\end{tabular}

Contact Angle Measurements. The effect of surfactant solution on wettability was determined by contact angle measurements. A computer-aided digital analyzer is used for determination of advancing and equilibrium contact angles on plain surfaces. The following procedure is used for the contact angle determination for flourosilanes.

Carbonate surfaces were made smooth by grinding on a diamond plate. This created a fresh surface. For sandstones, a freshly cleaved mica surface (AFM smooth) was used as a model surface. The plates were equilibrated with a synthetic brine $(0.1 \mathrm{~N} \mathrm{NaCl}$ Brine) for a period of 1 day, and then they were dried. A drop of brine is placed on the plate to measure the initial contact angle between untreated surface, water, and air. After measuring the initial contact angle, the plates were immersed in different surfactant solutions (4 wt \% prepared in methanol) for a period of 1-day. They were removed and air-dried. The contact angle between the treated surface, water, and air was measured again. The plates were again immersed back in the surfactant solution to see the effect of aging. The treated plates were placed in synthetic brine and field brine to see the stability of the deposited layer. 1-wt\% surfactant solutions were prepared for the best surfactants and the effect of dilution was studied on fresh calcite and mica surfaces. The surfactant solutions in 1:1 ratio field brine and methanol were also used to see the effect of field brine on contact angle.

Imbibition Studies. From studies at the slab-scale, two good surfactants, surfactants D and F, were chosen for further investigation on a larger scale. The following procedure was used to study the impact of wettability alteration in a core scale. The carbonate cores were vacuum 
dried and then fully saturated with the synthetic brine $(0.1 \mathrm{~N} \mathrm{NaCl})$. The brine permeability was measured. The cores were then flushed with humidified $\mathrm{N}_{2}$ gas to a residual brine saturation at a pressure gradient of 10-14 psi/ft. The gas permeability at this residual saturation was measured.

The cores were then flooded from the opposite end with 6 PV of ethanol to remove any residual brine. The core was then flooded for $3 \mathrm{PV}$ with surfactant solutions and aged in room temperature for a period of 24 hrs. The aged core was then again flooded with 6 PV of ethanol followed by 6 PV of synthetic brine to remove non-adsorbed surfactants and ethanol, respectively. The core was then flooded with humidified $\mathrm{N}_{2}$ gas to a residual brine saturation at a pressure gradient of $10-14 \mathrm{psi} / \mathrm{ft}$.

The core was then flooded with dry $\mathrm{N}_{2}$ gas at a high pressure gradient of $100 \mathrm{psi} / \mathrm{ft}$. It was then taken out of the core holder and immersed in brine. The spontaneous imbibition of brine was monitored. A reference core was also used to study brine imbibition without surfactant treatment. After the spontaneous imbibition the cores were flooded again with brine under vacuum to $100 \%$ brine saturation. They were then gas-flooded with humidified $\mathrm{N}_{2}$ to residual brine saturation at a pressure gradient of $10-14 \mathrm{psi} / \mathrm{ft}$ to obtain the gas permeability at residual saturation. The pressure gradients were increased and their influence on water saturation and gas permeability were monitored.

Table 2a. Characteristics of slim tube

\begin{tabular}{cccc|} 
Slim Tube & & & \\
\hline D $(\mathbf{c m})$ & 0.704 & $\mathrm{~A}\left(\mathrm{~cm}^{2}\right)$ & 0.389 \\
L $(\mathbf{c m})$ & 609.6 & $\mathrm{~V}\left(\mathrm{~cm}^{3}\right)$ & 237.01 \\
K $(\mathrm{d})$ & 25.0 & $\mathrm{~V}_{\mathbf{p}}\left(\mathrm{cm}^{3}\right)$ & 77.30 \\
& & $\square$ & 32.61 \\
\hline
\end{tabular}

\section{$\underline{\text { Slimtube Studies }}$}

A slim tube, 20 feet long $(609.6 \mathrm{~cm})$ and 3/8 in OD, is packed with 20-100 mesh Ottawa sand and coiled to circular shape of about 2 feet in diameter. The characteristics of the slim tube are listed in table 2a. The injection sequence was as follows. Oil injection: The slim tube (after cleaning) is injected with more than 2 pore volumes of Mary Marie oil before adjusting the flow rate to $1.351 \mathrm{ml} / \mathrm{hr}$. The flow is allowed to reach steady state after a day of continuous pumping 
at a constant rate. $\mathrm{CO}_{2}$ injection: The $\mathrm{CO}_{2}$, kept under the same upstream pressure, is injected into the slim tube by using a three-way valve and switching from oil to $\mathrm{CO}_{2}$ injection. The flow rate is kept constant throughout the experiment. The back pressure regulator is kept at a constant pressure for each experiment. The effluent is flashed after the back pressure regulator and the oil is collected using a graduate cylinder. The cumulative volume of outlet oil is monitored throughout $\mathrm{CO}_{2}$ injection.

Methane Huff-n-Puff

The Berea core, 7 in $(17.78 \mathrm{~cm})$ long and 2 in $(5.05 \mathrm{~cm})$ OD, is placed vertically in the core holder with a spacing ring on its top. The characteristics of the core are listed in table $2 \mathrm{~b}$.

Table 2b. Characteristics of Berea core

\begin{tabular}{|c|ccc|}
\hline Core & & & \\
\hline D $(\mathrm{cm})$ & 5.05 & $\mathrm{~A}\left(\mathrm{~cm}^{2}\right)$ & 20.03 \\
L (cm) & 17.78 & $\mathrm{~V}\left(\mathrm{~cm}^{3}\right)$ & 356.13 \\
K (md) & 132.1 & $\mathrm{~V}_{\mathrm{p}}\left(\mathrm{cm}^{3}\right)$ & 65.20 \\
& & $\square$ & 18.31 \\
\hline
\end{tabular}

The circular spacing area is $12 \mathrm{~cm}^{2}$ and height is $0.3 \mathrm{~cm}$. This spacing is filled with $\mathrm{CH}_{4}$ to allow methane diffusion into the core through the surface area where the core is exposed to methane. The injection sequence was as follows. Oil injection: The Berea core is injected with more than 2 pore volumes of Mary Marie oil at atmospheric pressure. Care is taken to eliminate methane residue from previous run. $\mathrm{CH}_{4}$ injection: The $\mathrm{CH}_{4}$ is first injected into the spacing area to blow out the oil in the spacing area while the pressure regulator is set at atmospheric pressure. After blowing out all the oil from the spacing area, the valve connecting the $150 \mathrm{~mL}$ $\mathrm{CH}_{4}$ storage tank and the spacing area is closed. Then $\mathrm{CH}_{4}$ is introduced into the storage tank until it is filled with $\mathrm{CH}_{4}$ at 1600 psi. The pressure regulator is also set at 1600 psi. The valve connecting the storage tank and the spacing area is then open to allow $\mathrm{CH}_{4}$ to get into the spacing area and diffuse into the core. A differential pressure gage is used to monitor the diffusion rate of $\mathrm{CH}_{4}$ into the core until near equilibrium is reached. The core is then left for a day to make sure no more diffusion takes place. Depressurizing the core: After $\mathrm{CH}_{4}$ diffusion ceases, the valve connecting the storage tank and the spacing area is shut. The pressure of the regulator is 
control by an Isco pump. By either slowly or rapidly reducing the pressure of the regulator, gas and oil are produced. The oil production is monitored with respect to time along with the pressure of the regulator.

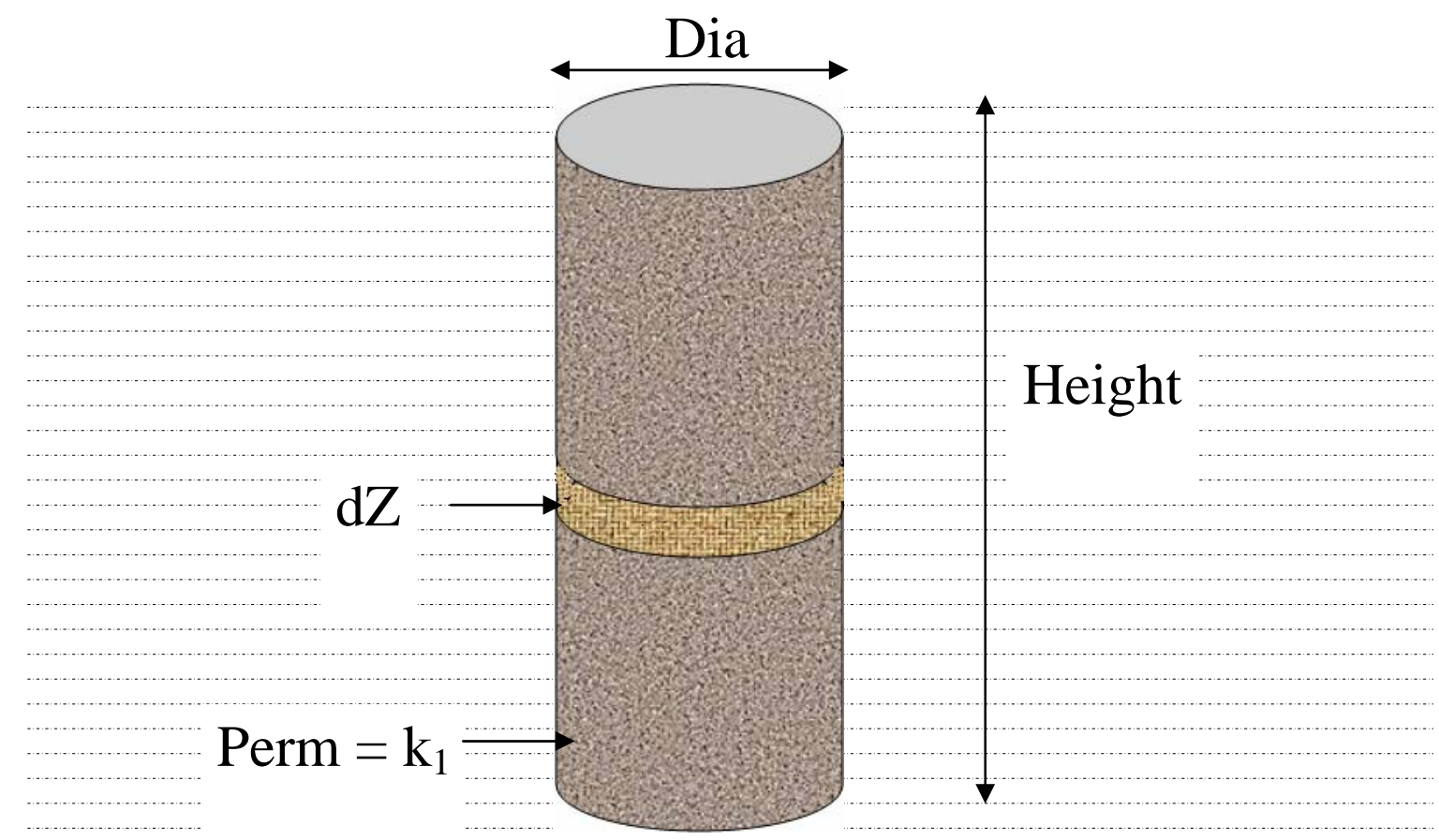

Figure 1: Illustration of simulation problem

\section{Phase III: Surfactant-aided Imbibition Simulation}

A single fracture block is simulated for surfactant brine imbibition process ${ }^{2}$. A cylindrical matrix block is considered, as shown in figure 1 . This is similar to the laboratory experiments done in cylindrical cores. The core is discretized in radial ( $r$ ) and axial (z) directions. In this simulation, surfactant brine surrounds the fracture block and the surfactant diffuses into the matrix. The surfactant then alters the IFT between oil and brine and also changes the wettability of the rock. This leads to further imbibition of the surfactant brine solution and oil recovery.

The features of the matrix block are given in table 3. The surfactant concentration surrounding the core as shown in figure 1 is taken to be at $0.05 \mathrm{wt} \%$ and it lowers the IFT to a 
final value of $0.01 \mathrm{mN} / \mathrm{m}$ and changes wettability to a final value of $75^{\circ}$, in the base case. The IFT and wettability are altered inside the porous media as function of surfactant concentration. The changes in IFT and wettability lead to changes in capillary pressure and relative permeability. ${ }^{2}$

Table 3. Properties of the core used for imbibition

\begin{tabular}{|l|c|}
\hline Porosity & $22.0 \%$ \\
\hline Permeability (mD) & 7 \\
\hline$S_{o x}$ & $27.5 \%$ \\
\hline$S_{w r}$ & 0.1 \\
\hline$k_{r w e t}^{0}$ & 4.5 \\
\hline$n_{w e t}$ & 0.9 \\
\hline$k_{r . n w}^{0}$ & 2.25 \\
\hline$n_{n w}$ & 30 to $0.01 \mathrm{mN} / \mathrm{m}$ \\
\hline IFT Reduction & $0.05 \mathrm{wt} \%$ \\
\hline Surfactant Concentration & $160^{0}$ to $75^{0}$ \\
\hline Wettability Alteration & \\
\hline
\end{tabular}

\section{Results and Discussion}

\section{Phase I: Core Analysis}

The cores analyzed are listed in table 4. The diameter of the cores was about 2 inches while the length of most of the cores was around 3 inches. They are all limestone except for core\#8, which is a dolomite. Cores 1 and 2 were put on a composite and relative permeability of the composite was determined. Core 3 was used for relative permeability where as its adjacent core (Core 4) was used for Amott wettability determination. It was observed that the spontaneous imbibition is small in these cores. In Core 5, spontaneous imbibition is first measured and then 
relative permeability is measured during the forced imbibition test. Thus both Amott wettability and relative permeability are measured on the same core. Cores 6 and 7 were found to be fractured. Thus relative permeability and wettability tests could not be run on these two samples.

Table 4. List of cores

\begin{tabular}{|c|l|c|}
\hline Core & \multicolumn{1}{|c|}{ Well } & Depth (ft) \\
\hline 1 & Mary Marie & 4967.7 \\
\hline 2 & Mary Marie & 4967.8 \\
\hline 3 & Mary Marie & 4968.6 \\
\hline 4 & Mary Marie & 4968.7 \\
\hline 5 & Wilkerson & 4974.9 \\
\hline 6 & Carter & 4995.2 \\
\hline 7 & Danny & 4972.0 \\
\hline 8 & Boone & 5065.5 \\
\hline
\end{tabular}

CT Scan. The CT scan images of Cores 3 and 4 are shown in figures 2 through 5. Figure 2 shows the cross-sections at 2, 4 and $6 \mathrm{~cm}$ from one edge of Core 3. Figure 3 shows the longitudinal sections through the same core. The darker regions in the image are lower density regions and correspond to vugs. Many vugs are apparent in these scans. There were no visible fractures in these scans. Figures 4 and 5 show the cross-sectional and longitudinal CT sections of Core 4. Again, a few vugs were visible, but no fractures. The major (visible) fractures in such formations are vertical and have a low probability of intersecting cores. Figure 6 shows three cross-sectional sections of Core 8. We observed visible fractures in Cores 7 and 8; these cores were not used in further analysis. 

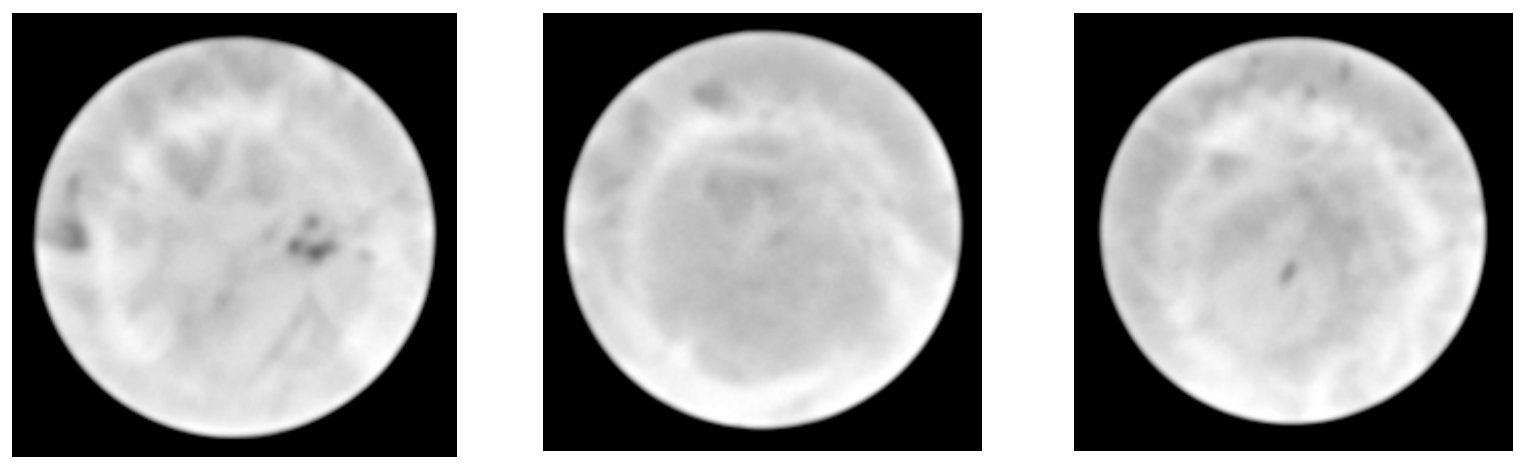

Figure 2: Cross-sectional CT scan at 2, 4, and $6 \mathrm{~cm}$ from one side of Core 3
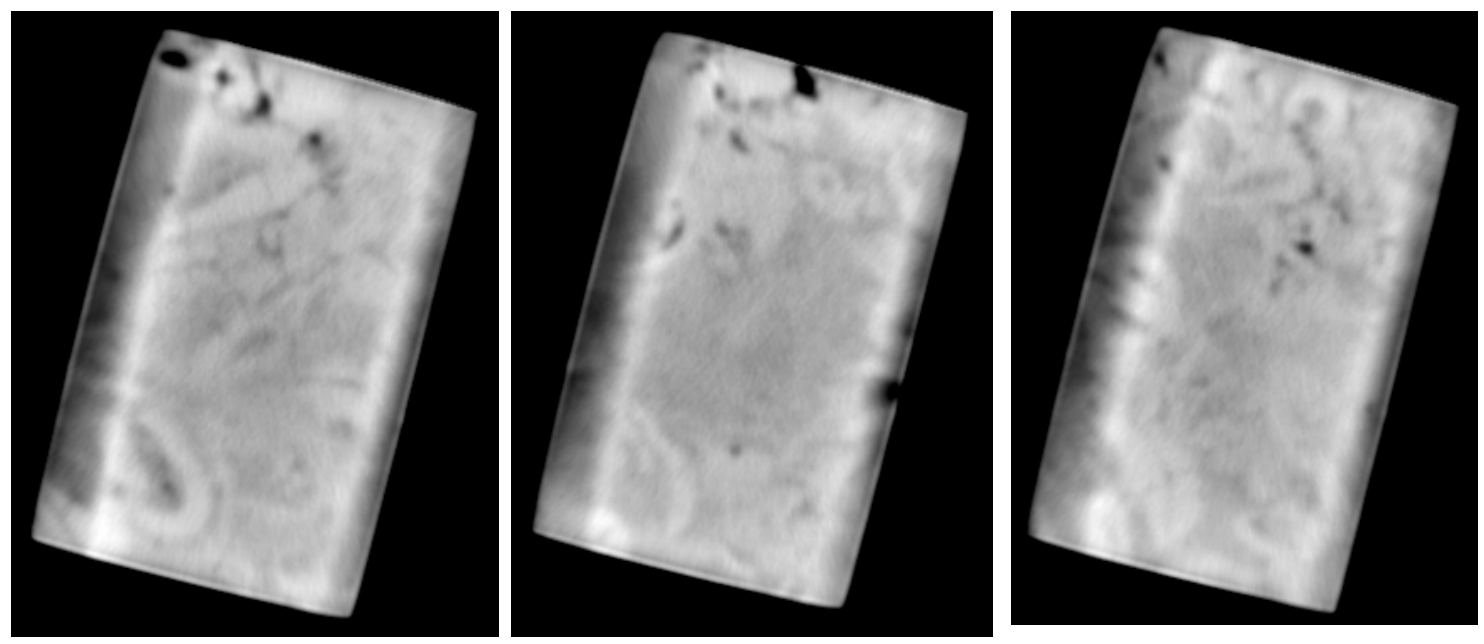

Figure 3: Longitudinal CT scan of Core 3
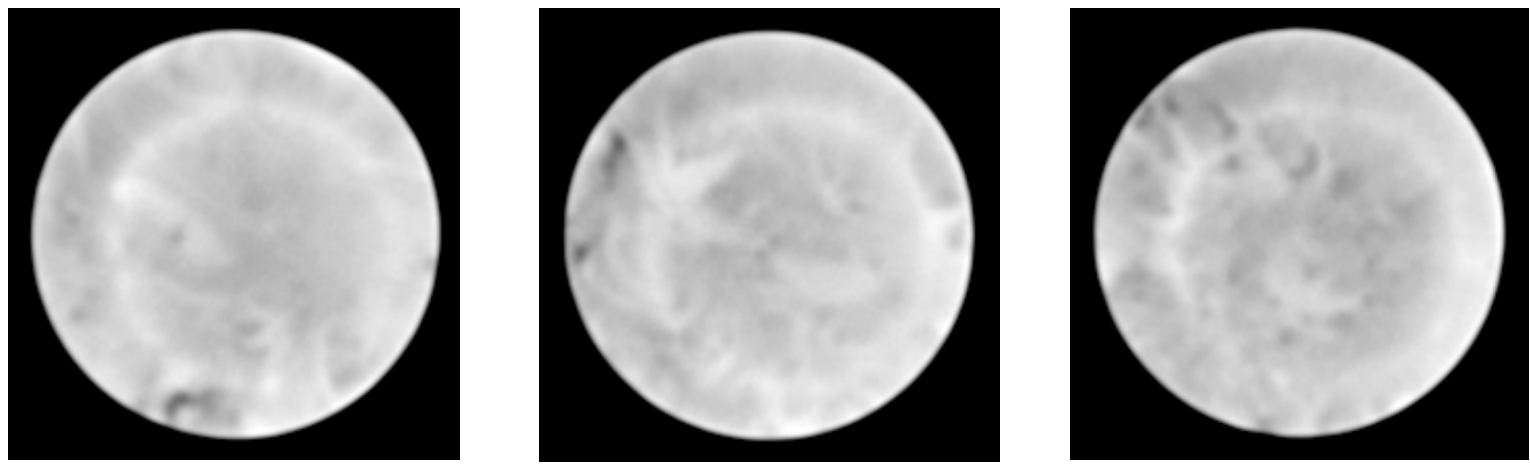

Figure 4: Cross-sectional CT scan at 2, 4, and $6 \mathrm{~cm}$ from one side of Core 4 

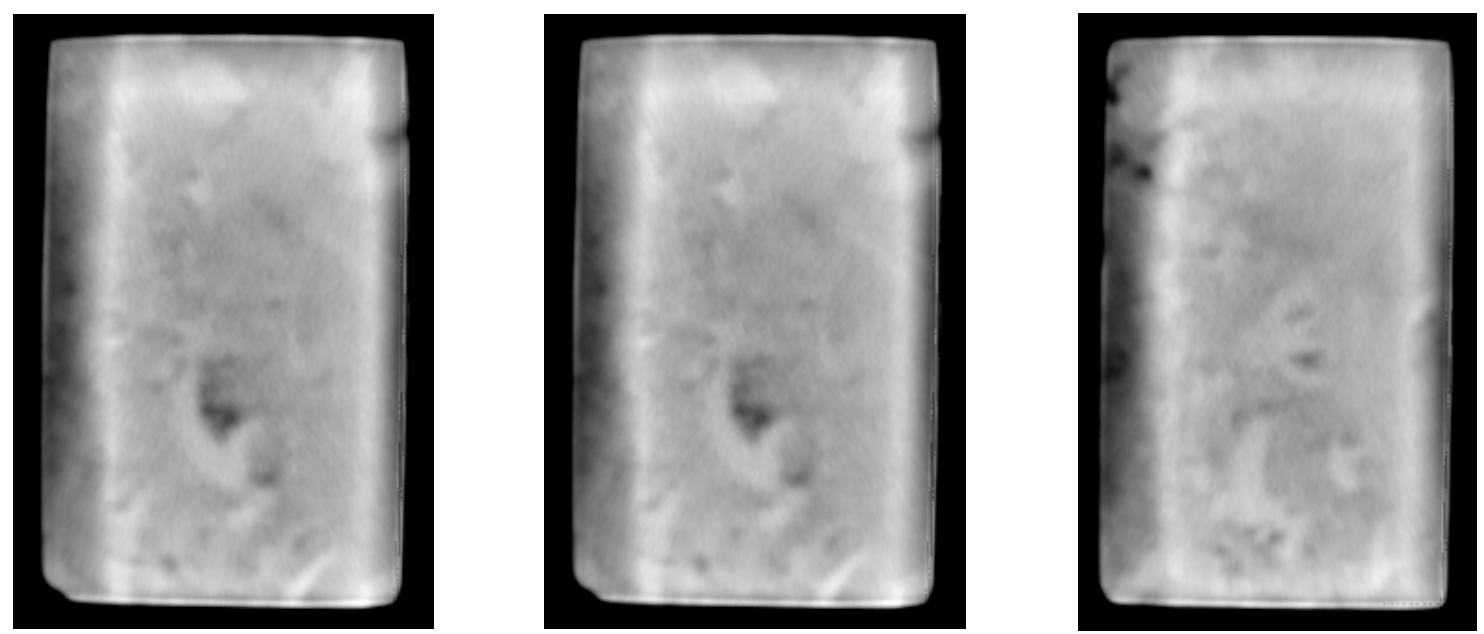

Figure 5: Longitudinal CT scan of Core 4
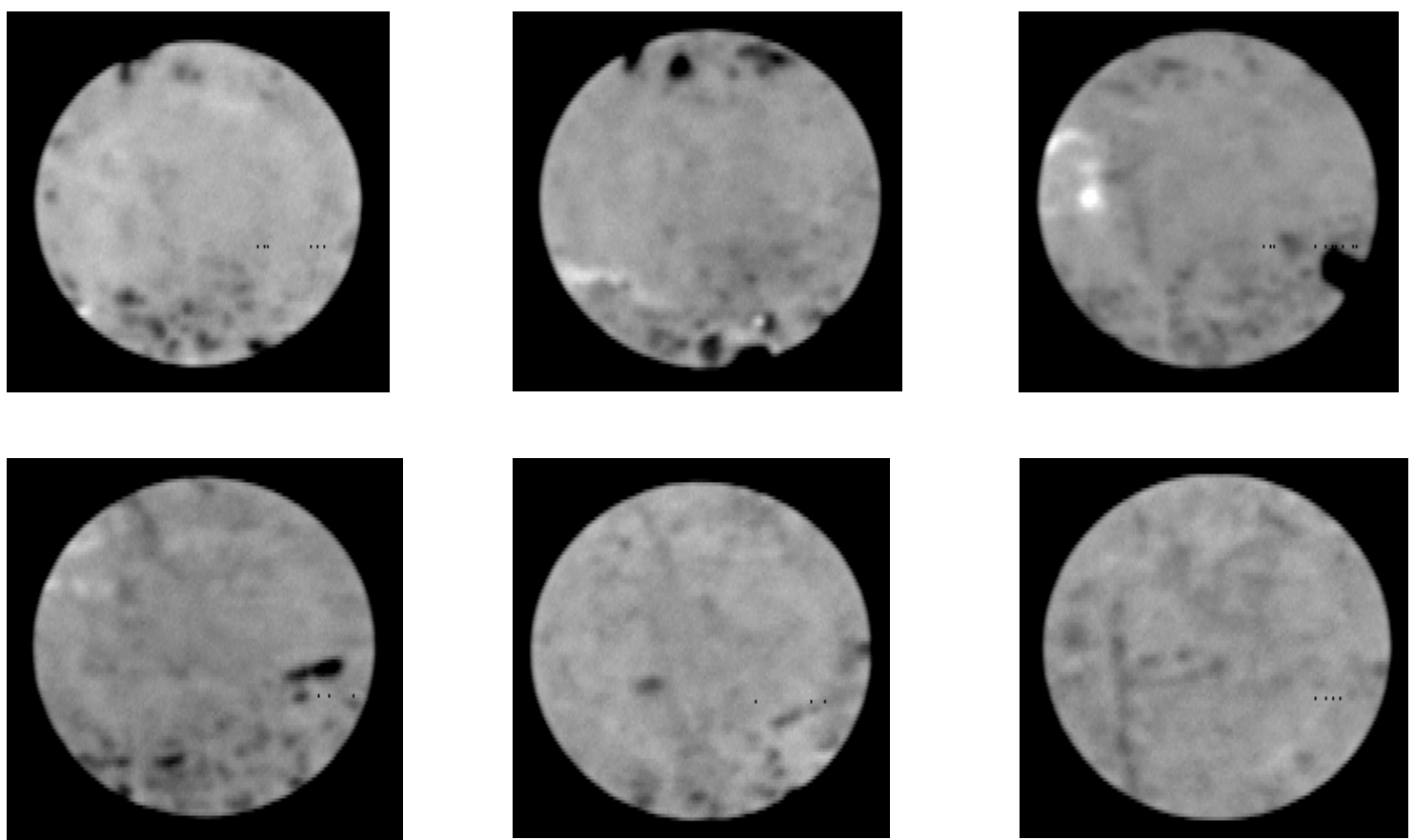

Figure 6: Cross-sectional CT scan at 2, 4, and $6 \mathrm{~cm}$ from one side of Core 8

Wettability. Core properties and wettabilities are listed in table 5. Cores 3 and 4 from the Mary Marie well had the lowest porosity and permeability. It imbibed spontaneously small amounts of water and oil. The Amott index was 0.04 indicating almost neutral wettability. Wikerson core had the intermediate permeability. It imbibed no water spontaneously and 
imbibed only a small amount of oil. The Amott wettability index is slightly negative, indicating slight oil wettability. Carter core was the most permeable of these samples. It did not imbibe any water spontaneously, but imbibed a significant amount of oil. Its Amott wettability index is negative, indicating significant oil wettability.

Table 5. Core properties and Amott wettability

\begin{tabular}{|l|c|c|c|}
\cline { 2 - 4 } \multicolumn{1}{c|}{} & Core 3-4 & Core 5 & Core 6 \\
\cline { 2 - 4 } \multicolumn{1}{c|}{} & Mary Marie 4968.6/4968.7 & Wilkerson 4974.9 & Carter 4995.2 \\
\hline Porosity (\%) & 9.7 & 12.2 & 11.5 \\
\hline Permeability (mD) & 1.32 & 4.4 & 13.7 \\
\hline Water Index & $\mathbf{0 . 1 5}$ & $\mathbf{0}$ & $\mathbf{0}$ \\
\hline Oil Index & 0.11 & 0.16 & 0.37 \\
\hline Amott Index & $\mathbf{0 . 0 4}$ & $\mathbf{- 0 . 1 6}$ & $\mathbf{- 0 . 3 7}$ \\
\hline
\end{tabular}

Relative Permeability. Imbibition relative permeabilities of cores 3-4, 5 and 6 are shown in figures 7 through 9. It can be observed that the brine relative permeability at residual oil saturation is consistently above 0.2 , typical of mixed/oil wet reservoirs. This end-point relative permeability is below 0.1 for water-wet reservoirs. The brine-oil cross-over relative permeability is above 0.1, another indication of mixed/oil-wettability. For Core 6, the brine relative permeability is high and almost linear with saturation, an indication of oil wettability. The initial brine saturation is low, from $2 \%$ to $25 \%$. The end-point brine relative permeability increases as the oil-wettability of the rocks increase (from samples 3-4 to 6). This is expected because as the oil wettability increases, brine occupies bigger throats and its relative permeability increases.

Drainage relative permeabilities of cores 3-4, 5 and 6 are shown in figures 10 through 12. It can be observed that the brine relative permeability in drainage is lower than that for imbibition. However, the oil relative permeability is higher. The final brine saturations are quite high, signifying a significant hysteresis. 


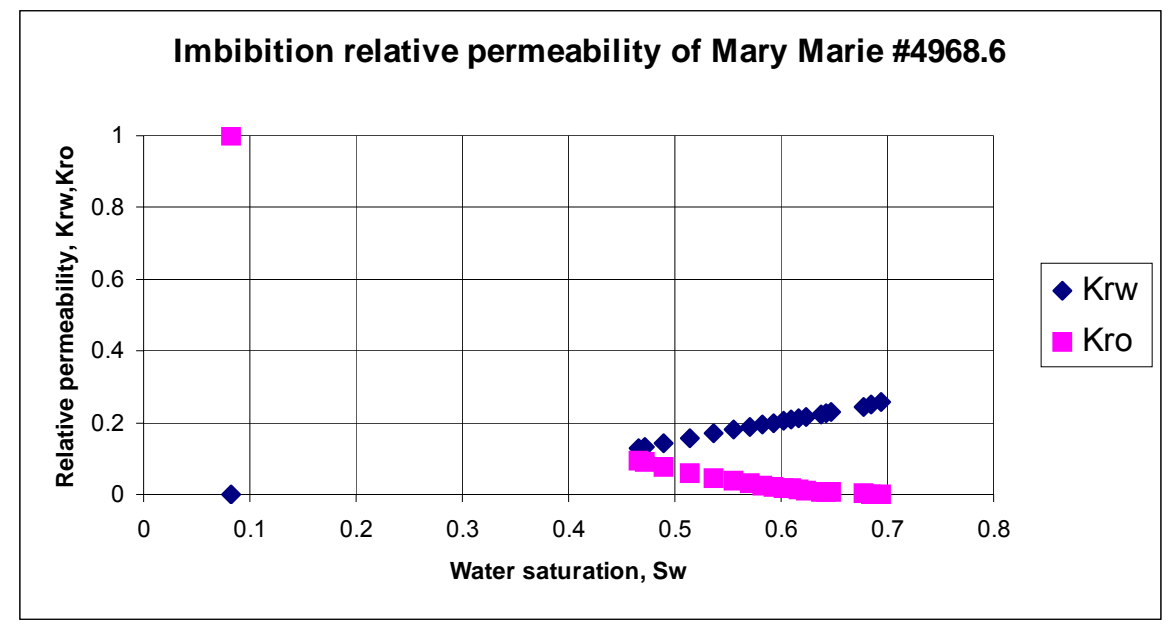

Figure 7: Imbibition relative permeability of Mary Marie 4968.6-7 (Cores 3-4)

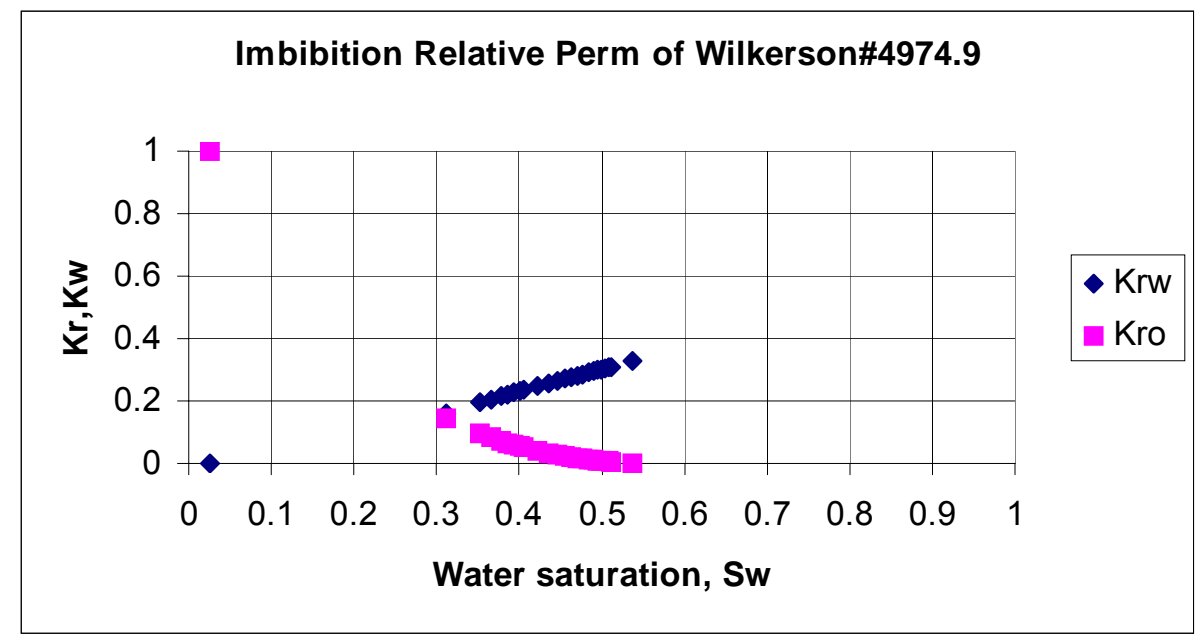

Figure 8: Imbibition relative permeability of Wilkerson 4974.9 (Core 5) 


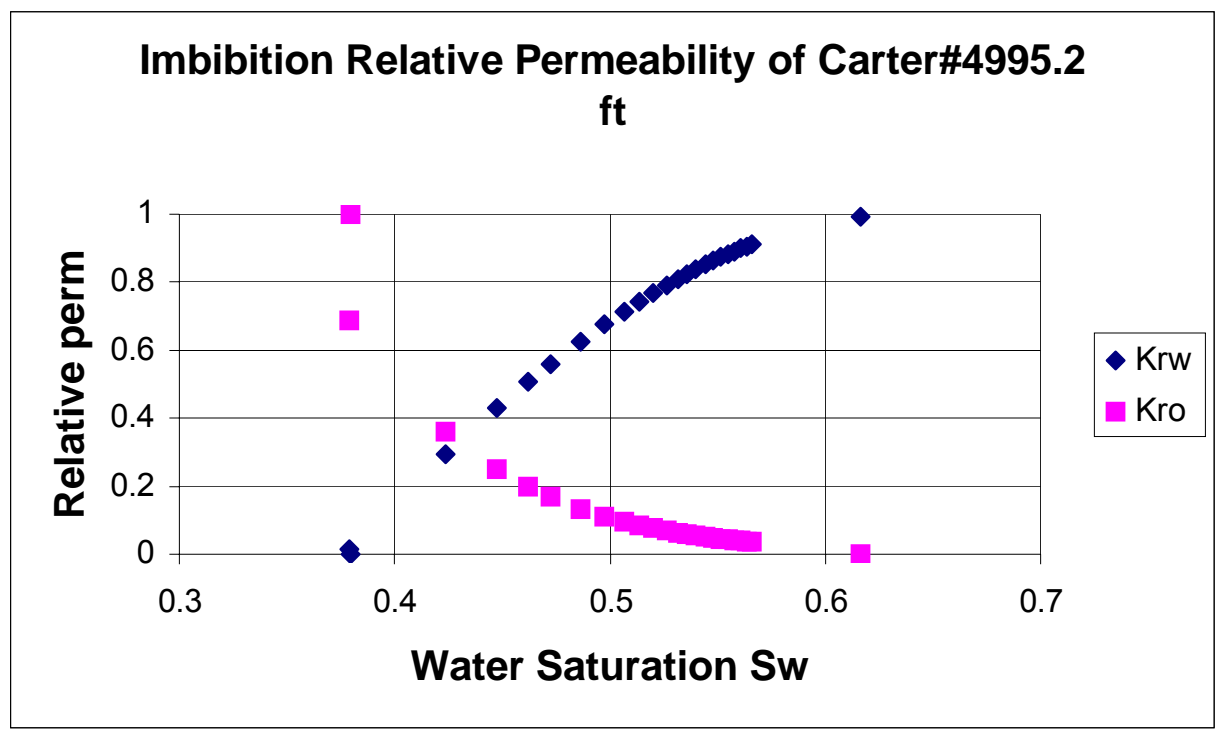

Figure 9: Imbibition relative permeability of Carter 4995.2 (Core 6)

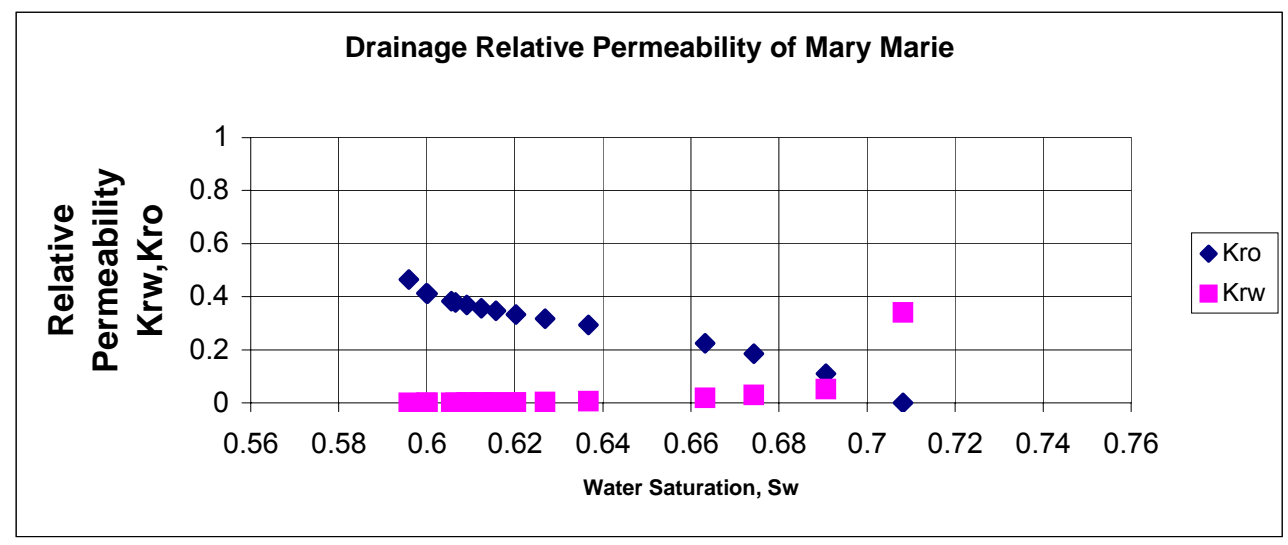

Figure 10: Drainage relative permeability of Mary Marie 4968.6-7 (Cores 3-4) 


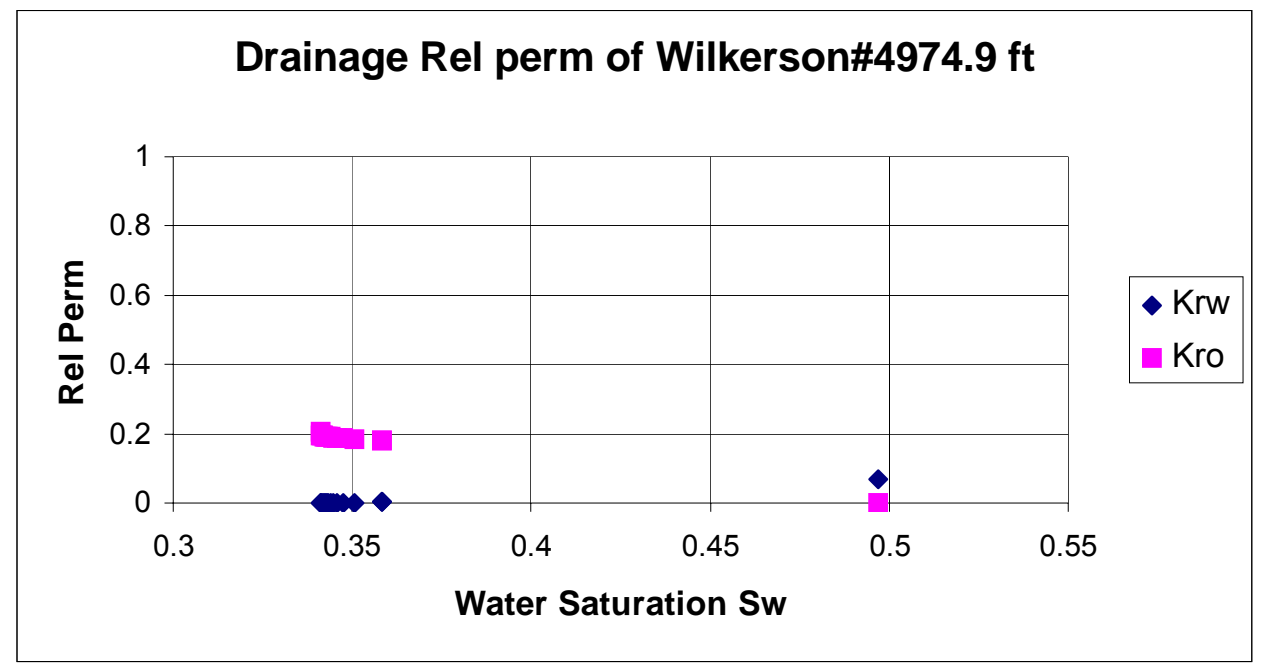

Figure 11: Drainage relative permeability of Wilkerson 4974.9 (Core 5)

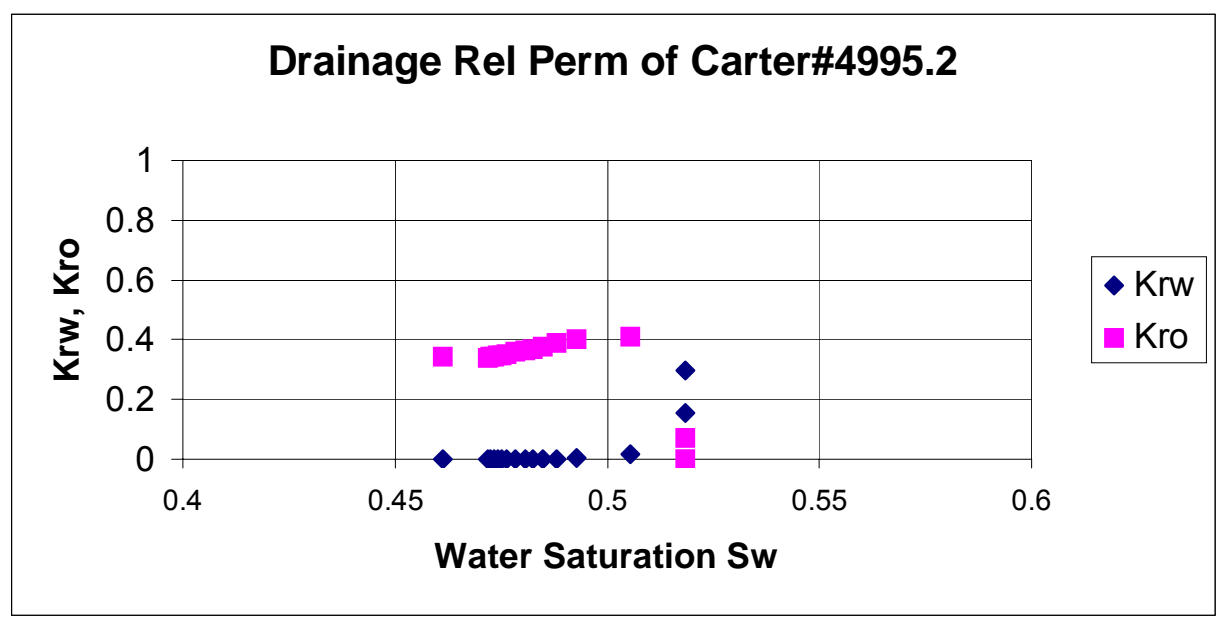

Figure 12: Drainage relative permeability of Carter 4995.2 (Core 6)

Thin-section. The thin-sections of cores 3-4, 5 and 6 are shown in figures 13 through 15 . All of these samples show extremely tight intergranular pore space with a few vugular pores of the size 50 to $500 \mu \mathrm{m}$. The microporosity of the grains cannot be seen in this resolution. The vugs in core sample 6 are larger for than those in the other two samples. 


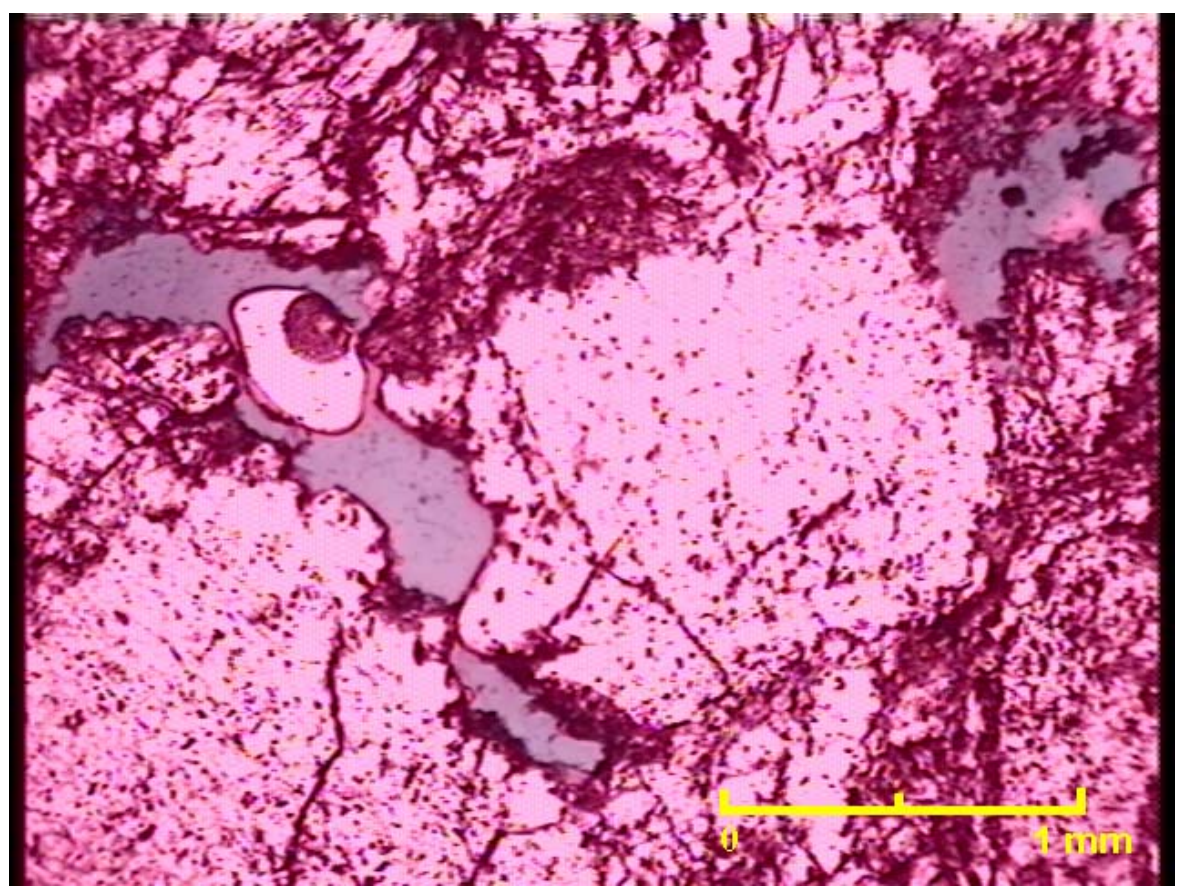

Figure 13a: Horizontal thin-section of Mary Marie 4968.6-7 (Cores 3-4)

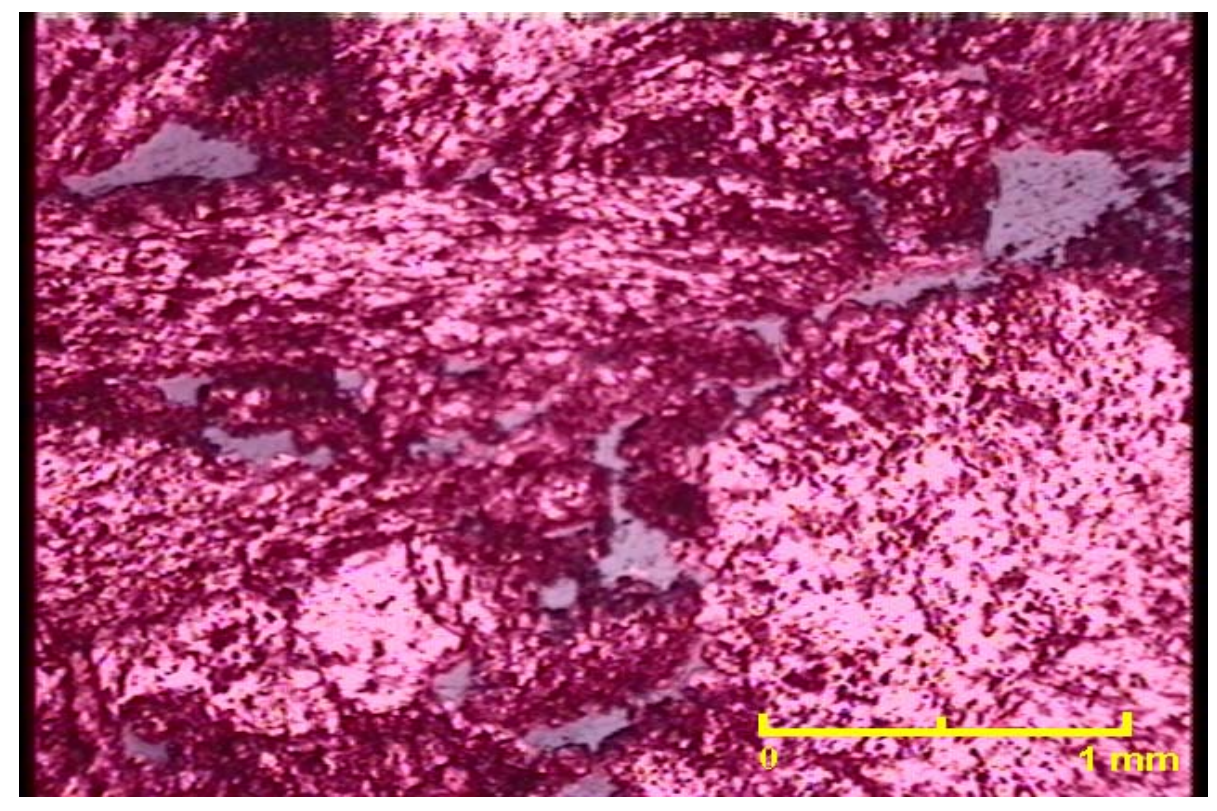

Figure 13b: Horizontal thin-section of Mary Marie 4968.6-7 (Cores 3-4) 


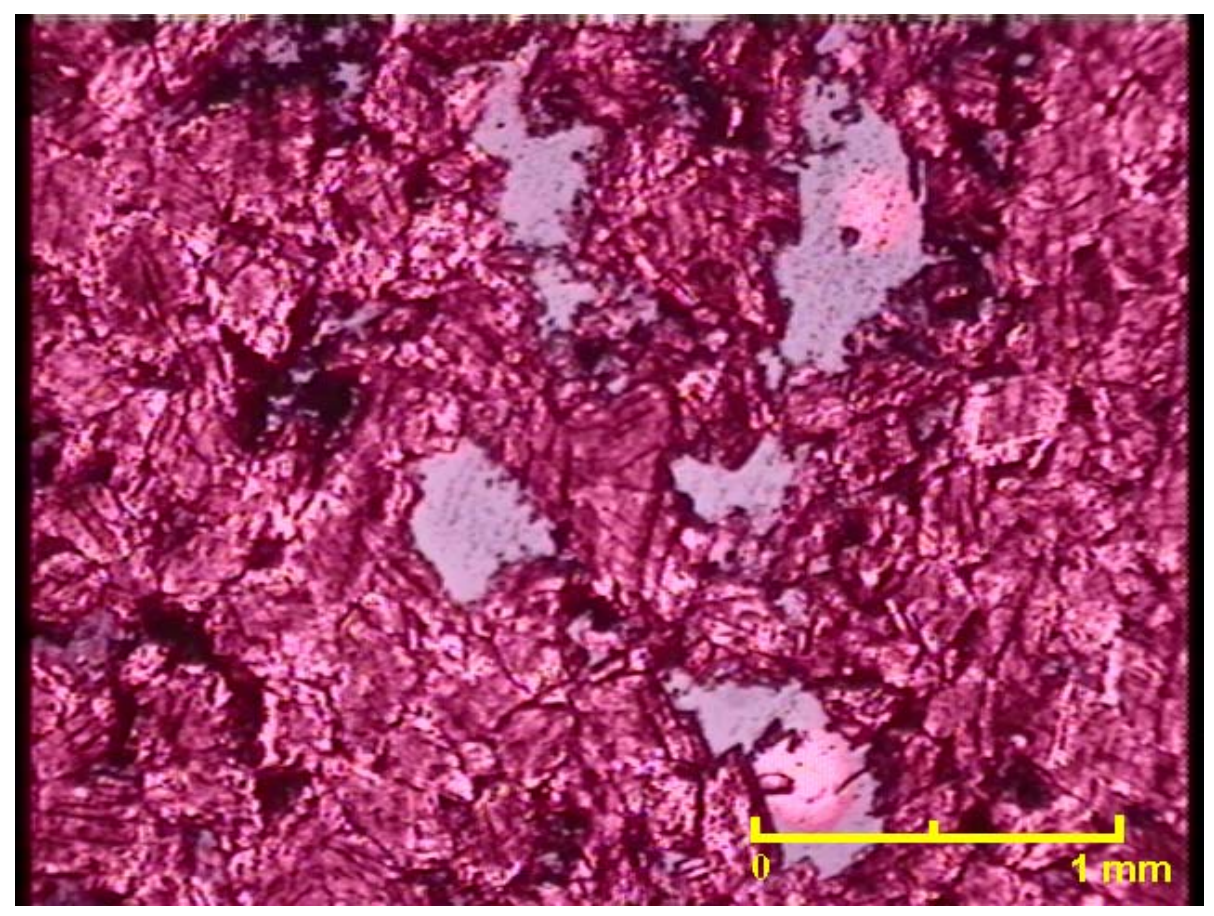

Figure 14a: Horizontal thin-section of Wilkerson 4974.9 (Core 5)

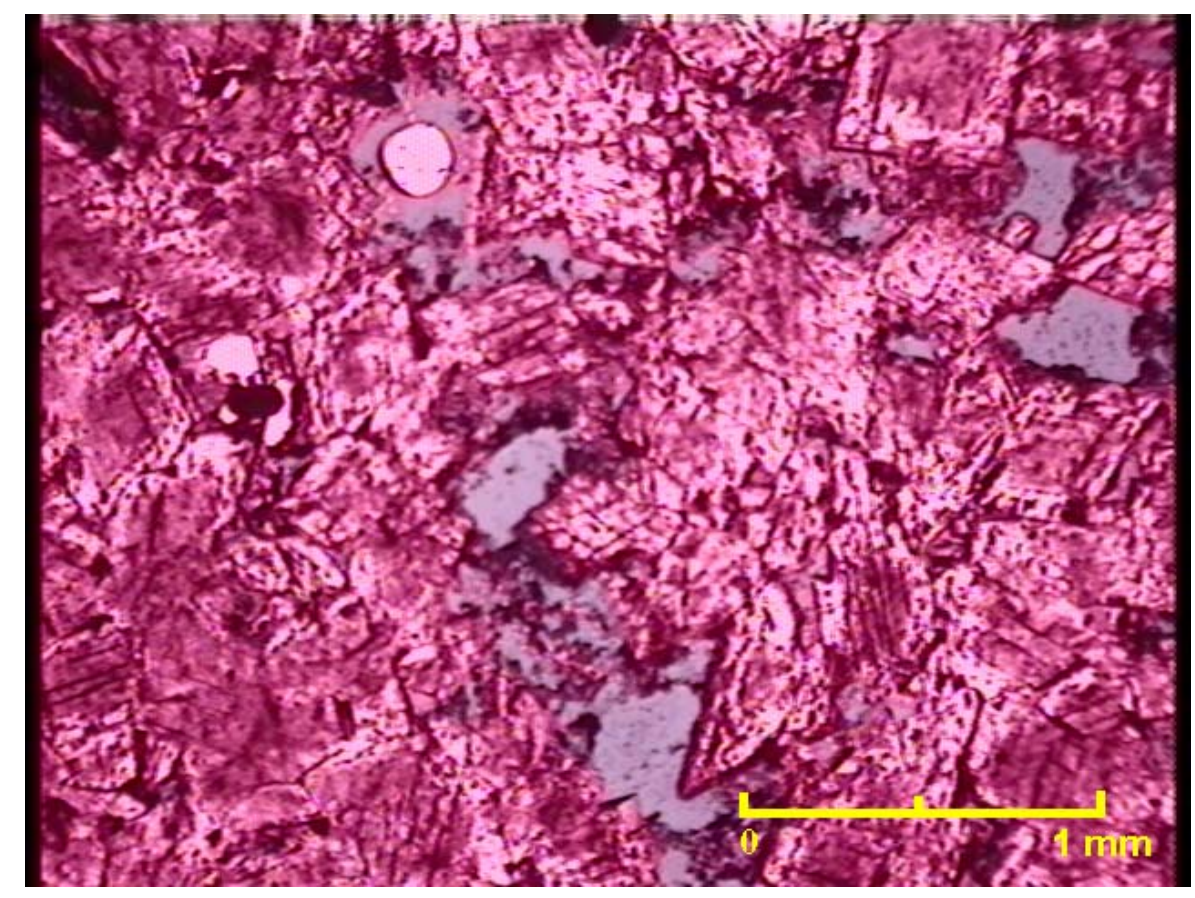

Figure 14b: Vertical thin-section of Wilkerson 4974.9 (Core 5) 


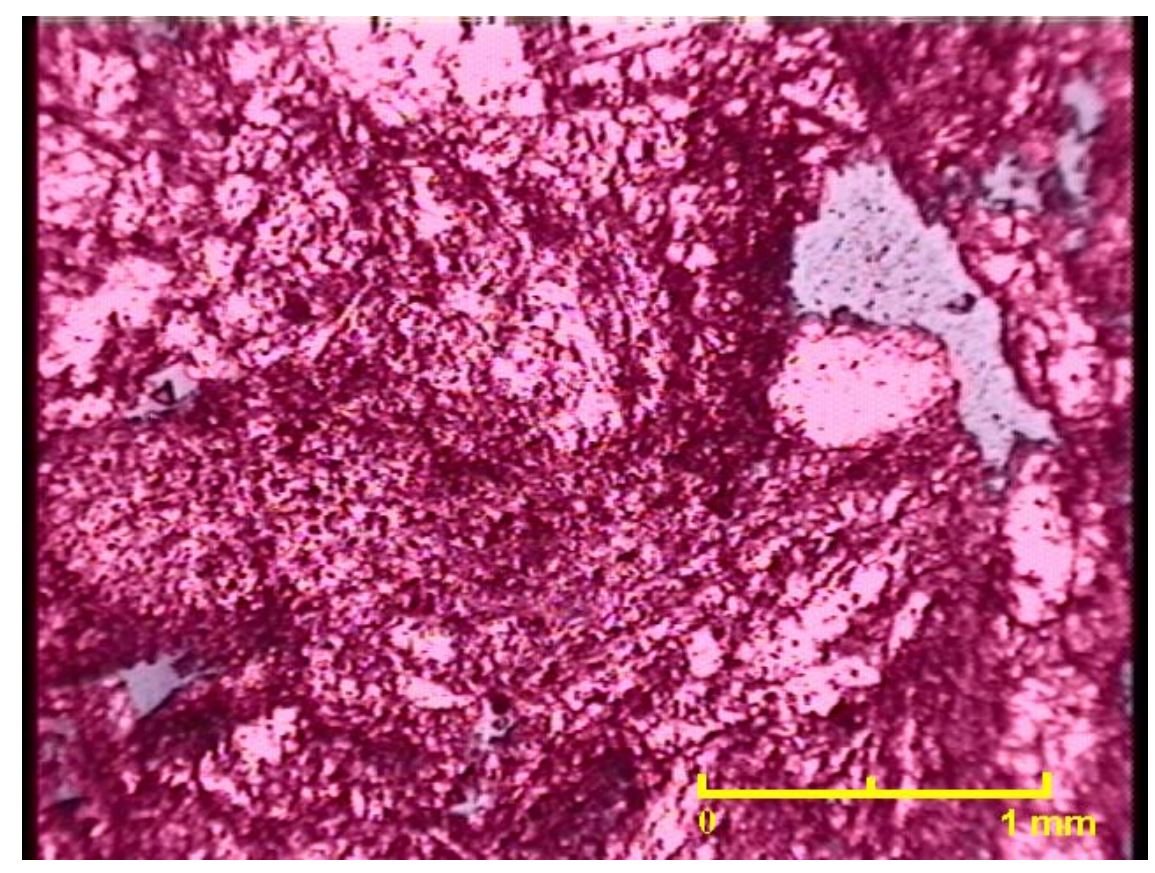

Figure 15a: Horizontal thin-section of Carter 4995.2 (Core 6)

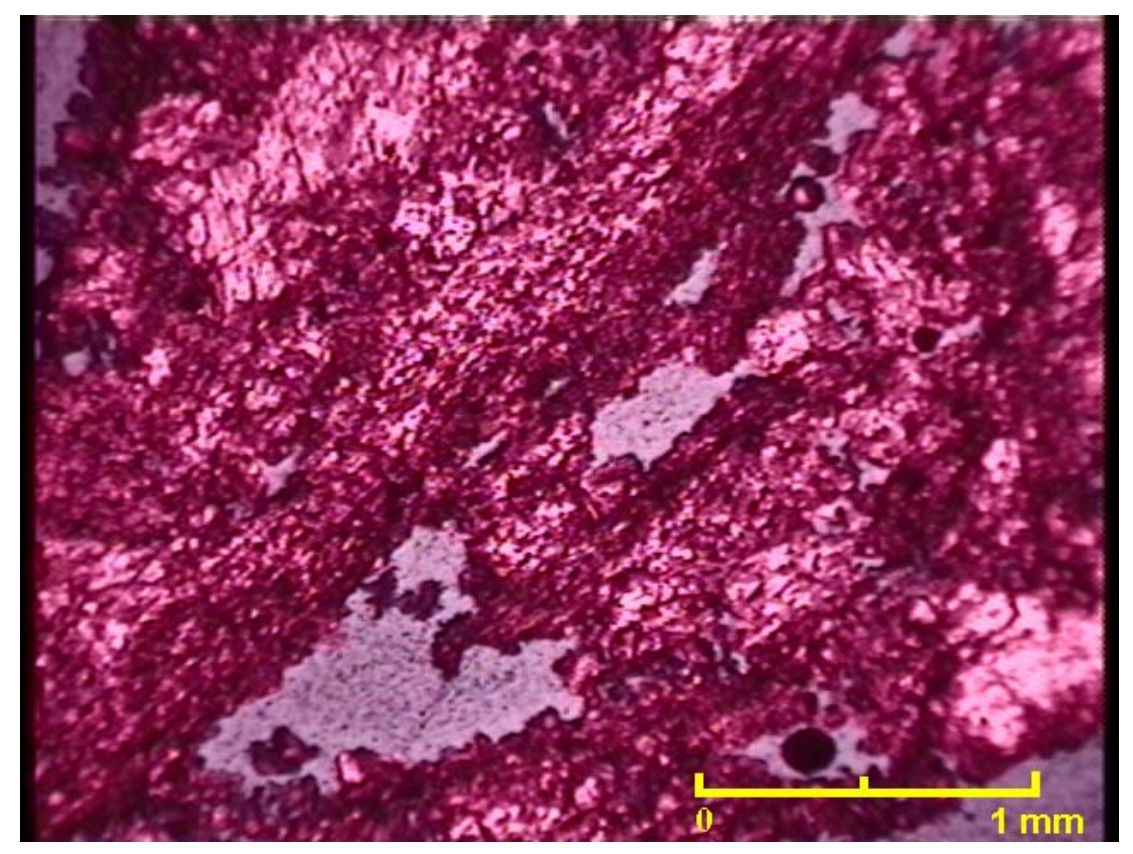

Figure 15b: Vertical thin-section of Carter 4995.2 (Core 6) 


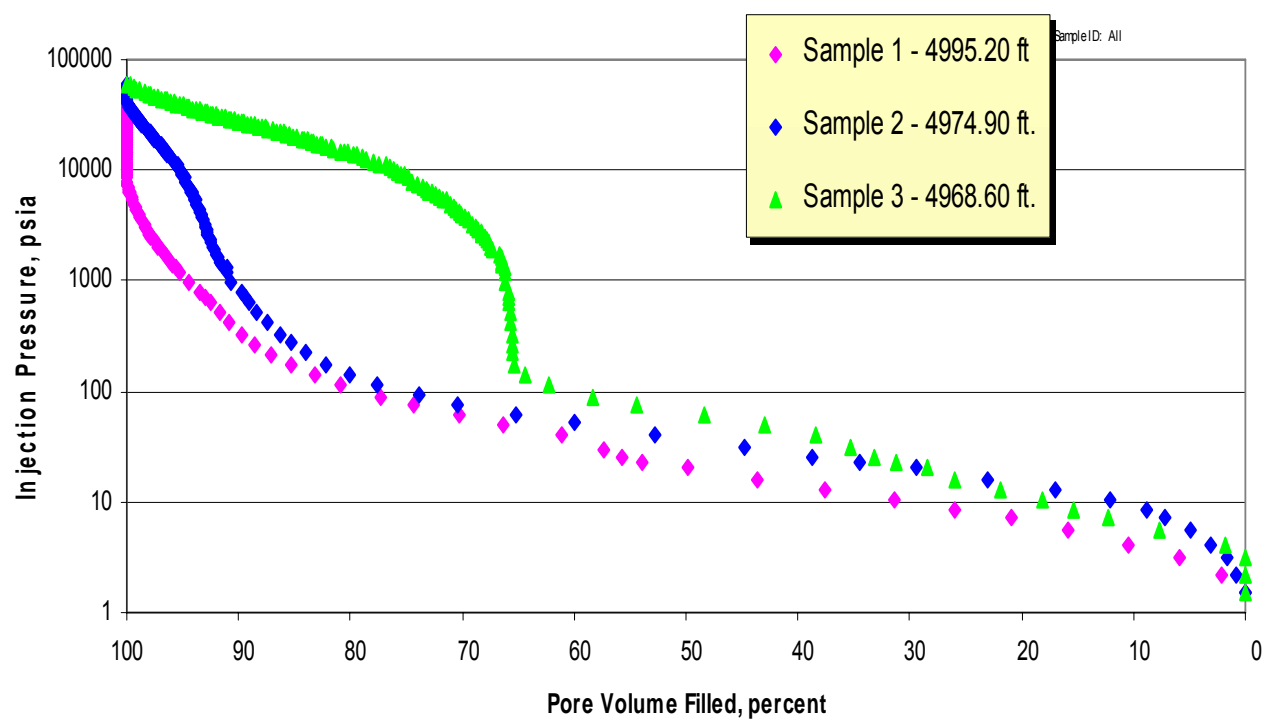

Figure 16: Mercury capillary pressure curves for Cores 4-6

Mercury Porosimetry. The mercury capillary pressure curves for cores 4, 5 and 6 are shown in figure 16. The capillary pressure is the highest for the Mary Marie sample and the lowest for the Carter sample. It inversely correlates with the permeabilities of these samples. Higher mercury capillary pressure indicates smaller pore throats. Smaller pore throats lead to lower permeabilities. The capillary pressure curve for Mary Marie shows a bimodal pore throat distribution. This sample has significant microporosity. 


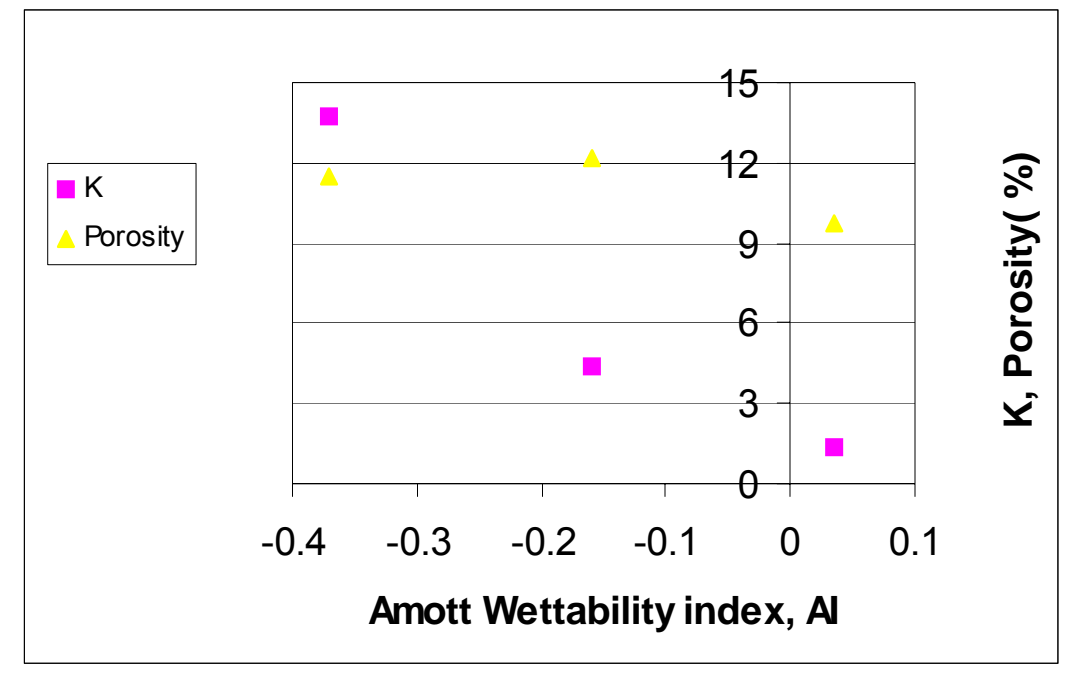

Figure 17: Correlation between absolute permeability, porosity and wettability

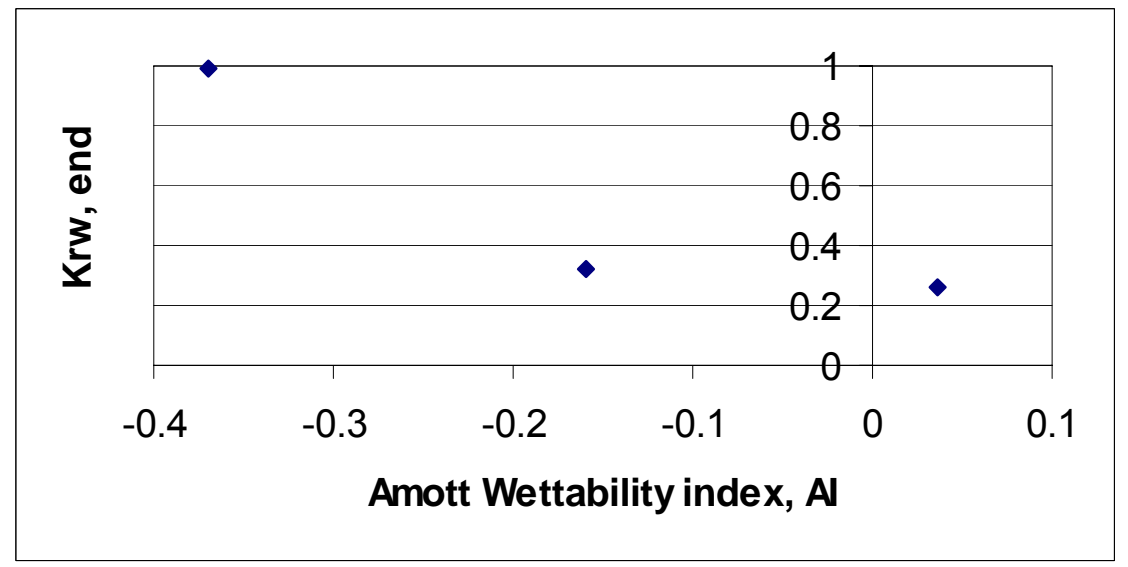

Figure 18: Correlation between end point water imbibition relative permeability and wettability

Mixed- or oil-wettability is developed in rocks when originally brine filled rocks are invaded by oils with polar organics. Capillary pressure during this invasion dictates the smallest pores oil can invade. Thus smaller pores remain occupied with brine and they remain water-wet. Thus one expects cores with more small pores and microporosity to be more water-wet than cores with larger pores. In these experiments, pore throat size increases from samples 4 to 5 to 6 . Thus, water wettability decreases from samples 4 to 5 to 6 as demonstrated in figure 17 . The 
permeability of the core samples shows a linear correlation with the Amott wettability index. The end-point water relative increases as cores become more oil-wet, as shown in figure 18.

\section{Phase II:}

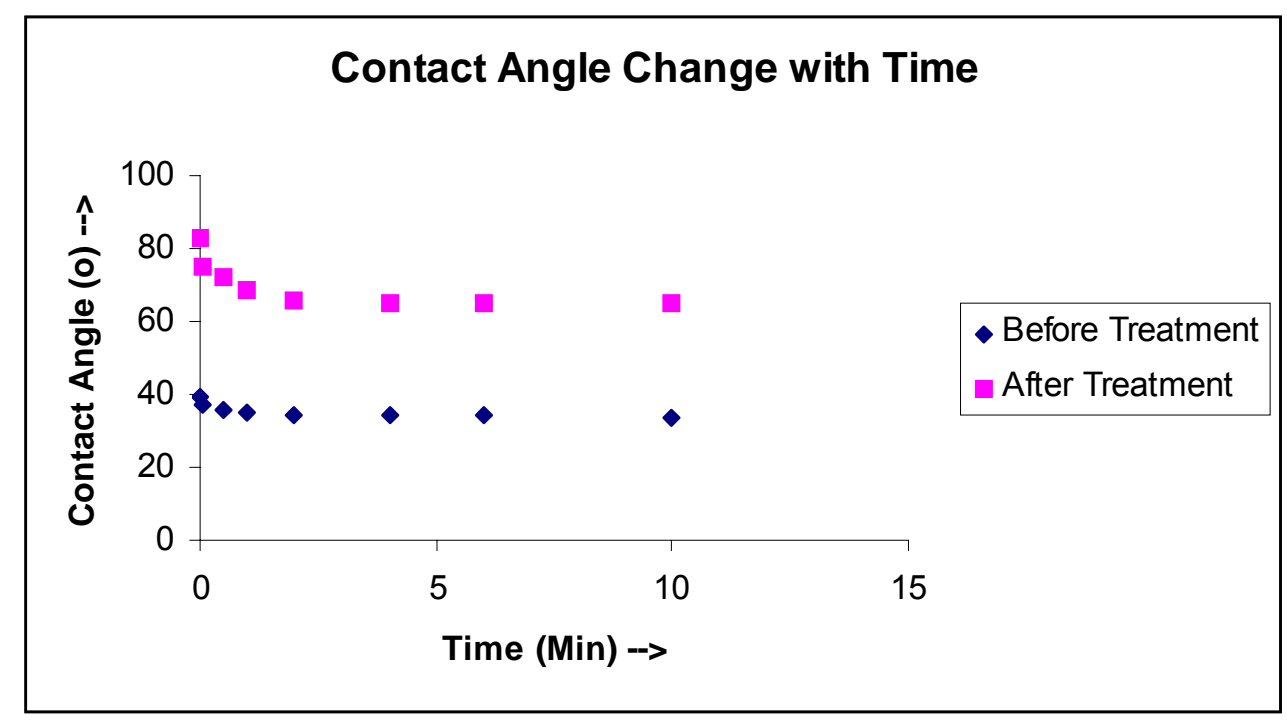

Figure 19: Contact angle change with time, at large times we get equilibrium contact angle

Contact Angle. In all cases of contact angle measurement, a high initial contact angle was observed which decreased to the final advancing contact angle in less than five minutes. Figure 19 shows a typical contact angle change with time (for surfactant B, before and after treatment). In all our analysis, we would be concerned about the final angle, which is listed in this report.

Table 6 shows the change in contact angle because of fluoro-silane surfactants on calcite surface. Table 7 shows the same for a silica surface. It can be seen that the surfactants C, D and E change both silica and calcite surfaces into intermediate wetting. As the number of fluoro groups increases in the surfactant, the extent of water repellency increases, hence, the surface becomes less water-wetting. This is clearly seen from tables 6 and 7. 
Table 6. Contact angle on calcite surface after 1-day aging

\begin{tabular}{|c|c|c|}
\hline Surfactant & \multicolumn{2}{|c|}{ Contact Angle (degree) } \\
\hline & Before Treatment & After Treatment \\
\hline A & 33.7 & 64.8 \\
\hline B & 32.6 & 50.6 \\
\hline C & 34 & 74.2 \\
\hline D & 32.7 & 111 \\
\hline E & 33.2 & 114.4 \\
\hline
\end{tabular}

Table 7. Contact angle on silica surface after 1-day aging

\begin{tabular}{|c|c|c|}
\hline Surfactant & \multicolumn{2}{|c|}{ Contact Angle (degree) } \\
\hline & Before Treatment & After Treatment \\
\hline A & 17 & 65.5 \\
\hline B & 16.2 & 67.7 \\
\hline C & 16.4 & 94 \\
\hline D & 17.2 & 100 \\
\hline E & 16.2 & 115 \\
\hline
\end{tabular}


Table 8. Effect of aging of surfactant on calcite surface

\begin{tabular}{|c|c|c|}
\hline Surfactant & \multicolumn{2}{|c|}{ Contact Angle (degree) } \\
\hline & 1-day aging & 6-day aging \\
\hline A & 64.8 & 69 \\
\hline B & 50.6 & 49.5 \\
\hline C & 74.2 & 73 \\
\hline D & 111 & 110 \\
\hline E & 114.4 & 115 \\
\hline
\end{tabular}

Table 8 gives the effect of aging time on the wettability alteration. It can be seen from table 8 that 1-day period is sufficient for the flouro-silanes to bond on the surface rendering it intermediate wetting. The weight of the mineral plates was also monitored. There was no change in the weight by repeated aging, suggesting a monolayer deposition of the surfactants than multiple layers. Table 9 gives the stability of the surfactant treated plates to different brines. It can be seen that once deposited, the surfactant is stable in different brines.

Table 9. Stability of deposited film in field brine calcite surface

\begin{tabular}{|c|c|c|}
\hline Surfactant & \multicolumn{2}{|c|}{ Contact Angle (degree) } \\
\hline & 6-Day aging & Additional 1 week in Field Brine \\
\hline A & 69 & \\
\hline B & 49.5 & 72.5 \\
\hline C & 73 & 111.2 \\
\hline D & 110 & 114.6 \\
\hline E & 115 & \\
\hline
\end{tabular}


Table 10. Effect of surfactant concentration on calcite contact angle

\begin{tabular}{|c|c|c|}
\hline Surfactant & \multicolumn{2}{|c|}{ Contact Angle (degree) } \\
\hline & 4 Wt \% (in Methanol) & 1 Wt\% (in Methanol) \\
\hline C & 73 & 78 \\
\hline D & 110 & 112.8 \\
\hline E & 115 & 112 \\
\hline
\end{tabular}

Table 11. Effect of surfactant concentration on silica contact angle

\begin{tabular}{|c|c|c|}
\hline Surfactant & \multicolumn{2}{|c|}{ Contact Angle (degree) } \\
\hline & 4 Wt \% (in Methanol) & 1 Wt\% (in Methanol) \\
\hline C & 94 & 65 \\
\hline D & 100 & 120 \\
\hline E & 115 & 112 \\
\hline
\end{tabular}

From the above results it is seen that the surfactants C, D and E change the wettability for both the silica and carbonate surfaces from water wetting to intermediate wetting conditions. These surfactants are studied at lower concentrations. The results of wettability change at $1 \mathrm{wt} \%$ surfactant are reported in table 10 for calcite and table 11 for silica plate. It can be seen that a 1 wt\% solution is as effective in wettability alteration as $4 \mathrm{wt} \%$ for surfactants D and E. 
Table 12. Effect of solvent in surfactant solution preparation on wettability

\begin{tabular}{|c|c|c|c|c|}
\hline Surfactant & \multicolumn{2}{|c|}{ Contact Angle (Calcite) } & \multicolumn{2}{c|}{ Contact Angle (Silica) } \\
\hline & (In Methanol) & $\begin{array}{c}\text { (In Methanol- } \\
\text { Field Brine) }\end{array}$ & (In Methanol- \\
(In Methanol) & Field Brine) \\
\hline C & 78 & 26.6 & 65 & 18 \\
\hline D & 112.8 & 120 & 120 & 108 \\
\hline E & 112 & 26 & 112 & 16.7 \\
\hline
\end{tabular}

Table 13. Properties of the carbonate cores used for spontaneous imbibition

\begin{tabular}{|l|c|c|c|}
\hline Core & $\mathbf{2}$ & $\mathbf{7}$ & $\mathbf{9}$ \\
\hline Surfactant & None & $\mathrm{F}$ & $\mathrm{D}$ \\
\hline Permeability k (mD) & 120 & 117 & 119 \\
\hline Length(cm) & 14.93 & 14.55 & 15.15 \\
\hline Diameter (cm) & 3.82 & 3.82 & 3.82 \\
\hline Porosity & 22.5 & 22.2 & 22.6 \\
\hline Residual brine saturation before treatment (\%) & 65 & 67.5 & 65 \\
\hline Gas permeability at residual saturation (mD) & .21 & 0.13 & .25 \\
\hline Residual brine saturation after treatment (\%) & - & 42.5 & 56.25 \\
\hline Gas permeability at residual saturation (mD) & - & 20.5 & 7.97 \\
\hline
\end{tabular}

Table 12 shows the contact angles for the flouro-silanes prepared in 1:3 methanol to field brine. It was observed that surfactant $\mathrm{E}$ formed a gel in these conditions, and surfactant $\mathrm{C}$ and D formed suspensions. The calcite and silica plates were dipped in these solutions and the left for aging for a period of 1 day. The contact angles measured after drying these aged plates is given 
in table 12. It can be seen that except only surfactant D renders the surfaces intermediate-wet when prepared with field brine. Core tests are being conducted to evaluate the effect of this surfactant treatment on effective gas permeability.

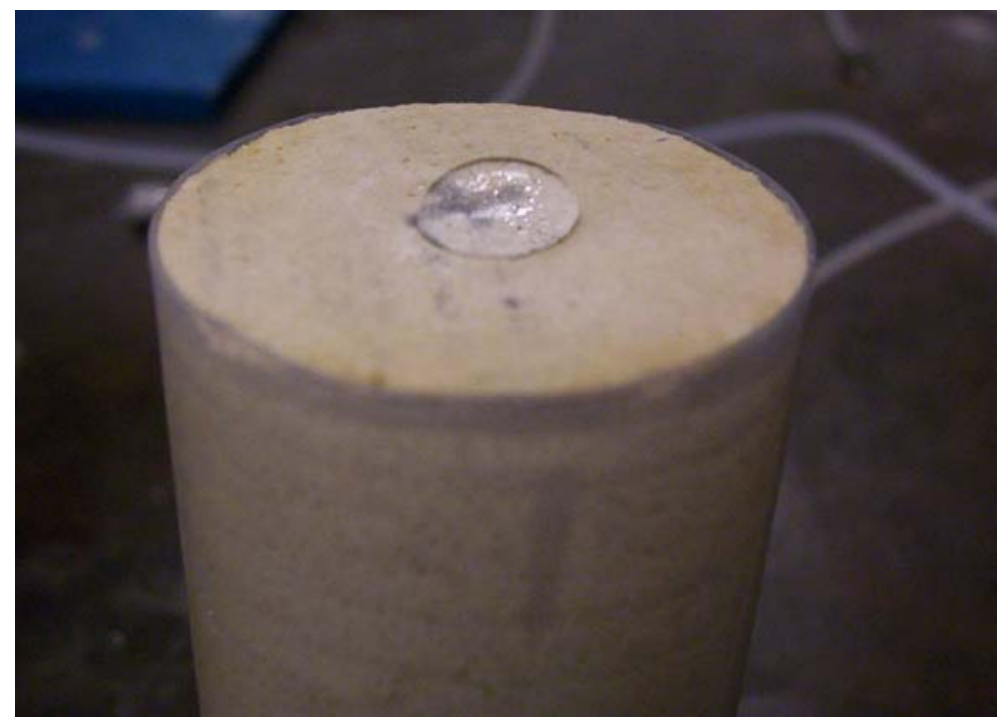

Figure 20: Photograph of the core after treatment with surfactant F, indicating change in wettability of the surface. The drop of brine does not imbibe spontaneously into the rock.

Imbibition. Table 13 gives the physical properties of the carbonate cores used for imbibition studies. It also gives the values of relative permeability of gas at residual brine saturation before and after treatment along with the saturations. It can be seen that in the case of surfactant $\mathrm{F}$, the residual brine saturation was altered considerably ( $25 \%)$ and the gas relative permeability increased almost 160 times after treatment. Figure 20 shows a photograph of a brine drop on top of the core after treatment with surfactant $F$, indicating a change in wettability of the surface. The drop of brine does not imbibe spontaneously into the carbonate rock because of the intermediate wettability of the rock. In the case of surfactant $\mathrm{D}$, the residual brine saturation decreased by $\sim 10 \%$ and the gas relative permeability increased by a factor of $\sim 30$. These are significant, but lower than that of surfactant F. It was noticed that the surfactant F-treated core was intermediate-wet on both flat sides (from the drop experiment shown in figure 20), but the 
surfactant D-treated core was intermediate-wet only on the surfactant injected flat side. There is a difference in the method of wettability alteration between the slab-scale and the core-scale experiments. In slab experiments, the slab was dried after the treatment. In the case of core experiments, the cores were all flushed with ethanol and brine after the treatment of the surface. The core flushing sequence can be improved in the future to achieve better wettability alteration.

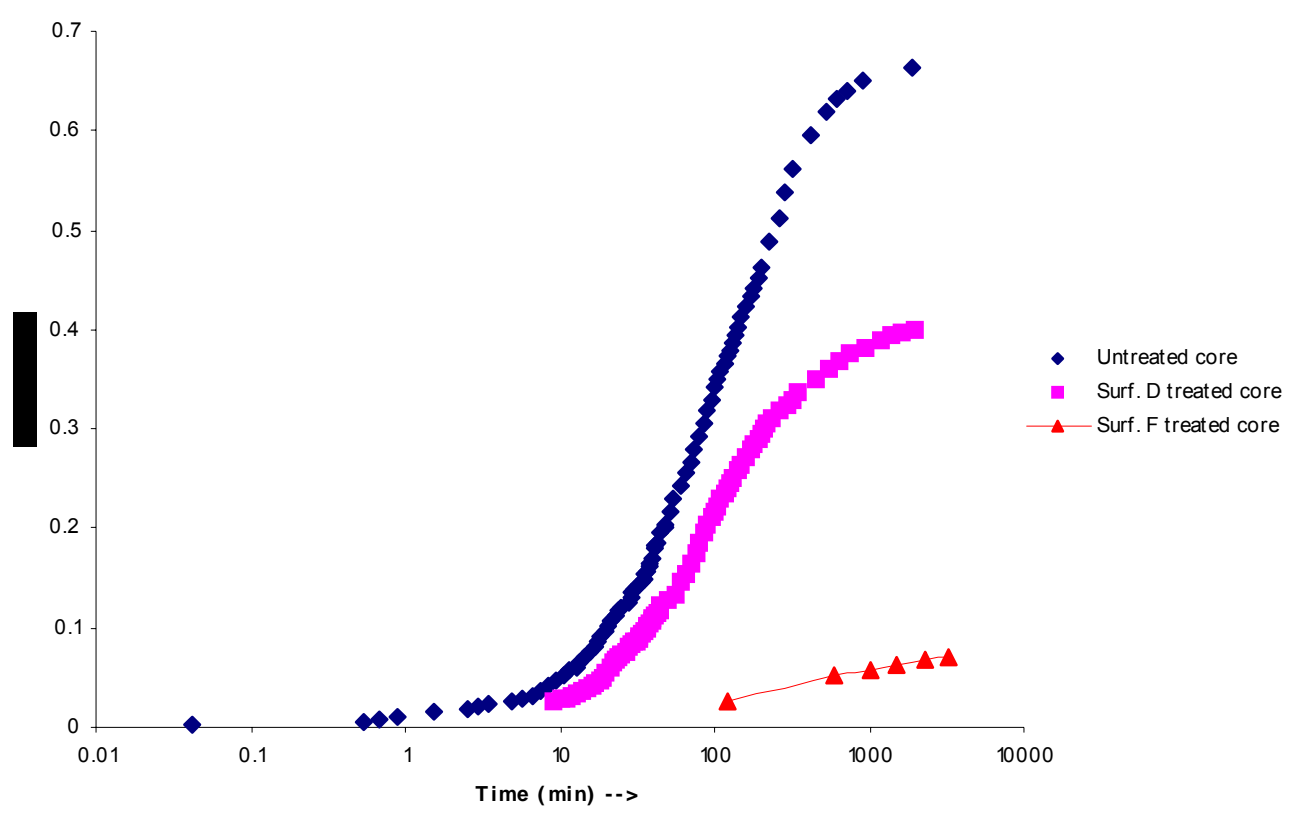

Figure 21: Spontaneous imbibition in carbonate cores at room temperature for case of untreated core, core treated with surfactant $D$ and core treated with surfactant $\mathrm{F}, \mathrm{S}_{\mathrm{wi}}=0 \%$, and $\mathrm{k}=120 \mathrm{mD}$

Figure 21 shows the amount of brine imbibed spontaneously as a function of time. The brine imbibition was 67.5\% OGIP (original gas in place) in about 20 hours for the untreated core. For the core treated with surfactant D, the brine imbibition was about 40\% OGIP. For the core treated with surfactant F, it reduced to 7.5\% OGIP. Surfactant F succeeded in changing the wettability of the core and increasing gas permeability at residual brine. 
Residual permeability curves

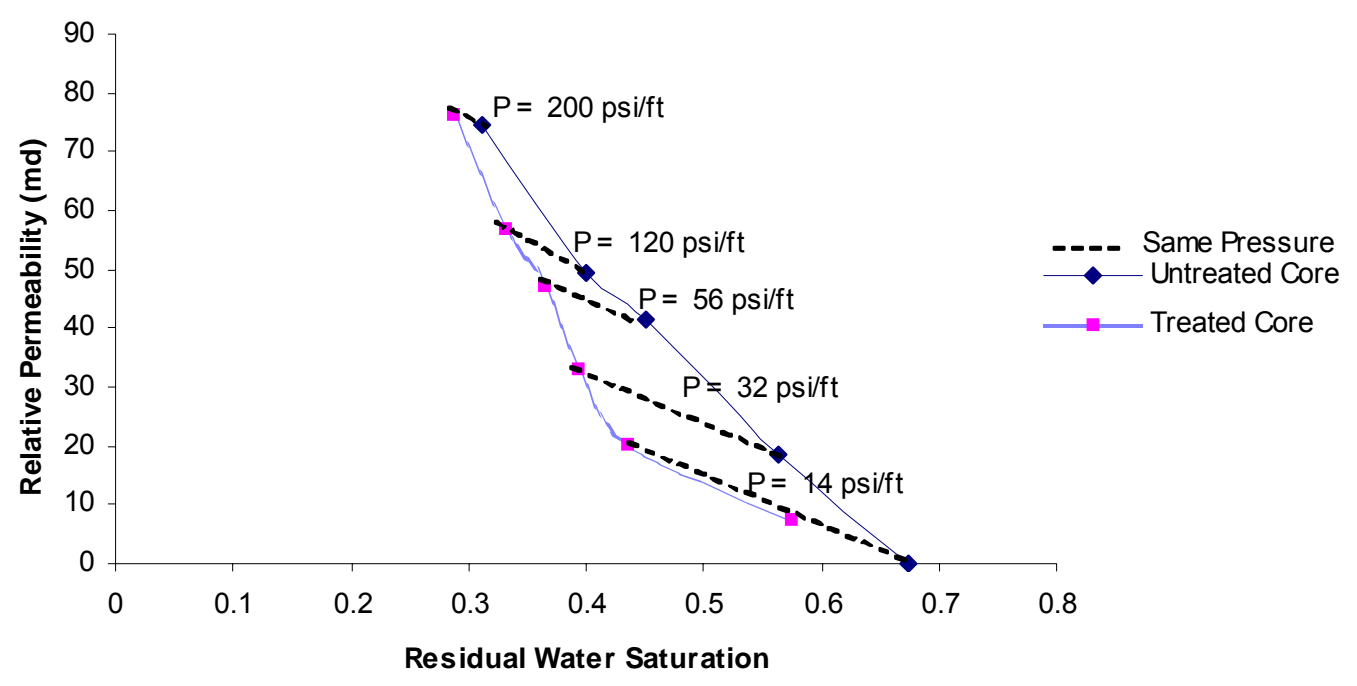

\section{Figure 22: Residual permeability of gas for treated and untreated cores at different pressure drops across the core.}

Two cores, one untreated and the other treated with surfactant F, were then used to study the gas relative permeability at different residual water saturations. The cores were initially $100 \%$ water saturated. Then, they were gas flooded with humidified $N_{2}$ gas at different pressure drops. The pressure gradients used were 14 psi/ft., 32 psi/ft., 56 psi/ft., 120 psi/ft. and 200 psi/ft. At each condition, the core was allowed to reach an equilibrium, which was noted by no additional production of water. The gas relative permeability was measured and the residual saturation was back-calculated by monitoring the production of water. The results of the experiment are shown in figure 22. It can be seen that for the same pressure gradient, the treated core showed a higher gas relative permeability than the untreated. For $200 \mathrm{psi} / \mathrm{ft}$, the capillary number defined as $N_{c}=\frac{\Delta P \mathrm{k}}{\sigma L}$ is $\mathrm{O}\left(10^{-5}\right)$. At this capillary number for gas as the wetting phase, the non-wetting phase (water) saturation starts decreasing with the increase of the capillary number. This could be the reason for the low saturation and high permeability at the highest 
pressure gradient for the treated core. Overall, the treated core gas permeabilities are higher than those of the untreated core at all pressure gradients. ${ }^{3}$

Slimtube. The oil production as a function of PV injection is shown in figure 23 for different regulator pressures (600-2000 psi). For each pressure, the oil production increases linearly with injection until the production reaches a plateau. The linear production profile implies piston-like displacement. The production history does not change significantly between 1170 and $2500 \mathrm{psi}$; the plateau oil recovery is about $76 \mathrm{ml}$. For lower pressures, the plateau oil recovery increases with the pressure.

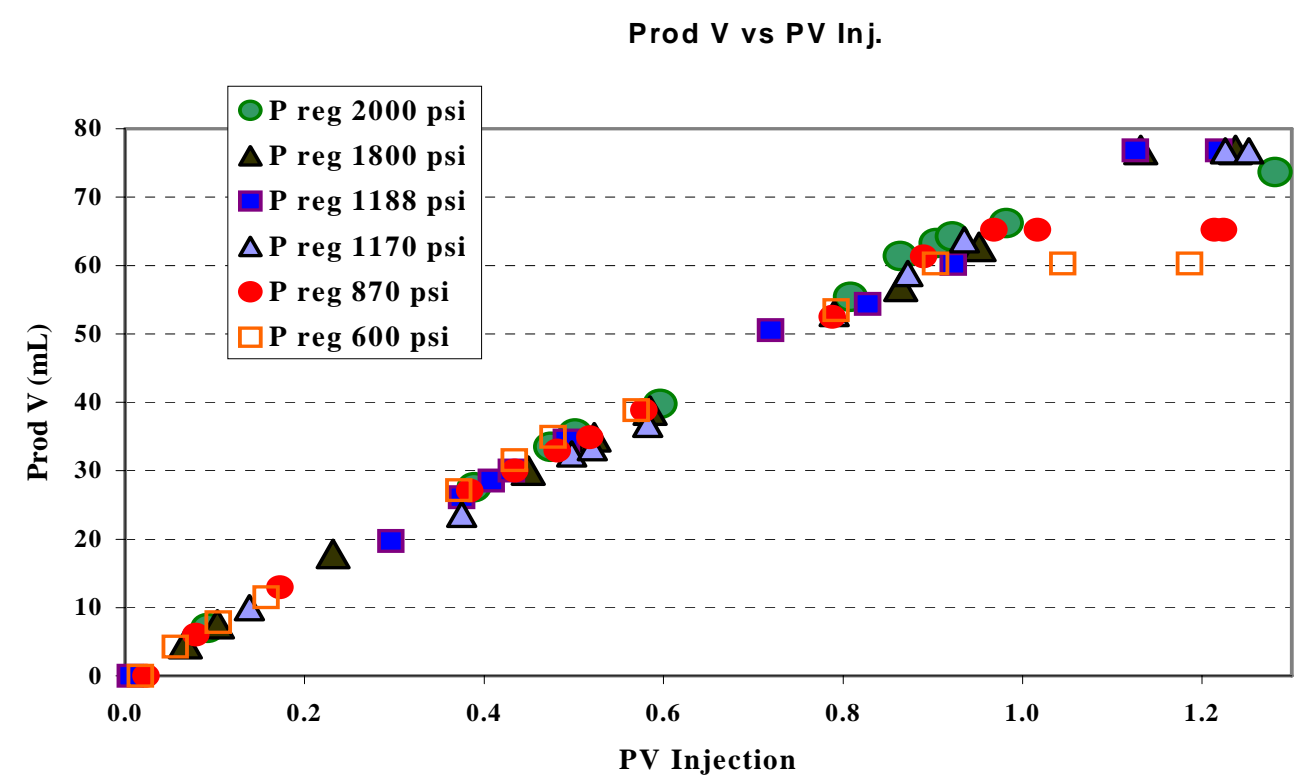

Figure 23: Oil production versus $P V$ injection

Figure 24 shows the percentage oil recovery as a function of $\mathrm{CO}_{2}$ injection. The oil recovery at $1.2 \mathrm{PV}$ is $>95 \%$ of the original oil in place for pressures greater than $1170 \mathrm{psi}$. 


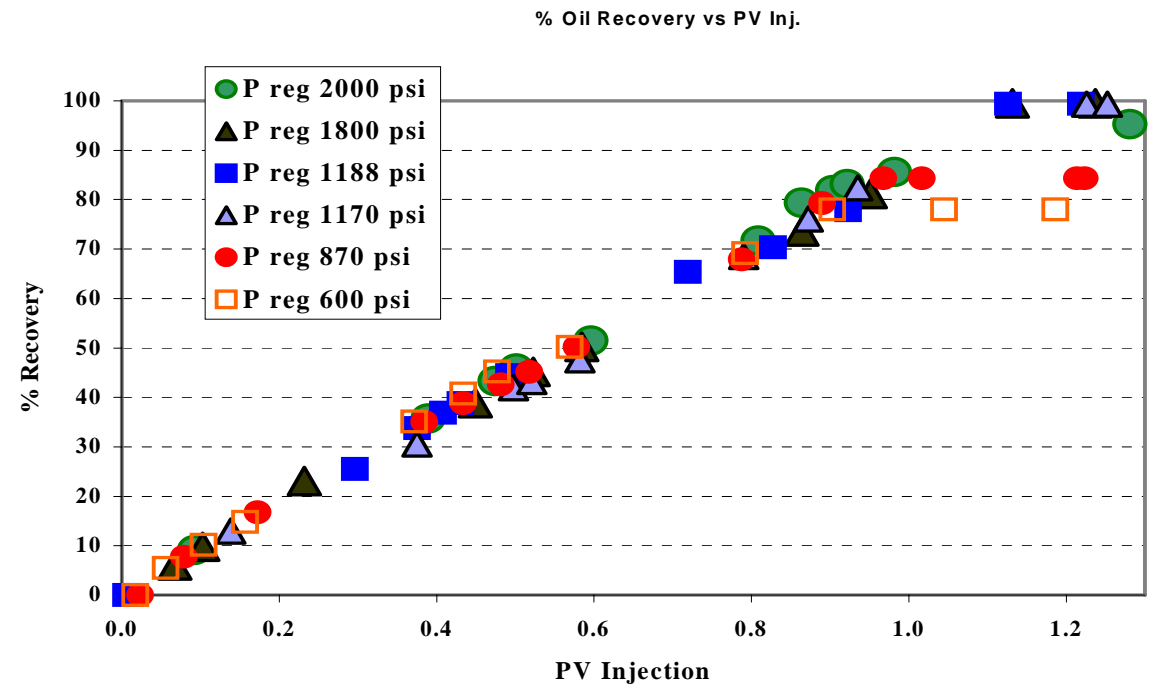

Figure 24: Percentage oil recovery versus PV injection

Figure 25 shows the plot of percentage oil recovery versus pressure of the regulator. As the pressure increases, the recovery at 1.2 PV increases and plateaus above 1,170 psi. Thus, MMP for this oil is about 1,170 psi for $\mathrm{CO}_{2}$ injection.

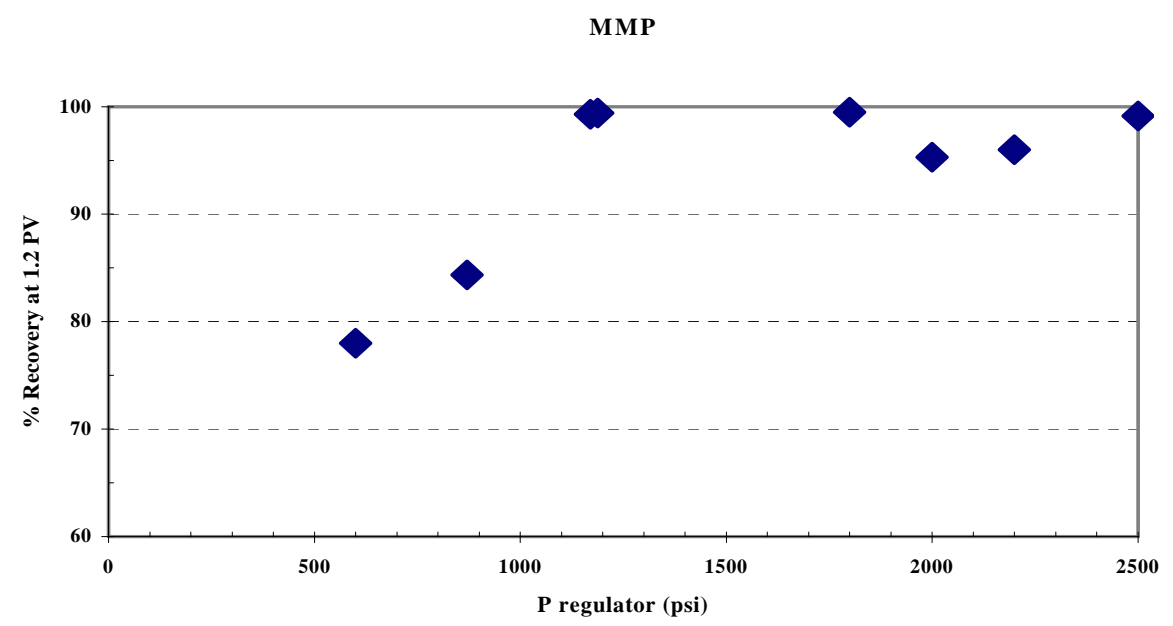

Figure 25: Recovery at 1.2 PV versus pressure 
Methane Huff-n-Puff. As methane is introduced into the core, the differential pressure between the top and the bottom of the core reduces rapidly before reaching a plateau region. The typical pressure drop through the core versus time is shown in figure 26.

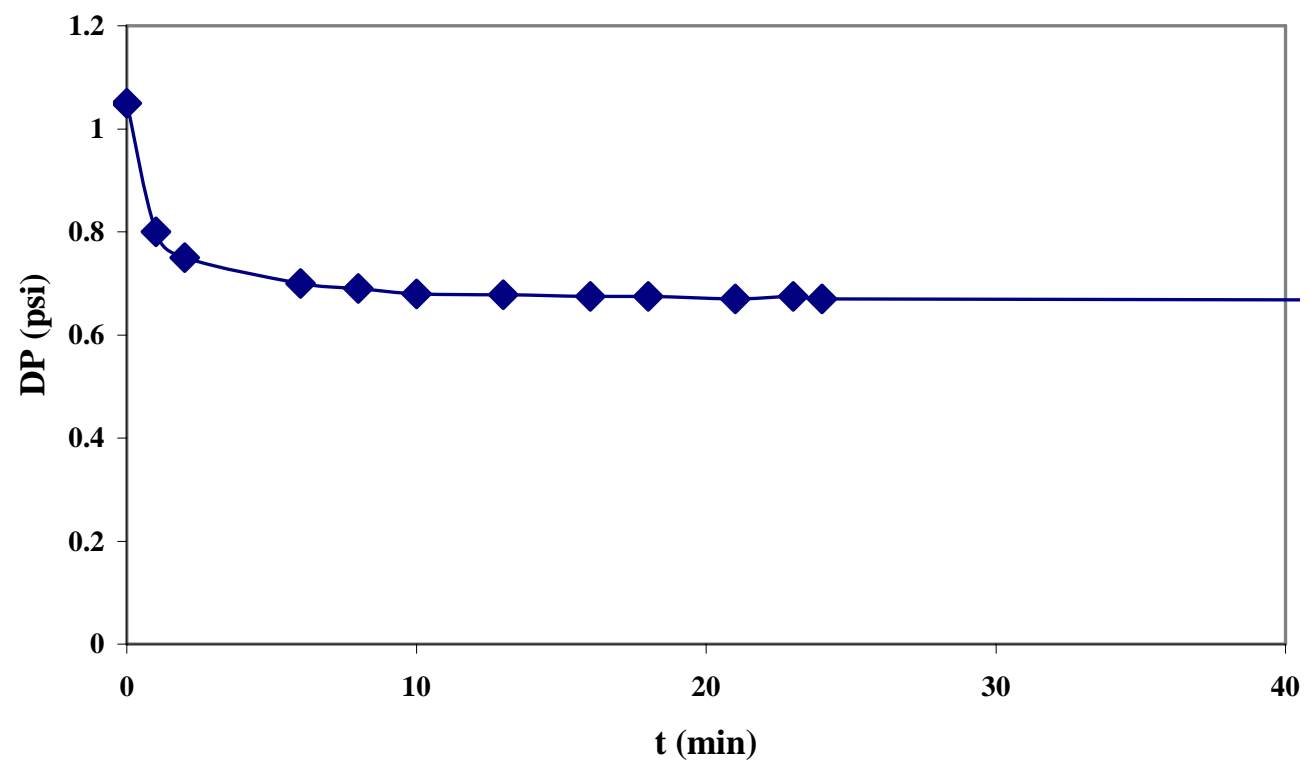

Figure 26: Pressure drop versus time

Figure 27 shows the pressure regulator setting as a function of time. In the first run (blue curve), the regulator pressure is slowly reduced. The pink curve shows a rapid depressurization of the core. 


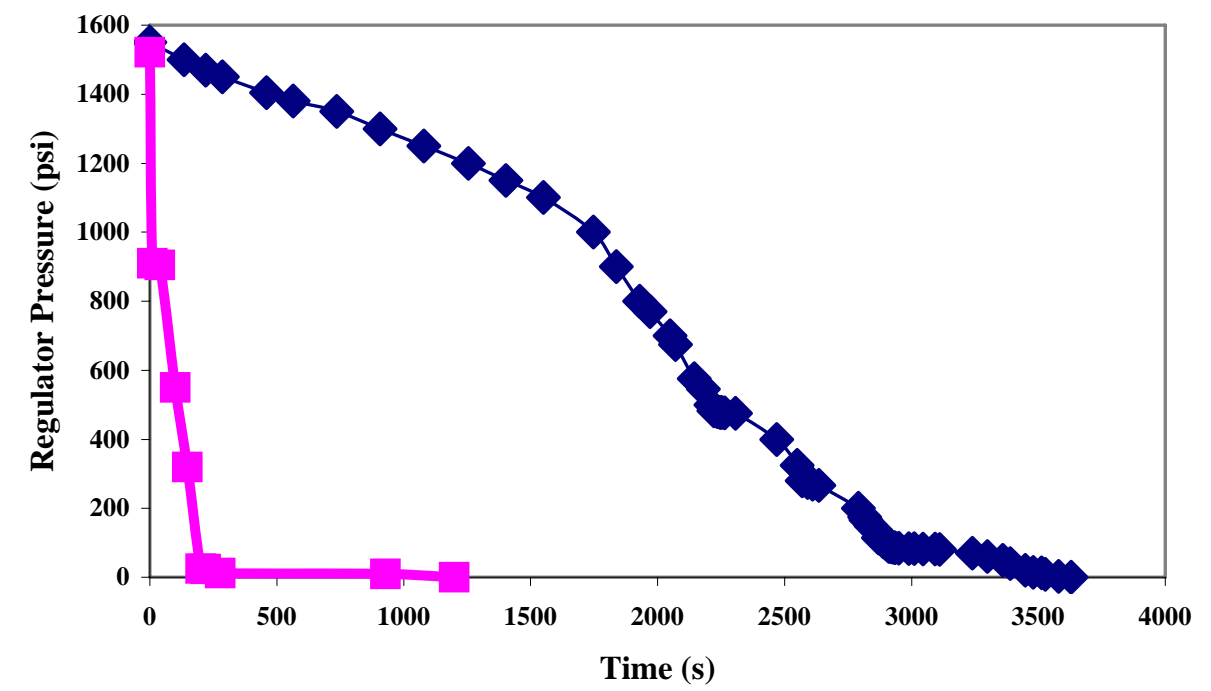

Figure 27: Regulator pressure versus time

Figure 28 shows the percentage oil recovery as a function of regulator pressure. The pink curve corresponds to rapid depressurization while the blue curve corresponds to slow depressurization.

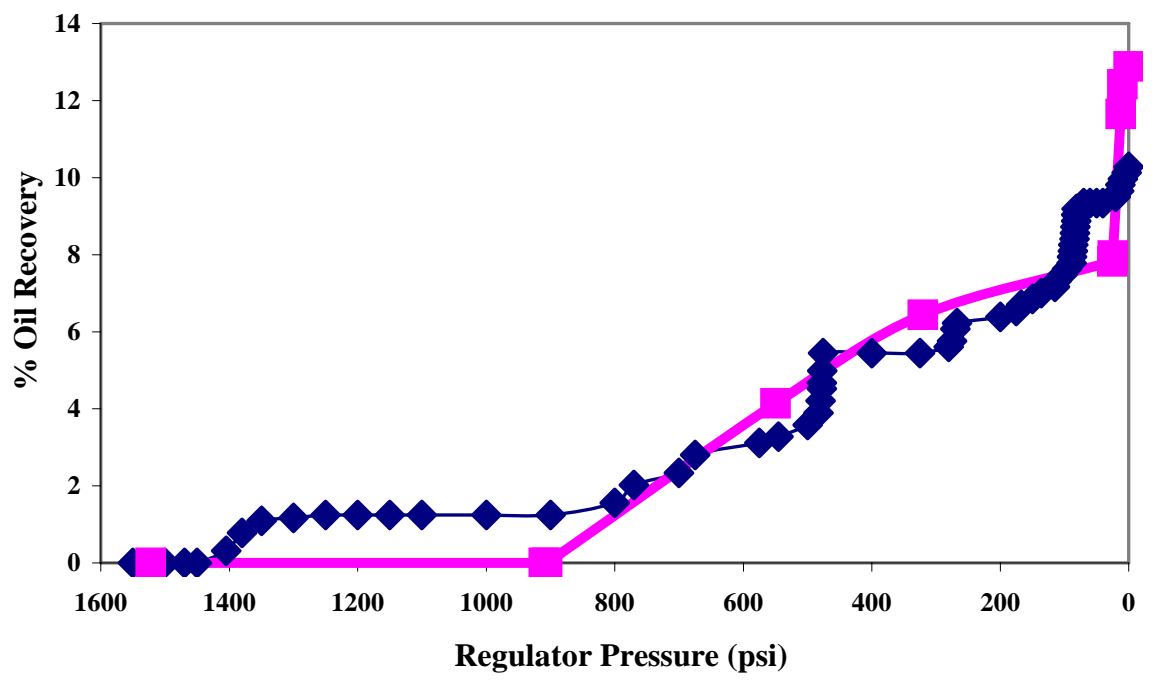

Figure 28: Percentage oil recovery versus regulator pressure 
Figure 29 shows the percentage oil recovery as a function of time. For the case of rapidly depressurization (pink curve) of the core, about $12.9 \%$ of oil in the core is recovered. On the other hand, slowly depressurization (blue curve) of the core results in $10.3 \%$ oil recovery.

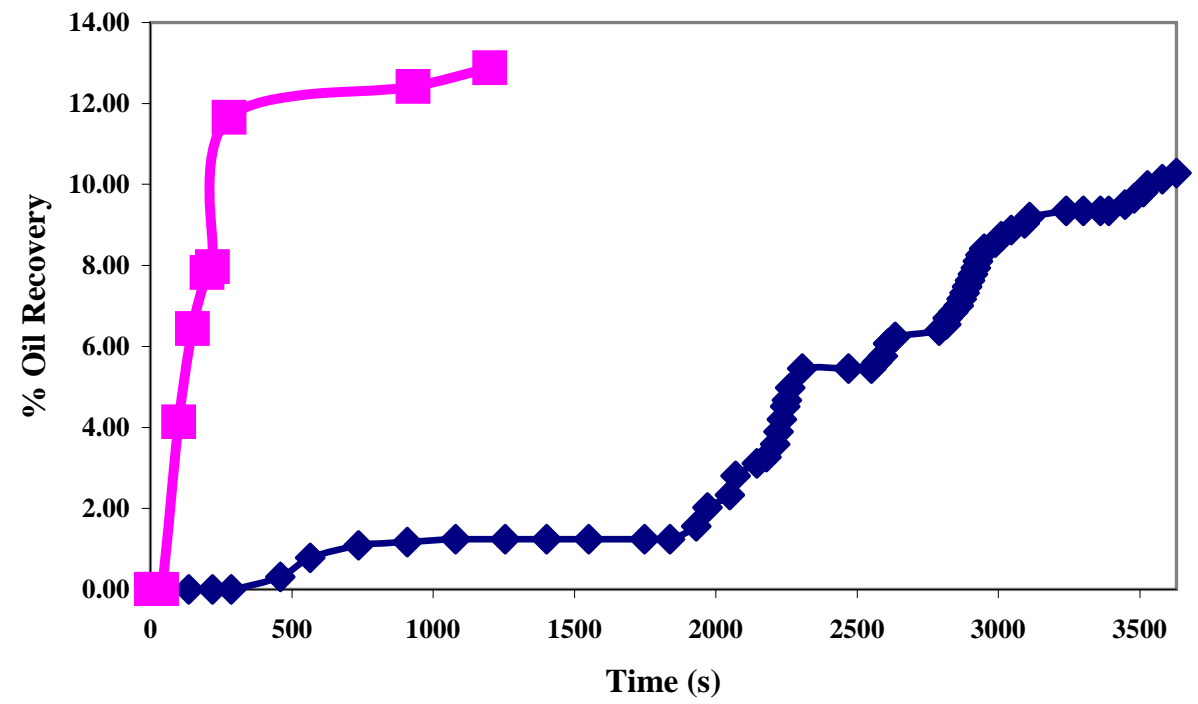

Figure 29: Percentage oil recovery versus time

\section{Phase III: Surfactant-aided Imbibition Simulation}

Recovery from an oil-wet core by using surfactants depends on various parameters. The important parameters which are analyzed by the simulator are the ability of the surfactant to alter wettability and to lower interfacial tension. The results of these simulations are discussed in this section.

Effect of IFT Reduction. The oil recovery from an oil-wet core starts by diffusion of the surfactant molecules into the porous media, and when the surfactant reaches the oil-water interface, it reduces the interfacial tension between the two phases. This reduction in the IFT leads to decrease in the macroscopic bond number $N_{B}^{-1}$. This reduction leads to imbibition of water into the rock surface thereby displacing the oil by buoyancy forces. The extent of recovery 
depends on the decrease in the IFT between the two phases but also depends on the extent of wettability alteration by the surfactant. Consider three cases:

A) Surfactant which alters the wettability of the porous media to water-wet in nature. In this case, the primary mode of oil recovery is by capillary forces. A reduction in IFT in this case reduces the capillary forces, thereby slowing the rate of recovery.

B) Surfactant which does not alter the wettability of the porous media, or alters wettability slightly where the final state is still oil-wet in nature. In this case the primary mode of oilrecovery would be by buoyancy forces and, hence, a decrease in IFT can lead to increase in the rate of recovery, as more area of the porous media can be invaded by decrease in IFT.

C) Wettability is altered to an intermediate wet regime. In this case, any reduction in IFT causes no reduction in the capillary forces, and no change to buoyancy forces; hence, the recovery should be independent of IFT. The recoveries also depend on the permeability of the porous medium. The effect of IFT and permeability for $75^{\circ}$ final contact angle is shown in the following.

In this case, surfactant is assumed to alter the wettability of the porous medium as a function of surfactant concentration (as explained in earlier section) from initial state of $150^{\circ}$ contact angle to a final state of $75^{\circ}$ contact angle. The dimension of the core is $0.04 \mathrm{~m}$ in diameter and $0.1 \mathrm{~m}$ in length. Note that the permeability is $7 \mathrm{mD}$. The IFT for the system is varied from 30mN/m (implying no decrease in IFT), $1 \mathrm{mN} / \mathrm{m}, 0.1 \mathrm{mN} / \mathrm{m}$ (as would be the case for cationic surfactants) and $0.001 \mathrm{mN} / \mathrm{m}$ (as would be the case with some anionic surfactants). The recovery rates for these cases are shown in figure 30 . 


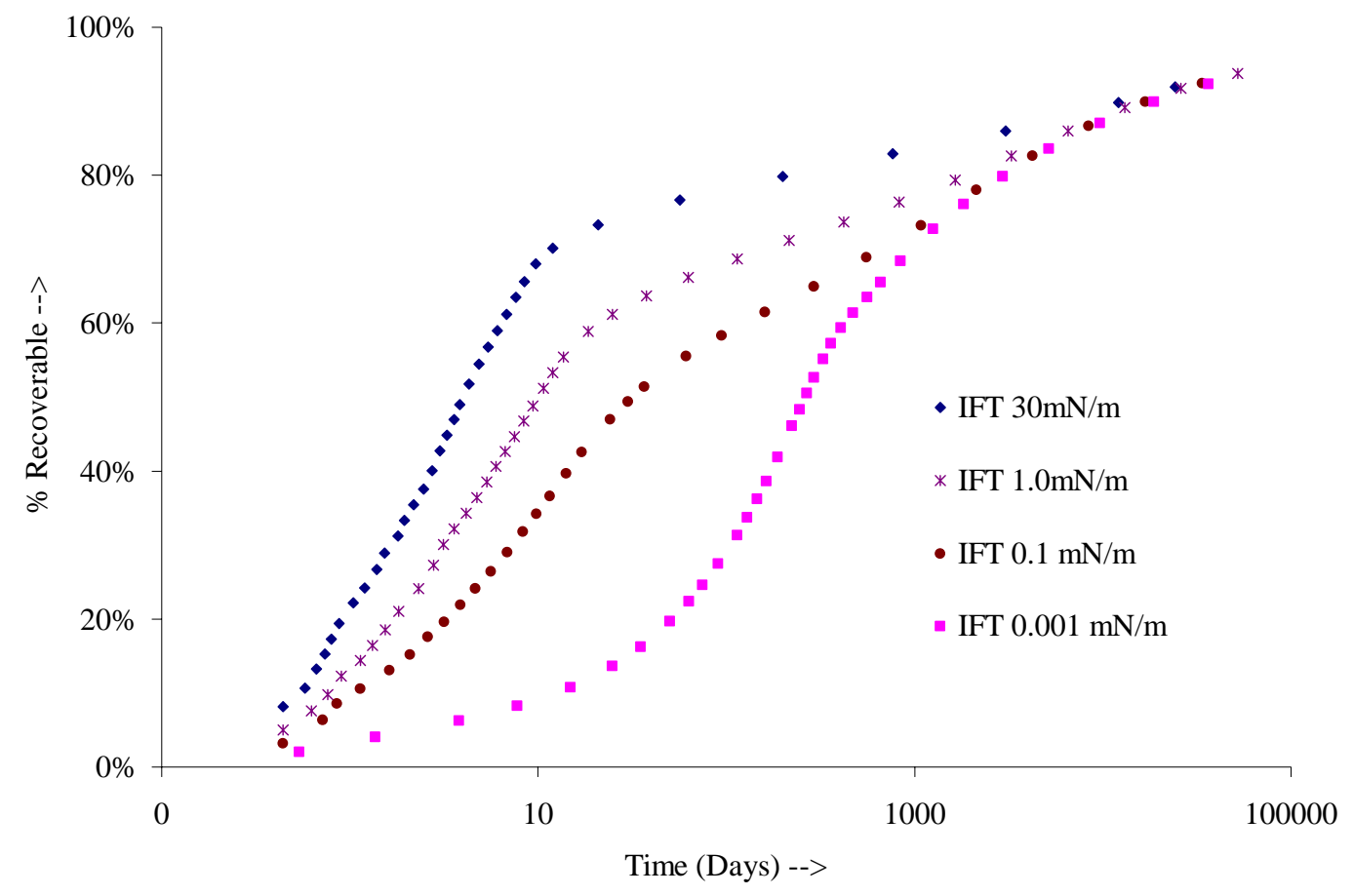

Figure 30: Recovery rates for a $7 \mathrm{mD}$ core

As expected a decrease in IFT leads to decrease in the rate of recovery, because for water-wet case decreasing IFT decreases the capillary pressure which is the driving force for recovery. As the IFT is reduced the effect of permeability reduction becomes more and more prominent. In case of IFT of $0.001 \mathrm{mN} / \mathrm{m}$, the $0.1 \mathrm{mD}$ and $7 \mathrm{mD}$ curves are recalibrated with capillary dimensionless group and gravity dimensionless group to $150 \mathrm{mD}$ curve. For example, for $0.1 \mathrm{mD}$ the time is readjusted by multiplying the original time by $(0.1 / 150)$ to match the 150 $\mathrm{mD}$ time with gravitational scaling, and multiplied by $(0.1 / 150)^{1 / 2}$ to match $150 \mathrm{mD}$ time with capillary scaling. Figure 31 shows the calibration of the gravitational scaling. Figure 31 shows that at later times with recovery $>60 \%$, all the plots match to a single curve, indicating that the major mechanism of recovery after $60 \%$ of oil is recovered is by gravitational means. 


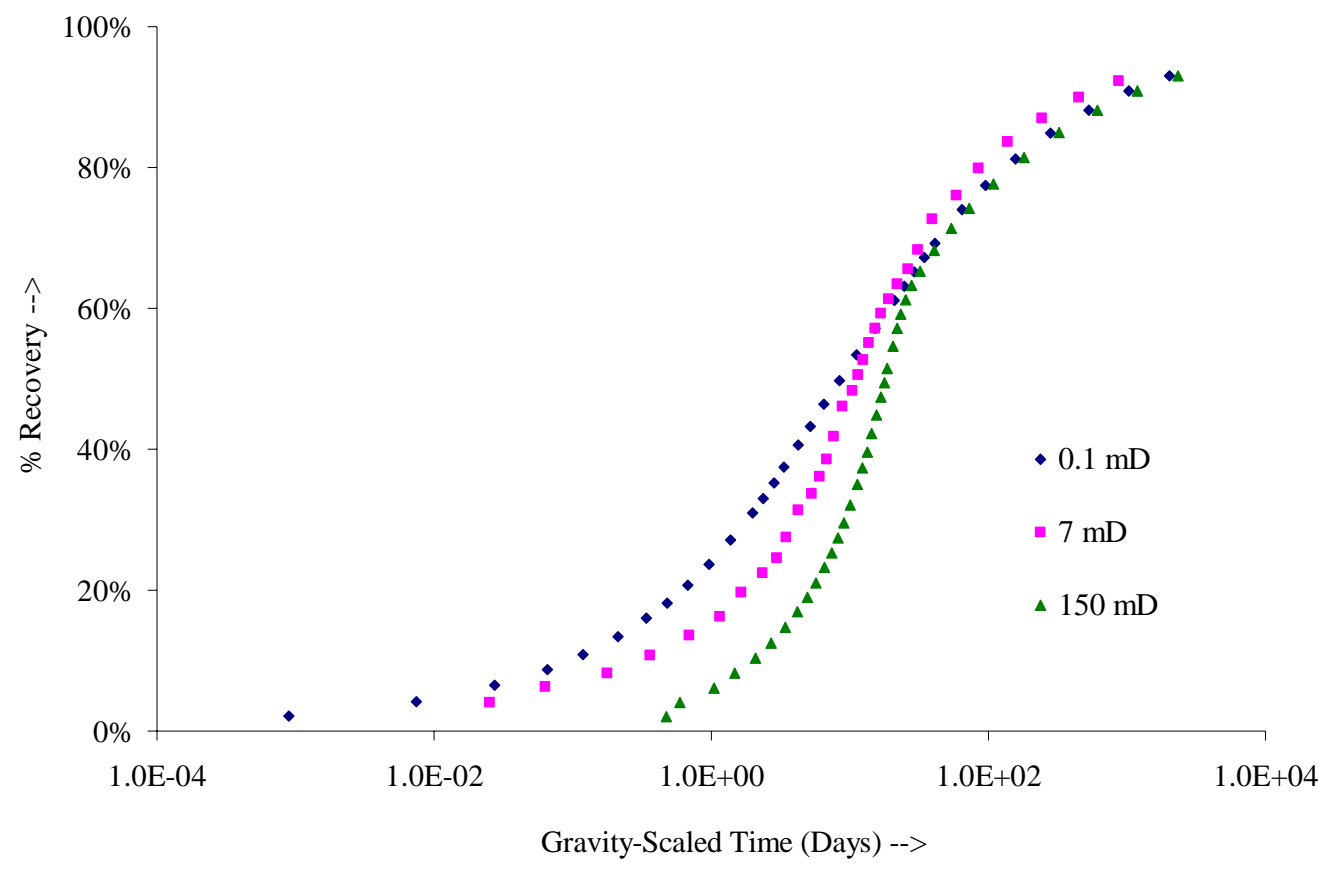

Figure 31: Scaling of $0.001 \mathrm{mN} / \mathrm{m}$ IFT reduction and $75^{\circ}$ final contact angle curve with gravitational scaling group to match $150 \mathrm{mD}$ curve.

Figure 32 shows the calibration of the capillarity scaling. At earlier times with recovery < $20 \%$, all the plots match to a single curve, indicating that the major mechanism of recovery before $20 \%$ of oil is recovered is by capillary forces. In the region of $20 \%$ recovery to $60 \%$ recovery, neither of the dimensionless groups work as both capillarity and gravity are equally important in this regime. 


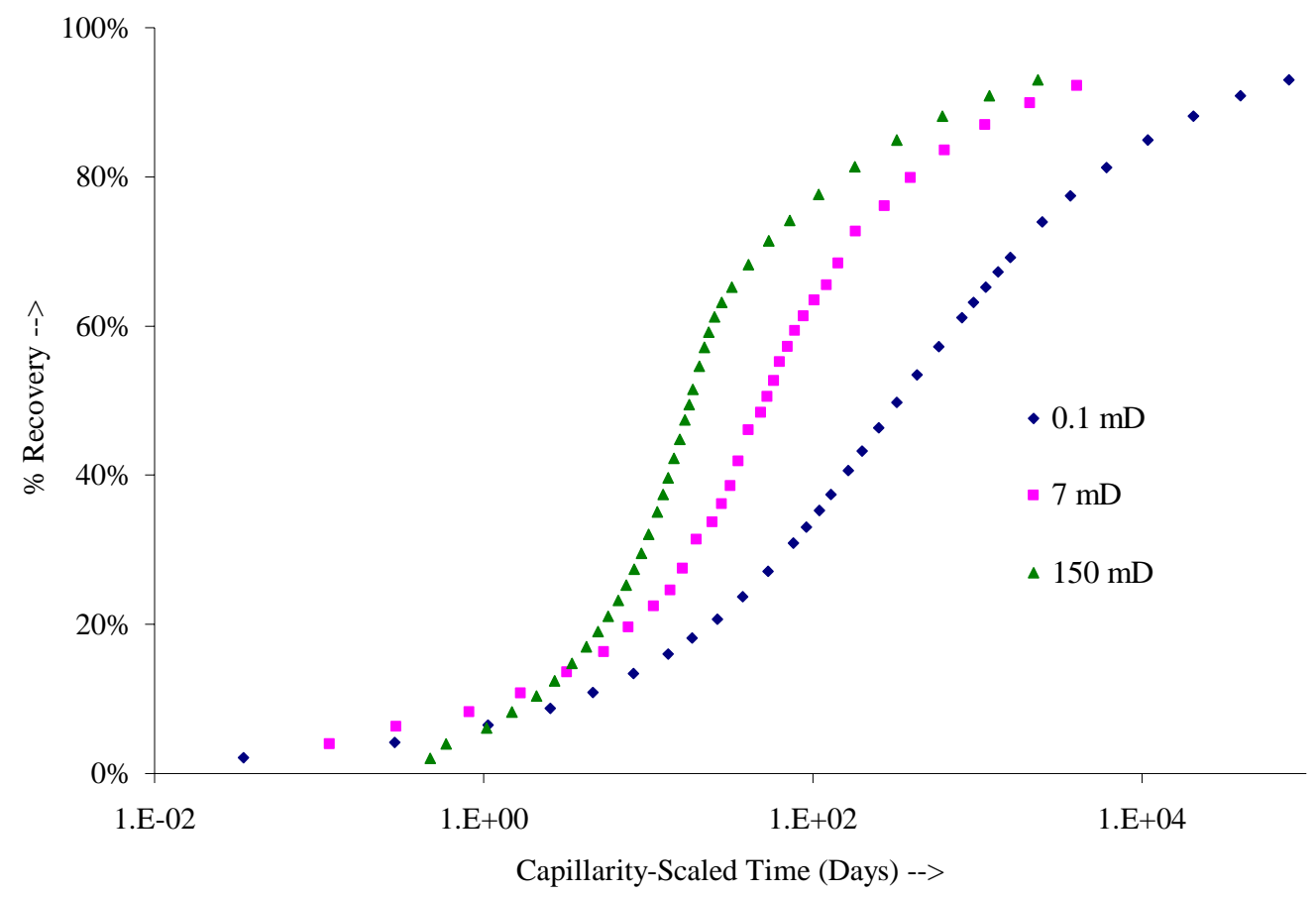

\section{Figure 32: Scaling of $0.001 \mathrm{mN} / \mathrm{m}$ IFT reduction and $75^{\circ}$ final contact angle curve with capillary scaling group to match $150 \mathrm{mD}$ curve.}

Effect of Wettability Alteration. The effect of wettability on oil recovery depends on the extent of IFT reduction, in principle. The simulations in the previous subsection can be used to plot the recoveries for a given IFT and permeability with varying contact angle. In general, as the contact angle decreases, meaning surfactant alters wettability towards water-wet regime, for a capillary driven process (high IFT surfactants), the capillary pressure becomes a higher positive value; hence, more water-wet rock increases the rate of recovery. For a low IFT system, as the contact angle decreases, the capillary pressure becomes a negative value, but because of low IFT, the capillary pressure is still a low value. On the other hand as the wettability becomes more towards water-wet regime, oil phase becomes non-wetting; hence, its relative permeability increases, which leads to increased oil recovery. From these arguments, it can be seen that irrespective of IFT reduction a decrease in contact angle, going towards more water-wet regime increases the rate of oil recovery. 
This section shows the effect of contact angle variation for a given IFT reduction and permeability of the core. Only IFT of $1 \mathrm{mN} / \mathrm{m}$ and $0.001 \mathrm{mN} / \mathrm{m}$ results are shown to explain the results for a cationic surfactant and anionic surfactant system. Figure 33 shows the effect of contact angle for a surfactant which lowers IFT to $0.1 \mathrm{mN} / \mathrm{m}$ for different permeabilities. We can see that as the surfactant alters wettability to water-wet regime, the rate of oil recovery increases. The effect of wettability alteration becomes more important as the permeability decreases.

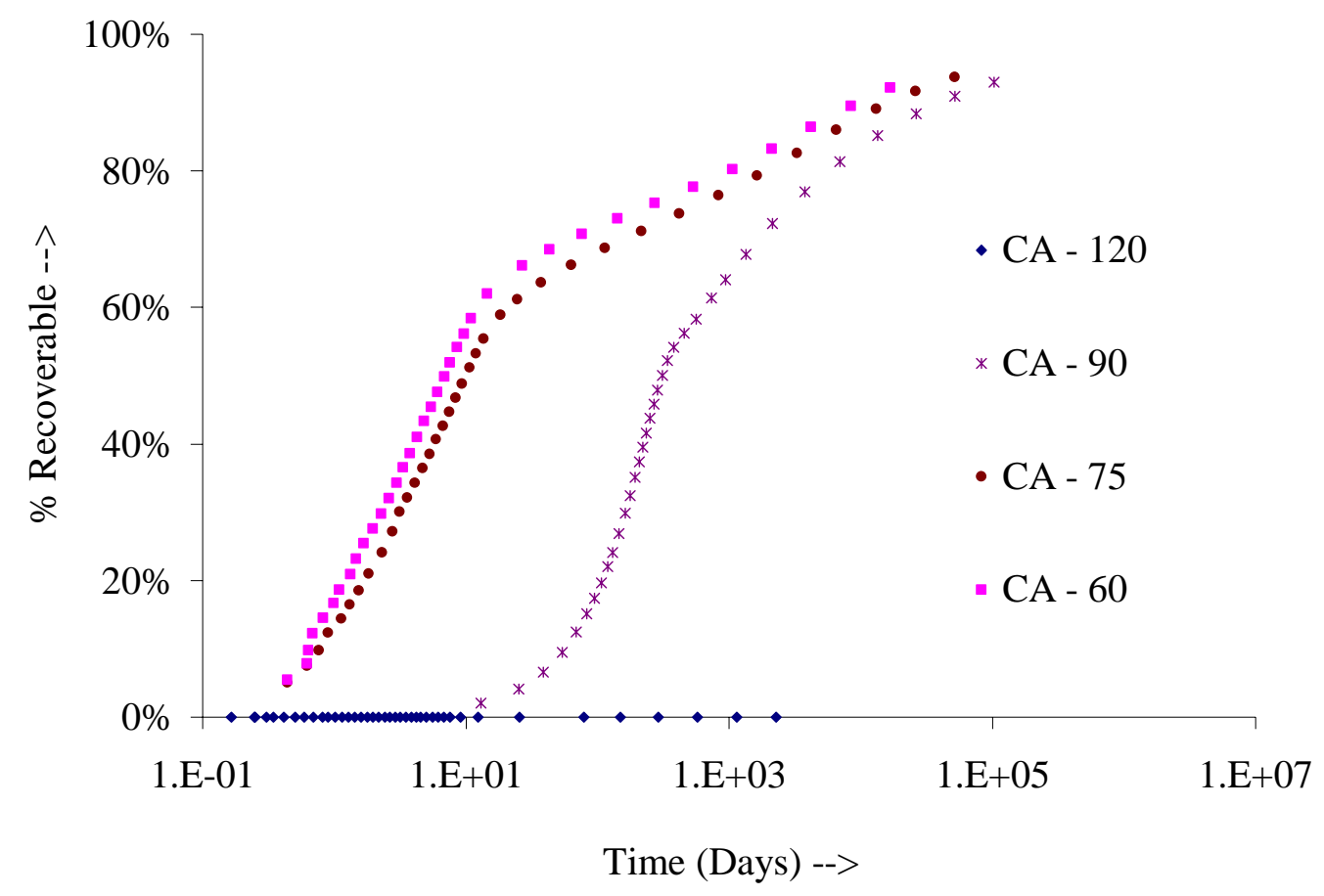

Figure 33: Effect of wettability alteration for a surfactant which lowers IFT to $1 \mathrm{mN} / \mathrm{m}$ for $7 \mathrm{mD}$ porous media.

Figure 34 shows the effect of contact angle for a surfactant which lowers IFT to 0.001 $\mathrm{mN} / \mathrm{m}$ for different permeabilities. This is a representative of anionic surfactant, and we can see that as the surfactant alters wettability to water-wet regime, the rate of oil recovery increases. The effect of wettability alteration becomes more important as the permeability decreases. ${ }^{4}$ 


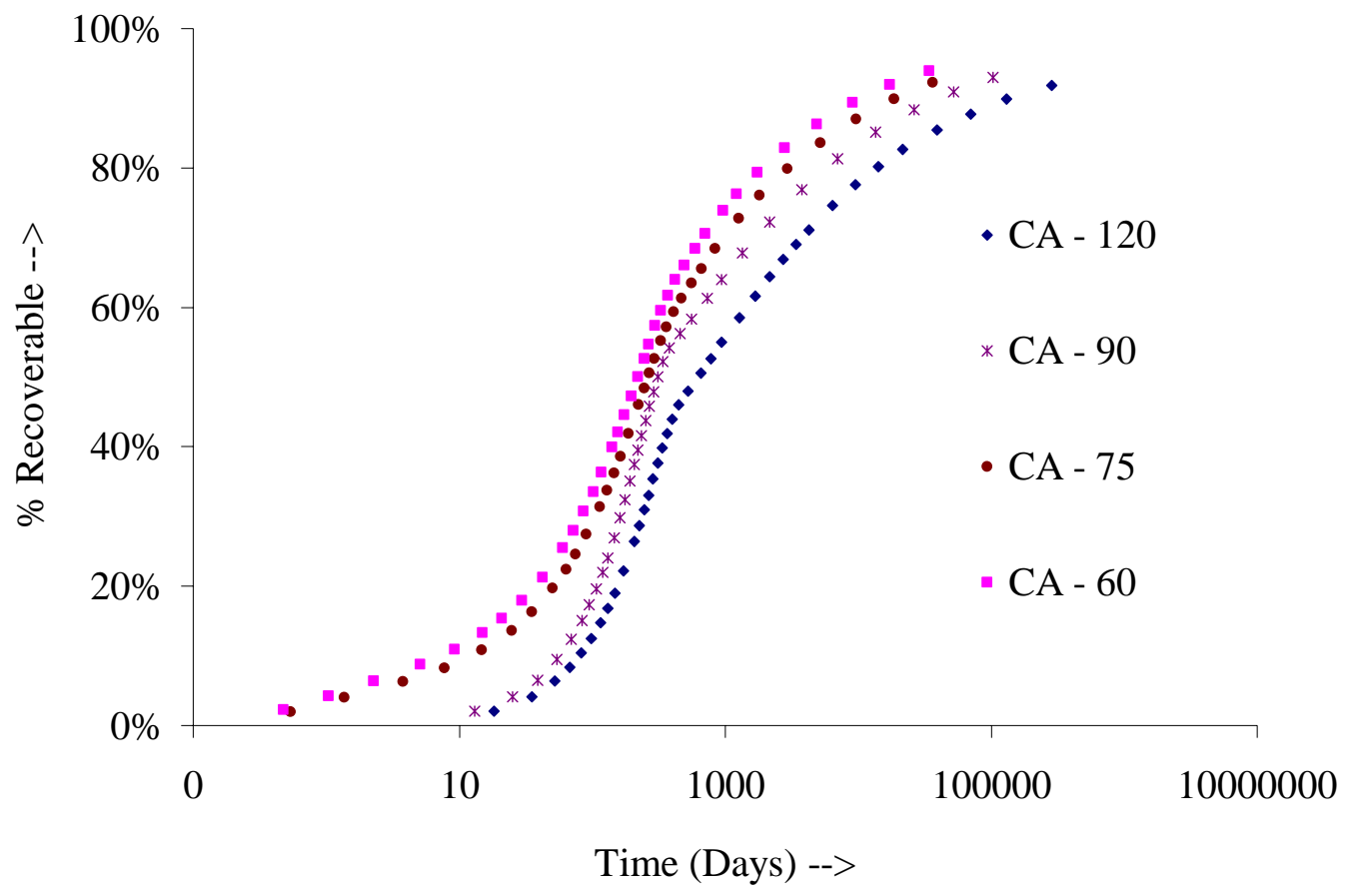

Figure 34: Effect of wettability alteration for a surfactant which lowers IFT to $0.001 \mathrm{mN} / \mathrm{m}$ for $7 \mathrm{mD}$ porous media. 


\section{Results and Discussion}

\section{Geological Analysis}

Jim Derby, Derby and Associates

\section{Introduction}

This report completes the data-gathering and basic stratigraphic analysis phase of studies of Marjo Operating Company well cores in West Carney Hunton field (West Carney Hunton field). ${ }^{5}$ The basic geologic setting of the field has been described by the writer and co-authors in earlier reports of this work, principally in the report for Budget Period I (DOE \#15125R08, http://www.tucrs.utulsa.edu/Hunton/Reports/15125R08.pdf) ${ }^{6}$, and a report published in the Shale Shaker ${ }^{7}$, the journal of the Oklahoma City Geologic Society, as well as in Search and Discovery, the electronic publication medium for the AAPG. ${ }^{8}$

This report includes all data developed in the field from detailed studies of 26 cores in West Carney Hunton field and 2 cores on the north and southeast flanks of the field. These data are:

- Core descriptions of 28 cores totaling 1510.9 feet of core; previous core descriptions have been revised with new data from petrographic study thin sections and peels, and from improved understanding of the Hunton fauna.

- Description of 219 thin sections with $35^{\text {th }}$ percentile pore diameter (not pore throat radii) measurements.

- Paleontologic data from 305 samples dissolved in acid to recover conodonts.

- Pore type and lithofacies characterization of each foot of core, assembled with porosity and permeability data from core analysis, with brief descriptions of thin sections and several hundred acetate peels.

- Composite plots of wireline well logs and porosity \& permeability core data, depth adjusted to bring cores and logs to equivalent depths, and graphically displayed for 27 cores, described as “core-log plots”. The $28^{\text {th }}$ core was not subjected to core analysis. 
- Core photographs for 14 cores (14 were published in the report for Budget Period I). To view these photographs, go to:

http://www.tucrs.utulsa.edu/Hunton/Reports/15125R08_CorePhotos/MASTER\%20LIST.pdf

- Lithologic descriptions of the 6 Hunton stratigraphic units present in the field and subdivision into megafacies complexes.

For detailed core descriptions, core-log plots, core photos, paleo-conodont samples, pore and facies codes and analysis, and thin section descriptions go to:

http://www.tucrs.utulsa.edu/Hunton/Reports/15125R20_Geology/bp2_geology.stm

Wells cored by Marjo Operating Company and studied for this report are listed alphabetically in table 14 and shown by geographic (Township-Range-Section) sort in table 15. Also shown are cored interval, Hunton tops and bases, number of thin sections studied, SEM samples, conodont samples, formation(s) and faunal zone(s) present, and major lithologies of the core. A map of cored wells and outlines of the field is provided in the Budget Period I Report. 
Table 14. Cored wells in West Carney Hunton field, alphabetical

\begin{tabular}{|c|c|c|c|c|c|c|c|c|c|c|c|c|c|c|c|c|}
\hline \multirow[b]{2}{*}{ well \# } & \multirow[b]{2}{*}{ Well Name } & \multirow[b]{2}{*}{ Iwp-Rng } & \multicolumn{2}{|l|}{ Hunton Top } & \multirow{2}{*}{$\begin{array}{c}\text { Core } \\
\text { log } \\
\text { Adj }\end{array}$} & \multirow[t]{2}{*}{$\begin{array}{l}\text { Top } \\
\text { LAS } \\
\text { Log }\end{array}$} & \multicolumn{2}{|c|}{ Hunton Base } & \multirow{2}{*}{$\begin{array}{l}\begin{array}{c}\text { Thick- } \\
\text { ness }\end{array} \\
\text { Feet }\end{array}$} & \multicolumn{7}{|c|}{ Status \& Data, $*=$ Completed } \\
\hline & & & Core & Log & & & Core & Log & & mk & IS & PC & SEM & Cono & Fmizone & Lithology \\
\hline \multirow{2}{*}{$\begin{array}{l}\text { All well } \\
5943 \\
5943\end{array}$} & IIs listed are Marjo operatingo & 0. Inc. wells & & & & & & & & & & & & & & \\
\hline & Anna 1-15 & $15-15 N-2 E$ & 4967.1 & 4947.0 & 20.1 & 4928.0 & 5004.7 & 4985.0 & \begin{tabular}{c|c}
37.6 \\
cored
\end{tabular} & c & $10^{*}$ & c & & $9^{*}$ & 3 & Dol \\
\hline 6011 & Bailey $2-6$ & 6-15N-3E & $x(4876)$ & 4875.0 & -2.8 & & $X(4934)$ & 4964.0 & $\begin{array}{c}58 \text { cored; } \\
289 \mathrm{iog}\end{array}$ & c & $20^{*}$ & c & & $25^{\star}$ & $5 a, 4 b, 4 a, ? 3$ & 14' Dollis \\
\hline 5913 & Boone 1-4 & $4-15 \mathrm{~N}-2 \mathrm{E}$ & $\times(5037)$ & 5028.0 & 6.5 & 5008.0 & 5066.5 & 5060.0 & $\begin{array}{c}29.5+ \\
\text { cored } 32 \\
\log \end{array} \mid$ & c & $6^{*}$ & c & & $6^{*}$ & 3 & Ls' dol LS' $4^{\prime}$ dol \\
\hline 6088 & Cal 1-11 & $\begin{array}{l}\text { NE_SE } 11- \\
15 N-1 E\end{array}$ & $\times(5034)$ & 5025.0 & 2.3 & & 5135.8 & 5133.5 & \begin{tabular}{|c|}
101.8 \\
cored \\
$108.5 / 0 g$
\end{tabular} & c & $0^{*}$ & c & & $21^{*}$ & 3 & \begin{tabular}{|c} 
no pent br facies, \\
LS, off-reef, deep \\
water at base
\end{tabular} \\
\hline 5992 & Carney Townsite 2-5 & $5-15 N-3 E$ & $\times(4906)$ & 4907.0 & 0.0 & & $\begin{array}{c}\times(4966) ; \\
49785 ;\end{array}$ & 4978.0 & $\begin{array}{c}60 \text { cored; } \\
71 \mathrm{jog}\end{array}$ & c & $8^{*}$ & c & & $16^{*}$ & $5,5 a, 4 a$ & Dolls \\
\hline 5934 & Carter $1-14$ & $14-15 N-2 E$ & $\times(4940)$ & 4927.0 & 13.3 & 4917.0 & 4995.8 & 4983.0 & $\begin{array}{c}56.1 \\
\operatorname{cosed} 56 \\
\log \end{array}$ & c & $16^{*}$ & c & & $18^{*}$ & 3,0 & 1'doll Ls' 2'dol \\
\hline 6051 & Carter Ranch 2-15 & $15-15 N-2 \mathrm{E}$ & 5006.0 & 5000.0 & 6.0 & & 5035.1 & 5030.0 & $\begin{array}{c}29.1 \\
\text { cored }\end{array}$ & c & $5^{*}$ & c & & $6^{*}$ & 3,0 & LSIDol \\
\hline 6281 & Chandler SNDW \# 1-5 & $5-14 N+3 E$ & $X(4810)$ & 4797.5 & 12.0 & & $\begin{array}{c}\times(4869.8) \\
4877.5 L\end{array}$ & 4865.5 & \begin{tabular}{|c|}
59.8 \\
cored 68 \\
$\log$
\end{tabular} & c & $6^{*}$ & c & & $14^{*}$ & $5,4 b, 4 a$ & $31^{\prime}$ dol/28' shaly LS \\
\hline 5838 & Danny 2-34 & $34-16 N-2 E$ & $X(4930)$ & 4918.0 & 10.8 & 4898.0 & 4984.3 & 4973.5 & $\begin{array}{l}54.3+ \\
\text { cored }\end{array}$ & c & $2^{\star}$ & c & & $11^{*}$ & 3,0 & LS \\
\hline & Geneva 2-32 (not analyzed) & $32-16 N+3 E$ & $x(4889)$ & 4873.0 & 15.0 & & $\begin{array}{l}\times(4898.7) \\
4968 M L\end{array}$ & $\begin{array}{c}4952.0 \\
\text { mudlogger }\end{array}$ & $\mid \begin{array}{c}9.7 \mathrm{ft} \\
\text { cored } 64^{4} \\
\text { by } \\
\text { mudlogge } \\
r\end{array}$ & c & $6^{*}$ & NA & & $4^{*}$ & 5 & Ls, Dol (Cri pkstn) \\
\hline 5874 & Joe Givens $1-15$ & $15-15 N+2 E$ & 5017.8 & 5010.0 & 9.0 & 4990.0 & 5044.0 & 5035.0 & $\begin{array}{l}26.2 \\
\text { cored }\end{array}$ & c & $0^{*}$ & c & & $4^{*}$ & 3 & Lsi $0.1^{\prime}$ dol \\
\hline 6209 & Griffen 1-14 & $\begin{array}{l}\text { NW-NW-SN } \\
\text { 14-15N-1E }\end{array}$ & $\times(5082)$ & 5077.0 & 5.0 & & $\begin{array}{l}\times(5142) ; \\
5191.5 i\end{array}$ & 5186.5 & $\begin{array}{l}60 \text { cored } \\
109.5 \mathrm{log}\end{array} \mid$ & c & $6^{*}$ & c & & $14^{*}$ & 5 & Lsidollimy dol \\
\hline 5818 & Henry 1-3 & $3-15 \mathrm{~N}-2 \mathrm{E}$ & $X(4966)$ & 4958.0 & 7.5 & 4938.0 & $\begin{array}{c}\times(4996.6) \\
5004.5 L\end{array}$ & 4997.5 & \begin{tabular}{l|l}
$30.6+$ \\
cored
\end{tabular} & c & $3^{*}$ & c & & $4^{*}$ & 3 & Lsi $5^{\prime}$ dolils \\
\hline 6100 & Mark Houser 1-11 & 11-15N!E & $\mathrm{x}(4961)$ & 4940.0 & $12 ?$ & & $\begin{array}{c}\times(5077.6) \\
750781\end{array}$ & 5066.0 & $\begin{array}{c}116.6 \\
\text { cored } \\
126 \log \end{array}$ & c & $6^{*}$ & c & & $7^{*}$ & 3 & Ls \\
\hline 6112 & J日 1-13 & $13-15 N+1 E$ & 4971.9 & 4966.0 & 5.9 & & $\begin{array}{c}\times(5058.8) \\
5125.9 L\end{array}$ & 5120.0 & $\begin{array}{c}86.9 \\
\text { cored } \\
154 \mathrm{log}\end{array}$ & c & $2^{*}$ & c & & $24^{*}$ & 3 & $\begin{array}{c}\text { Ls, reeffflank \& } \\
\text { reef }\end{array}$ \\
\hline 6029 & Kathryn 2-14 & $14-15 N+2 E$ & $\mathrm{X}(4994)$ & 4990.0 & 3.5 & & 5030.5 & 5027.0 & $\begin{array}{c}36.5 \text { core } \\
38 \mathrm{log}\end{array}$ & c & $4^{\star}$ & c & & $8^{*}$ & 3 & LSIDol/LsiDol \\
\hline 5705 & Mary Marie 1-11 & $11-15 N-2 E$ & 4961.0 & 4944.0 & 17.0 & 4924.0 & 5003.5 & 4988.5 & $\begin{array}{c}42.5 \\
\text { cored }\end{array}$ & c & $33^{*}$ & c & 4 & $14^{*}$ & 3,0 & Ls' 2'dol \\
\hline 5899 & McEride South 1-10 & $10-15 \mathrm{~N}-2 \mathrm{E}$ & $\times(4962)$ & 4947.0 & 13.3 & 4927.0 & 4996.2 & 4983.0 & $\begin{array}{c}34.3 \\
\operatorname{cored} 36 \\
\log \end{array}$ & c & $1 *$ & c & & $5^{*}$ & 3 & Lsidolls \\
\hline 6150 & Mercer $1-28$ * & $28-17 N+2 E$ & $\mathrm{x}(4527)$ & 4526.0 & 0? & & $\begin{array}{r}\times(4583) \\
4606 L\end{array}$ & 4606.0 & $\begin{array}{c}56 \text { cored } \\
80 \mathrm{log}\end{array}$ & c & $5^{*}$ & c & & $17^{\star}$ & $5,5 a, 4 b, 4 a$ & $\begin{array}{c}16^{\prime} \mathrm{Dol}, 40^{\prime} \text { shaly } \\
\text { Ls }\end{array}$ \\
\hline 6247 & Morrow 1-27 & $27-16 N+2 E$ & $\mathrm{X}(4905)$ & 4886.0 & 0.5 & & 4956.5 & 4956.0 & $\begin{array}{c}53 \text { cored } \\
68 \log \end{array}$ & c & $8^{*}$ & c & & $15^{*}$ & $4 a, 3,1 ?, 0$ & $\begin{array}{l}\text { Ls/5' dol, keel } \\
\text { oolite }\end{array}$ \\
\hline 6143 & Points 1-13 & $13-15 \mathrm{~N}-1 \mathrm{E}$ & 4989.5 & 4978.0 & 11.5 & & $\begin{array}{l}\times(5107) \\
5107.5 \mathcal{L}\end{array}$ & 5096.0 & \begin{tabular}{|c|}
117.5 \\
core 118 \\
$\log$
\end{tabular} & c & $6^{*}$ & c & & $8^{*}$ & 3 & $\begin{array}{l}2.5^{\prime} \text { Wifd, } 60^{\prime} \text { big } \\
\text { br, vuggy, } \\
57 \text { whstn, }\end{array}$ \\
\hline 6131 & Saunders $1-13$ & $\begin{array}{l}\text { SE-NE } 13- \\
15 N-1 E\end{array}$ & 4917.3 & 4911.0 & 6.3 & & $\begin{array}{c}\times(4940.5) \\
5050.3 L\end{array}$ & 5053.0 & $\begin{array}{c}23.2 \\
\text { cored } \\
142 \log \end{array}$ & c & $1 *$ & c & & $4^{*}$ & 3 & $\begin{array}{l}\text { LS, Pent } B r \text {, reef } \\
\text { flank }\end{array}$ \\
\hline 6302 & Stevenson 1-14 & $\begin{array}{l}\text { WN } 14-15 N \\
1 E\end{array}$ & $x(5143)$ & 5103.0 & 2.0 & & $\begin{array}{c}\times(5167.6) \\
5188 \mathrm{~L}\end{array}$ & 5186.0 & $\begin{array}{c}24.6 \\
\operatorname{cored~} 83 \\
\log \end{array}$ & c & $7 *$ & c & & $7^{*}$ & 5 & LSIDol \\
\hline 5733 & Toles $1-10$ & $10-15 N-2 E$ & 4964.0 & $x$ & na & па & $\begin{array}{l}5003.8 \\
5005.0 L\end{array}$ & $x$ & \begin{tabular}{c|}
39.8 \\
cored
\end{tabular} & c & $8^{*}$ & c & & $5^{*}$ & 3 & Ls' 2'dol \\
\hline 6061 & W Carney Ext SWDW \#1 & $14-15 N+1 E$ & 5042.7 & 5038.0 & 4.7 & & $\left|\begin{array}{c}\times(5131) ; 5156 \\
L\end{array}\right|$ & 5151.0 & $\begin{array}{c}88.7 \\
\text { cored } \\
113 \log \end{array}$ & c & $15^{*}$ & c & & $10^{*}$ & 3 & $L$ s, reef-flank \\
\hline 6563 & W Carney Ext SWDW \#2 & $10-15 N-1 E$ & $\mathrm{X}(5140)$ & 5133.5 & 4.5 & & $\begin{array}{l}\times(5232) \\
5275 L\end{array}$ & 5270.5 & $\begin{array}{c}92 \text { cored } \\
137 / \mathrm{log}\end{array}$ & c & $12^{*}$ & c & & $13^{*}$ & 5 & $\begin{array}{l}\text { Dol \& doltc is } \\
\text { crinoid grnstn, } \\
\text { shoal water facies }\end{array}$ \\
\hline 5712 & Wilkerson 1-3 & $3-15 \mathrm{~N}-2 \mathrm{E}$ & 4953.4 & 4937.5 & 15.8 & \begin{tabular}{|l|}
4917.0 \\
\end{tabular} & 4999.8 & 4984.0 & \begin{tabular}{c|c}
46.4 \\
cored
\end{tabular} & c & $19^{*}$ & c & 1 & $11^{*}$ & 3,0 & Ls' 2'dol \\
\hline 5887 & Williams 1-3 & $3-15 \mathrm{~N}-2 \mathrm{E}$ & 4943.5 & 4934.0 & 9.5 & 4914.0 & 4983.7 & 4974.0 & \begin{tabular}{c|c}
$\begin{array}{c}40.2 \\
\text { cored }\end{array}$ & 0 \\
\end{tabular} & c & $4^{*}$ & c & & $5^{*}$ & 3 & LS' $5^{\prime}$ dol \\
\hline Totals & & & & & & & & & 1510.9 & & 219 & & & 305 & & \\
\hline $\begin{array}{l}W \mathrm{~W}=\mathrm{W} \\
\mathrm{TS}=\mathrm{T} \\
\mathrm{UH}=\mathrm{C} \\
\mathrm{Hg} \ln \mathrm{j}= \\
\text { Numbe }\end{array}$ & $\begin{array}{l}\text { Work status (Core description) } \\
\text { Thin Sections, \# made }{ }^{*} \text {, descri } \\
\text { Core Plug samples at Univ. Ho } \\
=\text { Mercury injection porosimet } \\
\text { ers in front of Well Name is Sti }\end{array}$ & $\begin{array}{l}C=\text { Completer } \\
\text { bed: } S E M=S \\
\text { uuston; Wett }=W \\
\text { In } \\
\text { inLab well Ident }\end{array}$ & $\begin{array}{l}=\ln P \\
\text { ing Ele } \\
\text { ability A } \\
\text { ation No }\end{array}$ & $\begin{array}{l}\text { cess; } \mathrm{PC} \\
\text { ron Micro } \\
\text { alysis, } \\
\text { ber }\end{array}$ & & $\begin{array}{l}\text { =con } \\
=\end{array}$ & nodont microl & ology, & of samples, * & * & npleted & & & & & \\
\hline
\end{tabular}


Table 15. Cored wells in West Carney Hunton field - thickness, core/log adjustment data

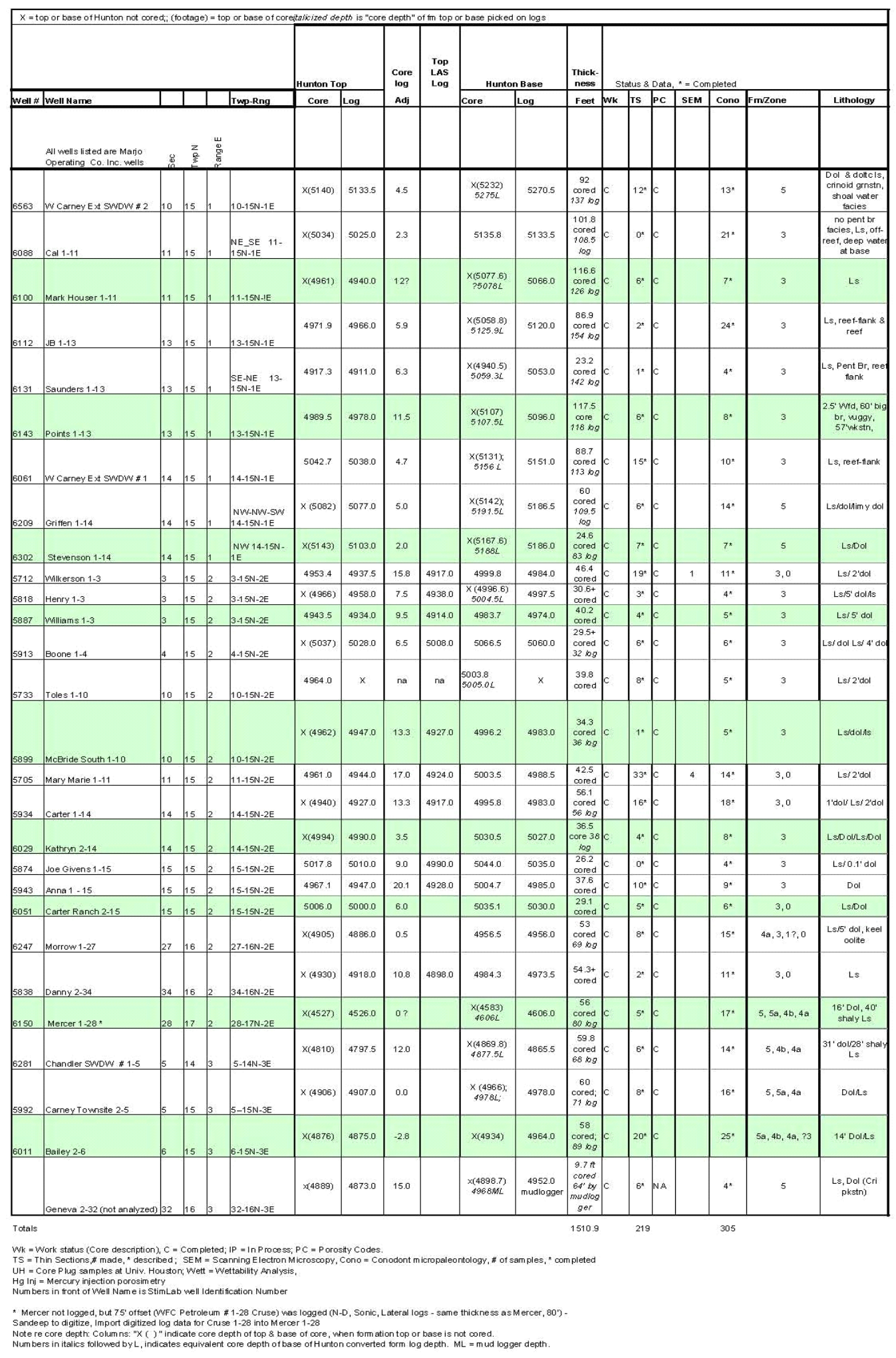


The central part of West Carney Hunton field is a reef-dominated carbonate shoal that formed as an isolated platform in the Early Silurian sea, equivalent in age to the Cochrane formation of the southern Oklahoma outcrop. Like most reef-dominated platforms, the stratigraphic continuity of lithologic units is poor, lateral transitions are abrupt and traceable subdivisions within the formation are rare. Distal to the field well-log correlations ${ }^{9,} 10$ suggest more ramp-like conditions exist and thin traceable units are present; however we have yet to prove the existence of units directly correlative to the reef-dominated Lower Cochrane limestones of the central West Carney Hunton field. Deeper-water ramp sediments in the distal cores are Upper Cochrane or younger. In the northeast quadrant of the field shoal-water limestone units are present which we call Upper Cochrane; the deposition of these units was probably affected and controlled by minor syn-sedimentary structural movements. The Upper Cochrane beds grade laterally into shaly deep-water limestones to the north and southeast of the field.

Flanking the field on nearly all sides is the dolomitic grainstones of the Clarita formation, which unconformably overlie the Cochrane. On the west side of the field, the lateral transition from thick reefal and reef-flank Lower Cochrane to equally thick Clarita is abrupt. On the east and north the transition appears more gradual.

During low stands of sea level during the Silurian, West Carney Hunton field stood high, as an island, which subjected the limestones and dolomites to subaerial weathering and development of karst. Karst features are present throughout the thickness of the Hunton in nearly every well, and both greatly enhance and totally destroy pre-existing porosity and permeability. Karst features such as solution-enhanced fractures, breccias, and interconnected vugs are probably the principal flow units in the limestone portion of the field. Karst features are also important in the dolomitic areas, however conventional interparticle porosity and permeability is better developed in the dolostones. 
Stratigraphy and Stratigraphic Analysis

The stratigraphy of West Carney Hunton field is shown as the "Local Stratigraphy" in figure 35 .

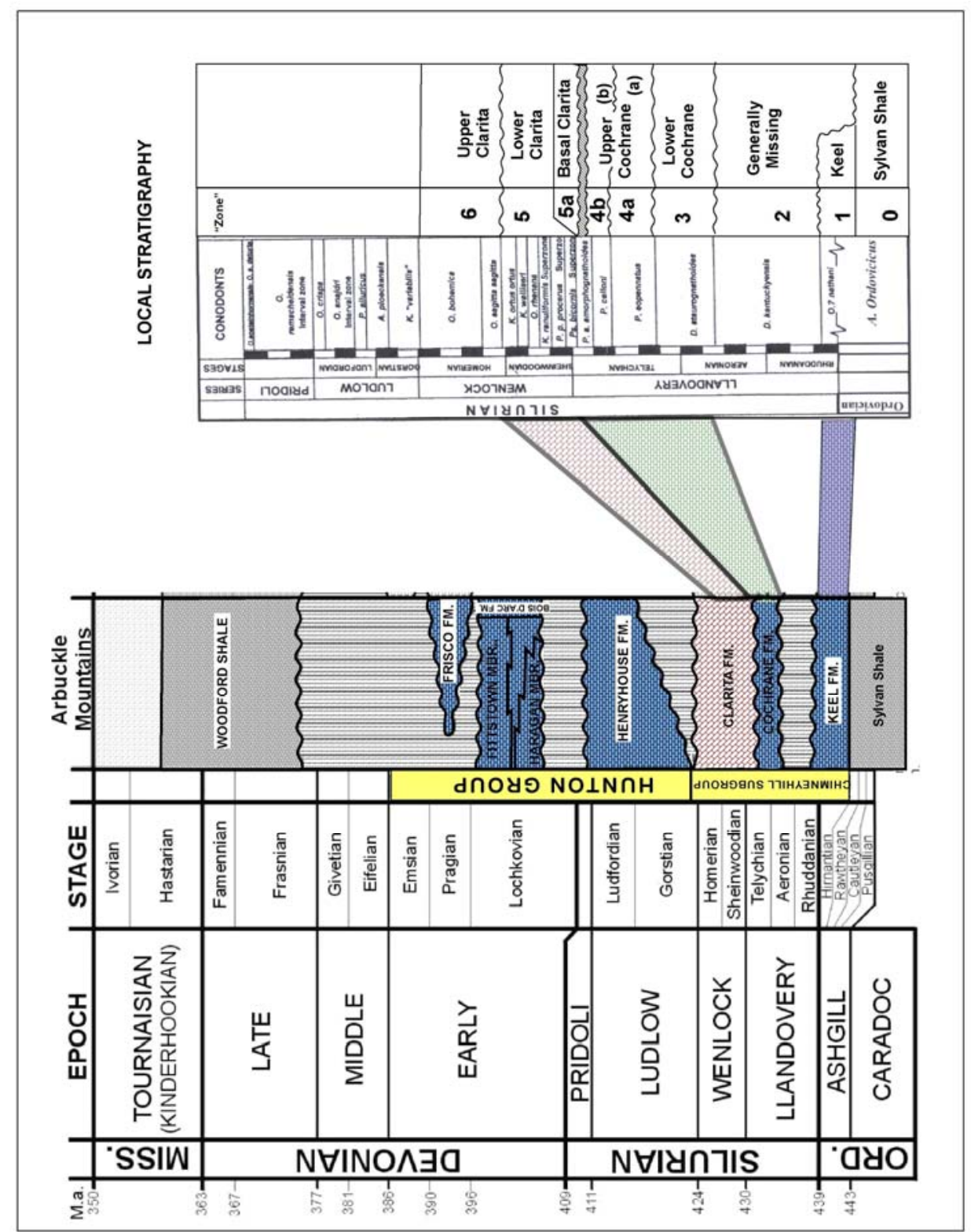

Figure 35: Stratigraphic chart for Hunton Group, comparing Arbuckle Mountain sequence (modified from Stanley, 2001, fig. 2) ${ }^{11}$, with the West Carney Hunton field sequence, labeled local stratigraphy, by Barrick and Derby. 


\section{Note that Upper Cochrane units are present in West Carney Hunton field, but not on the outcrop, whereas Upper Clarita is present on the outcrop, but not in West Carney Hunton field.}

The Hunton Group in West Carney Hunton field, overlying the Sylvan Shale and underlying the Woodford formation, is comprised of three formations that can generally be recognized on physical characteristics. These three formations are subdivided into 6 units based on their biostratigraphic age as determined by conodont faunal studies by Dr. James Barrick of Texas Tech University. These formations and their subdivisions are shown in figure 35 and will be described below. In West Carney Hunton field all formations except the Keel have been found in both shallow water and deep-water facies. Formation descriptions are based entirely on lithologic descriptions of cores, thin sections and acetate peels, and do not rely on studies of logs or samples from non-cored wells. The distribution of formations in the 28 studied wells in and adjacent to West Carney Hunton field is shown on tables 16 and 17.

Table 16. Explanation of coding of porosity types

LIMESTONES (grain density 2.71 to $<2.73$ )

(Grain density numbers not shaded in Pore \& Facies Code tables)

\section{Interconnected Vuggy porosity}

Vug or Moldic with Intergranular, Solution-enhanced Fracture or other connection, Touching Vugs in general. Not separate vugs with tight matrix.

\section{Coarse Matrix porosity}

Inter-particle or Inter-crystalline of coarse- and medium-grained and coarse crystalline rock, $>.25 \mathrm{~mm}$ particle size. May include dissolution porosity that is inter-particle micro vugs (dissolution of spar or matrix).

\section{Fine Matrix porosity}

Inter-particle, Inter-granular or Inter-crystalline of fine-grained and fine- to mediumcrystalline rocks, $<.25 \mathrm{~mm}$ particle size. Includes fine non touching vugs and non touching fine Moldic porosity along with intra-particle porosity 


\section{Fracture}

Fracture or Solution-enhanced Fracture without significant matrix or vugs.

For this study, includes solution enhanced fractures with sand in-fill.

DOLOMITE (> 50\% dolomite; grain density 2.79 or higher)

(Grain density numbers bold on Pore \& Facies Code tables)

5. Vuggy or Moldic in coarse crystalline matrix ( $>.25 \mathrm{~mm}$ )

6. Coarse crystalline with Inter-crystalline porosity (>.25 mm)

7. Medium to fine crystalline: Inter-crystaline (.25 $\mathrm{mm}$ to $.02 \mathrm{~mm})$

8. Fracture or Solution-enhanced Fracture without significant matrix porosity

PARTLY DOLOMITIZED LIMESTONE (10 - 50\% dolomite; grain density 2.73-2.78)

(Grain density shaded gray on Pore \& Facies Code tables)

\section{Interconnected Vuggy porosity}

Vug or Moldic with Inter-granular, Solution-enhanced Fracture or other connection, Touching Vugs general, Vug general. Not vugs with tight matrix.

\section{Coarse Matrix porosity}

Inter-particle, Inter-granular or Inter-crystalline of medium- to coarse-grained and coarsely crystalline rock, > .25 mm particle size. May include dissolution porosity that is inter-particle micro vugs (dissolution of spar or matrix).

\section{Fine Matrix porosity}

Inter-particl, Inter-granular, or Inter-crystalline of fine-grained and fine- to mediumcrystalline rocks, $<.25 \mathrm{~mm}$ particle size. Includes fine non touching vugs and non touching fine Moldic porosity along with intra-particle porosity

\section{Fracture}

Fracture or Solution-enhanced Fracture without significant matrix or interconnected vuggy porosity.

For this study, includes solution enhanced fractures with sand in-fill. 


\section{Table 17. Explanation of coding of facies types}

\section{Code \#}

1. Argillaceous Dolomite: Greenish-gray, Sylvan Fm and similar facies.

2. Crystalline Dolomite: Original fabric obscured, or simply fine crystalline replacement

3. Small Brachiopod Grainstone/Packstone/Wackestone

4. Fine Crinoid Grainstone/Packstone/Wackestone: Medium-grained and smaller.

5. Coarse Crinoid Grainstone/Packstone: Coarse-grained and larger

6. Mixed Crinoid-Brachiopod Grainstone/Packstone/Wackestone

7. Pentamerus Brachiopod Coquina: Robust, thick-shelled pentamerid brachiopods dominate rock.

8. Corals, Stromatoporoids, \& Brachiopods: Diverse fauna grainstones to wackestones, crinoid debris \& byrozoa common.

9. Coral \& Crinoid Grainstone-Wackestone: Similar to 8, lacks significant brachiopods

10. Sparse Fossil Wackestone: sparsely fossiliferous

11. Calcimudstone: Lime mudstone, very sparsely fossiliferous.

12. Fine- to Medium Grainstone: a description used only when the faunal components cannot be identified.

13. Shale: siliciclastic

14. Fine Sandstone: siliciclastic.

15. Stricklandid Brachiopod Facies: Brachiopod grainstones dominated by big thin-shelled pentamerids, probably Stricklandia.

16. Oolitic carbonate: Includes oolitic dolomite, and oolitic chert replacing carbonate.

17. Karst Breccia \& Cave Fill Parabreccia

18. Nodular Calcimudstone or Wackestone: Shaly partings create nodular fabric.

19. Shale with Calcimudstone Nodules: Dominantly shale, but calcimudstone nodules common.

20. Fine Fossil Wackestone: Very fine-grained wackestone \& packstone with diverse microfauna; typically < 125 micron size. Commonly contains crinoid debris, ostracodes, brachiopod spines \& fragments, bryozoa, small trilobites, sponge spicules, coral fragments, and calcispheres.. 
Figure 36 and 37 are of the West Carney Hunton field Paleontological Studies, showing faunal zones and formations identified paleontologically in each well. Also shown are the faunal zones identified in outcropping formations in the Arbuckle Mountains, and in eastern Oklahoma. 


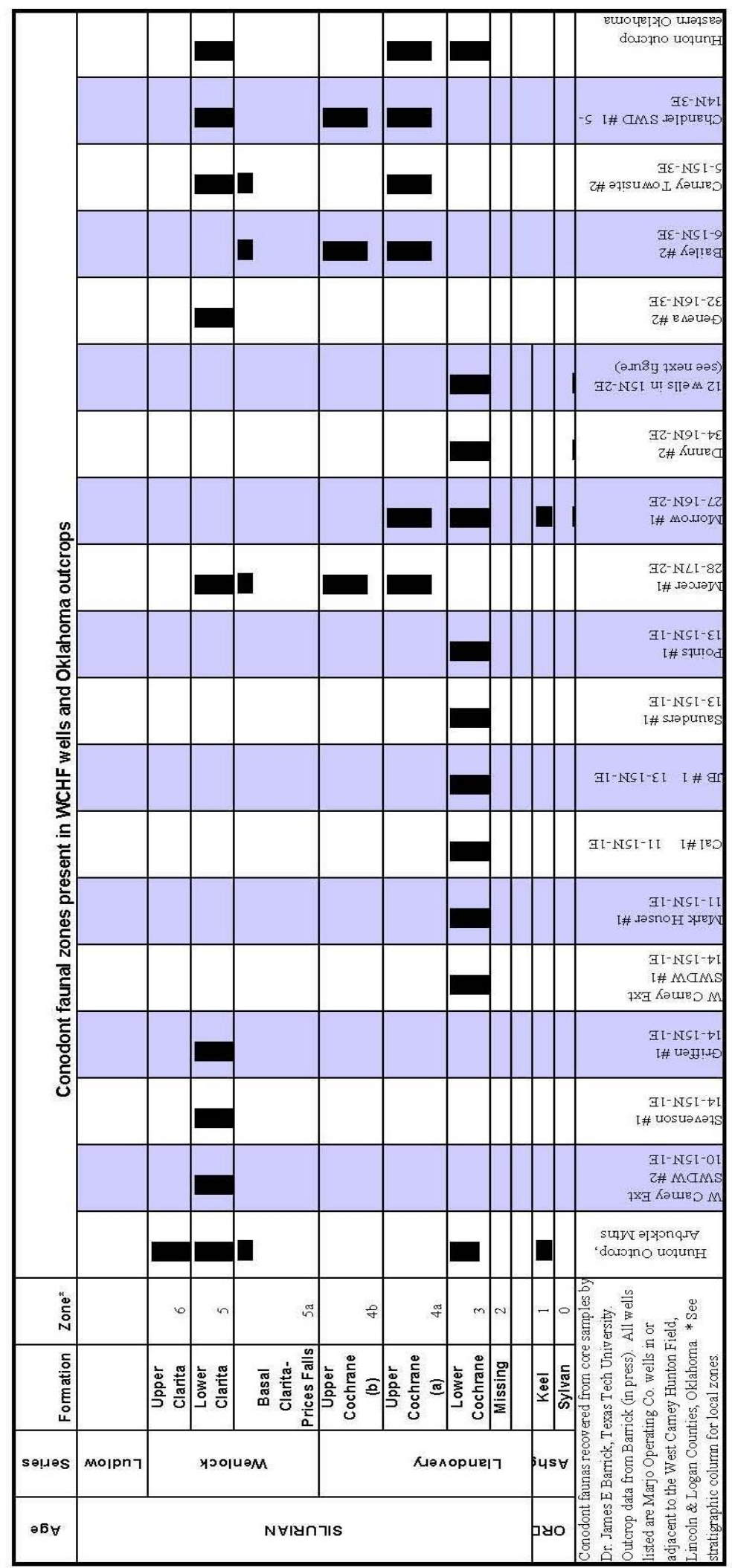

Figure 36: 17 wells in the west, north, and east sides of the fields 


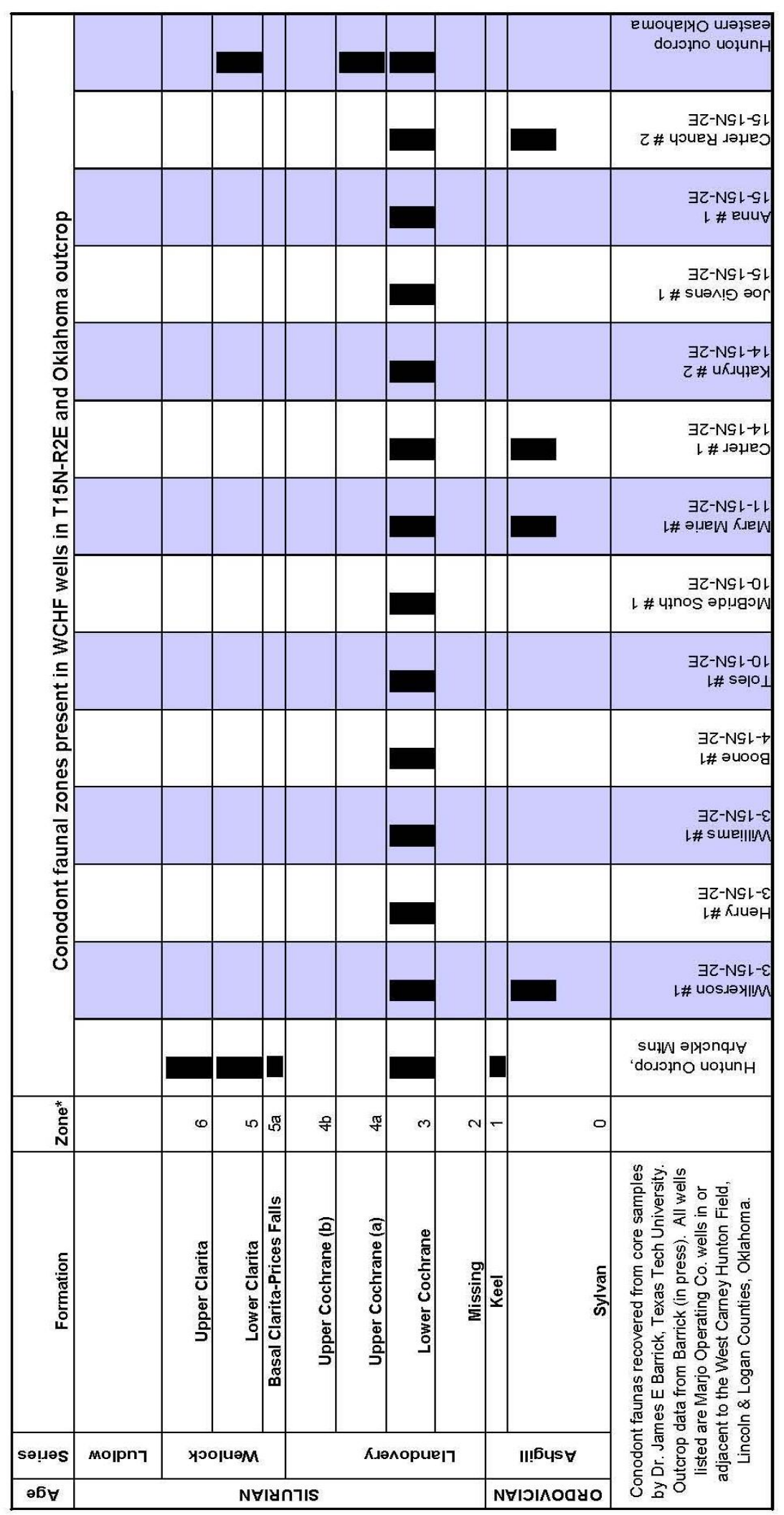

Figure 37: 12 wells from the central part of the field, T15N-R2E 
Deposition of stratigraphic units in West Carney Hunton field was controlled predominately by changes in sea level, with localized effects from structural movements. Figure 38 shows a sea level curve for the Silurian from Johnson, $1996 .{ }^{12}$ On that diagram sea level rise 2 equates to deposition of the Lower Cochrane, \#3 to the Upper Cochrane A, \#4 to the Upper Cochrane B, and \#5 to the Lower Clarita. In a previous report (DOE \#15125R15, http://www.tucrs.utulsa.edu/Hunton/Reports/15125R15.pdf), figure 10 demonstrates that structural movements are necessary to allow deposition of thick Upper Cochrane units and the over thickened Basal Clarita in the Bailey well. 


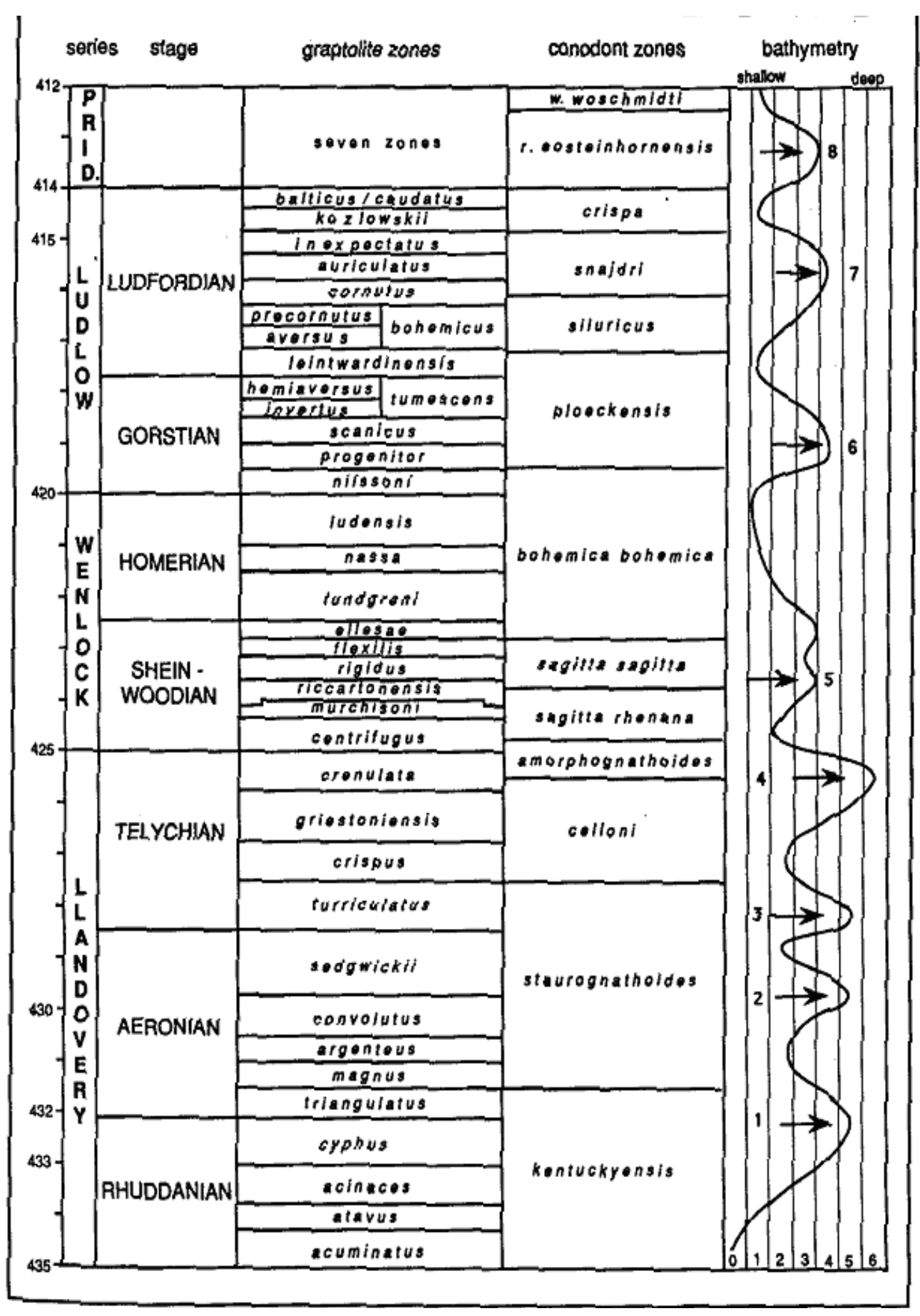

Figure 38: Sea level curve for the Silurian (from Johnson, 1996) ${ }^{12}$. Sea level rise \#2 equates to deposition of the Lower Cochrane, \#3 to the Upper Cochrane A, \#4 to the Upper Cochrane B, and \#5 to the Lower Clarita. 


\section{Lower Clarita Formation}

The Clarita formation in West Carney Hunton field is formally called Lower Clarita to emphasize that the Clarita present in West Carney Hunton field is only the lower part of the Clarita as recognized on the outcrop in the Arbuckle Mountains of south-central Oklahoma. Barrick $^{13}$ (in press) correlates the Lower Clarita with the Quarry Mountain formation of the eastern Oklahoma outcrop $^{14}$. The Lower Clarita (zone 5) is present in 8 wells in West Carney Hunton field, and generally occupies stratigraphic space lateral to the older Cochrane formation. In most wells the Lower Clarita is easily recognized by being dominantly dolomitic, crinoidal grainstones to wackestones, typically with moderate to good porosity. The Lower Clarita and its basal subdivision each contain a distinctive and abundant conodont fauna that is usually clearly diagnostic for the formation. The Basal Clarita (zone 5a in our terminology) is the equivalent of the Prices Falls member of the Clarita, typically a shaly unit. In West Carney Hunton field, the Basal Clarita is lithologically similar to the overlying Lower Clarita; except in the basal 4 feet of the unit in the Mercer well, where it is a nodular shaly limestone.

Wells containing the Lower Clarita and/or the Basal Clarita are:

1. Bailey, Carney Townsite, and Geneva on the northeast side of the field

2. Chandler SWDW (salt water disposal well) southeast of the field

3. Mercer north of the field

4. Griffen, Stevenson, and West Carney SWDW \#2 on the west side of the field. 


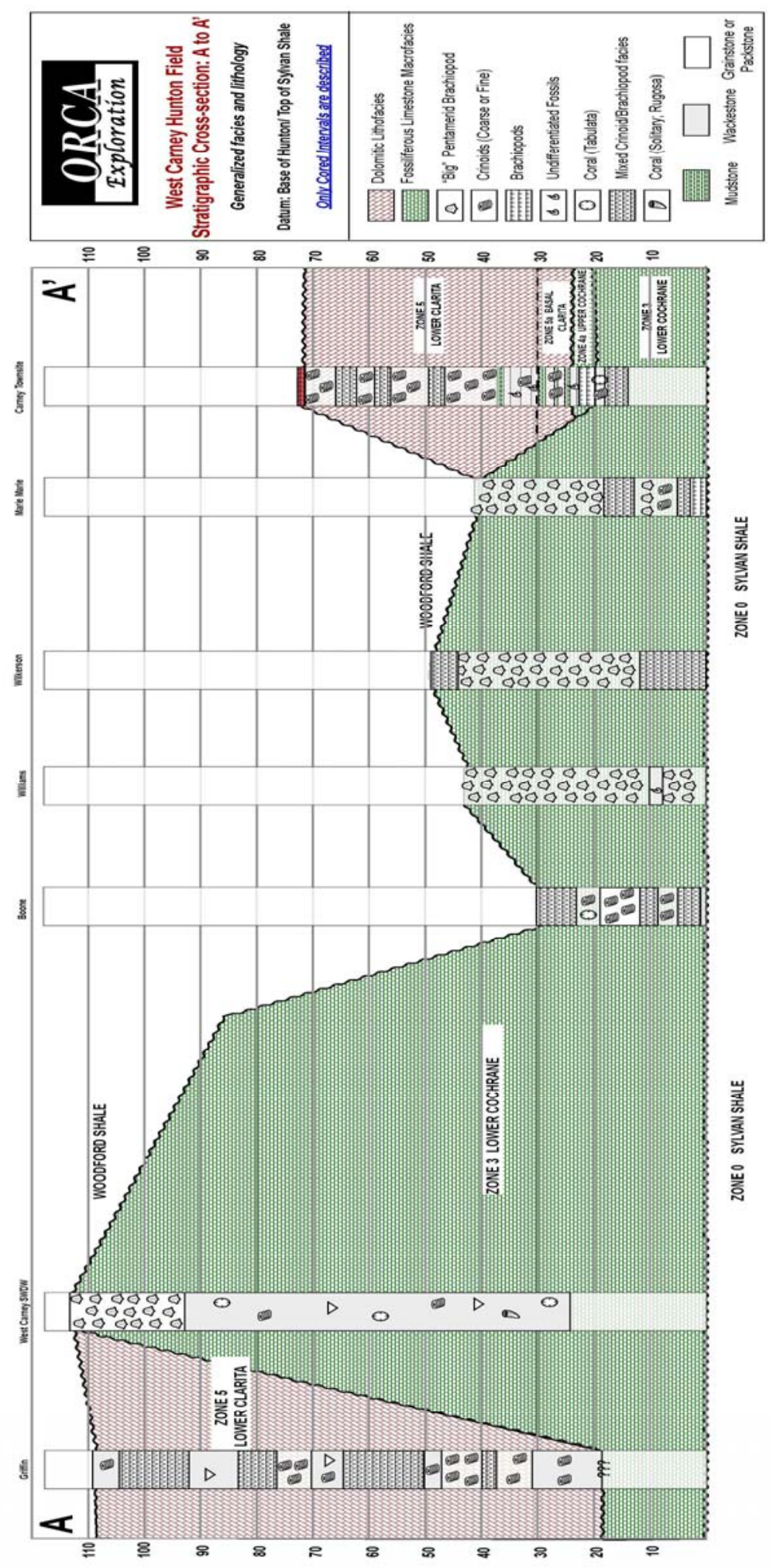

Figure 39: West-East stratigraphic cross-section of West Carney Hunton field. 
Figure 39 shows the relationship of Clarita to Cochrane units across the field. In the west, the thick Cochrane is a reefal buildup with the west-facing slope probably approximating the original reef front. Clarita was deposited as an encroaching shallow-water grainstone during a subsequent sea level rise. In the east, syndepositional faulting probably complicates the Clarita/Cochrane relationship. Please note that in the Carney Townsite well conodont evidence now shows the base of the core is Upper Cochrane 4a; no Lower Cochrane is present in the core.

\section{Cochrane Formation}

The Cochrane formation is predominately limestone and is the only stratigraphic unit present in the central portion of West Carney Hunton field. The formation varies in thickness from 152 feet in the JB 1-13 in the western part of the field, to as little as 30 feet in the Carter Ranch in the east. The formation is highly variable and contains reefal complexes with abundant coral and stromatoporoid debris, pentamerid brachiopod biostromes up to 70 feet thick, and areas dominated by crinoidal grainstones. In two wells in the west part of the field, and in a well to the north and one to the southeast, shaly deep-water limestone facies are present.

Conodont faunas permit subdivison of the Cochrane into 3 units, a Lower Cochrane (zone 3) and two Upper Cochrane units, A (zone 4a) and B (zone 4b). The Cochrane in the central and western parts of the field is entirely Lower Cochrane (Zone 3) (See figure 37). Twenty-one wells contain Lower Cochrane strata; five have Upper Cochrane strata (figure 36).

The Lower Cochrane of West Carney Hunton field is equivalent to the Cochrane formation of the Arbuckle Mountain outcrop and to the Blackgum formation of eastern Oklahoma. The Upper Cochrane is missing by unconformity in Southern Oklahoma. The Upper Cochrane A (Zone 4a) is equivalent to the Tenkiller formation of Eastern Oklahoma. The Upper Cochrane B is a time-stratigraphic unit not previously known in the central US.

\section{Keel Formation.}

The Keel is a thin oolite, discontinuously present at the base of the Hunton. ${ }^{15}$ Since the Keel contains Ordovician fauna, a major hiatus exists between it and the overlying Cochrane. The Keel is present in only one West Carney Hunton field well, the Morrow 1-27. Elsewhere, the Cochrane rests directly on the underlying Sylvan Shale. 


\section{Facies Analysis}

Twenty different lithofacies types were recognized in the process of describing the 28 cores in this study. These lithofacies types were given a numerical code to be used as a convenient label in data sheets: core descriptions, thin section descriptions, pore and facies codes with core analysis. Tables 16 and 17 list these 20 lithofacies, and a generalized porosity type subdivision used for the same purpose. Subsequently the lithofacies types have been used to recognize larger facies assemblages, here termed “megafacies”.

\section{Reef and Reef-flank Megafacies}

Five wells on the west side of the field contain this megafacies. Diagnostic facies are Facies 8 and 9, but many other lithologic types may be present. Steep dips in debris-flow beds are proof positive of being in a reef tract. Very coarse crinoid debris is common.

The West Carney SWDW\#1 and JB 1-13 have abundant corals and stromatoporoids, and debris-flow grainstone beds with dips up to 35 degrees. The Mark Houser, Cal, and Points wells have reef-flank to distal reef-flank beds. All are significantly karsted, with extensive breccia and cavern development, due to exposure and high topographic relief at sea level lowering. 
$\longleftarrow$ Shore

Shelf lagoon on platform

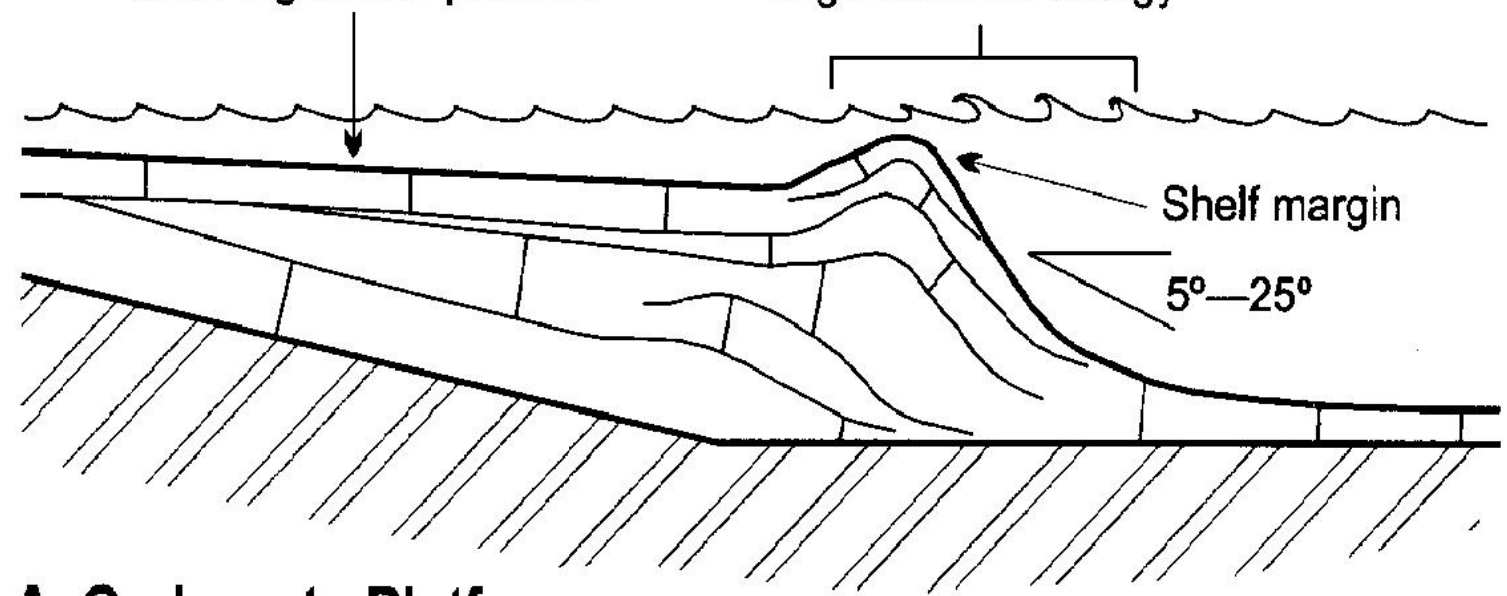

\section{A. Carbonate Platform}

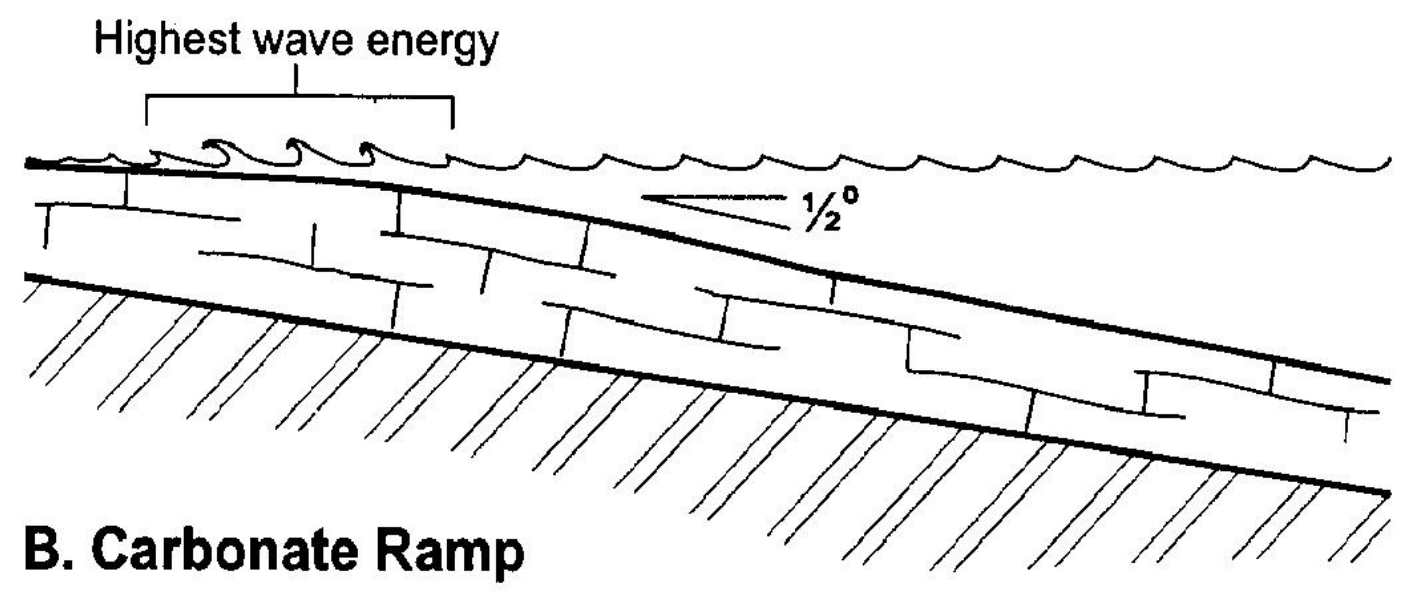

Figure 40: Comparison of reef platform vs. ramp environments of deposition (figure 4 of Stanley, 2001). ${ }^{11}$ The west edge of West Carney Hunton field Cochrane resembles the steep ocean-facing slope of the platform. The reef platform lagoon is analogous to the central area of West Carney Hunton field with a mix of brachiopod biostromes and lagoonal facies. 


\section{Brachiopod Biostrome Megafacies}

Major accumulations of large pentamerid brachiopods are common in the Cochrane in West Carney Hunton field. Biostromes up to 66 feet thick (Points well) are present across the entire central limestone facies of West Carney Hunton field. The brachiopod biostrome in the Points overlies an equally thick reefal interval. The nearby Saunders only cored 23 feet at the top of the Hunton, but probably has an equally thick biostrome. Thick biostromes are composed of both types of pentamerid brachiopods, the thick-shelled Pentamerus and the thin-shelled Stricklandia. Detailed studies of similar facies in coeval outcrops in Iowa $^{16}$ show that Pentamerus usually occupies a Benthic Assemblage (BA) (figure 41) position, low in the waveagitated spectrum. Stricklandia is typically assigned a BA 4 position, near the maximum stormwave base. Johnson (1987) ${ }^{17}$ suggested depths of 30-60 meters for BA 3 and 60-90 meters for BA 4. Witzke and Johnson $(1999)^{16}$ found that the two genera are commonly mixed, and physical evidence suggests an intermediate depth.

While the brachiopod biostromes were deposited in considerable depth of water, they were clearly exposed to subaerial weathering at the next lowering of sea level, as evidenced by characteristic early fresh-water cements (see core and thin section descriptions), leaching, and karst infill. The brachiopod biostromes contain spectacular vuggy porosity in some cases, but commonly are either cemented tightly by secondary cements and grain collapse, or tightly plugged by karst infill.

Diagnostic for the Brachiopod Biostrome megafacies are Facies 7 and 15. Wells with biostromes greater than 20 feet thick are: Anna, Henry, Kathryn, Mary Marie, McBride, Points, Saunders, Williams, and Wilkerson. 


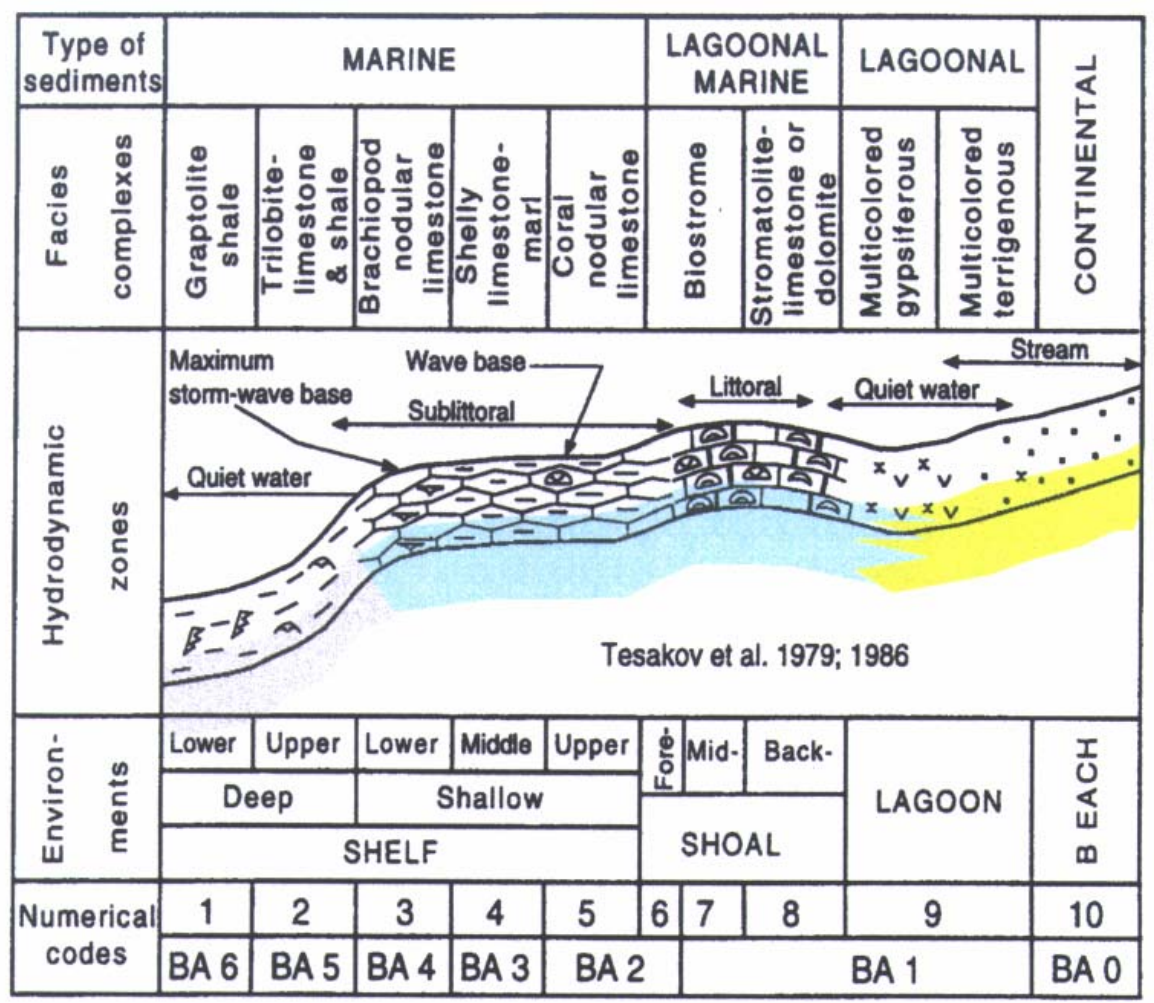

Figure 41: Facies model for Early Silurian Shores and Shelves of North America and Siberia. B.A. 0 - 6 indicate Benthic Assemblage zones (from M. Johnson, et al., 1997)

\section{Lagoonal Megafacies}

This megafacies includes the environments of deposition in the reef-platform lagoon, apart from the Brachiopod Biostromes. Included are a broad variety of crinoidal grainstones to wackestones, mixed crinoid-brachiopod grainstones to wackestones, and scattered coral faunas. Depositional environments include wave-worked crinoid flats, small patch reefs, and small $(<20$ m thick) brachiopod biostromes. Depths were probably in the BA 2 to BA 3 range, 10 to 60 meters. Primary porosity was high in sediments in this megafacies, but early marine cementation followed by exposure and fresh-water dissolution and recementation has destroyed much of the original porosity.

Lower Cochrane wells containing Lagoonal Megafacies are Boone, Cal (from 5076.5 to top of core), Carter, Carter Ranch, Danny, Joe Givens, McBride, Morrow, and Toles. 
Upper Cochrane Lagoonal Megafacies wells are Bailey and Morrow.

\section{Dolomitized Shoal-water Grainstone Megafacies}

This megafacies is essentially limited to the Lower Clarita formation. Facies 2-6 are common, all having been subjected to early dolomitization. Horizontal burrowing is common, which serves to increase permeability. Early dissolution is pervasive. Karst is present, but small-scale in wells on the east side of the field, however karst is intense and large-scale in the western wells. Distribution of this megafacies is same as the Lower Clarita formation (see above).

\section{Deepwater Megafacies}

Facies 18, 19, and 20 are diagnostic for this megafacies. Benthic Assemblage depth zone is BA 5, probable depth is 90 to 120 meters, certainly below storm wave base. The fauna listed for Facies 20 is characteristic for this facies. The abundance of fine mud prevents this facies from being a reservoir, but it is possibly a poor source rock. Despite being deposited at considerable depth, all sequences in the megafacies show evidence of subaerial exposure and minor karsting, attesting to the range of fluctuations in sea level. Deep water megafacies are found in all stratigraphic units in West Carney Hunton field. For all but the Upper Cochrane A, the sedimentological interpretation is supported by conodont evidence of a deep-water fauna.

\section{Lower Cochrane deep-water intervals:}

- Points-basal one foot is facies 20

- Cal - basal 60 feet is deep-water facies, including shaly nodular limestone and shale; gradually shoaling up to distal reef tract sediments.

Upper Cochrane deep-water intervals:

- $\quad$ Mercer and Chandler SWDW, zones 4a \& 4b in both. Facies 18 \& 19.

Basal Clarita (5a)

- $\quad$ Mercer: shaly limestone , facies 19, in basal four feet, 4545.8-4549.9 


\section{Conclusions}

This report completes the data-gathering and basic stratigraphic analysis phase of studies of Marjo Operating Company well cores in West Carney Hunton field. This report includes:

- $\quad$ Core descriptions of 28 cores totaling 1510.9 feet of core.

- Description of 219 thin sections with $35^{\text {th }}$ percentile pore diameter measurements.

- Paleontologic data from 305 samples dissolved in acid to recover conodonts.

- Pore type and lithofacies characterization of each foot of core, with porosity and permeability data from core analysis.

- Composite plots of wireline well logs and porosity \& permeability core data, depth adjusted to bring cores and logs to equivalent depths

- $\quad$ Core photographs for 28 wells.

- Lithologic descriptions of the 6 Hunton stratigraphic units and subdivision into 4 megafacies complexes.

For detailed core descriptions, core-log plots, core photos, paleo-conodont samples, pore and facies codes and analysis, and thin section descriptions go to:

\section{http://www.tucrs.utulsa.edu/Hunton/Reports/15125R20_Geology/bp2_geology.stm}

The central part of West Carney Hunton field is a reef-dominated carbonate shoal that formed as an isolated platform, consisting of Reef \& Reef-Flank Megafacies in the Lower Cochrane and Lagoonal Megafacies in both the Lower and Upper Cochrane. Like most reefdominated platforms, the stratigraphic continuity of lithologic units is poor, lateral transitions are abrupt and traceable subdivisions within the formation are rare. Well-log correlations suggest more ramp-like conditions exist and thin traceable units are present distal to the field. However their age is uncertain except where we have core control. Deeper-water ramp sediments in the distal cores are Upper Cochrane or younger. In the northeast quadrant of the field shoal-water Upper Cochrane limestone units are present; minor syn-sedimentary structural movements probably controlled their deposition. 
The shoal-water dolomitized grainstone megafacies of the Clarita formation flanks the limestone central part of the field. The Clarita unconformably overlies the Cochrane formation.

Karst features are present throughout the thickness of the Hunton in nearly every well, and both greatly enhance and totally destroy pre-existing porosity and permeability. Karst features such as solution-enhanced fractures, breccias, and interconnected vugs are probably the principal flow units in the limestone portion of the field. Karst features are also important in the areas dominated by dolostones, however conventional interparticle porosity and permeability is better developed in the dolostones than in the limestones. 


\section{Fluid Properties Analysis}

\section{Introduction}

Because of the unique behavior of reservoir performance, it was critical that we understand what type of fluid is present in the reservoir. PVT (pressure, volume, temperature) analysis of reservoir fluid samples was carried out to study the nature of reservoir fluid and to generate a representative reservoir fluid model. Fluid samples were collected from two wells, Schwake 1-10 and Morrow 1-27, and were analyzed by PENCOR Reservoir Fluid Specialists. Schwake 1-10 lies in the depleted region of the reservoir, whereas Morrow 1-27 lies in a relatively virgin part of the reservoir.

Fluid samples were analyzed by flashing the sample at standard conditions and recombining vapor and liquid at surface GOR to determine the well-stream fluid composition. The report also gave the detailed well stream composition along with a characterized component and the properties (molecular weight/specific gravity) of each component and flash summary results. Standard laboratory tests, such as constant composition expansion (CCE), were carried out to determine the bubble/dew point of the fluid system and to calculate the two-phase properties below saturation pressures. The data from these tests was used in developing the fluid model that would generate fluid properties that are consistent with those observed in the field.

Schwake Well Sample. Fluid samples were collected from Schwake 1-10 and were analyzed for PVT properties. The fluid was flashed at surface conditions and recombined at a GOR of 4130 SCF/STB to generate the well stream composition. The well stream consisted of 15 components with $\mathrm{C} 7+$ as the characterized component. Appendix B, table B1 shows the well stream fluid composition. PENCOR also performed a CCE test (Appendix B, table B2) and calculated the dew point of the fluid. The dew point was reported as 7,000 psia. The fluid is probably a gas condensate but it has an unusually high dew point, which does not agree well with the initial reservoir pressure of 1,900 psia. Also log data has indicated the presence of oil in the reservoir. Since this fluid sample was collected from a depleted reservoir region, it is also 
possible that the fluid may not be a representative sample. The fluid sample was not considered for any further processing and a new fluid sample from a virgin zone was analyzed.

Morrow Well Sample. The fluid sample obtained from Morrow 1-27 was flashed at surface conditions and recombined at a GOR of 3,017 SCF/STB to generate the well stream composition. The well stream consisted of 35 components with $\mathrm{C} 30+$ as the characterized component. Well stream compositions and CCE test results are shown in Appendix B. The bubble point of the fluid sample was reported as 1,869 psia. The result was encouraging as the initial reservoir pressure was 1900 psia and the bubble point was found to be very close to initial pressure. Also since the fluid sample was collected from a virgin reservoir region, the fluid may be considered as a representative sample. Further processing of the fluid sample is done to generate the fluid model to be used in modified material balance procedure and compositional simulation.

\section{Generation of Reservoir Fluid Model}

The fluid model was generated using a 3 parameter Soave-Redlich-Kwong (SRK) equation of state (EOS). The EOS determines fluid properties at different fluid pressure, temperature and composition, which helps in performing compositional simulation. A GeoQuest PVTI module is used for fluid modeling. The components of Morrow well fluid were grouped into pseudo-components (grouping consecutive components with small mole fractions) such that the monotonocity is preserved. Using the composition of the Morrow well fluid and the EOS, a phase plot for the reservoir fluid was generated. Figure 42 shows the phase plot. A CCE test was simulated using the PVTI module and the results of simulated test were plotted with the laboratory observed test. Figure 43 shows comparison between experimental CCE and simulated pressure-volume relation. As can be seen from the plot, there is a significant difference between the simulated and observed curves. The aim here is to match the simulated values with the laboratory observed values. This involves tuning the EOS, which is achieved by performing regression. 
The tuned EOS was used to simulate a CCE and pressure-volume plot was generated. Figure 44 shows the regressed pressure-volume plot from CCE test. It can be seen from the figure that there is a good match between simulated and laboratory observed data. This tuned EOS was then used to generate the phase plot for the initial reservoir fluid. Figure 45 shows the phase plot obtained from using the regressed 3-parameter SRK EOS. It can be seen from this plot that the initial reservoir fluid (marked in the figure) lies close to the critical point and can be categorized as volatile oil. This fluid model was used for performing compositional simulation as well as generating necessary fluid properties for material balance calculations.

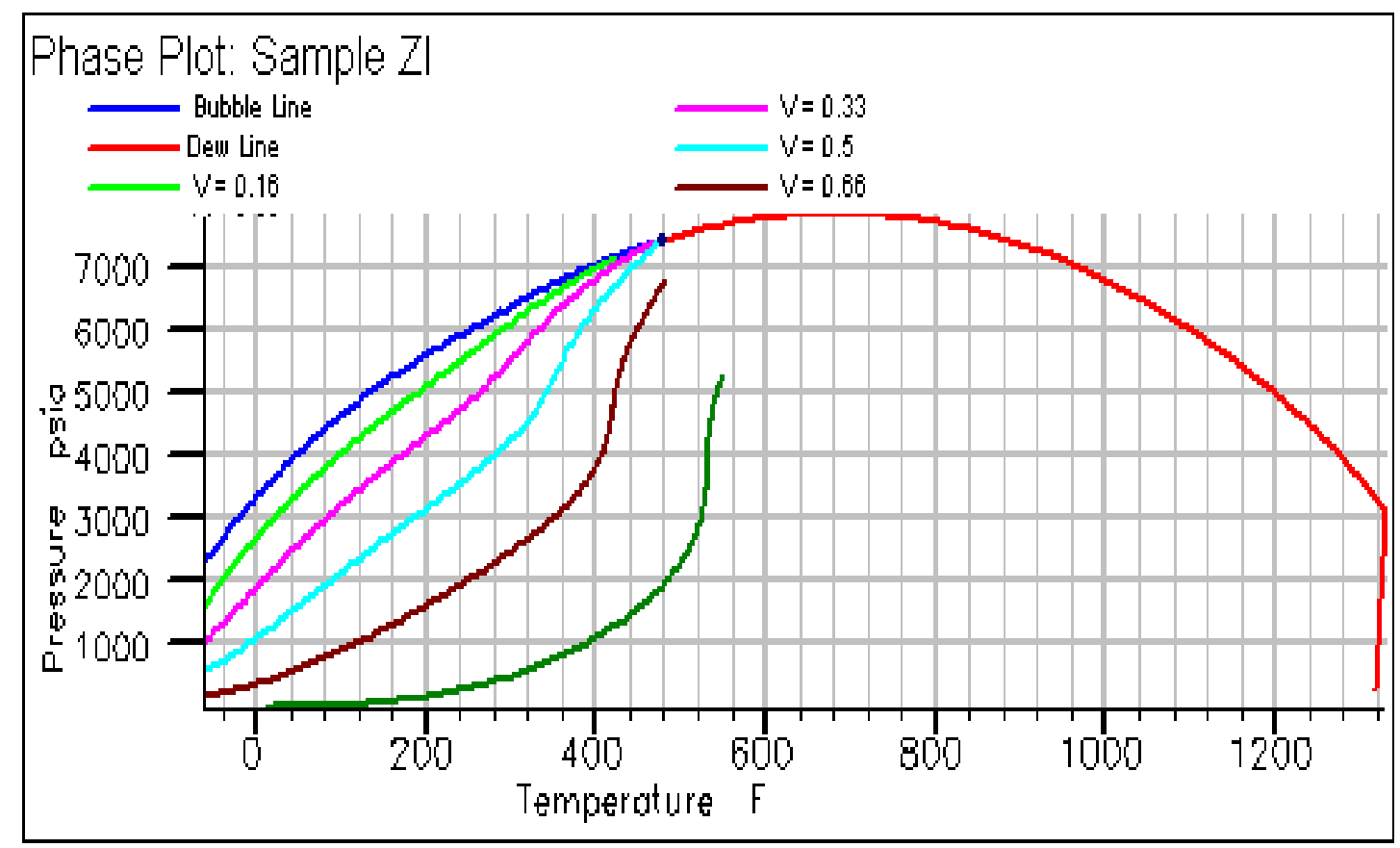

Figure 42: Non-regressed phase plot 


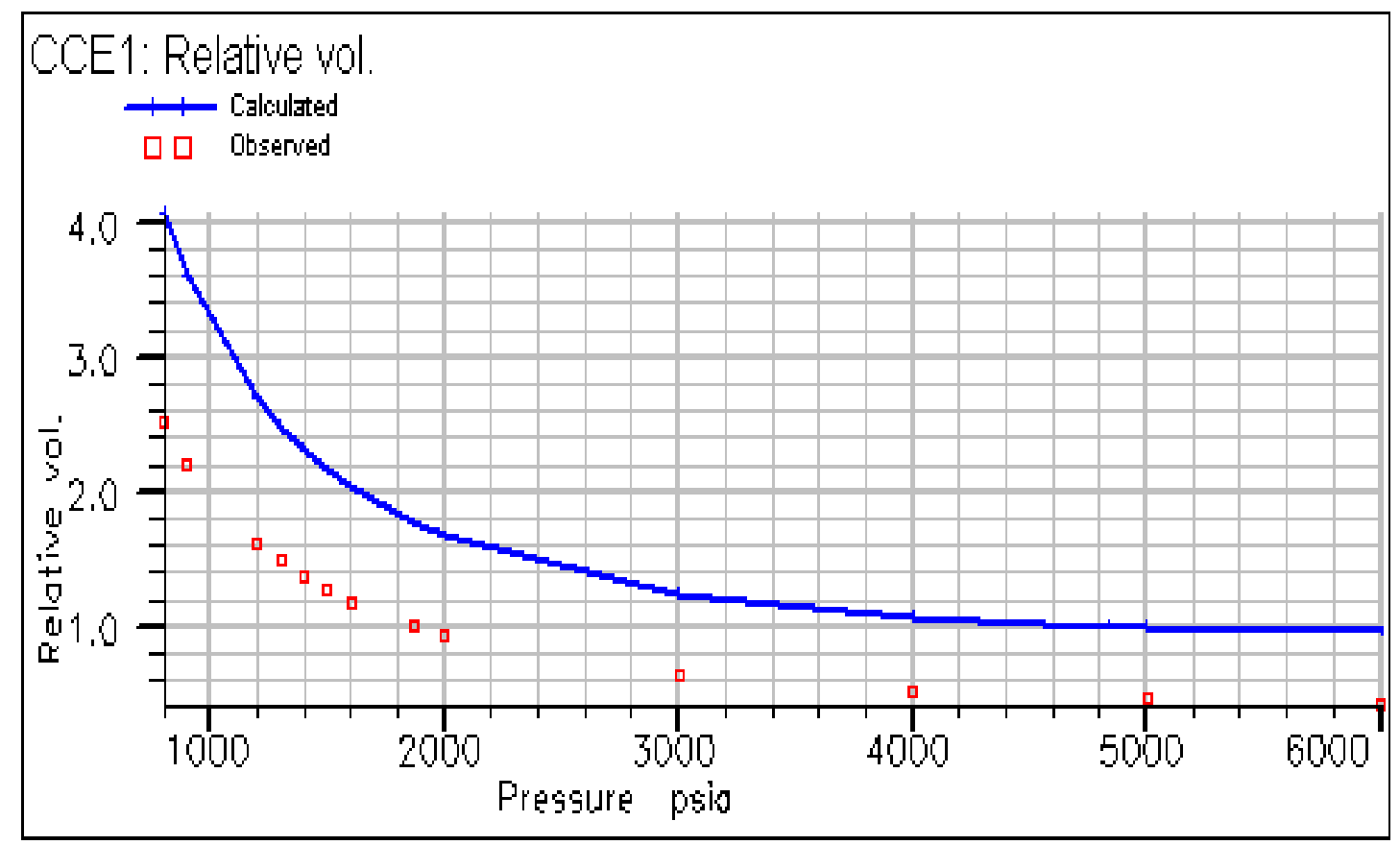

Figure 43: Non-regressed CCE plot

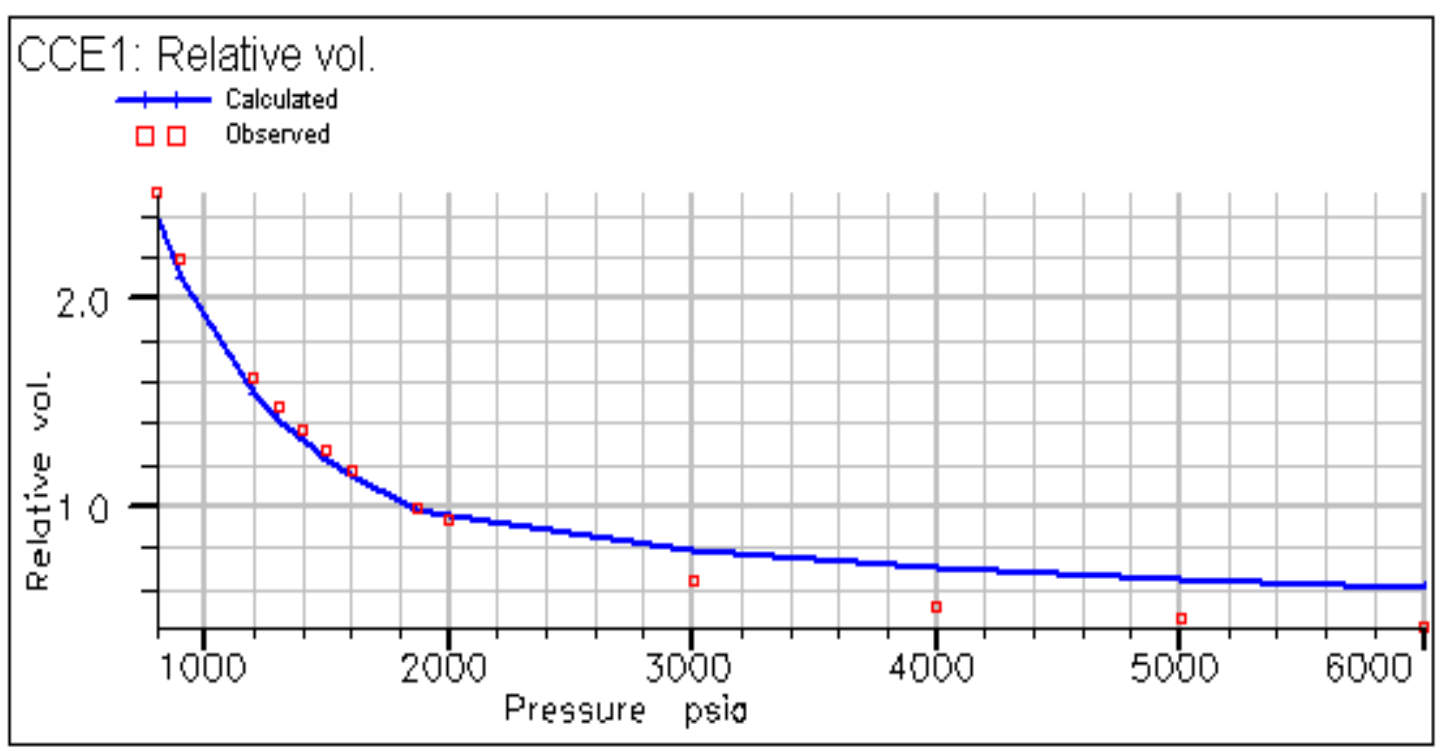

Figure 44: Regressed CCE plot 


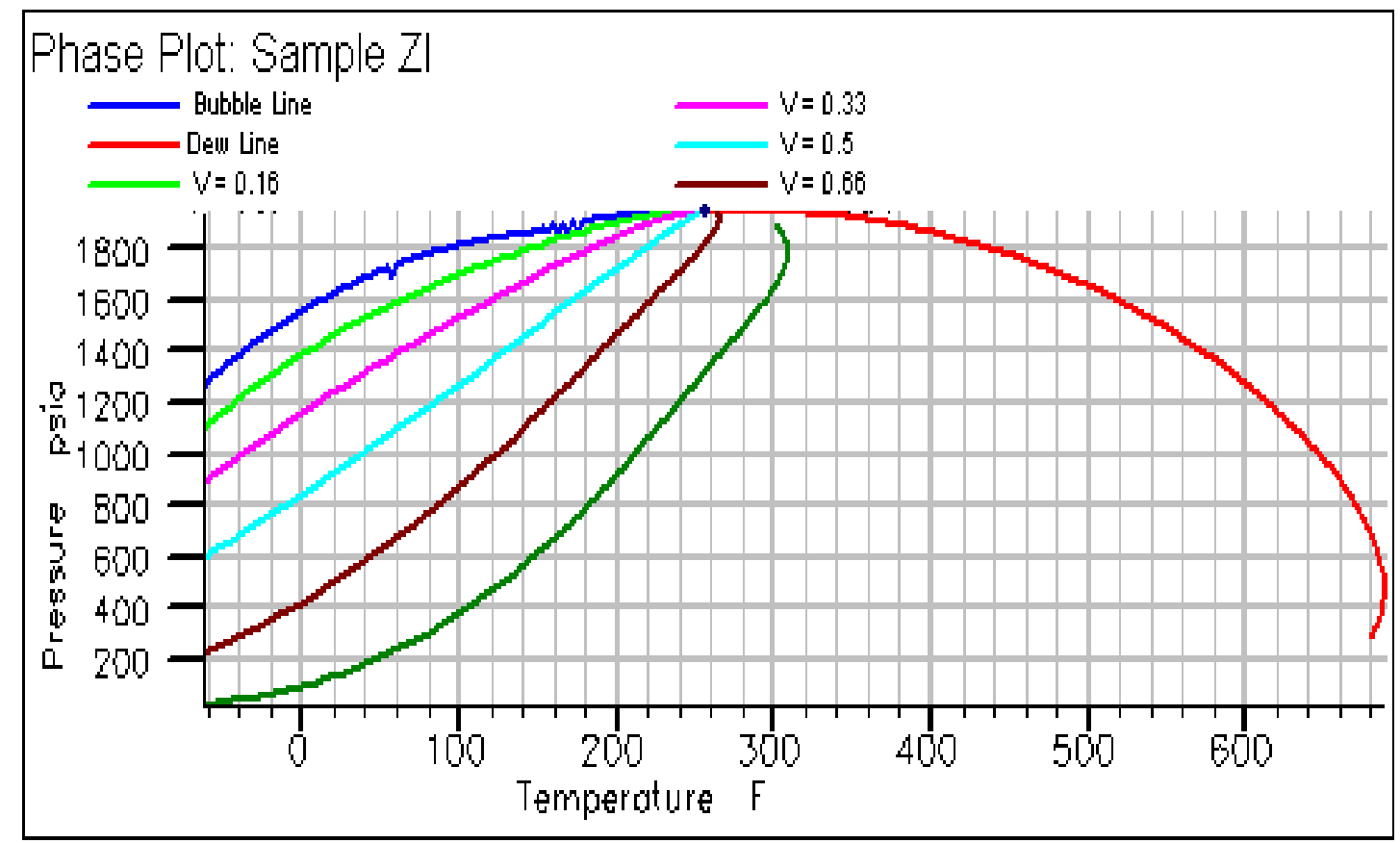

Figure 45: Regressed phase plot 


\section{Petrophysical Analysis}

The petrophysical analysis involved using the available log and core data to understand both the static and the dynamic characteristics of the reservoir. We collected over 500 logs from the four core areas as well as surrounding areas for evaluating the reservoir characteristics. Several alternative methods were used to extract the relevant information from the data. Some methods turned out to be successful; some not so helpful. We describe all the approaches we tried in our petrophysical analysis.

\section{Core - Log Correlation}

One key element of petrophysical analysis is how the data ties to the core data. If we have limited core information but we can relate that information to log data, we will be able to extend the analysis to the logged wells. We describe different approaches we tried to reconcile core data with log data in this section.

Development of Correlation between Core and Log Data. The development of the correlation began with the geological description of the cores. The geologist provided detailed core descriptions from twenty-four wells in terms of lithology, pore and facies types, fractures, stylolites and karst. The core analysis showed three lithologies namely; limestone, dolomite and partly dolomitized limestone to be present in the West Carney Hunton formation (West Carney Hunton field). The geologist identified four pore types: vugs, coarse matrix, fine matrix and fractures in each of the rock type and twenty facies types. Tables 16 and 17 give a detailed account of the pore types and facies types identified from the twenty-four cored wells in the West Carney Hunton field. A detailed account of the geology is presented in the geological analysis of this report. Please refer to the Appendix A for the core-log plots for more information on the -cored wells.

Our goal was to develop a correlation that would help us determine the pore types for the uncored wells, using only the available log data. Limited digitized log data was available and, hence, we had to digitize most of the log data from hard copies of logs taken from the log library. Since the Gamma ray and PE logs do not reveal a lot of characteristics of the Hunton formation we decided to digitize only the deep resistivity, density porosity and neutron porosity logs from uncored wells in the West Carney Hunton field. We began to analyze the data based on similar 
characteristics. We made groups based on similar rock type and similar pore types. Since the geological facies and rock types did not show us very good correlations, we decided to analyze the data based on the pore types; hence, the twelve pore types described by the geologist were further divided into four groups by grouping vugs and coarse matrix together and fine matrix and fractures together for limestones and dolomites. We included partly dolomitized limestone along with dolomite to obtain better correlation. This data was then used to perform discriminant analysis. $^{18}$

Discriminant Analysis is a method of creating a function or a model that explains the grouping of the given individuals, and can further be used to assign additional observations to the correct group. Relationships among feature variables (principal components of log data) to the grouping variable (cluster type) are expressed by their mean values and their variance-covariance matrices.

The discriminant analysis was performed on data available from cored wells, as well as the logged wells. We used the log-derived data from cored wells and assigned them into 4 groups as mentioned above. Each data point was assigned its corresponding group from the deep resistivity, density porosity and neutron porosity from log signatures. Then discriminant analysis was performed on this data set. The principal components of each logs are calculated. The link of the groups assigned to each data with its corresponding principal components creates a discriminant function. This is then applied to other raw datasets to classify that data into four groups. Now we have all the data from logged wells divided into four groups based on pore types.

The cross validation is done by using the same dataset (cored wells) that was used to generate the discriminant function. Upon cross validation the match was observed to be $65 \%$ i.e. only about $65 \%$ of the groups assigned by the discriminant function to a particular data matched the original assignment of the groups. That is, geological assignments match $65 \%$ of the times with log signatures.

We could not further improve this match using the geological pore types; hence, we thought of another approach, generation of the electrofacies. 


\section{Electrofacies Analysis}

The concept of electrofacies ${ }^{19}$ is introduced to extend the information about porositypermeability obtained from cored wells to log data for the uncored wells. The underlying principle of electrofacies is purely statistical in nature, but its results are seen to be geologically consistent. Using this concept, the data obtained from logs is classified into groups, which are homogeneous within themselves and distinct from each other. The electrofacies calculation involves three basic statistical procedures explained below.

Principal component analysis ${ }^{19}$ (PCA) is a statistical method used to reduce data to lower dimensions (reducing the number of variables) with minimal information loss. The principal components are the Eigen-vectors of the variance-covariance matrix of the variables. The Eigenvectors constitute the directions of principal component axes in the transformed space, whereas the Eigen-vectors determine the length of the axes. By multiplying the original data by the components of Eigen-vectors the principal component scores are obtained. The variancecovariance matrix of this transformed data is a diagonal matrix, whereby each diagonal term represents the variance of the data independent of the other. Typically the first diagonal term explains the maximum variance of the data followed by the second and so on. Usually the first three or four principal components explain about $90 \%$ of the variance of the data. In this way, the number of variables is reduced, with the loss of at most $10 \%$ of the variance.

Three logs (density porosity, neutron porosity, and deep resistivity) were selected and principal component analysis was carried out. Since there were only three variables, all the three principal components were taken into consideration for further analysis.

We also used five logs (density porosity, neutron porosity, deep resistivity, density correction, and photo electric) for our analysis; however, we did not see any significant improvement by adding two more logs; hence, we continued with the three log analysis.

Figure 46 shows a screen plot that describes the variance percentage of the principal components. As can be seen, the first component explains $66 \%$ of the variance of data; and the first two components explain $88 \%$ of the variance. 


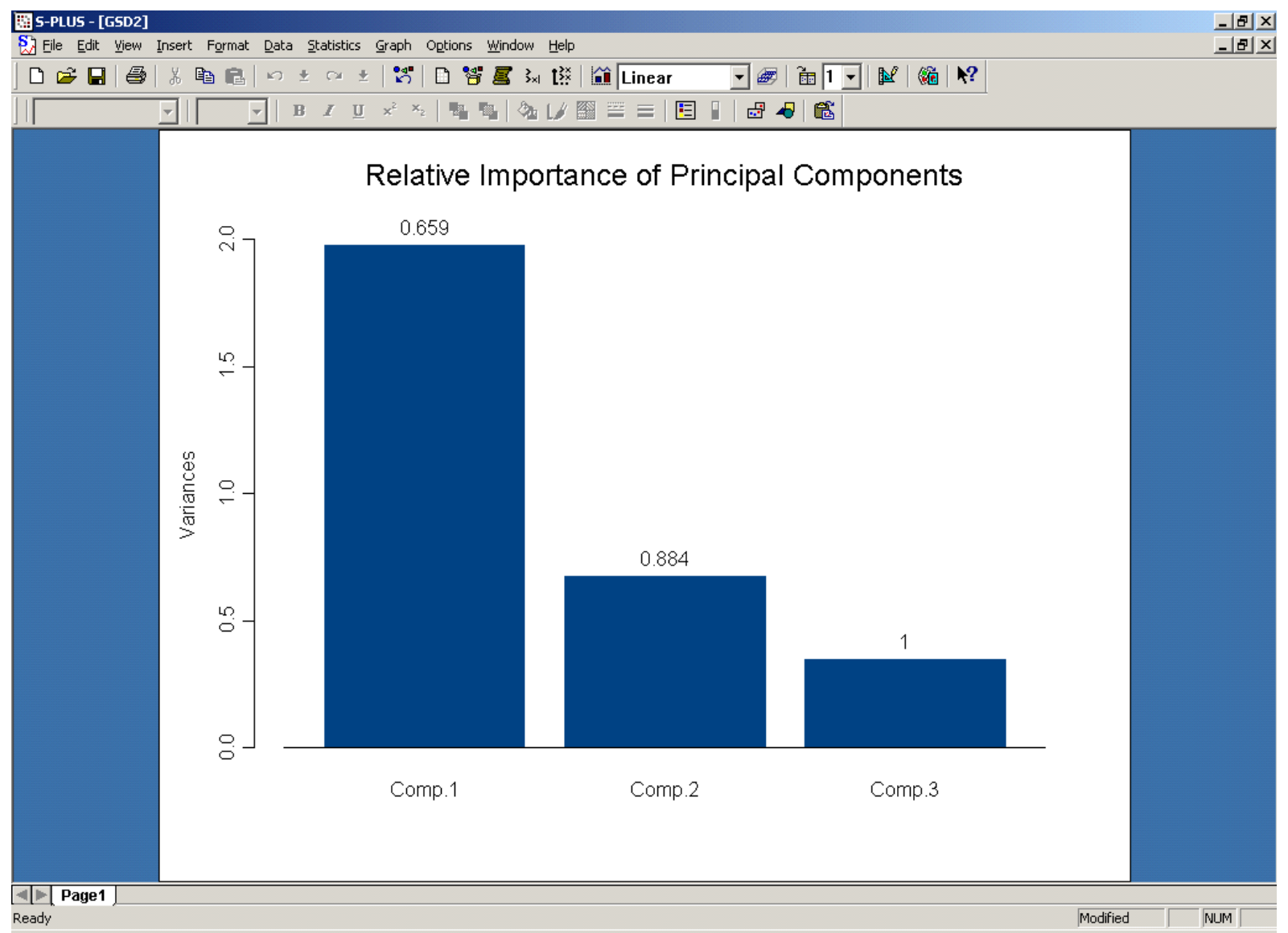

Figure 46: Screen plot showing the different principal components and their variance percentage $^{18}$

Cluster analysis is the method for classifying the data (principal components) into clusters, which are distinct from each other. These clusters will represent the electrofacies. The process by which these clusters are assigned is mathematical in nature. The algorithm used is a $k$ means partitioning around medoids. In this algorithm $k$ representative objects called medoids are computed and each object is assigned a cluster corresponding to the nearest medoid. These $k$ representative objects should minimize the sum of dissimilarities of all objects to their nearest medoid. The algorithm basically proceeds in two steps. In the first step, called the build up, the algorithm sequentially selects $k$ centrally located objects. In the second step, called the swap step, the selected object is swapped with an unselected object if the objective function can be minimized with this operation. This process is continued until the objective function is minimized and each data is assigned a particular cluster. Selecting the number of clusters to be 
used is a trial-and-error process, the best indication of which is obtained by observing a cluster plot as shown in figure 47.

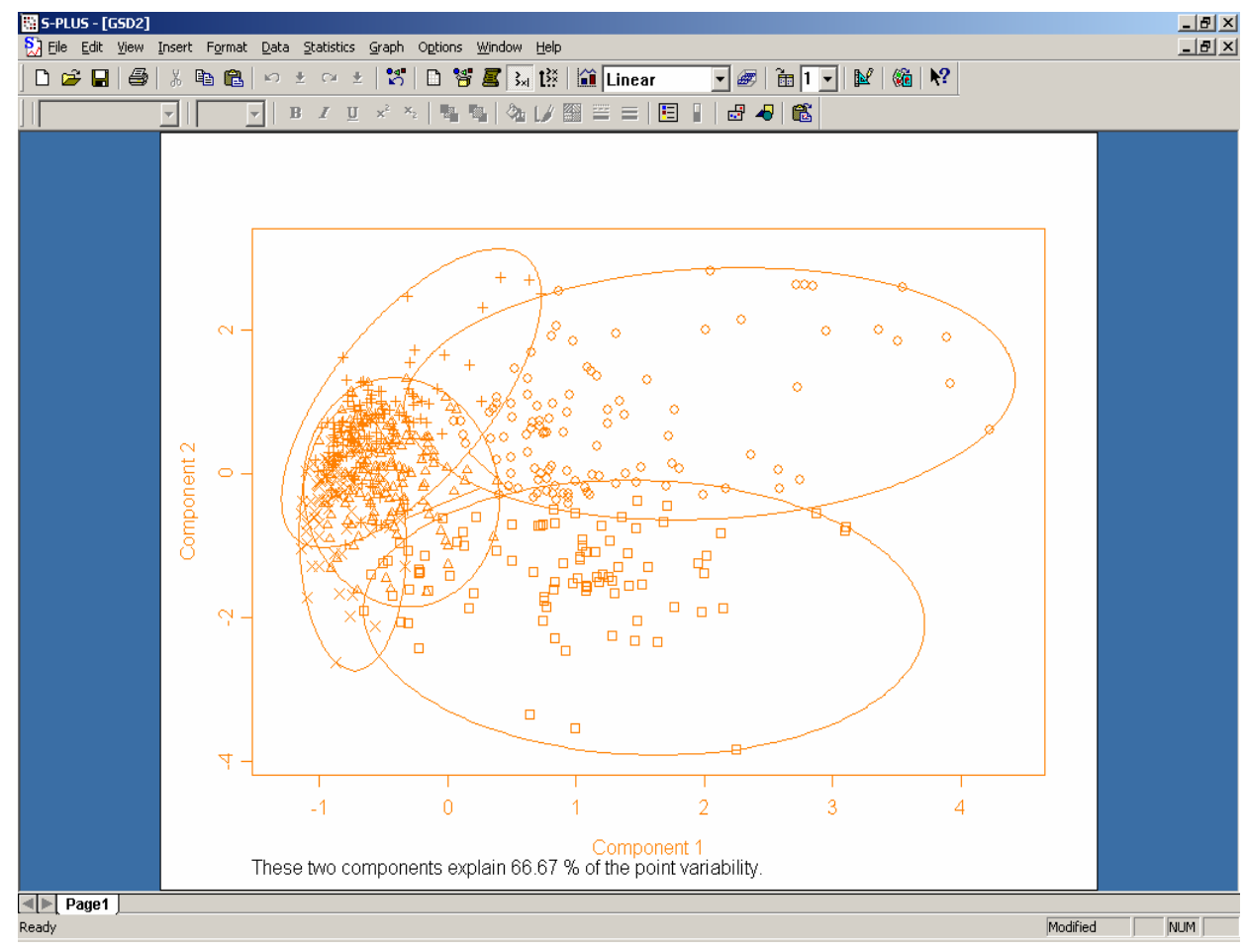

Figure 47: Cluster plot using five groups ${ }^{19}$

Figure 47 shows a plot with 5 clusters. By trial-and-error we found that 5 clusters would be the best way to group the data.

In our analysis we considered the 13 cored wells and each log data was assigned a particular cluster. By trial-and-error and reviewing the cluster plot we found that using 5 clusters gives us a good classification; hence, the number of electrofacies is 5. Once the principal components for each log data and its corresponding electrofacies is known, the information is applied to other uncored logged wells using discriminant analysis.

The discriminant analysis is a method used to extend the information to any number of logged wells. The discriminant analysis creates a discriminant function using the cluster number and the principal components of the data of the cored wells. It then applies this function on the 
principal components of the logged data from uncored wells and generates clusters for each log data value. In this way, all the log data from all the wells were assigned a cluster (electrofacies).

Once the electrofacies were assigned to each log data for all the cored wells, a comparison was done with the assigned geological facies. During the comparison different geological facies were combined together with one electrofacies depending on the way they were assigned. Figure 48 shows the results of electrofacies analysis and its comparison to geological facies.

Comparison of Electrofacies and Geological pore types

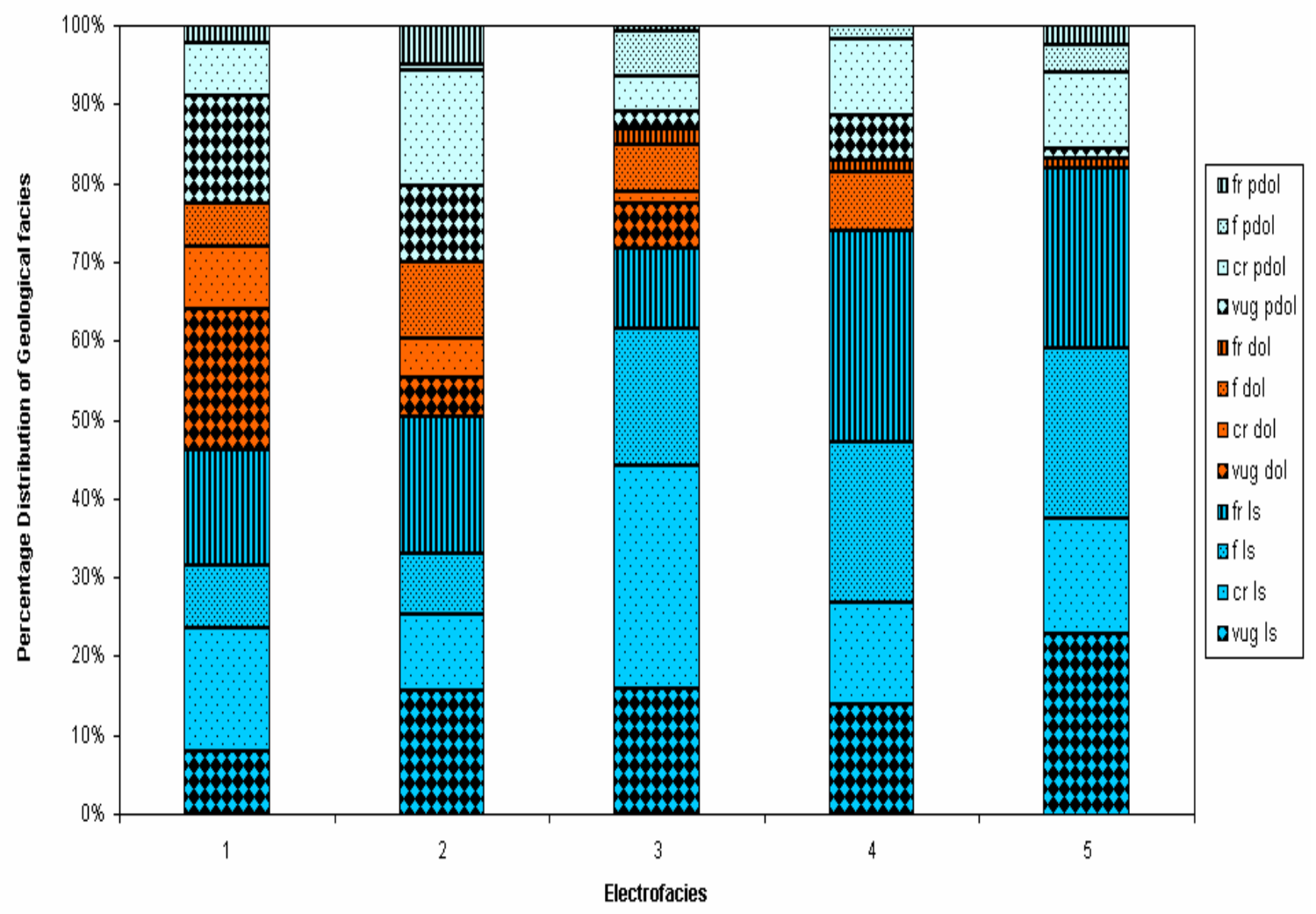

Figure 48: Comparison of electrofacies with geological pore types 
We see from figure 48 that electrofacies \#1, \#2, and \#3 show substantial proportions of coarse matrix and vugs in limestone, dolomite and some partly dolomitized limestone. The amount of dolomite decreases going from electrofacies \#1 to electrofacies \#3 and is reduced significantly in \#4 and \#5. Electrofacies \#4 and \#5 show substantial proportions of limestone with fine matrix and fractures. It can be seen that electrofacies analysis is successfully able to obtain a compositional segregation. Although there is some overlap, we can state that electrofacies \#4 and \#5 mostly are comprised of fine matrix and fractures; whereas, electrofacies \#1, \#2 and \#3 are comprised of coarse matrix and vugs.

The electrofacies analysis helped us to generate the electrofacies at all the wells considered in our study. We had very good core coverage in the area of study, which were cored as well as logged. These were used to develop porosity - permeability correlation.

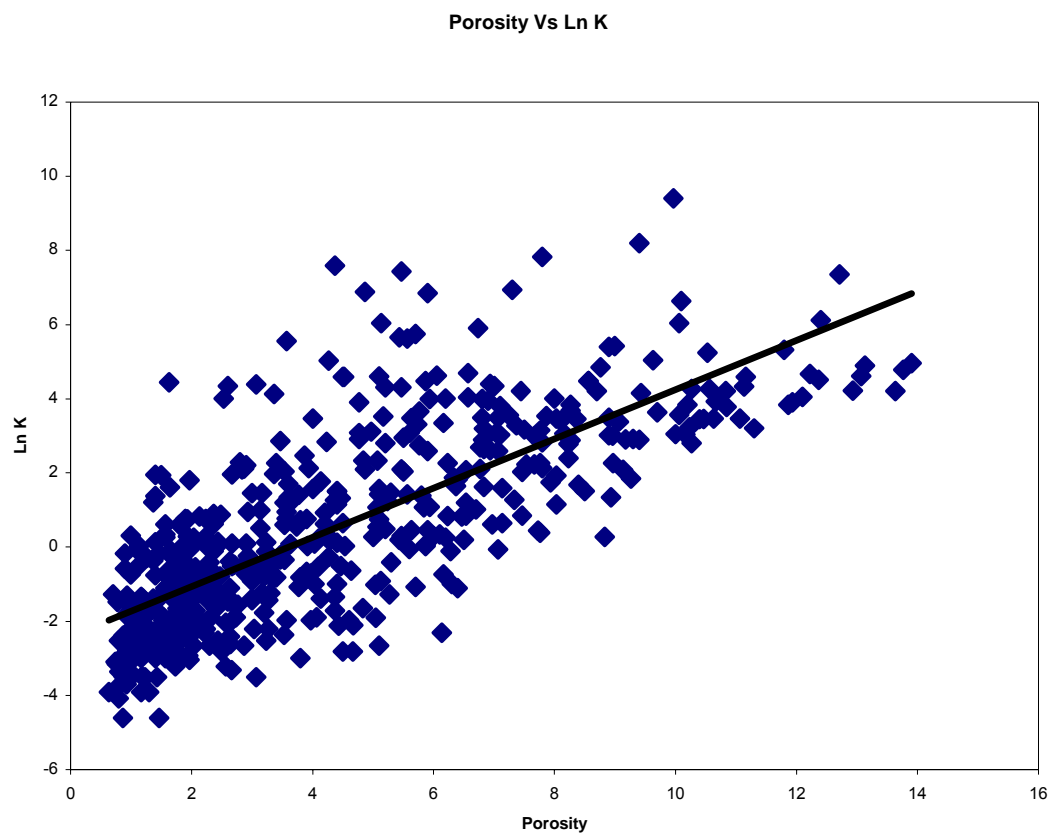

Figure 49: Log porosity versus Ln K

Figure 49 shows a plot of log porosity versus Ln K. We used this correlation to obtain permeability values at uncored wells. 


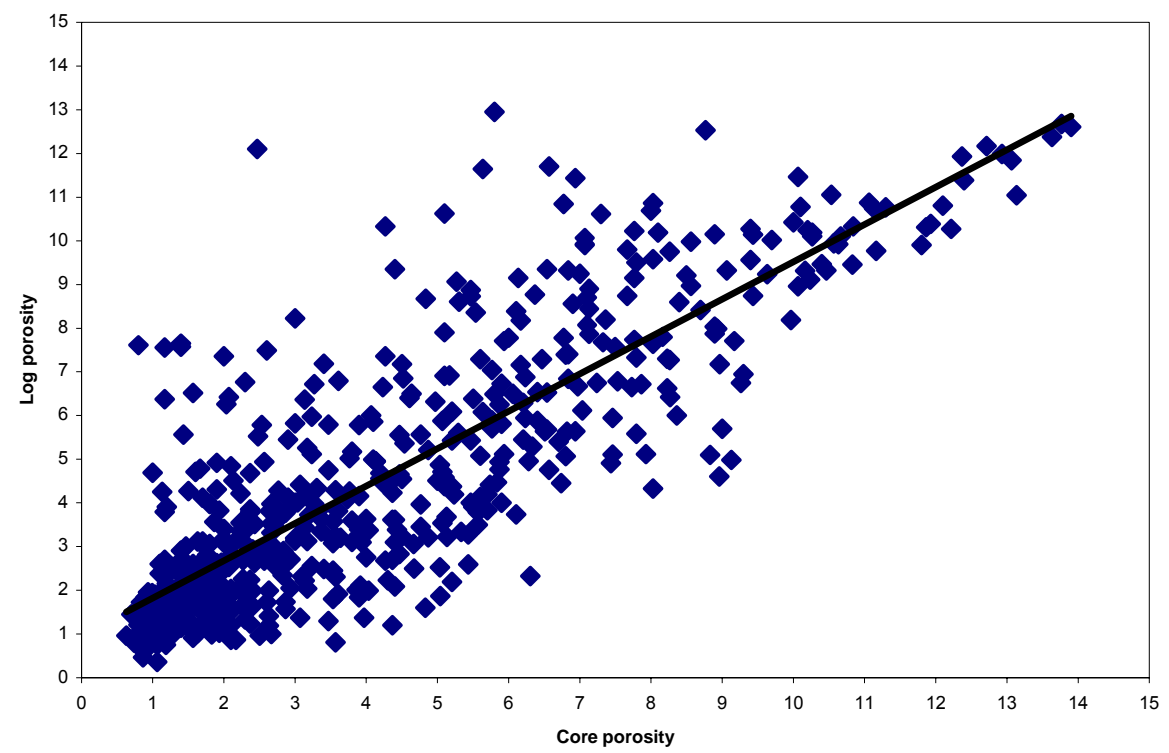

Figure 50: Correlation between log porosity and core porosity

Figure 50 shows good correlation between log derived porosity and core derived porosity.

We examined correlations developed for each individual electrofacies, but this did not provide significantly different results as compared to the correlation using all the data together; hence, the correlation equation that was developed using all the available porosity permeability data was used to generate permeability values at uncored wells. In the development of the correlation, we were not able to capture some of the extreme values that we suspect are from highly fractured regions and could be a key to the successful production from certain wells.

Once the permeability data was generated at all the well locations, we began to calculate the Productivity $\left(\mathrm{K}^{*} \mathrm{H}\right)$. All the permeability data was ranked and the $1^{\text {st }}, 5^{\text {th }}$ and $10^{\text {th }}$ percentile values were calculated. The values were found to be $228 \mathrm{mD}, 40 \mathrm{mD}$ and $9 \mathrm{mD}$ for $1^{\text {st }}, 5^{\text {th }}$ and $10^{\text {th }}$ percentile of the permeability data. Then the productivity was calculated for all the wells 
having permeabilities greater than the cutoffs considered. It was necessary to recognize these high conduit zones, as they were considered to be the key to good water production. Some of the results obtained from these correlations are discussed in the following sections.

Rock Types based on Petrophysical Properties. The electrofacies analysis provided satisfactory clusters in terms of log data; however, the porosity permeability characteristics for each of the electrofacies were similar. Therefore, from dynamic performance point of view, it would have been difficult to separate them into distinct characteristics. To provide for better separation of dynamic characteristics, we made another effort where we grouped twelve different pore types based on petrophysical properties. Recall that these pore types include fine pore matrix, coarse scale matrix, interconnected vugs and fractures. Three different rock were identified - limestone, dolomite, and partial dolomite. This makes the total number of pore types equal to twelve.

We first wanted to find out if any of the pore types have similar porosity characteristics so that for the purposes of petrophysical characterization, they can be combined. To achieve this goal, we generated Q-Q plots. Q-Q plots represent porosity values at a particular percentile against porosity value at the same percentile for another pore type. Figure 51 shows a plot of pore code 1 versus pore code 11 . The advantage of Q-Q plot is that it would show the similarities in porosity distributions for two sets of data irrespective of the type of porosity distribution. If the distribution is similar, the data would fall on 45 degree line. If data are not similar, it would indicate deviation from the 45 degree line. In figure 51, we can assume that pore code 1 and pore code 11 have similar porosity distributions. 


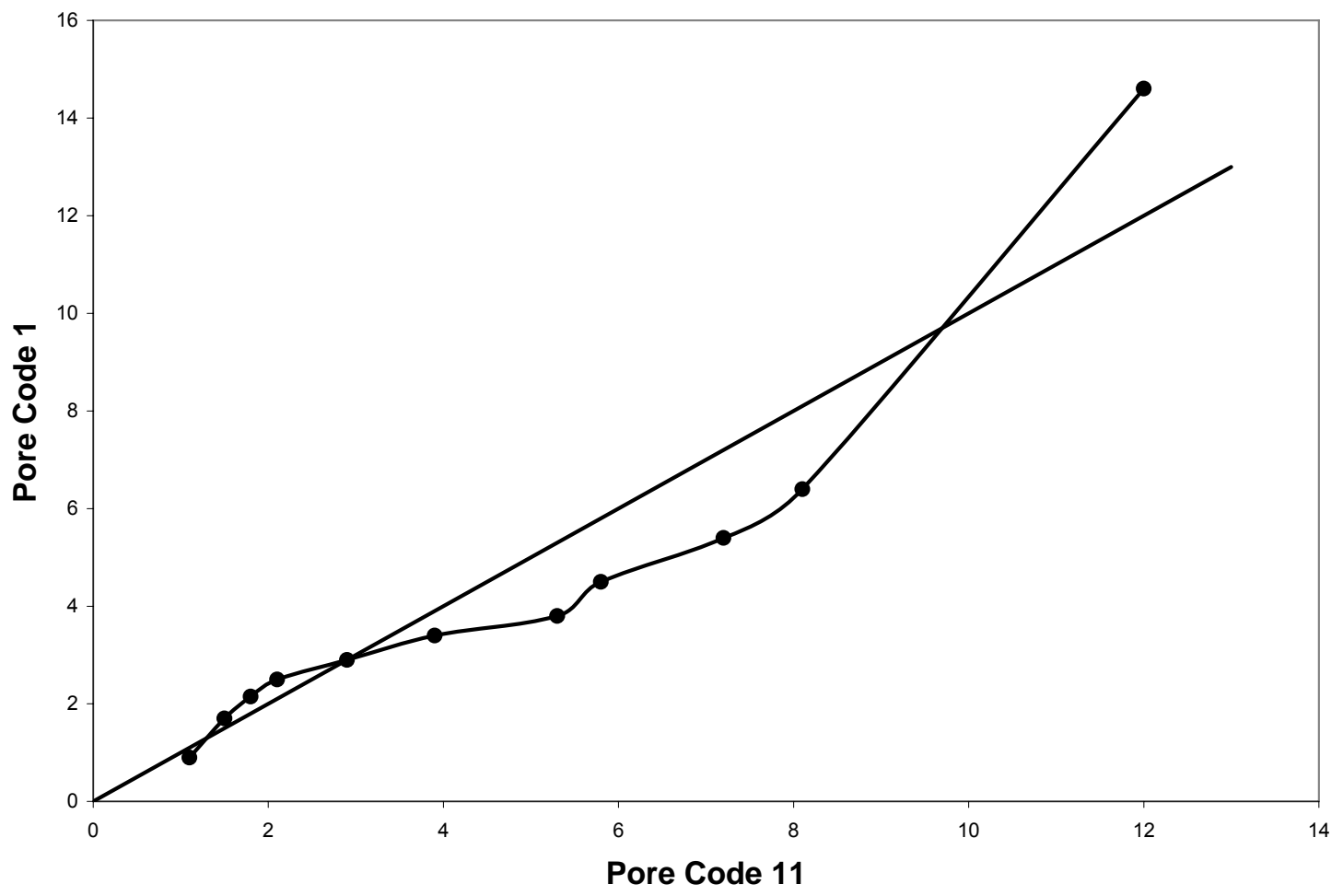

Figure 51: Q-Q plot for pore code 1 versus pore code 11

Figure 52 show another Q-Q indicating similarities in porosity distributions. This plots show similarities among the porosity values among various pore codes. Although not shown, similar plots are created for each of the pore types against the other pore type to examine the similarities and the differences. The goal is to group together the pore types which have similar porosity characteristics and keep the pore types separate which have distinct pore type characteristics. 


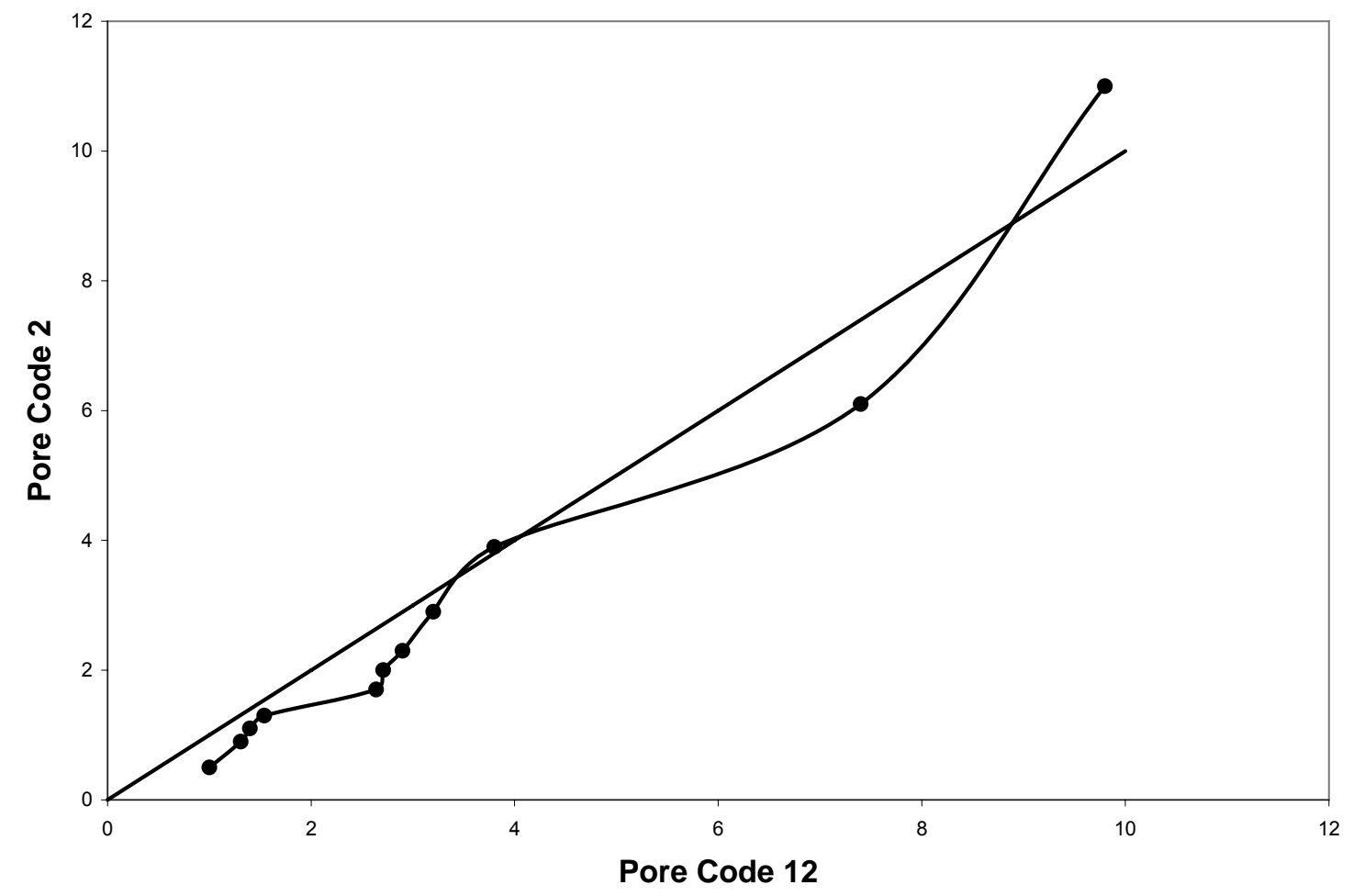

Figure 52: Q-Q plot of pore code 2 versus pore code 12

Using the Q-Q plot as a guideline, we divided the data into five rock types as shown below:

\begin{tabular}{cc} 
Rock Type & Pore Type \\
\hline 1 & 3 \\
2 & $1,2,8,11,12$ \\
3 & $6,7,9,10$ \\
4 & 5 \\
5 & 4 \\
\hline
\end{tabular}

In effect, the twelve pore types are divided into 5 different rock types. To validate our analysis, after combining the pore types, we generated porosity distribution for each rock type and is presented in figures 53 through 57. 


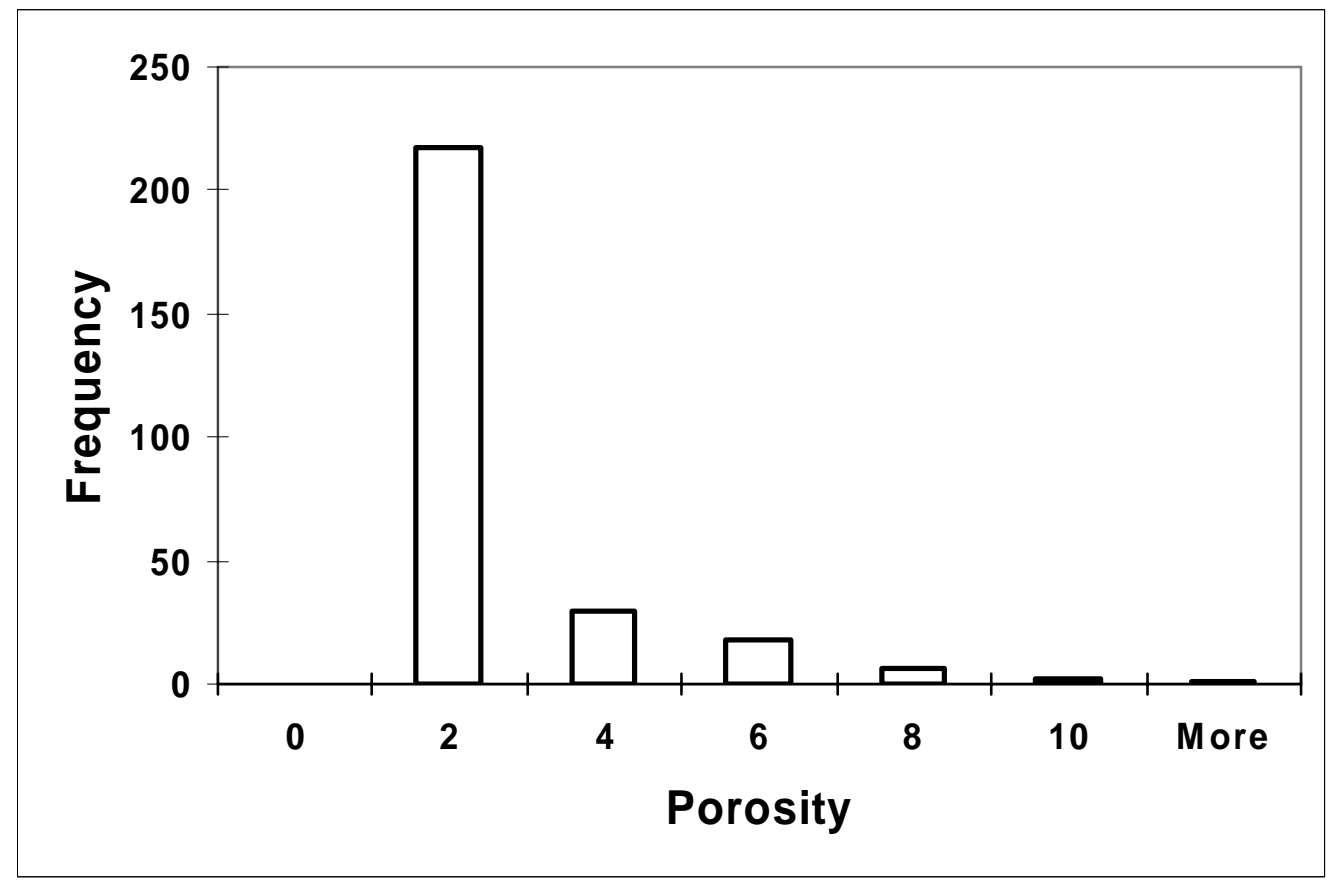

Figure 53: Porosity distribution of rock type 1

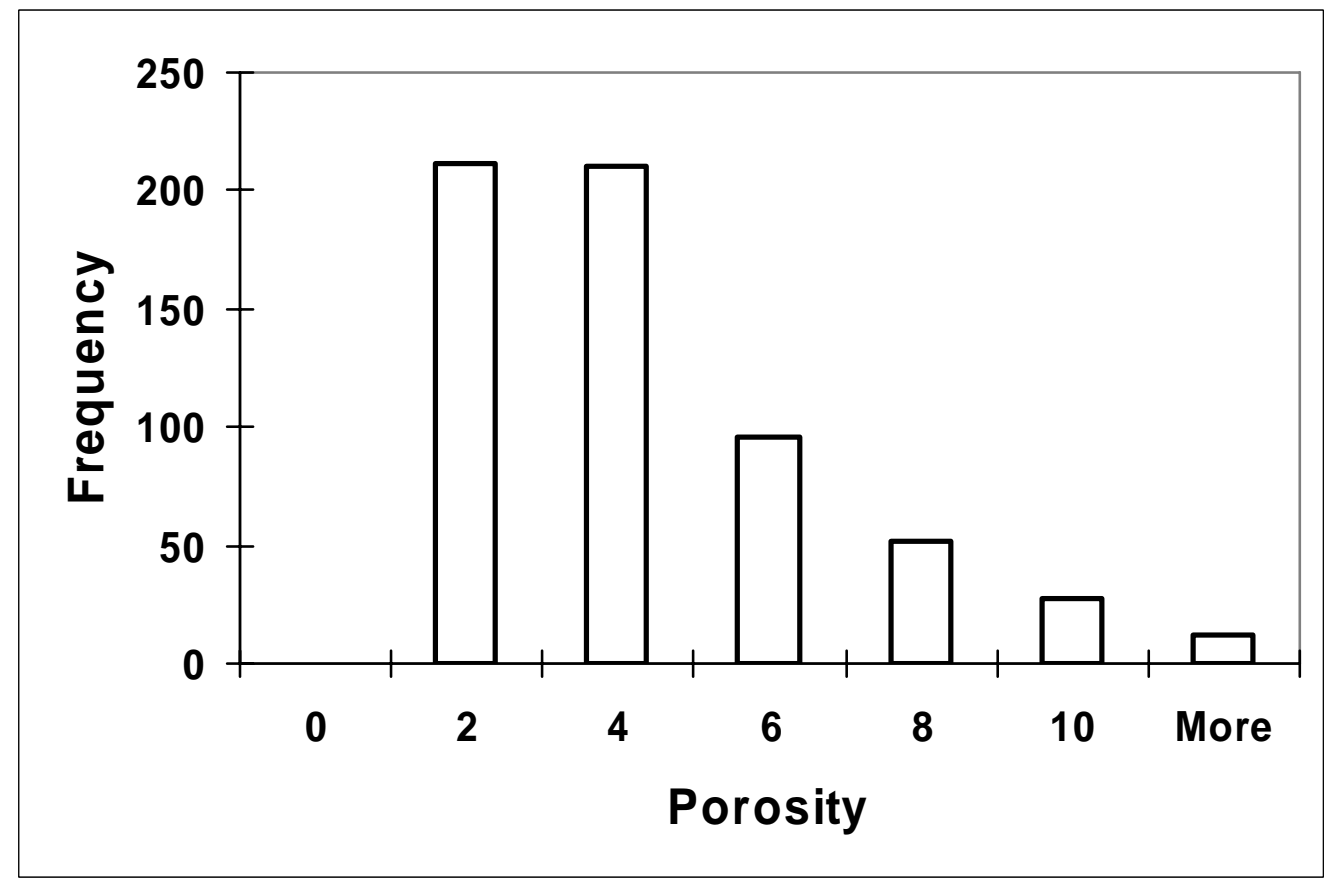

Figure 54: Porosity distribution of rock type 2 


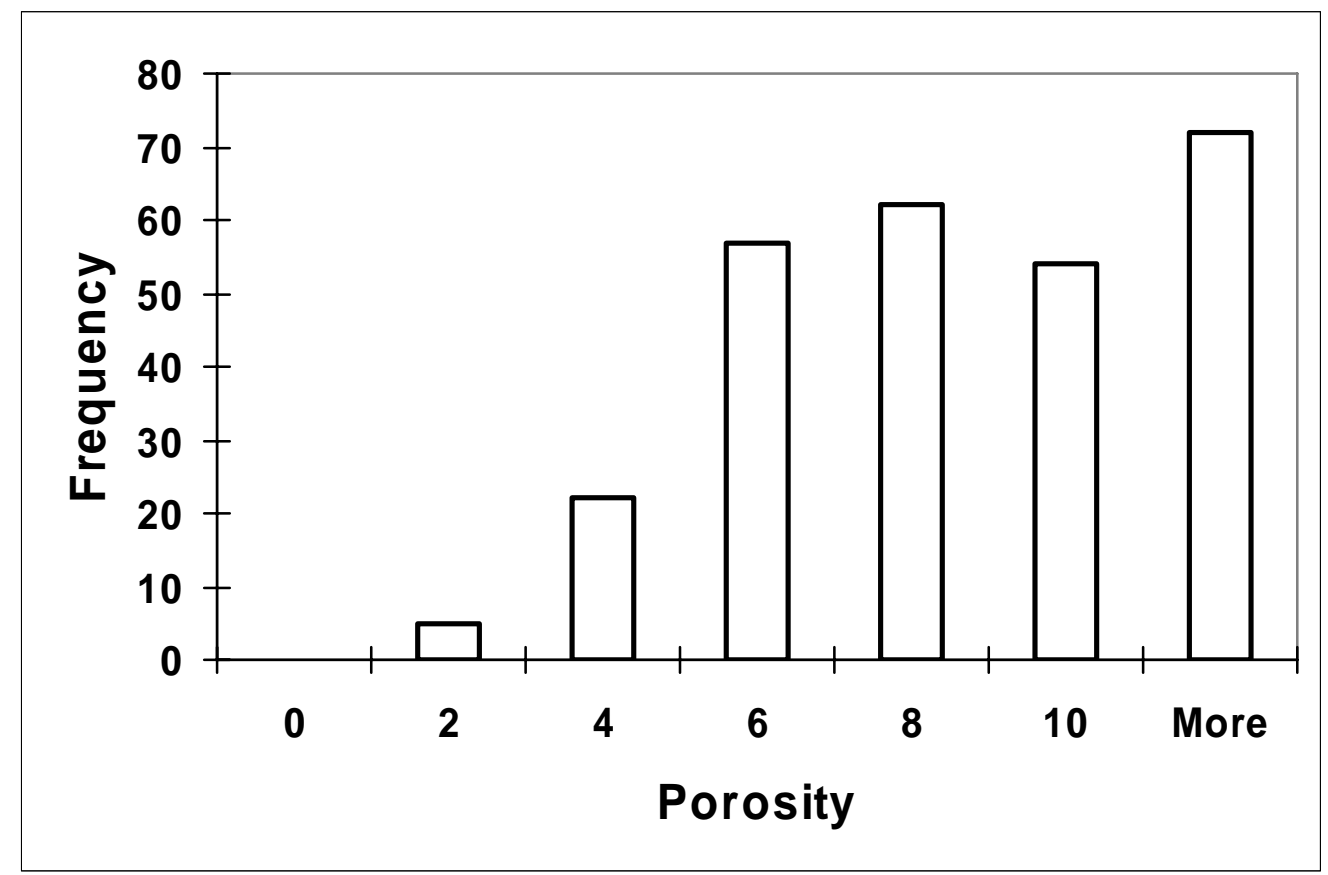

Figure 55: Porosity distribution of rock type 3

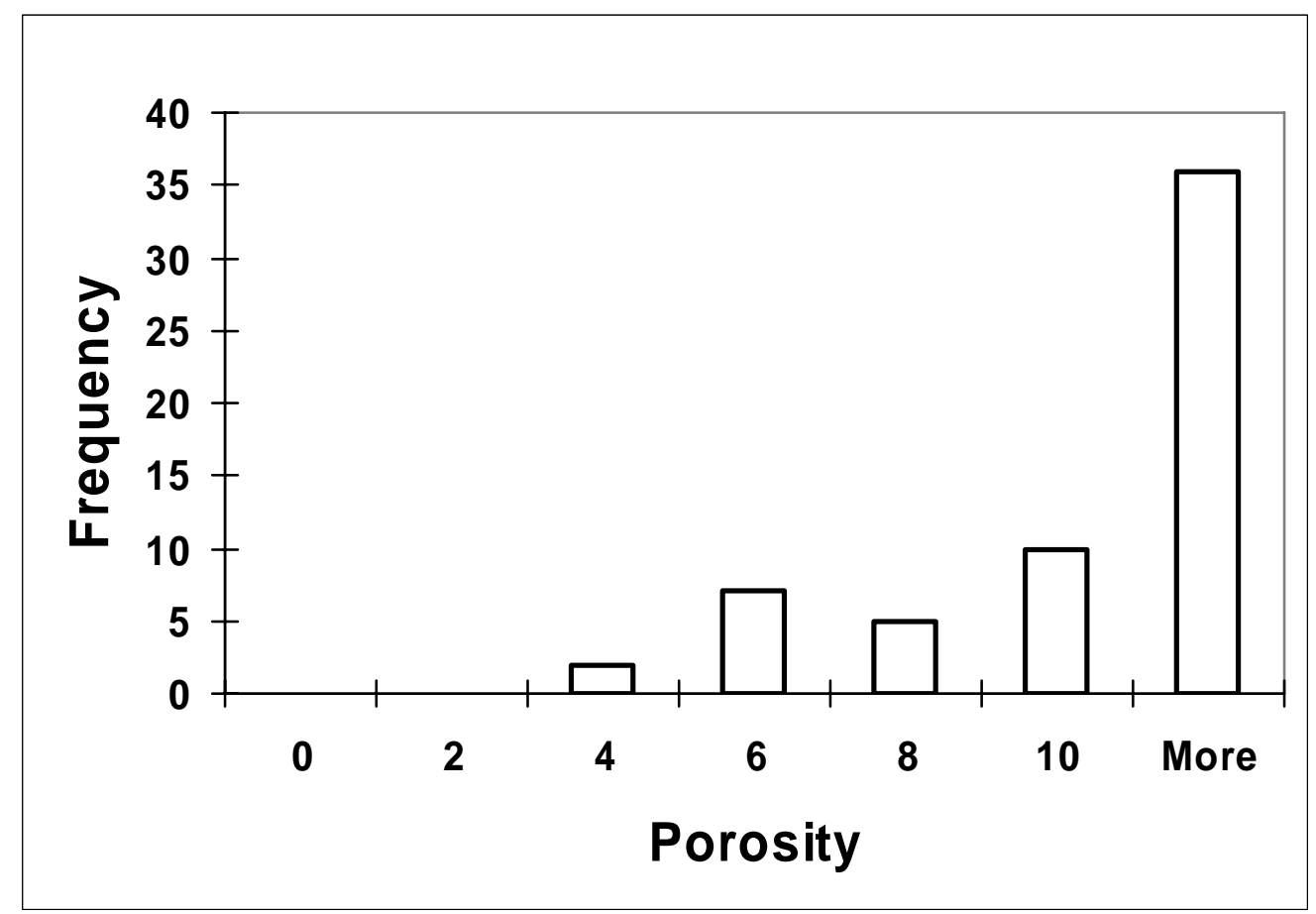

Figure 56: Porosity distribution of rock type 4 


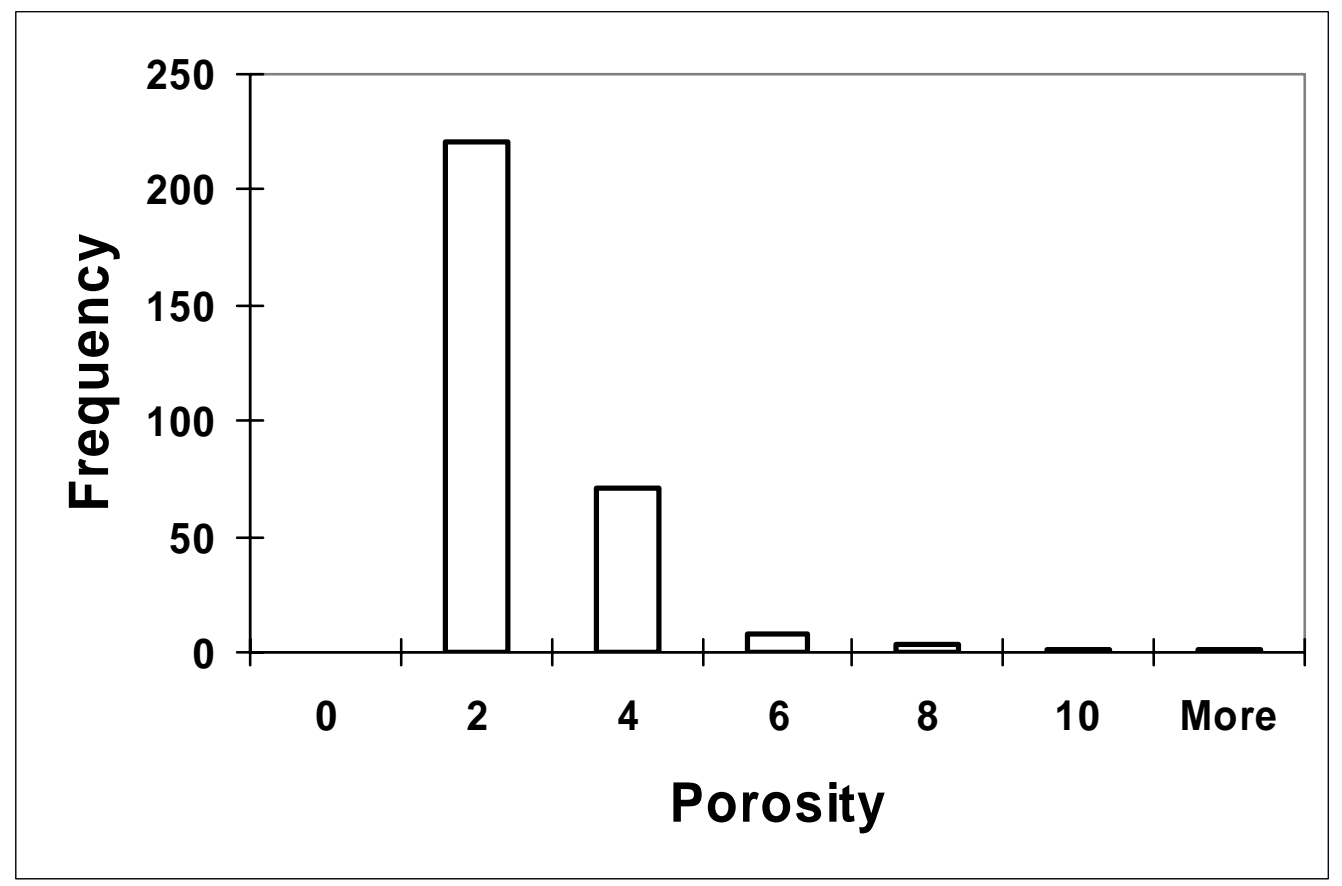

Figure 57: Porosity distribution of rock type 5

As can be seen from the figures above, the porosity distribution for each rock type is unique. As one observes the porosity distribution from rock type 1 to rock type 4 , the distribution indicates higher porosity values. This is consistent with the pore types. In rock type 1 , it is mostly limestone or partially dolomitized limestone; whereas, rock type 4 represents vuggy dolomite indicating high porosity values. Rock type 5 and rock type 1 have similar porosity characteristics; however, their permeability distributions are different as discussed below.

Once the rock types are classified, we generated permeability - porosity relationships for each of the rock types. We would expect a different relationship for each of those rock types. The figures for each of the rock types are shown below: For rock type 1, most of the data are below $4 \%$ porosity, and the permeability values are typically less than $1 \mathrm{mD}$. 


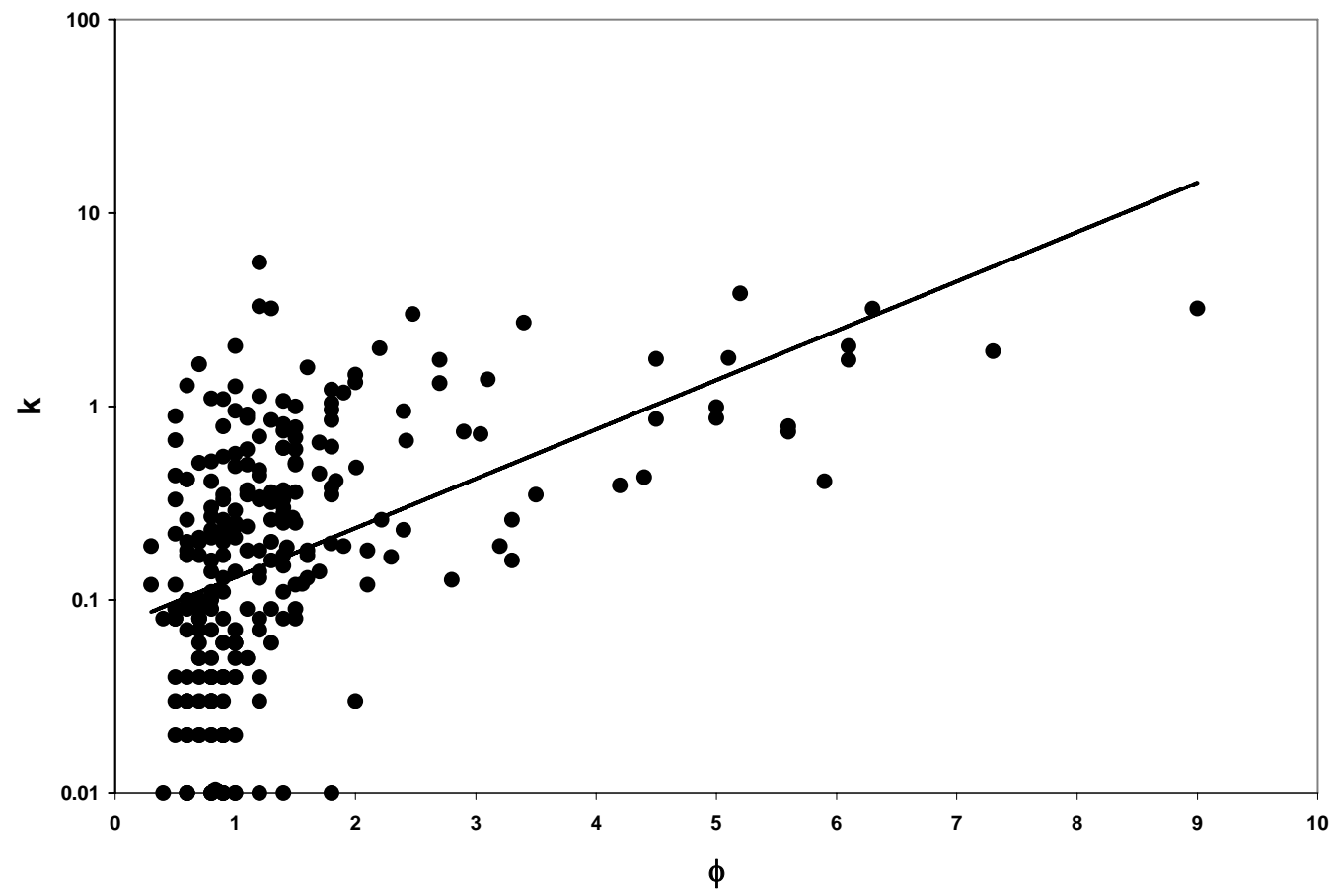

Figure 58: Log k versus porosity relationship for rock type 1

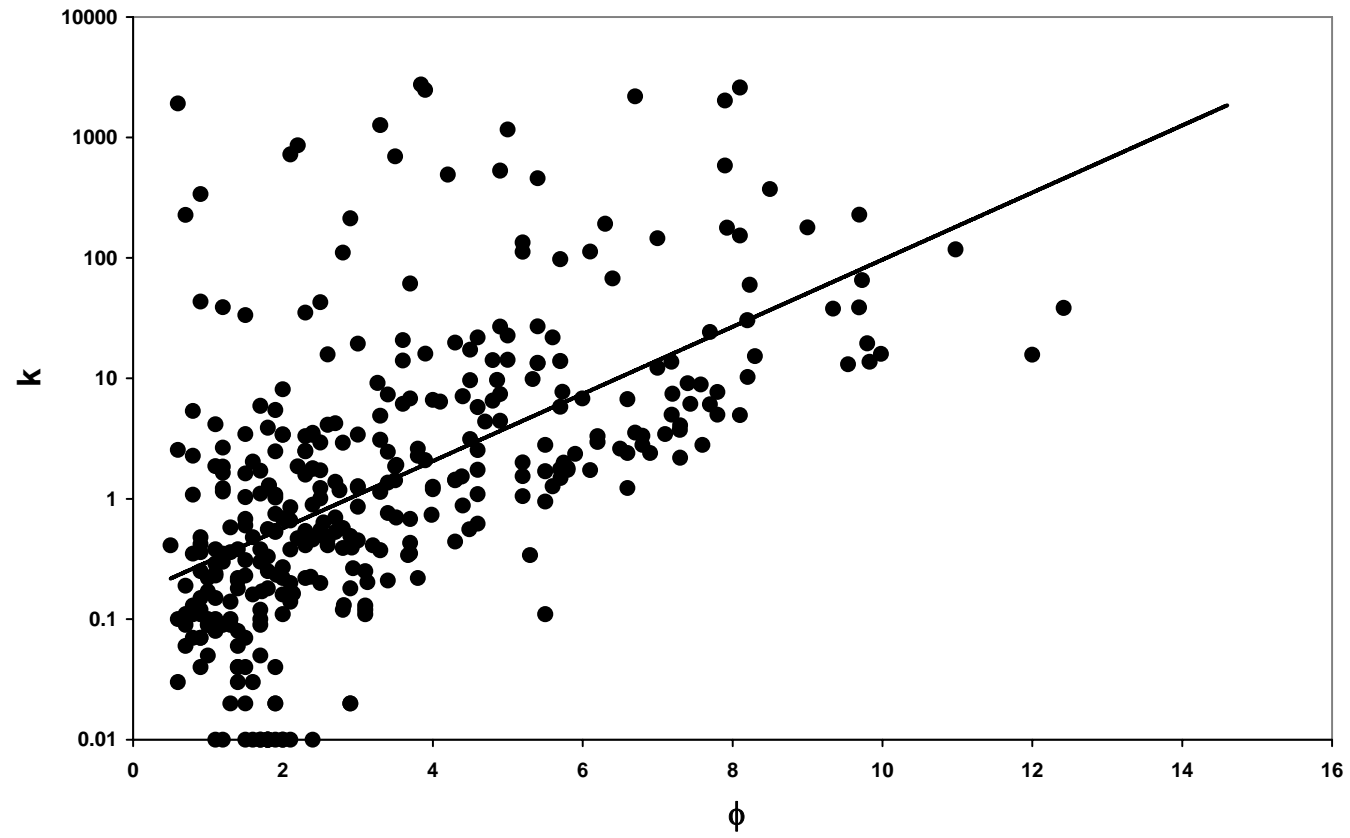

Figure 59: $\log k$ versus porosity for rock type 2 


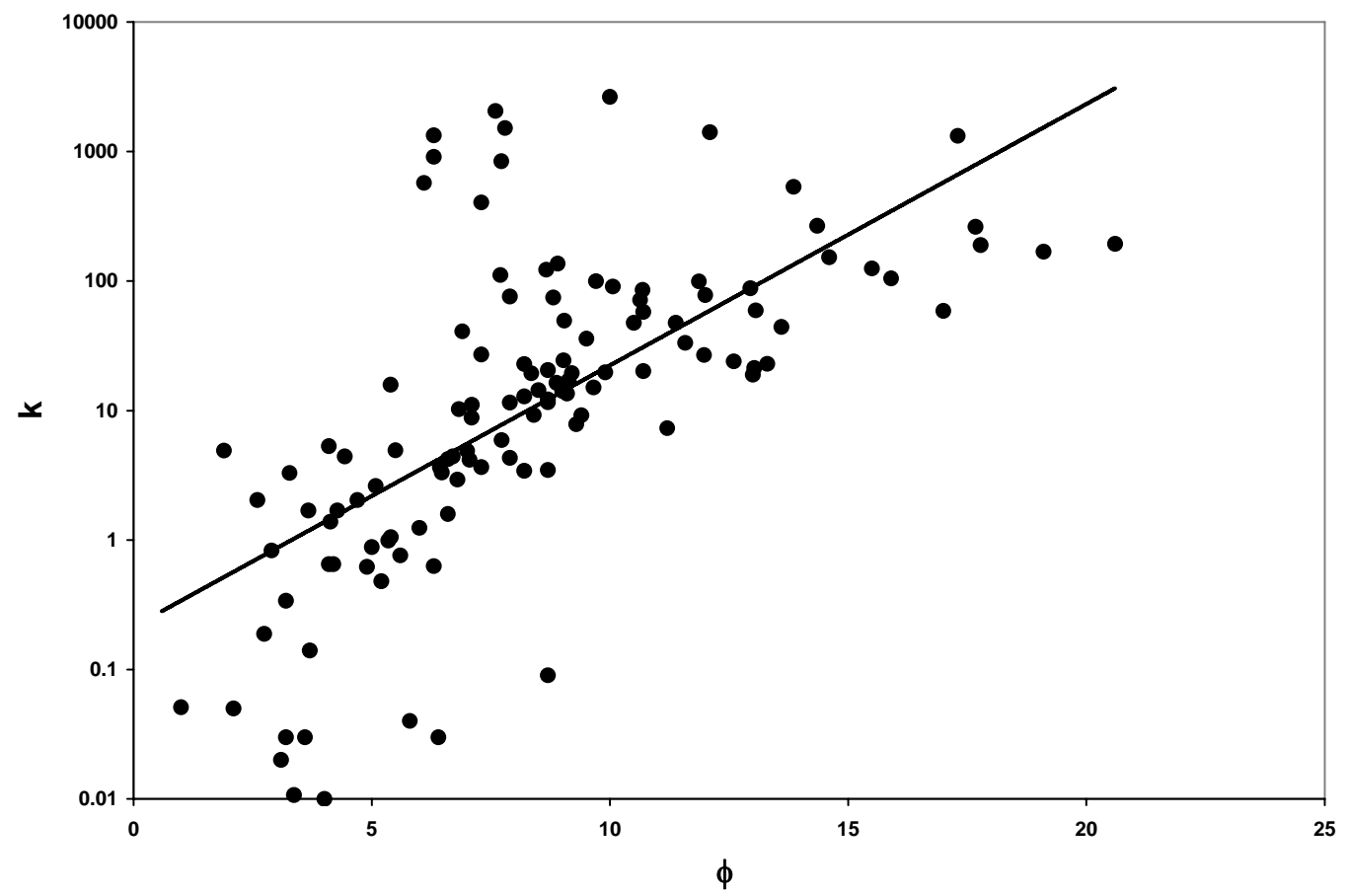

Figure 60: Log k versus porosity for rock type 3

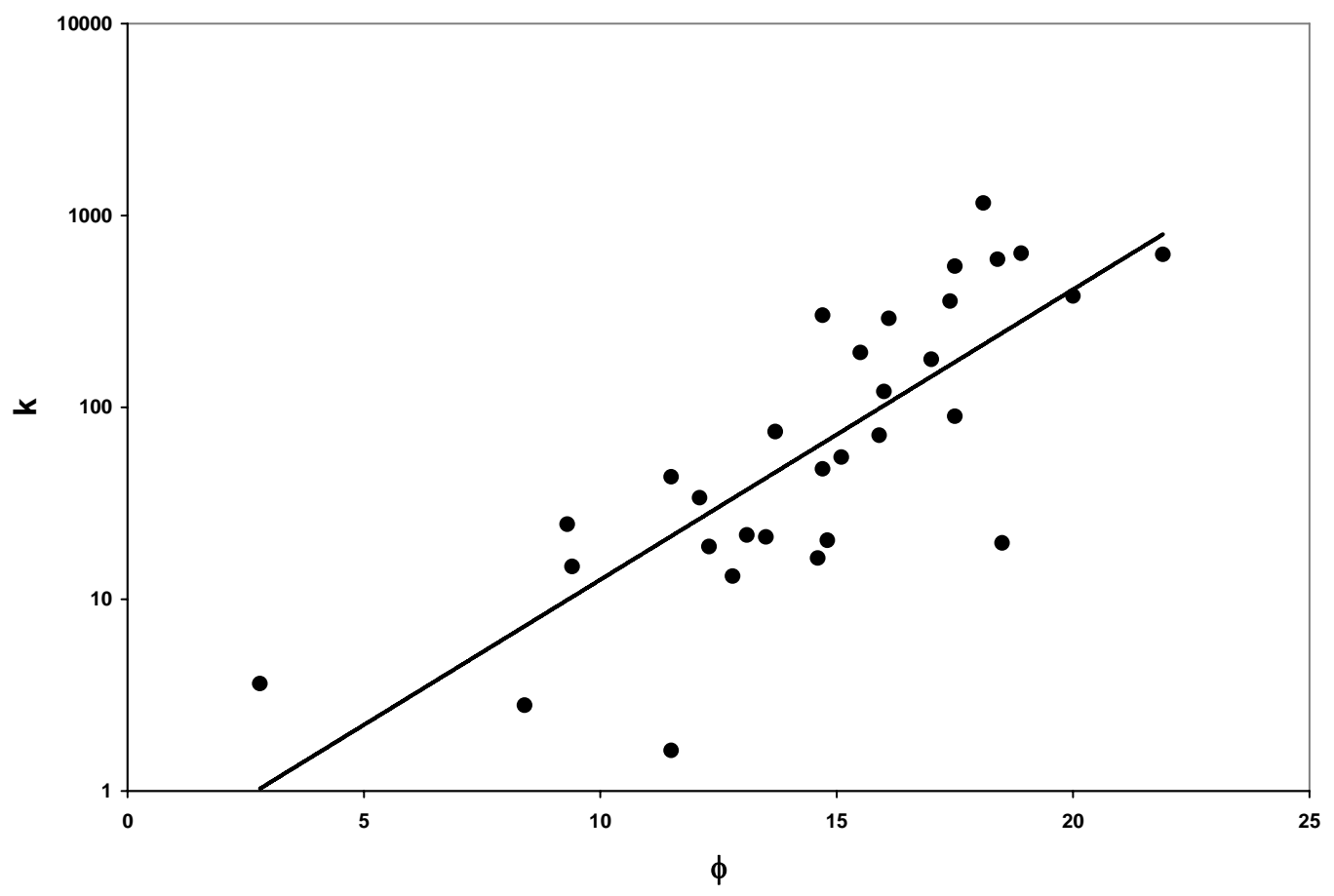

Figure 61: Log k versus porosity for rock type 4 


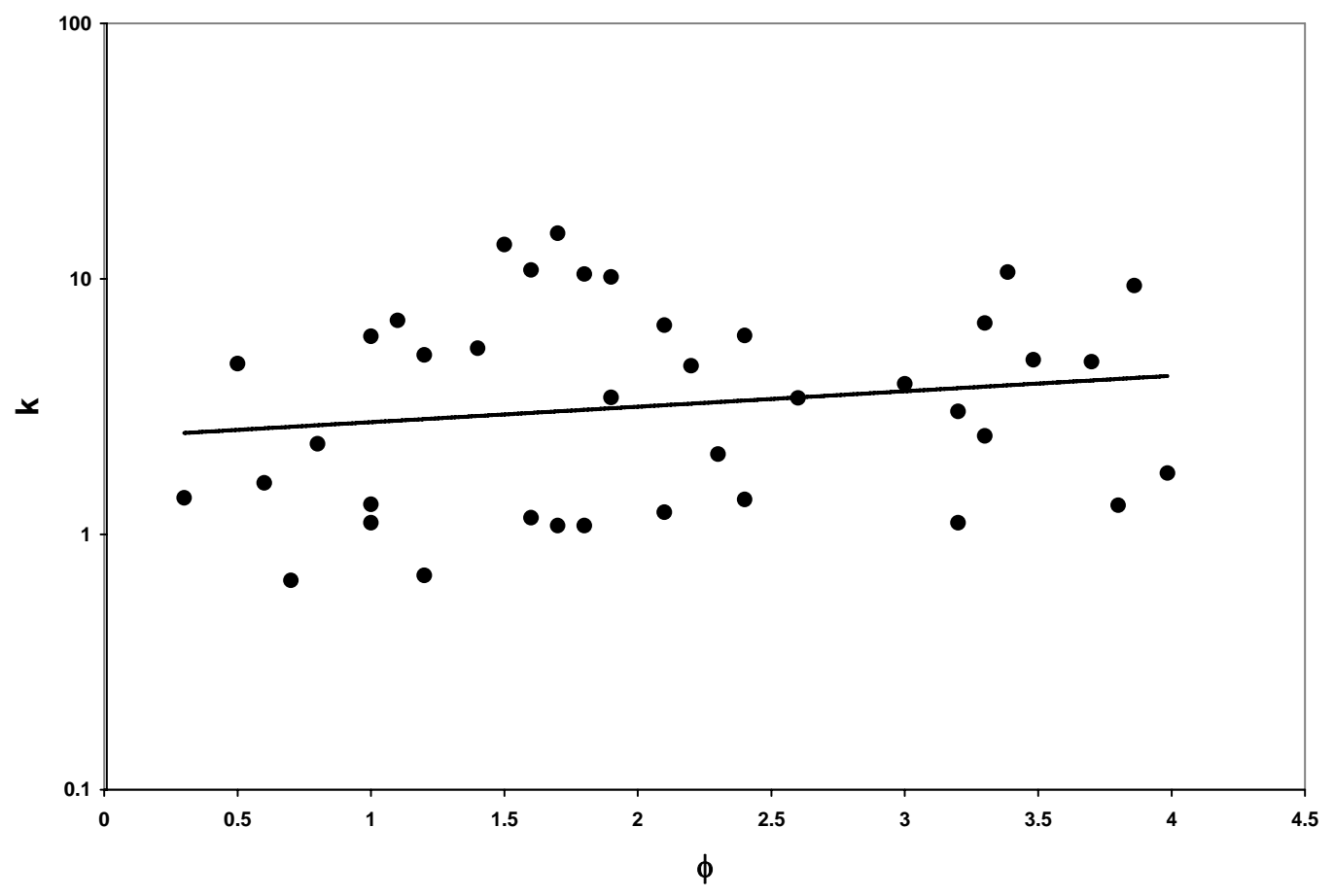

Figure 62: Log k versus porosity for rock type 5

For rock type 2, the permeability values can go up to $10 \mathrm{mD}$, for rock type 3 , the permeability values can go up to $100 \mathrm{mD}$, and for rock type 4, the permeability values go up to $1000 \mathrm{mD}$. Higher porosity values for rock type 5 also indicate better permeability characteristics. For rock type 5 - which represents fractured reservoir in dolomite, the average permeability is about $5 \mathrm{mD}$ and is not dependent on the porosity. This is consistent with fractures in the reservoir in limestone rocks. Limestone rock is so tight (see rock type 1 - figure 58) that the permeability is quite low. Less than $1 \mathrm{mD}$. However, the enhancement can be achieved by introducing fractures. Since fracture provide the major source of conductivity, the permeability does not depend on the porosity of the rock.

The next task in the description is to develop a procedure such that log data can be used to generate rock types at wells where no core data are available. This is important since the core data are sparse and not available at every well. We examined the relationships between rock types and logs at the cored wells, and concluded that the only relationship we have between rock 
types and log data is the porosity information. That is, we can relate neutron and density porosity logs to rock types.

To generate rock types at logged wells, we first assigned probability of rock type for a given porosity class. See figure 63 for an example. In this figure, the observation of rock types for a porosity range between 0 to $2 \%$ is plotted. The number of occurrences for a given rock type are indication of the probability of occurrence for a given rock type. So, for example, for the porosity range in figure 63, rock type 1 and rock type 2 are much more common than other rock types. In contrast, in figure 64 , for a porosity distribution of 10 to $20 \%$, rock types 3 and 4 are much more common. Using the information for each porosity class, we can determine the probability of occurrence of a given rock type.

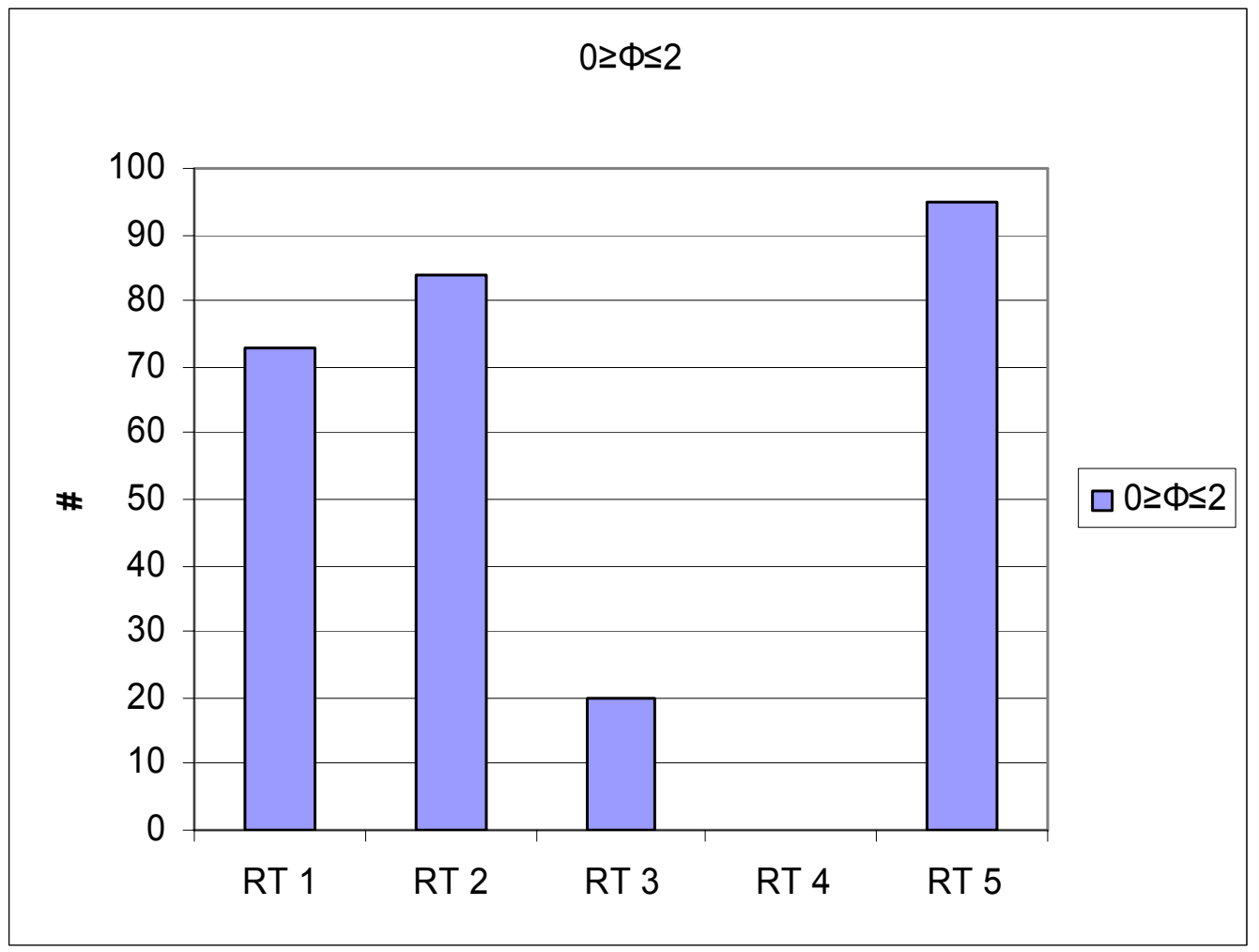

Figure 63: Rock type distribution for porosity in the range of 0 to $2 \%$ 


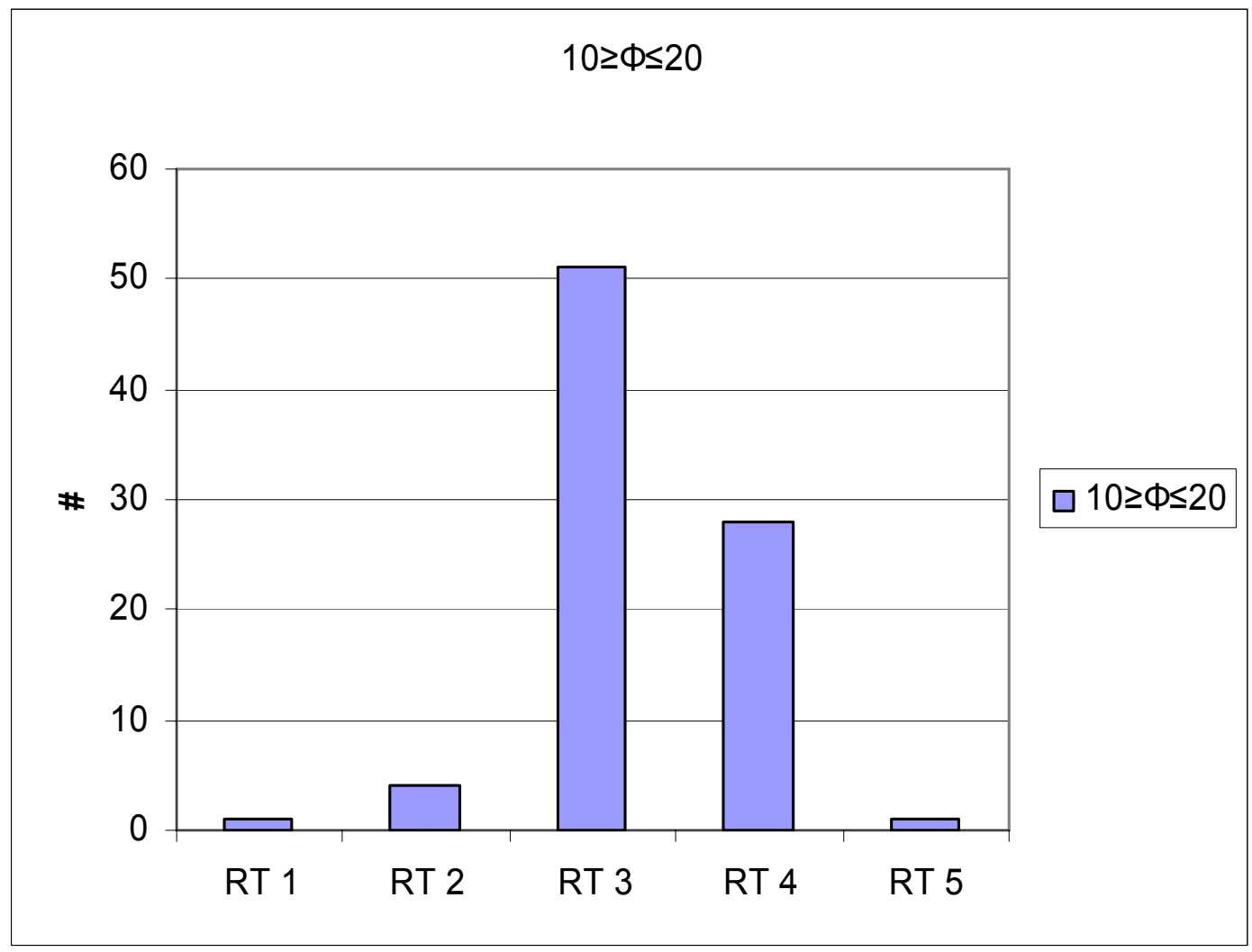

Figure 64: Rock type distribution for porosity in the range of 10 to $20 \%$

Once the information about the probabilities is known, we can sample a rock type at logged wells by using a random number generator - a number which falls between 0 and 1 , and can be assigned to a particular depth. By comparing that number with cumulative probability distribution, we can assign a rock type at a given depth. Once the rock types at individual wells are assigned, we would be able to assign the permeability values using the relationship between permeability and porosity for a given rock type.

Among all the approaches we have tried, this approach seems to be the most viable. It has the advantage of capturing geological information as well as unique petrophysical information. Further, it is simple to implement and captures the uncertainties in petrophysical properties as well as rock types as part of the reservoir description.

Static to Dynamic Relationship. Ultimately the petrophysical data has to be used to develop the relationship between the dynamic data and the petrophysical data. This is needed so 
that using the petrophysical properties, we can predict the dynamic behavior. We used several methods to understand and quantify the relationship between the static and the dynamic data. Below is a brief description of the attempted methodologies.

\section{$\underline{\text { Pickett and Buckle Plots }}$}

Earlier in the project, the two approaches were tried to better understand and study this relationship: the Pickett plot $^{20}$ approach and the Buckles $\operatorname{plot}^{21}$ approach. Both these are discussed below.

As discussed in the previous section, the geological pore types were assigned at every data point in all the 152 wells. We considered, for calculation purposes, that each pore type represented a small unit thickness of the West Carney Hunton field reservoir. We also calculated the corresponding porosity, resistivity, water saturation, bulk volume water and hydrocarbons in place associated with that unit thickness. Based on those calculations we were able to calculate the hydrocarbons in place for all the 152 wells from the West Carney Hunton field considered in our study.

As mentioned earlier the main highlight of this correlation was to understand some of the diagnostic characteristics of the static data like the porosity, permeability, rock type, pore type, facies data and also be able to address the question; what makes a good producer? Therefore, we had to study the dynamic data such as the oil and gas production, (availability of water production data was limited, but has been studied wherever available), and we determined the decline rates and the cumulative oil and gas produced from the 152 wells. 


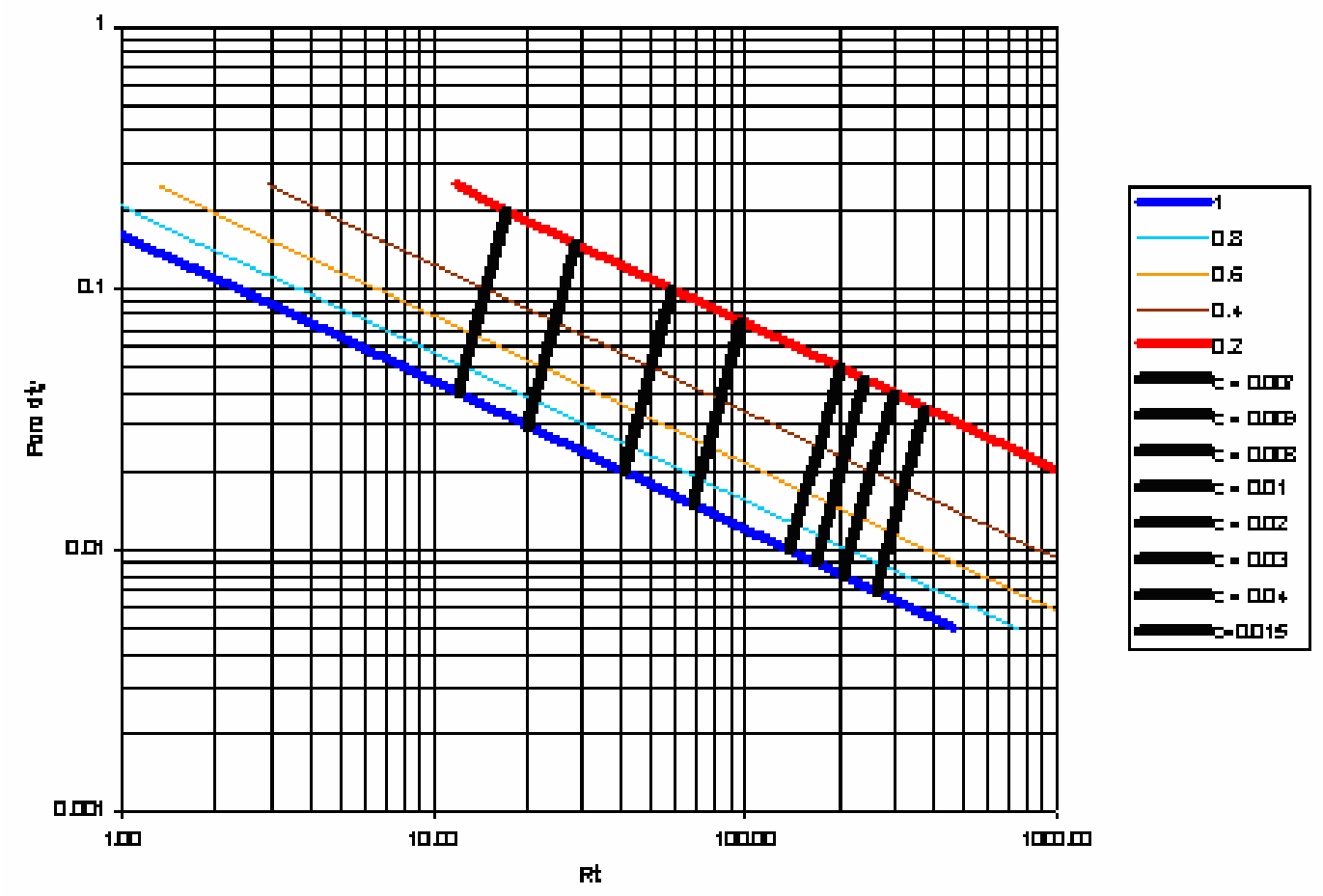

Figure 65: A typical Pickett plot

Figure 65 is an example of the Pickett plot. Porosity is calculated from the neutron porosity and density porosity logs and is plotted against the resistivity data obtained from the deep resistivity log. Porosity is plotted on the ' $\mathrm{Y}$ ' axis with a logarithmic scale ranging from $0.1 \%$ to $100 \%$ while the resistivity is plotted on the ' $\mathrm{X}$ ' axis with a logarithmic scale ranging from 1 to 1,000 ohm meter. The colored inclined lines represent water saturation; dark blue line indicates $100 \%$, decreasing as we go towards red, which is $20 \%$ water saturation. The dark black lines that are perpendicular to the colored water saturation lines are the bulk volume water lines. The value of these lines is decreasing as the resistivity is increasing.

Porosity was calculated using the data available from the neutron and density porosity logs by taking square root average. Water saturation was calculated using Archie's formula. The value of cementing factor, m, was experimentally determined to be 1.77. Bulk volume water is the product of porosity times saturation. 
The Pickett plots with geological pore types did not show any correlation to production data; hence, we had to abandon that approach and consider plotting the electrofacies on the Pickett plot.

We had access to the daily production records of the wells operated by Marjo Oil Company. We considered 27 wells for which we had log data and classified them into three groups, good average and bad producers. Then, we made the Pickett plots using electrofacies for all these 27 wells, and began examining the data.

The figures below show some of the Pickett plots using the electrofacies along with the production data for some of the good and bad producers amongst the 27 Marjo wells that we considered for this study. Our aim was to determine the diagnostic characteristics, based on these 27 wells and then validate using the data from the remaining wells.

Below we show as an example a good producer (Danny 2) and the associated Pickett plot. The production data are plotted assuming that day 1 represents when the production started from the field.
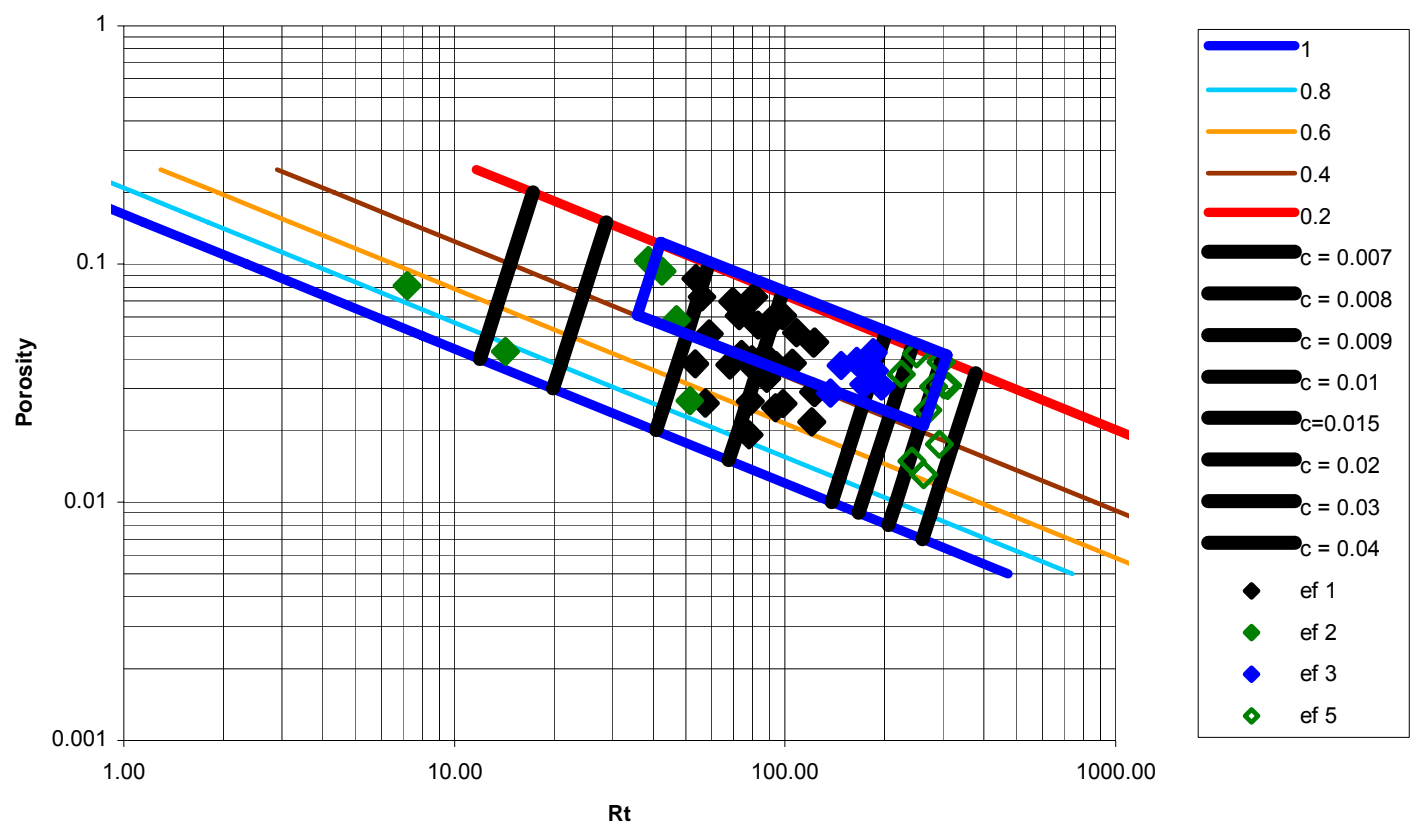

Figure 66: Pickett plot for the well Danny \#2; legend: ef = electrofacies 


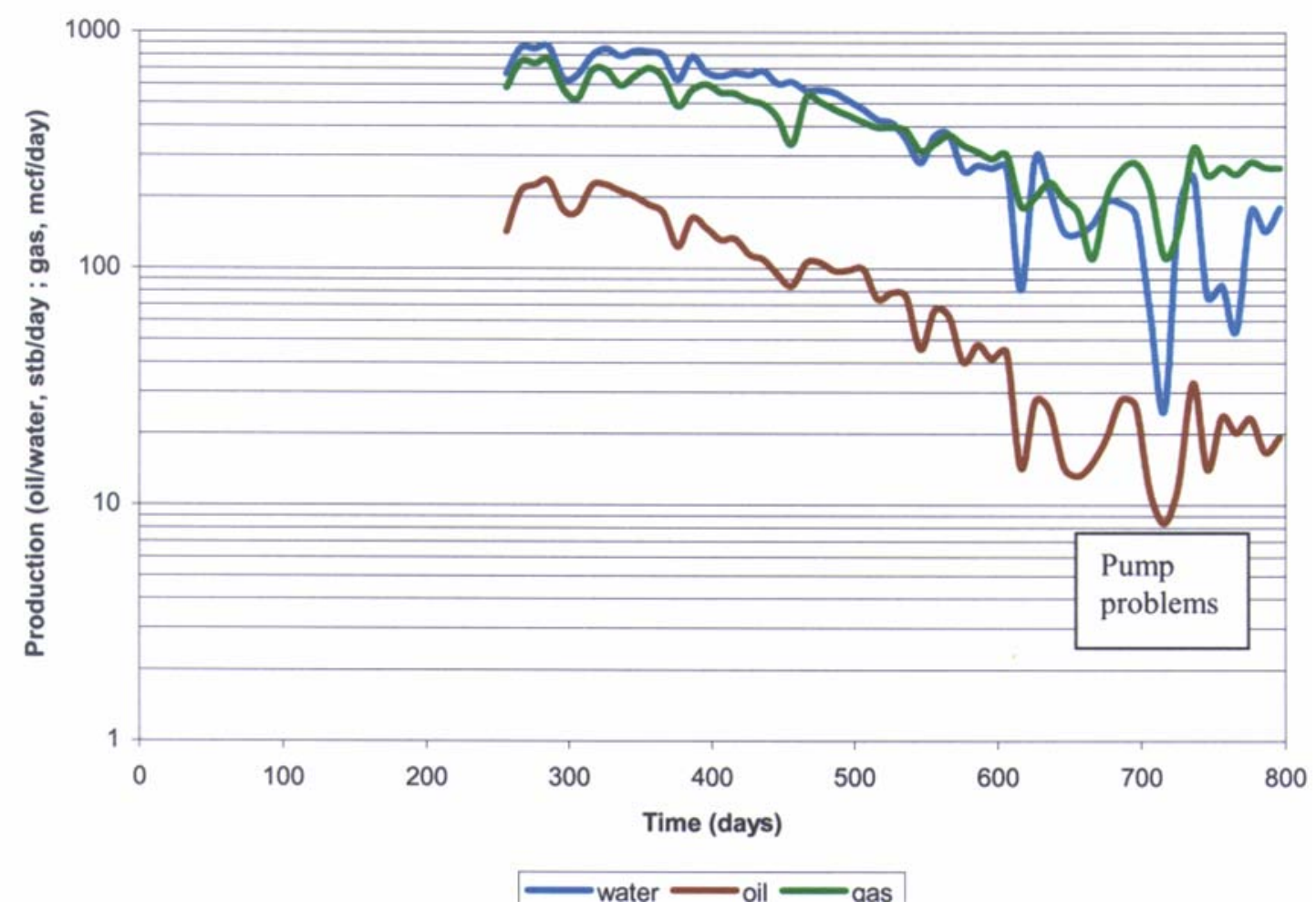

Figure 67: Production from well Danny \#2

The Pickett plot does not show any distinct characteristics from a well which is considered a poor producer. The following table summarizes our attempt to relate petrophysical characteristics to the well performance. 
Table 18. Petrophysical, electrofacies and production characteristics of some of the wells

\begin{tabular}{|c|c|c|c|}
\hline Well Name & $\begin{array}{c}\text { Production } \\
\text { Characteristics }\end{array}$ & Electrofacies & Petrophysical characteristics \\
\hline Carter 1 & $\begin{array}{l}\text { High WOR (100 approx), } \\
\text { low oil production rate }\end{array}$ & Mostly $1 \& 2$, some 3 & $\begin{array}{c}\text { More than } 50 \% \text { data has lower } \\
\text { than } 4 \% \text { porosity }\end{array}$ \\
\hline Henry & $\begin{array}{c}\text { High WOR } \\
(50-100 \text { approx })\end{array}$ & Mostly $1 \& 2$, some 3 & $\begin{array}{l}\text { More than } 50 \% \text { data has } \\
\text { greater than } 4 \% \text { porosity }\end{array}$ \\
\hline Cal & Low water and oil producer & All present & $\begin{array}{c}90 \% \text { data has lower than } \\
4 \% \text { porosity }\end{array}$ \\
\hline Schwake & $\begin{array}{c}\text { Low WOR , ( } 4-5 \text { approx) } \\
\text { sustained oil \& water } \\
\text { production, GOR constant }\end{array}$ & $\begin{array}{l}\text { Bulk of the data } 4 \text {, } \\
\text { with some } 2 \& 3\end{array}$ & $\begin{array}{l}\text { Bulk of the data between } 2 \& 4 \\
\% \text { porosity, high perm in type } 4\end{array}$ \\
\hline Alan Ross & $\begin{array}{c}\text { Sustained production, low } \\
\text { water, Gas rate decreasing }\end{array}$ & $\begin{array}{l}\text { Large } \% \text { of } 4 \text { with } \\
\quad \text { some } 2,3,5\end{array}$ & $\begin{array}{l}\text { Characteristics similar to } \\
\text { schwake }\end{array}$ \\
\hline Townsend & $\begin{array}{l}\text { Sustained oil and water } \\
\text { rate, gas rate decreasing }\end{array}$ & $\begin{array}{c}\text { Bulk } 4 \text { with } \\
\text { significant } 1 \& 3\end{array}$ & $\begin{array}{c}\text { Porosity greater than } 2 \%, \\
15 \% \text { data having porosity } \\
\text { greater than } 10 \%\end{array}$ \\
\hline Franny & $\begin{array}{c}\text { Sustained production, } \\
\text { WOR (approx 6), gas rate } \\
\text { decreasing }\end{array}$ & Bulk 4, some $1 \& 2$ & $\begin{array}{l}\text { Bulk of porosity greater than } \\
\qquad 2 \%\end{array}$ \\
\hline Lewis & $\begin{array}{l}\text { WOR (approx 8), poor } \\
\text { producer }\end{array}$ & $\begin{array}{l}\text { Equal distribution of } \\
\text { all electrofacies }\end{array}$ & No porosity greater than $10 \%$ \\
\hline Wilkerson 1 & $\begin{array}{c}\text { Sustained water rate, WOR } \\
\text { (approx 4), sustained gas } \\
\text { production, GOR } \\
\text { decreasing }\end{array}$ & Bulk 1,2 \& 3 & $\begin{array}{l}\text { Bulk of porosity greater than } \\
3 \% \text { (connected, hence oil } \\
\text { coming from somewhere else) }\end{array}$ \\
\hline Danny 2 & $\begin{array}{l}\text { WOR (approx } 5 \text { ), good } \\
\text { producer, sustained gas } \\
\text { production, GOR } \\
\text { decreasing }\end{array}$ & Bulk 1,2 \& 3 & $\begin{array}{c}\text { Bulk of the porosity greater } \\
\text { than } 3 \% \text { (well connected, } \\
\text { hence oil coming from } \\
\text { elsewhere) }\end{array}$ \\
\hline Williams & $\begin{array}{c}\text { Oil and gas rate sustained, } \\
\text { water rate decreasing, } \\
\text { WOR (approx 10) }\end{array}$ & $\begin{array}{c}1,2,3 \& 5, \text { all in equal } \\
\text { proportions }\end{array}$ & $\begin{array}{c}\text { Bulk of the porosity is greater } \\
\text { than } 2 \%\end{array}$ \\
\hline Wilson & $\begin{array}{l}\text { Sustained oil, water and } \\
\text { gas production WOR } \\
\text { (approx 2) }\end{array}$ & High $\%$ of 4 & $\begin{array}{l}\text { Bulk of the porosity is less than } \\
\qquad 2 \%\end{array}$ \\
\hline
\end{tabular}

The study of these plots did not successfully answer our question; what makes a good producer, but then we could infer some of the probable reasons for a good producer from this study. Some wells with substantial proportions of electrofacies 1, 2, and 3 having $2 \%$ and greater porosity OR substantial proportions of 4 and 5 having $4 \%$ and greater porosity, seemed to be good producers. But we were not able to identify any diagnostic characteristics, which can consistently identify good producers. 


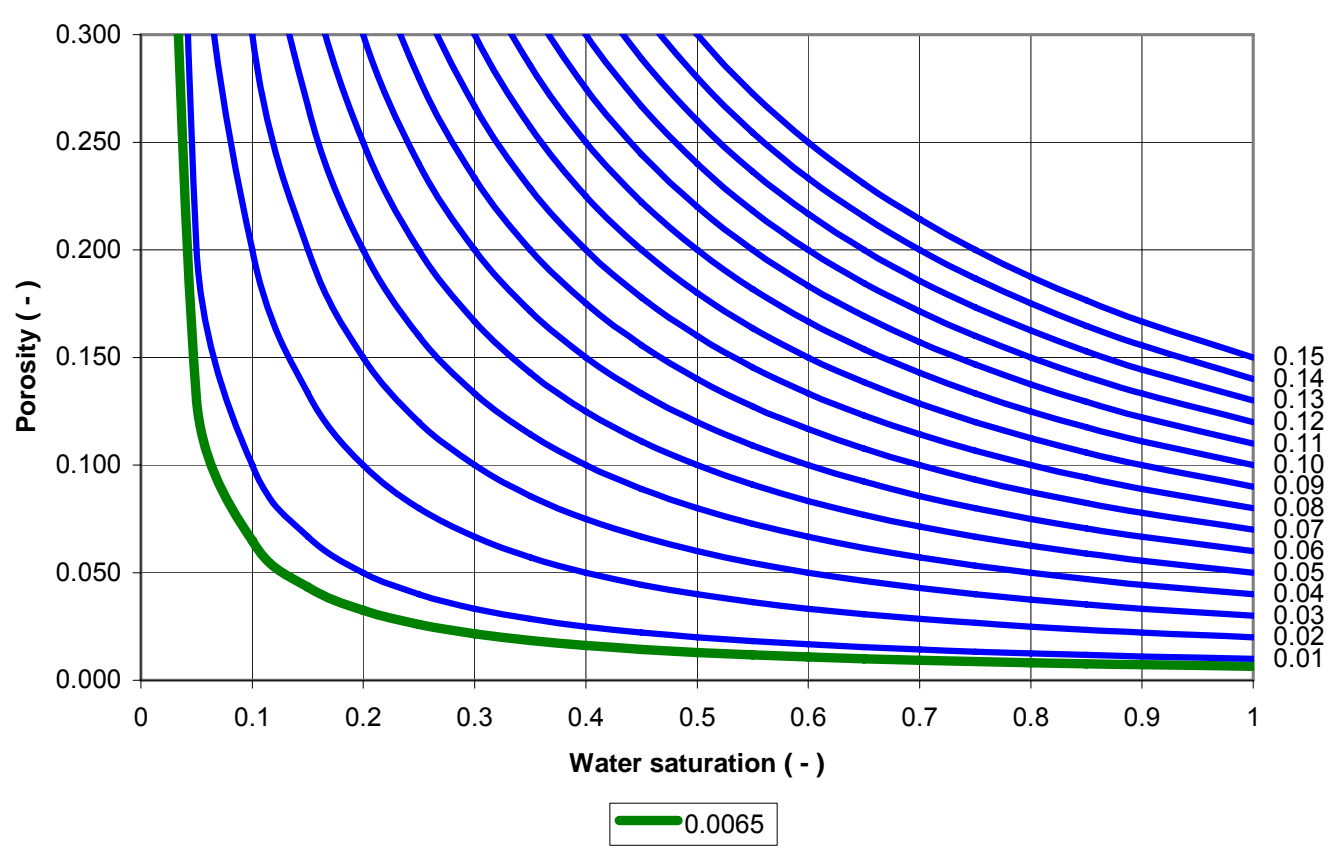

Figure 68: A typical Buckles plot

Figure 68 is an example of the Buckles plot. Porosity is plotted against the water saturation. Porosity is plotted on the ' $\mathrm{Y}$ ' axis with a scale ranging from 0 to $30 \%$ porosity (shown in decimals) while Water saturation is plotted on the ' $\mathrm{X}$ ' axis with a scale ranging from 0 to $100 \%$ (shown in decimals) water saturation. The blue lines represent lines of constant bulk volume water. The scale for bulk volume water lines (blue lines) ranges from 0.01 to 0.15 and is shown as a secondary ' $\mathrm{Y}$ ' axis. The green line (value 0.0065) is also a bulk volume water line that is used to demarcate between the reservoir and transition zones.

The implicit assumption in the Buckles plot approach is that the product of irreducible water saturation and porosity is constant. The region closest to the blue line (bulk volume water line) is considered to be the reservoir zones, since they contain irreducible water saturation. The regions above and away from the blue line are considered as the transition zones and the regions close to $100 \%$ water saturation are considered as the water zones. This type of analysis is useful in traditional oil reservoirs to identify oil zones and water zones. The well will be completed in the oil zone to minimize the water production. In West Carney Hunton field, however, such 
traditional approach will not work since water is present and is mobile in all parts of the reservoir.

The geological pore types were plotted individually and in combination with one another and the best match was obtained on combining the coarse matrix and the vugs together and the fine matrix and the fractures together. Geological core descriptions also confirm that in most cases the fine matrix rock is fractured; hence, we decided to combine the fine and fractured pore type together, and the coarse and the vuggy pore types together.

At this point, as we discuss the Buckles plots, we would like to comment on the wettability of the West Carney Hunton field reservoir rock and also refer to some of the unique characteristics of the reservoir.

The West Carney Hunton field reservoir rock was originally thought to be water wet. The oil migrated into the reservoir and was trapped in place for a very long time. The oil migrated preferably to the larger pores and vugs. In due course, the wettability of the West Carney Hunton field began to change to oil wet. Oil began to enter the smaller pores and displaced the water. During the later stages of geological time, water migrated into West Carney Hunton field and selectively entered larger pores and vugs because of oil wet characteristics. Oil remained trapped in the smaller pores. This is seen in Buckles plots, which show the fine matrix rock to be coincident with irreducible water saturation, whereas, coarse matrix rock to be in the invaded zone.

Figure 69 shows the limestone vug and coarse matrix pore type data plotted on a Buckles plot. 


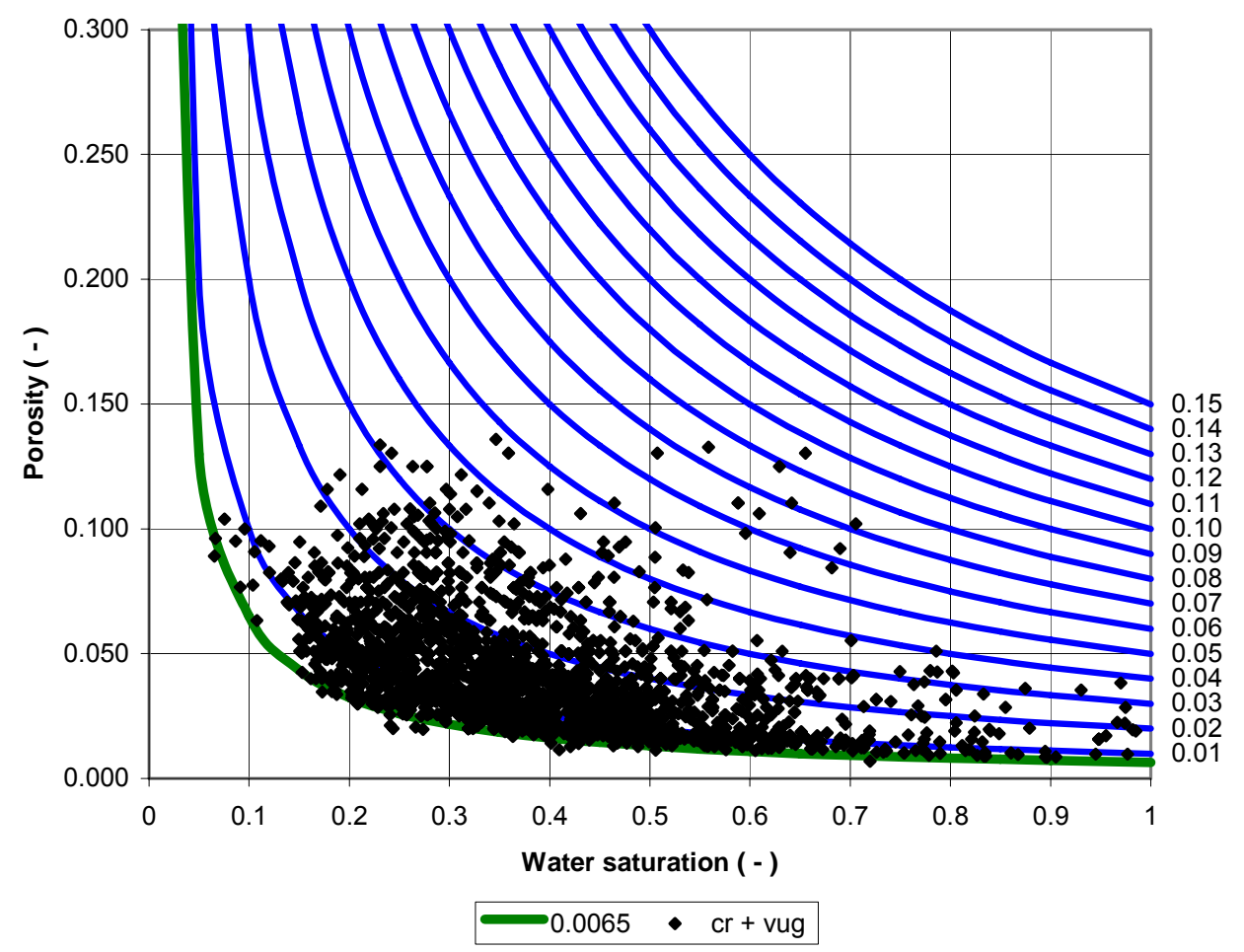

Figure 69: Buckles plot for limestone with coarse matrix and vuggy pore types; Legend: cr = coarse matrix

Figure 70 shows limestone fine matrix and fracture pore type data plotted on a Buckles plot. 


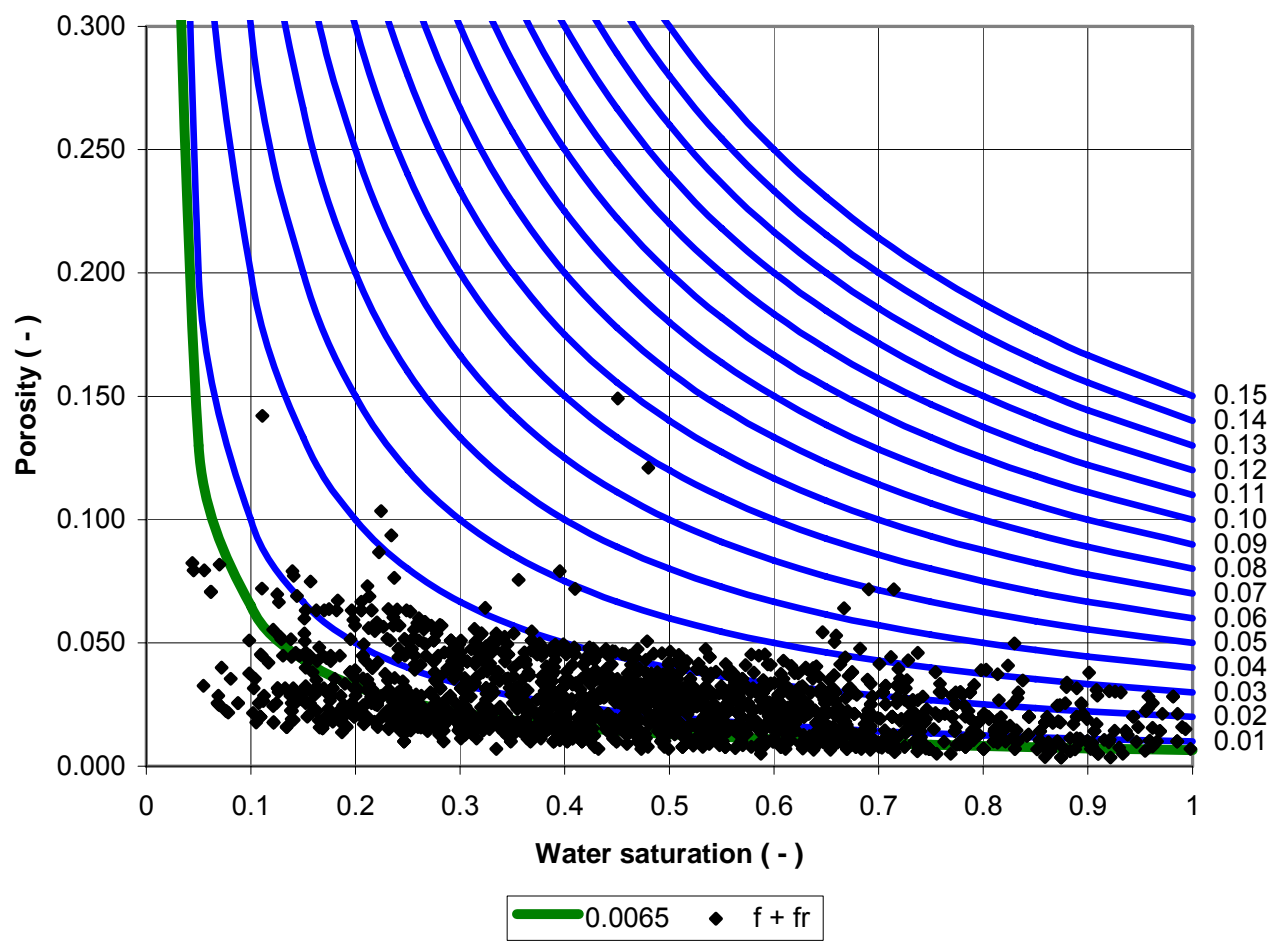

Figure 70: Buckles plot for limestone with fine matrix and fracture pore types; legend: $f=$ fine matrix and $f r=$ fracture

By reviewing the two plots shown above, we can see that the rock having fine matrix and fracture pore types are representing the irreducible water saturation, and the rock with coarse matrix and the vuggy pore types are representing the invaded zones along with some reservoir zones. 


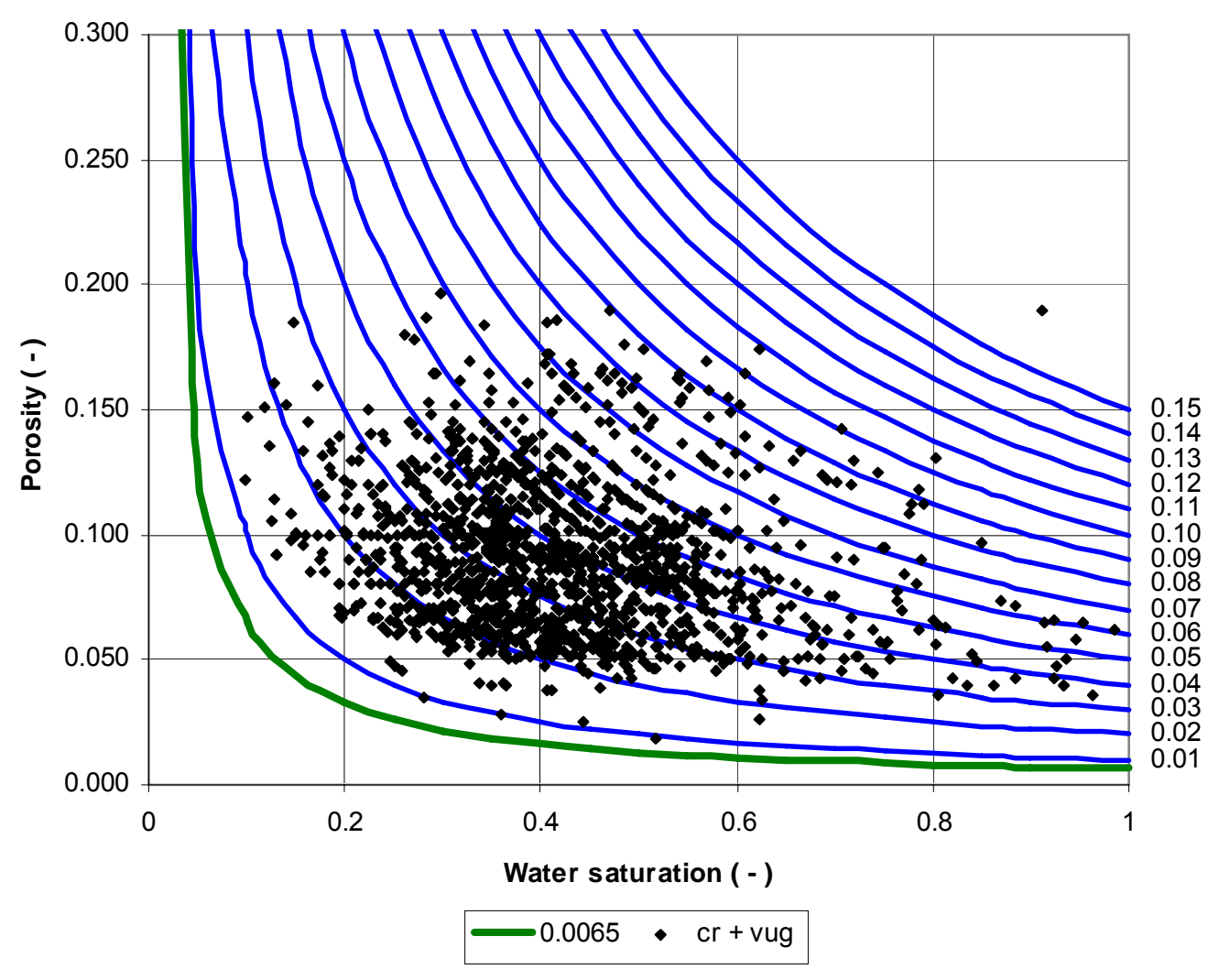

Figure 71: Buckles plot for dolomite and partly dolomitized limestone with coarse matrix and vuggy pore types; legend: $c r=$ coarse matrix

Figure 71 shows the coarse matrix and vuggy pore types for dolomite and partly dolomitized limestone. Figure 71 suggests that the coarse matrix and the vugs contain water. The Buckles plot with fine matrix and fracture pore types for dolomite and partly dolomitized limestone did not show us the expected results. That is, the data did not fall on a constant bulk volume water line. Therefore, we could not establish a good relationship between the static and the dynamic data using the geological pore types on Buckles plot. We also made an attempt to use Buckle plots based on electrofacies analysis. Although electrofacies analysis was able to separate them on Buckle plot, the relationship between Buckle plot and the production data was tenuous at best. Therefore, we abandoned the approach. 


\section{$\underline{\text { Regional Relationships between Saturation and Porosity }}$}

After unsuccessfully trying to relate individual well production data to individual well logs, we made an effort to relate the data on a regional basis.

Parameters such as log data are easily available and because of this the present work deals with evaluation using this easily measured data. Instead of focusing on only the four core areas, we extended our work to surrounding areas as well. Log data was extensively available from the large number of wells drilled in the West Carney, Seminole, Chandler, and Alabama areas. Evaluation based on log data is extremely useful and can develop a better understanding of the possible relationship between log data and the production performance. For this evaluation the log data was collected for the areas noted above. The map (figure 72) shows the location of the West Carney area with respect to Chandler, Alabama and Seminole areas. West Carney field data was divided into four regions: Central East, Central West, West and East Carneys. Central East and Central West regions represent limestone lithology, whereas East and West regions represent dolomite lithology. The field observations also indicate that Central East and Central West regions are prolific in terms of oil and gas production compared to both East and West regions. The East region is a good gas producer; whereas the West region is the poorest producer. The log data used were resistivity, neutron and density logs. 


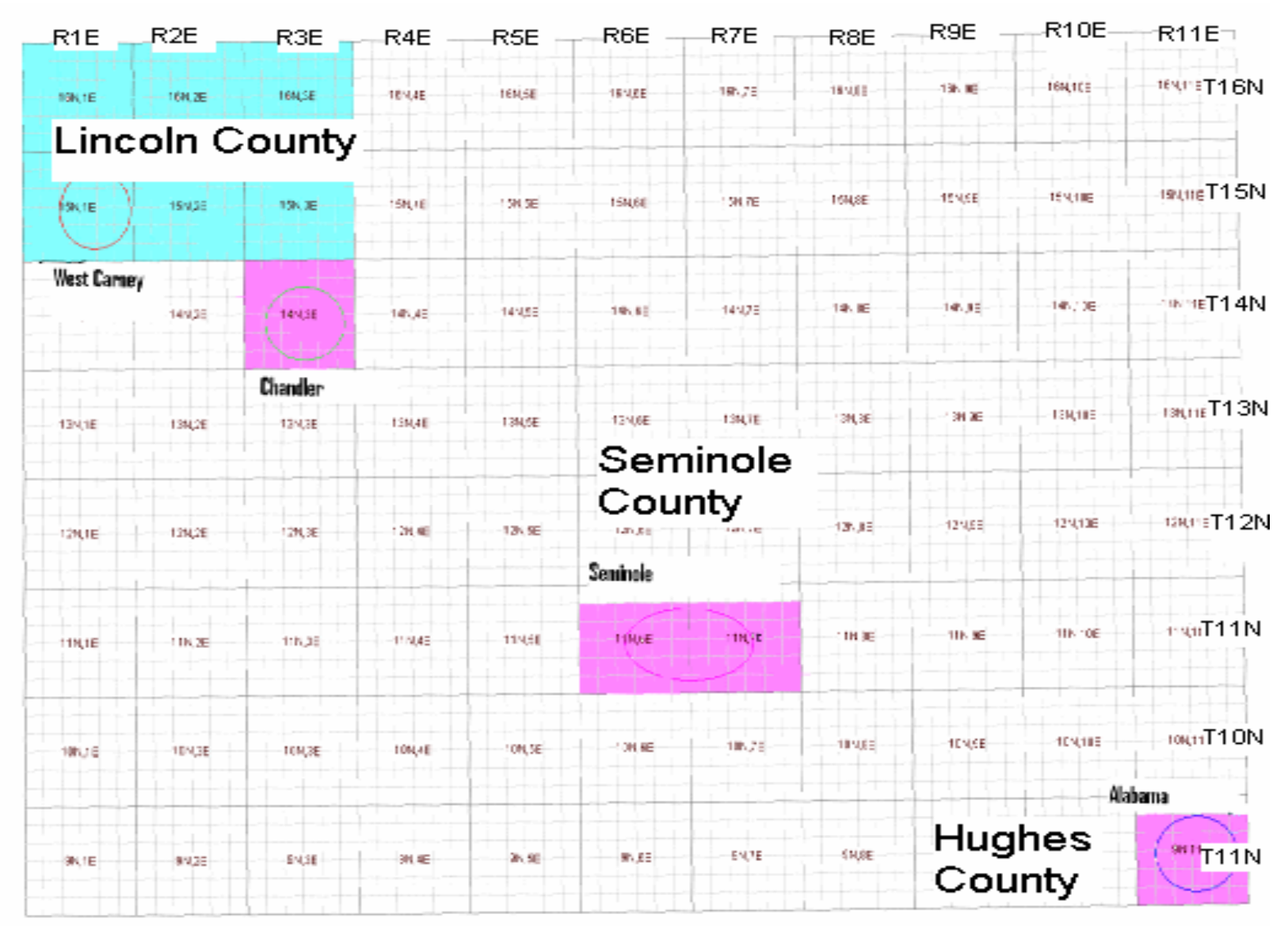

Figure 72: Areal map of the areas studied

Resistivity, neutron, and density logs were used to calculate porosity and hydrocarbon saturation at the well locations. Porosity was the average of the neutron and density porosities. Water saturation was calculated using Archie's equation, and hydrocarbon saturation was determined by subtracting water saturation from 1 . We then examined the average and standard deviation for both porosity and saturation at each well. We observed that no relationship is evident between petrophysical properties and the production performance on an individual well basis. Therefore we concentrated on the average properties for the entire region. Table 19 shows the statistical properties for each region, 
Table 19. Summary of saturation and porosity data from different regions

\begin{tabular}{lcccccc}
\hline Region & Oil Saturation & $\begin{array}{c}\text { Water } \\
\text { Saturation }\end{array}$ & Porosity & Std Porosity & Std Saturation & Well Density \\
& \multicolumn{7}{c}{} & & & & \\
\hline Central West & 0.48 & 0.52 & 0.0454 & 0.024 & 0.203 & 0.71 \\
Central East & 0.486 & 0.513 & 0.0452 & 0.027 & 0.220 & 0.77 \\
East & 0.382 & 0.617 & 0.067 & 0.034 & 0.170 & 0.8 \\
West & 0.279 & 0.72 & 0.079 & 0.045 & 0.195 & 0.57 \\
Seminole & 0.578 & 0.421 & 0.045 & 0.013 & 0.091 & 0.277 \\
Chandler & 0.384 & 0.616 & 0.130 & 0.052 & 0.174 & 0.215 \\
Alabama & 0.484 & 0.515 & 0.048 & 0.018 & 0.075 & 0.17 \\
\hline
\end{tabular}

From this table, certain distinguishing characteristics emerge. The average porosity for Central East and Central West regions are very similar and this is consistent with limestone lithology. The average porosity in East region is slightly lower than average porosity in West region. Both these regions exhibit dolomite lithology; however, the West region has a slightly higher value indicating more dolomatization. Conventional t-tests also revealed the differences in reservoirs based on log data. The average porosity of Seminole and Alabama areas is very similar to Central East and Central West regions. Central East, Central West, Seminole and Alabama areas show low values of standard deviation of porosity and high hydrocarbon saturation. Seminole exhibits the highest hydrocarbon saturation and the lowest value of standard deviation of porosity. Thus, from this analysis, it can be concluded that there exists a relation between porosity and saturation. High porosity values indicate low oil saturation (figure 73). The higher the porosity variation, the lower will be the remaining oil saturation (figure 74). That means, if the rock has overall high porosity and high standard deviation, the remaining oil saturation is smaller. 


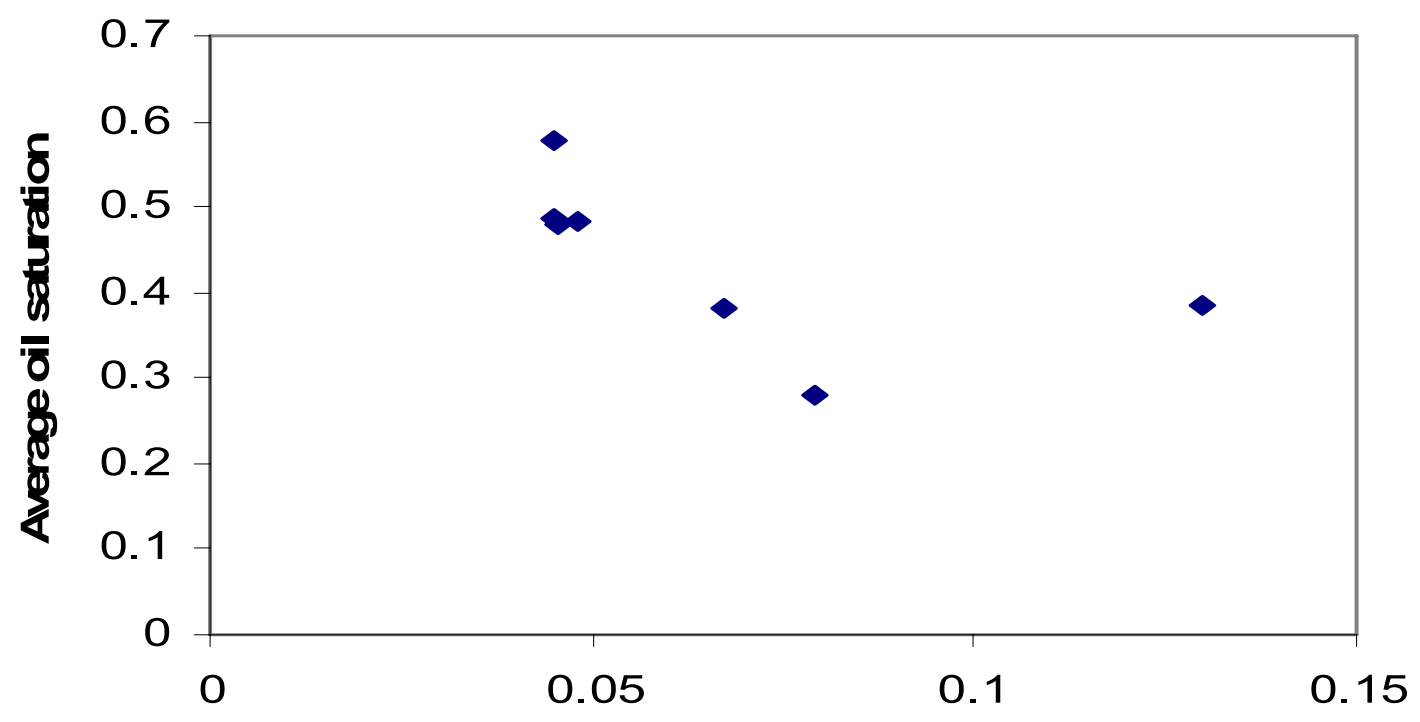

Average Porosity

Figure 73: Average oil saturation versus average porosity

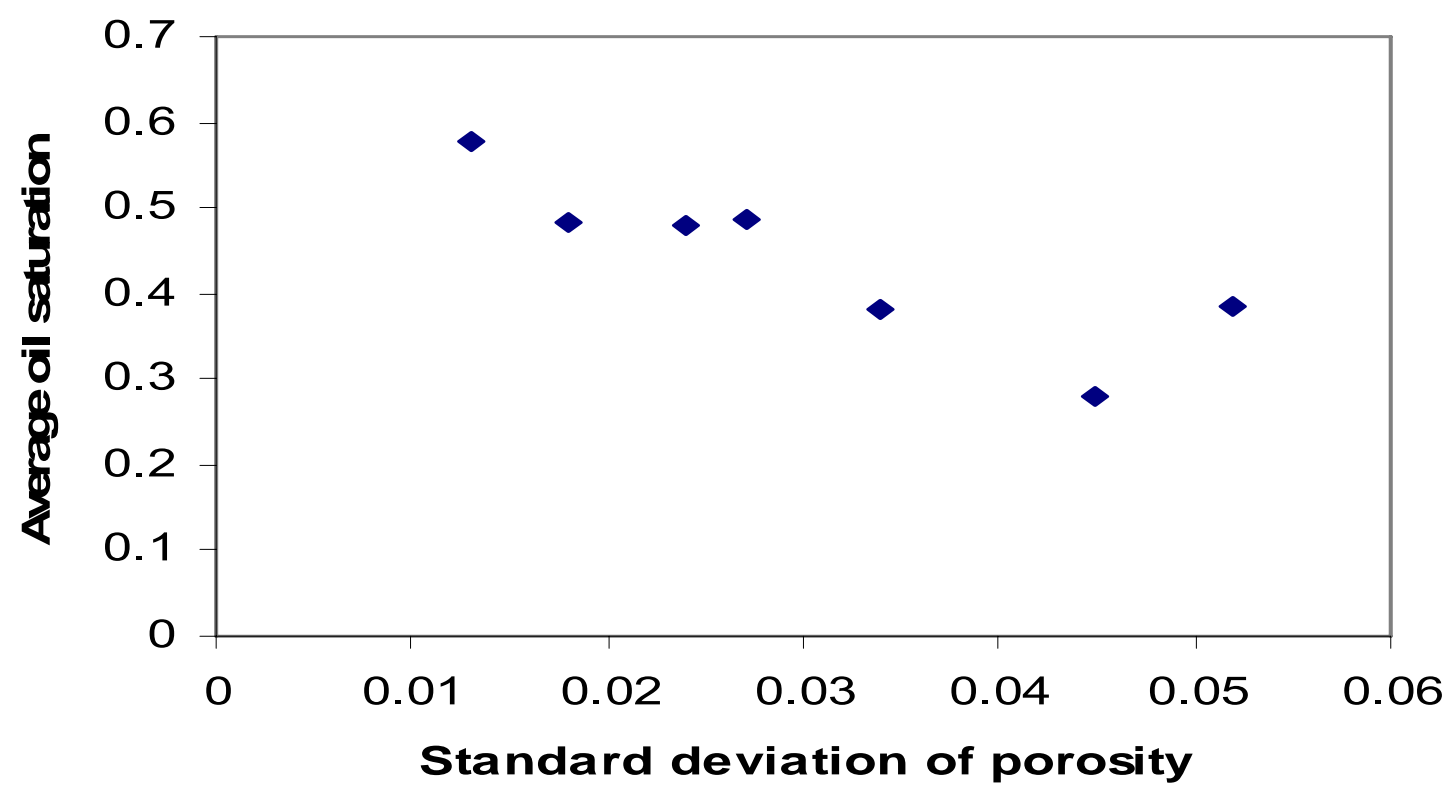

Figure 74: Average oil saturation versus standard porosity

To develop a better understanding of the saturation distribution, Q-Q plots were generated to compare the distribution of two regions. This plot represents quantile comparison of 
the two data sets. For example, the 10th quantile value of one set is plotted versus the 10th quantile of the other set. If the two samples have essentially the same distribution, the Q-Q plot shows a perfect $45^{\circ}$ straight line.

First, Q-Q plots of porosity were generated and then, on the basis of these plots, further plots between saturation and resistivity were generated. These plots showed the following results:

From this plot (figure 75), it can be seen that CE and CW have essentially the same porosity distribution, as the Q-Q plot shows a nearly perfect 45 degree line. The plot shows a slight deviation from the $45^{\circ}$ line at a porosity value of $3 \%$.

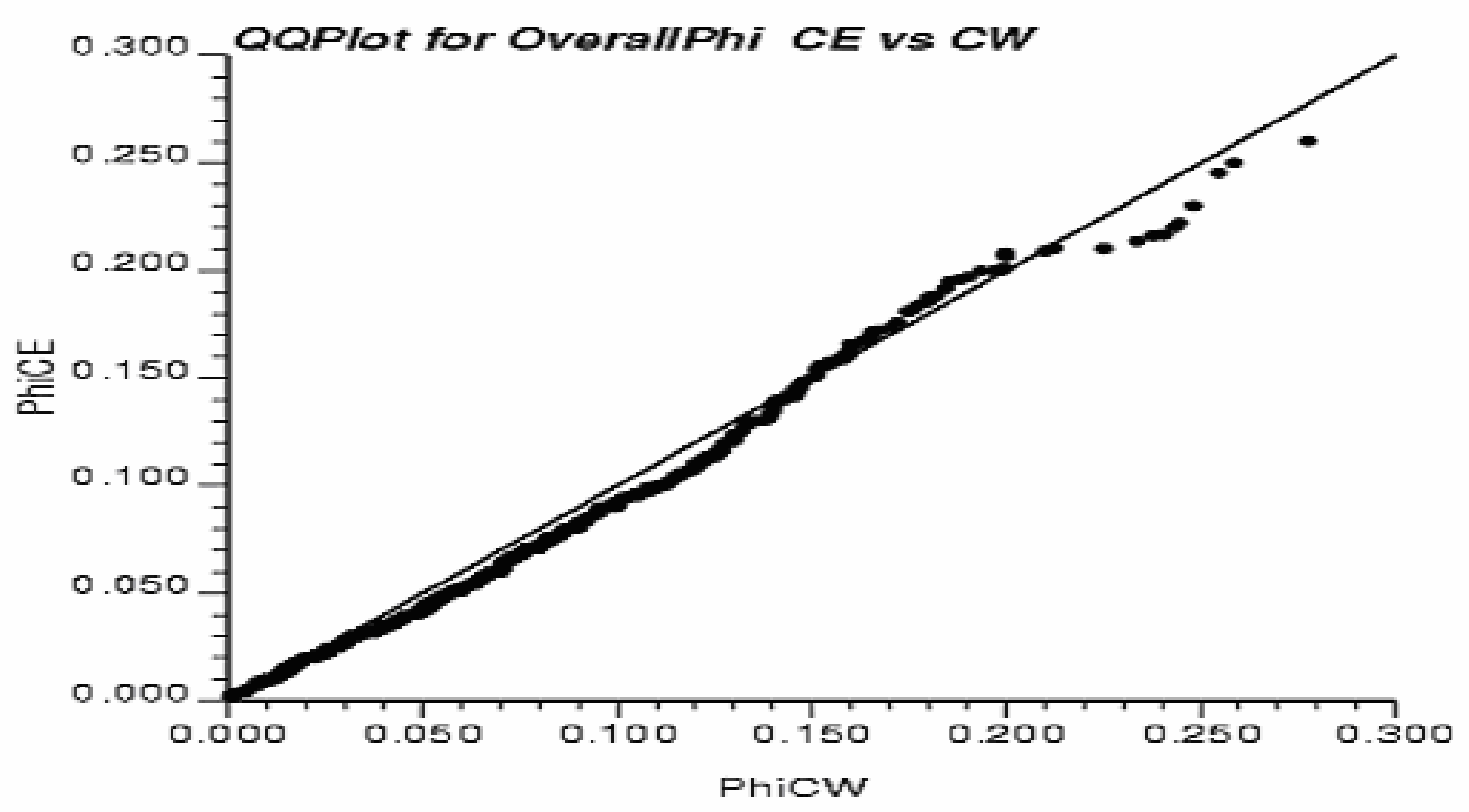

Figure 75: $Q-Q$ plot of porosity for $C E$ versus $C W$ regions

The porosity Q-Q plot (figure 76) shows that the porosity distribution for the two regions is the same for porosity values less than $3 \%$ (plot lies on the $45^{\circ}$ line), but for porosity values greater than 3\%, East Carney shows a higher porosity than Central West porosity, which is consistent with East representing dolomite lithology and CW representing limestone lithology. 


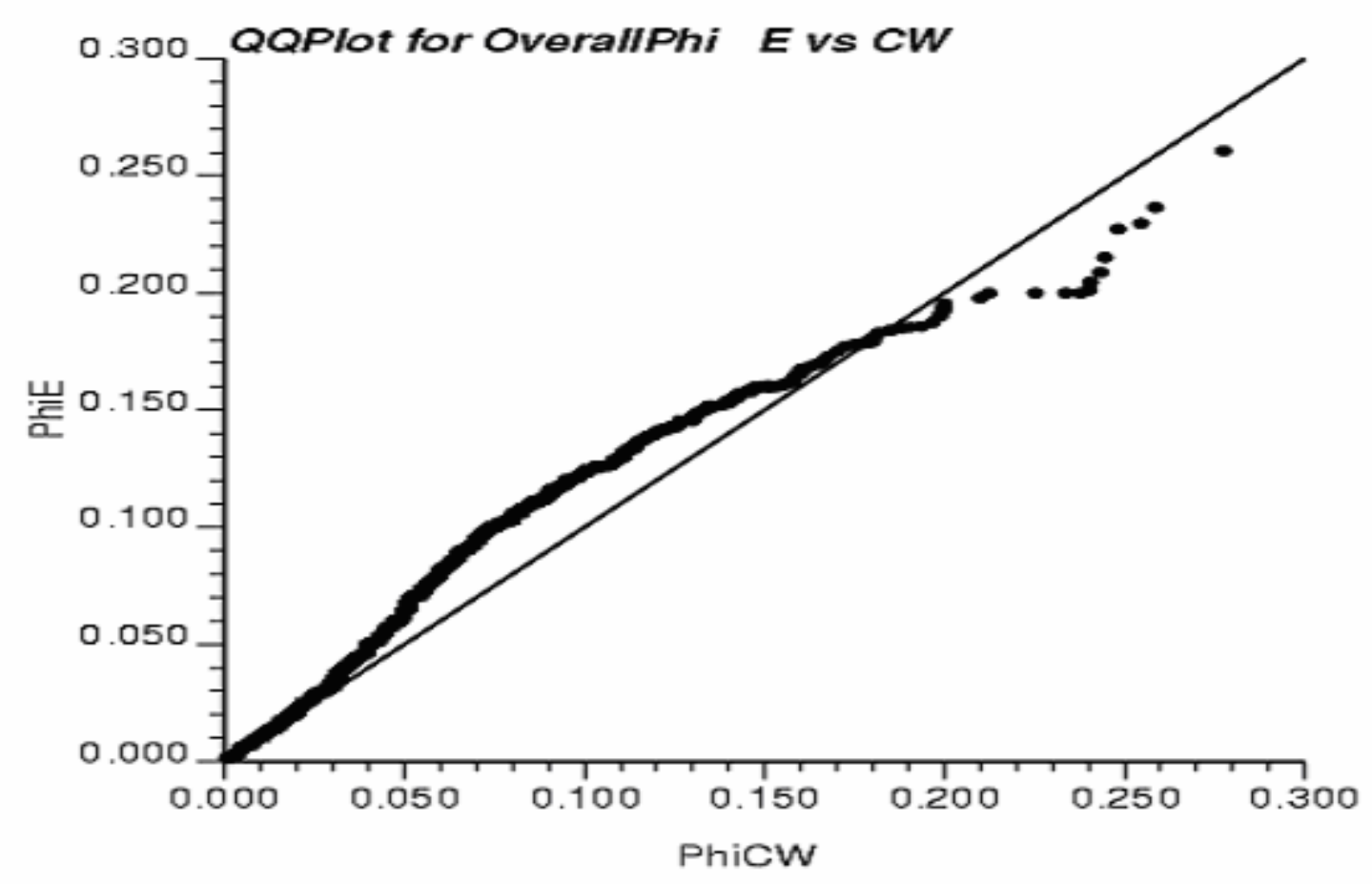

Figure 76: Q-Q plot for porosity - E versus CW

Separate Q-Q plots were then generated for porosity, resistivity, and saturation by dividing the log data for porosity values greater than $3 \%$ and less than $3 \%$.

For a porosity value greater than $3 \%$, it was observed that porosity (figure 77 ) and resistivity (figure 78) plots are mirror images of each other. The porosity Q-Q plot shows that East Carney has higher porosity than Central West Carney. The higher the porosity, the lower the resistivity, indicating the presence of water in high porosity regions. Saturation also shows consistent trend indicating that the higher the porosity distribution, lower the oil saturation. 


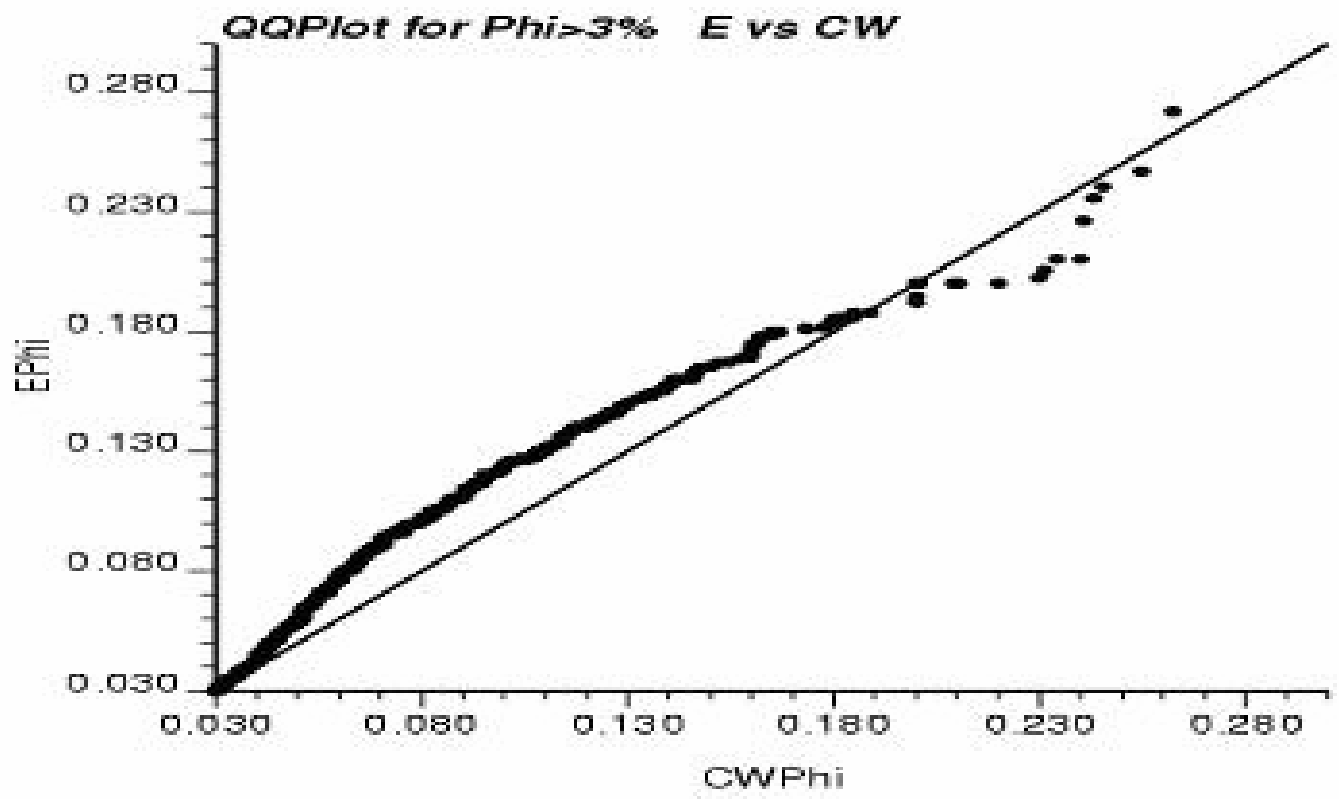

Figure 77: Q-Q plot (porosity > 3\%) - E versus CW

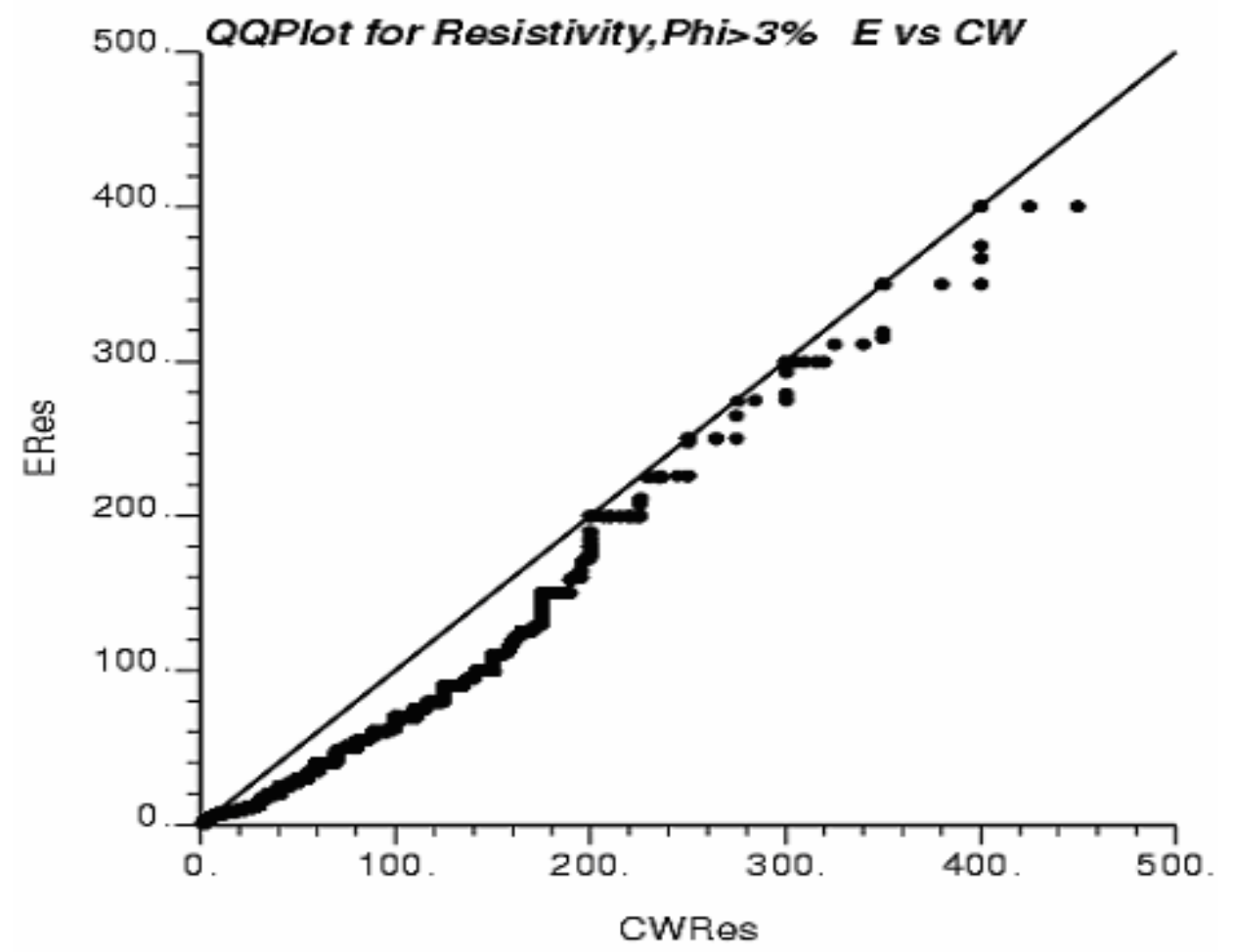

Figure78: Q-Q plot for resistivity (porosity $>3 \%$ ) - E versus $C W$ 
Also the relationship between East and Central East regions was observed to be similar to East and Central West regions as observed above.

From the Q-Q plots, it can be concluded that the porosity distribution governs the resistivity distribution. The combined effect of resistivity and porosity also indicates that saturation distribution is controlled by porosity distribution. Conventional t-tests also revealed the differences in reservoirs based on log data. The higher the porosity, the lower the oil saturation. This seems to indicate that water tends to move in the regions of high porosity and hydrocarbons remain trapped in the regions of low porosity.

Spatial Mapping of Hydrocarbons and Production Data

Since we could not correlate individual well production data with the logs, we wanted to find out if spatial mapping of hydrocarbon reserves can yield useful information regarding production. Therefore, using the log information from individual wells, we generated hydrocarbon in place maps for all the regions under investigation. These models were generated using the well locations and depth of Hunton at each well location. Resistivity and porosity logs were then imported for each of the wells into Petrel software. Hydrocarbon saturation was calculated using these values of porosity and resistivity. Saturation values at inter-well locations were determined using kriging technique to generate a saturation map for the region. Petrel then calculates the oil in place (OIP) at reservoir conditions using this saturation map and the geological model constructed for each of the regions. OIP for each of the regions is shown in table 20.

The gas in place (GIP) is calculated by multiplying OIP by initial solution gas-oil ratio (Rsi). Using the observed reservoir fluid properties and assumed bubble point, we have estimated the initial gas in oil ratio to be $650 \mathrm{SCF} / \mathrm{STB}$. Thus the OIP and GIP under standard conditions are as follows: 
Table 20. Oil in place for different regions

\begin{tabular}{lccc}
\hline \multicolumn{1}{c}{ Region } & $\begin{array}{c}\text { Oil in Place } \\
\text { (Reservoir Condition) } \\
\text { MMRB }\end{array}$ & $\begin{array}{c}\text { Oil in Place } \\
\text { (MSTB) }\end{array}$ & $\begin{array}{c}\text { Gas in Place } \\
\text { (bcf) }\end{array}$ \\
\hline Central West & 226.69 & 174,380 & 113 \\
Central East & 33.06 & 25,400 & 17 \\
East & 77.07 & 53,900 & 35 \\
West & 91.82 & 70,630 & 46 \\
Seminole & 731.48 & 562,600 & 366 \\
Chandler & 530.27 & 407,900 & 265 \\
Alabama & 59.29 & 45,600 & 30 \\
\hline
\end{tabular}

Table 20 shows that Chandler and Seminole Areas show high values of Hydrocarbon in place. It must be stated that OIP calculations and Chandler area have lot of uncertainties because of limited well control. In contrast, in other areas, we have a better well control.

Plots of OIP for the Central West, Central East, East, West, Alabama, Seminole and Chandler Areas are shown in the following figures. 


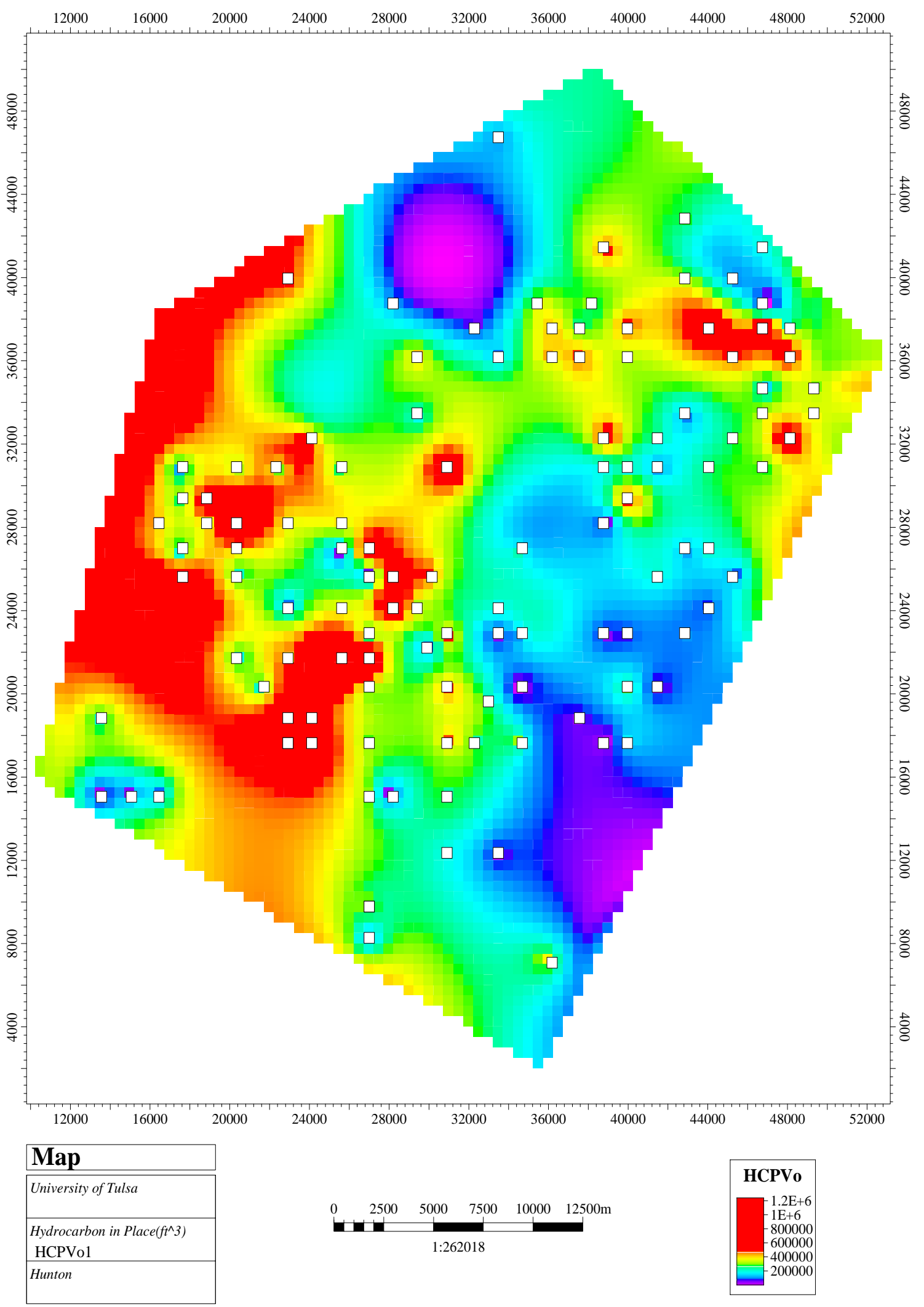

Figure 79: Oil in place (OIP) for Central West region 

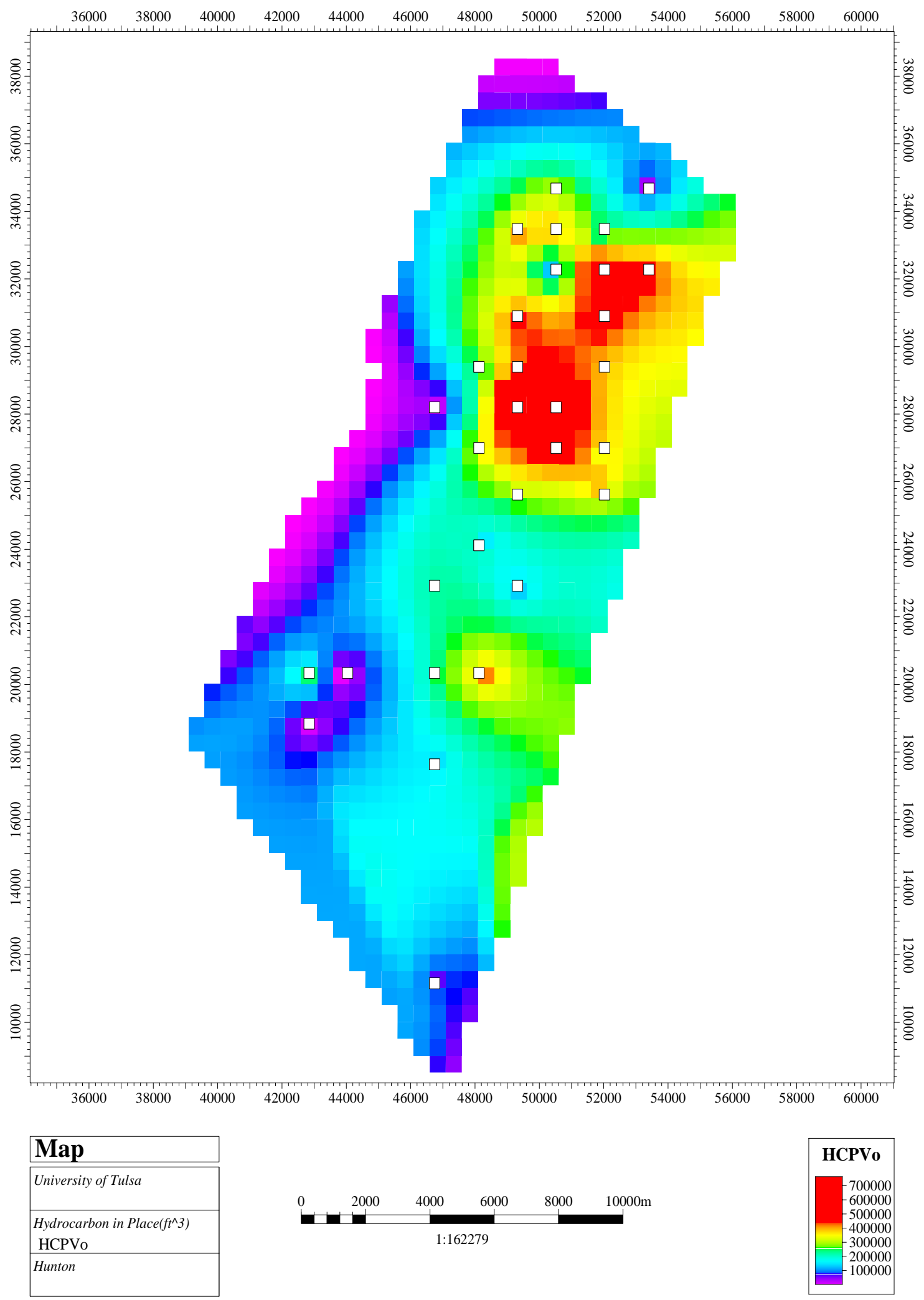

Figure 80: Oil in place (OIP) for Central East region 


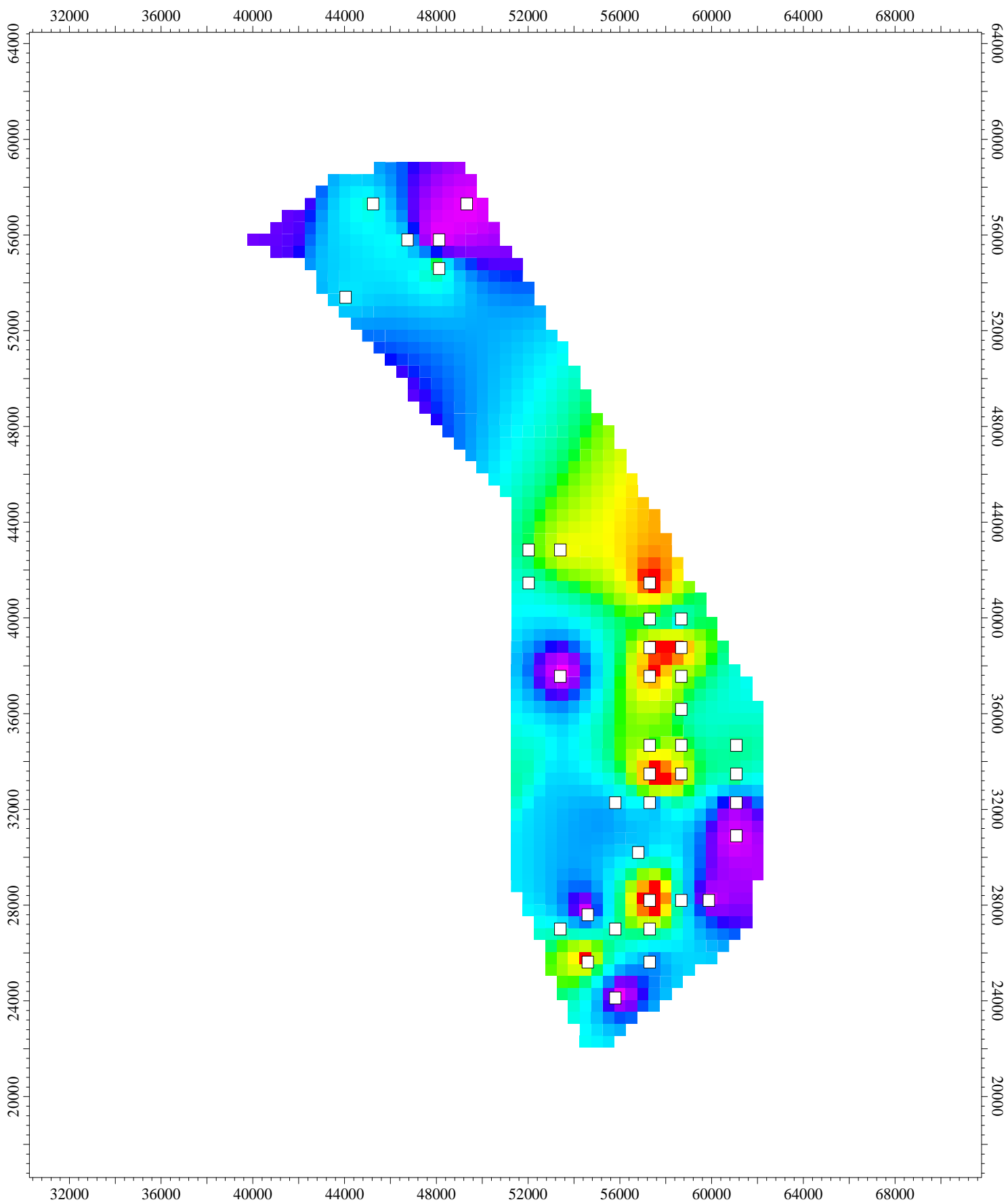

\begin{tabular}{|l|}
\hline Map \\
\hline University of Tulsa \\
\hline Hydrocarbon in Place(ft`3) \\
HCPVo(Volume Run 1) \\
\hline Hunton \\
\hline
\end{tabular}

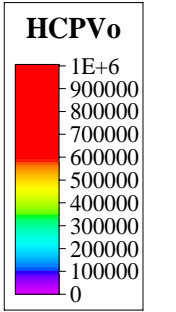

Figure 81: Oil in place (OIP) for East region 


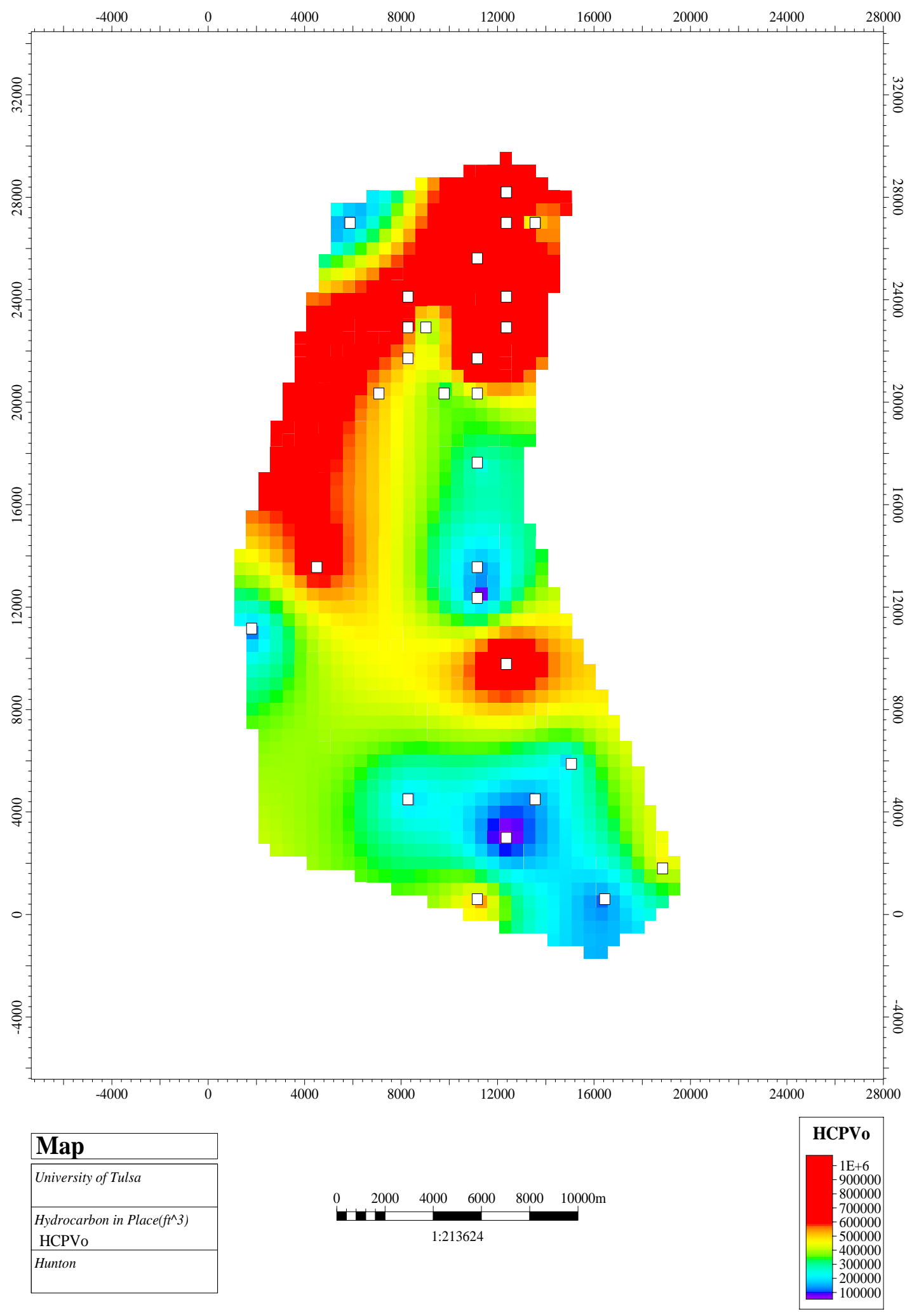

Figure 82: Oil in place (OIP) for West region 


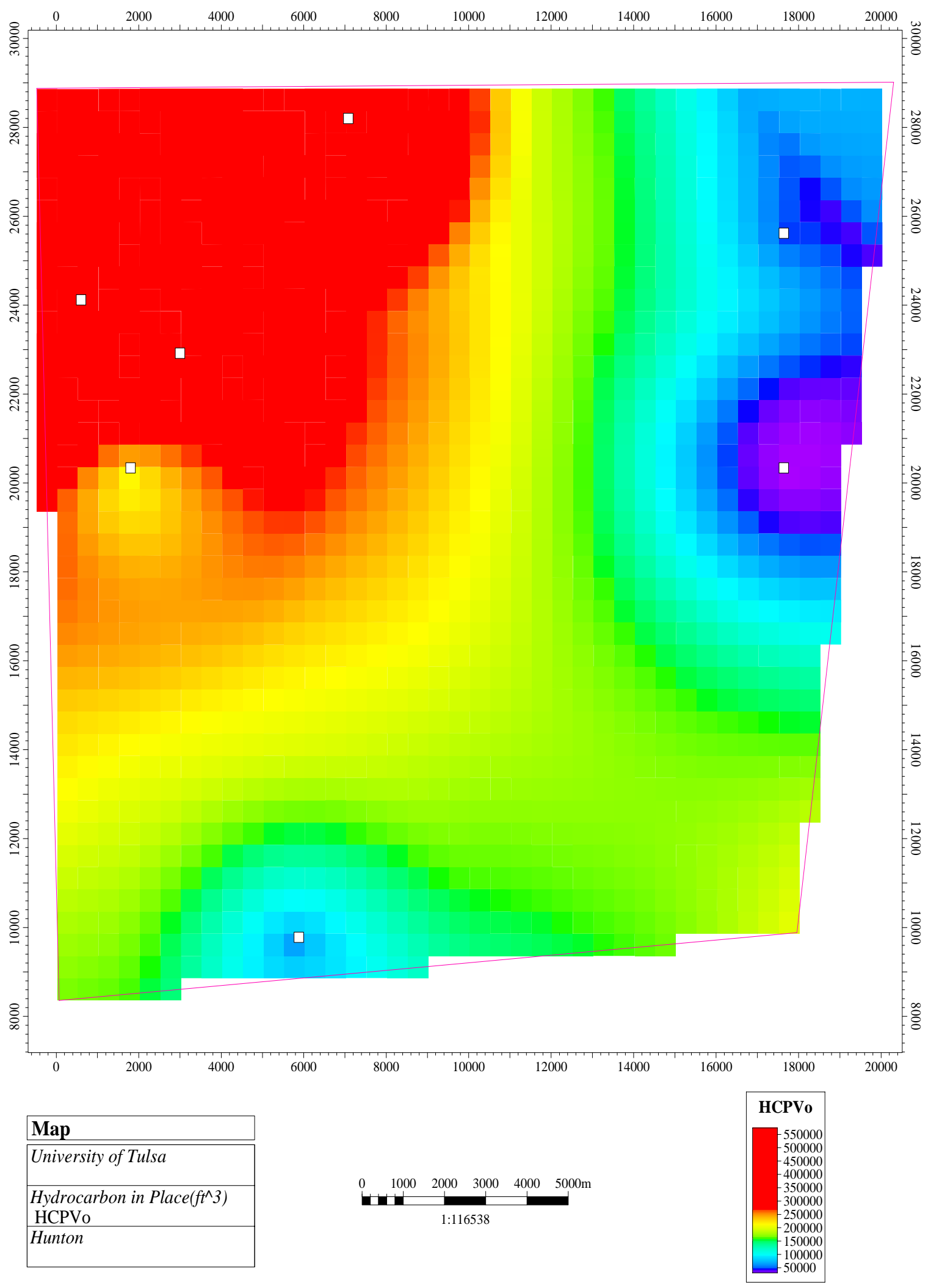

Figure 83: Oil in place (OIP) for Alabama 


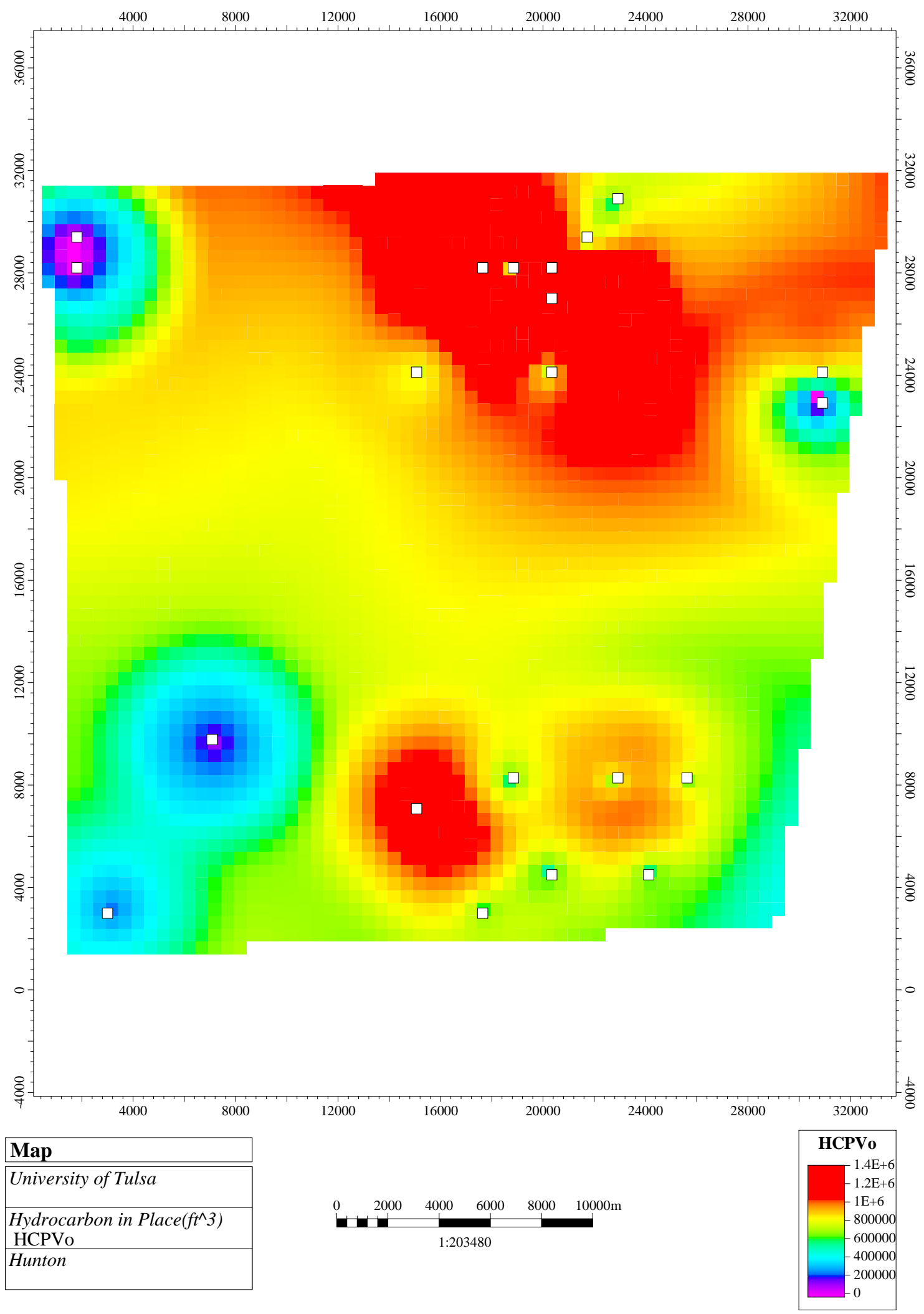

Figure 84: Oil in place (OIP) for Chandler 


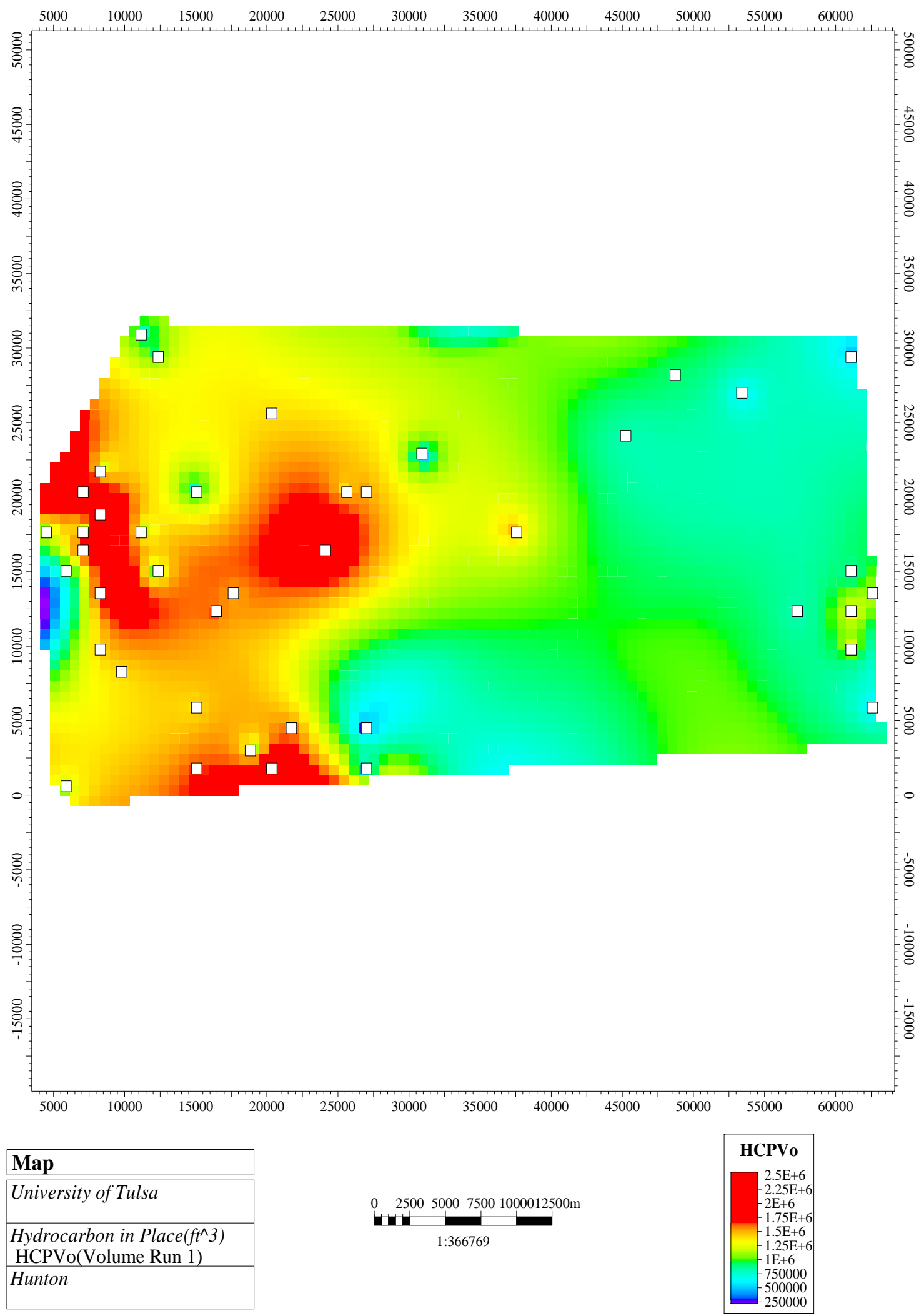

Figure 85: Oil in place (OIP) for Seminole 
Oil and gas production data for each well were collected and decline curve analysis was conducted to determine the ultimate recoverable reserves from each well. The abandonment rate of oil and gas was taken as $0 \mathrm{BBL} / \mathrm{D}$ and $0 \mathrm{MSCF} / \mathrm{D}$ respectively. Thus, the total recoverable reserve for a region is the sum of recoverable reserves from each well.

The total recoverable reserves for each of these regions are as follows:

Table 21. Recoverable reserves based on individual wells

\begin{tabular}{lcc}
\hline Region & $\begin{array}{c}\text { Oil Reserves } \\
\text { (MBBL) }\end{array}$ & $\begin{array}{c}\text { Gas Reserves } \\
\text { (bcf) }\end{array}$ \\
\hline Central West & $4,635.11$ & 40.27 \\
Central East & $2,234.60$ & 6.96 \\
East & $2,226.50$ & 24.94 \\
West & 416.60 & 11.50 \\
Seminole & 237.70 & 5.59 \\
Chandler & $1,378.80$ & 1.07 \\
Alabama & 977.70 & 0.81 \\
\hline
\end{tabular}

To confirm whether these values are accurate, decline curve analysis was also done on a regional basis for the West Carney field. Total hydrocarbon produced from a region was calculated for each month and then regional decline curve analysis was done. The total recoverable reserves thus calculated are shown in table 22. 
Table 22. Recoverable reserves in West Carney based on regional decline

\begin{tabular}{lcc}
\hline \multicolumn{1}{c}{ Region } & $\begin{array}{c}\text { Oil Reserves } \\
\text { (MBBL) }\end{array}$ & $\begin{array}{c}\text { Gas Reserves } \\
\text { (bcf) }\end{array}$ \\
\hline Central West & $4,430.00$ & 42.55 \\
Central East & $2,177.20$ & 6.95 \\
East & $2,417.50$ & 19.50 \\
West & 394.80 & 12.49 \\
\hline
\end{tabular}

It can be seen that the reserves calculated by the two methods are in close proximity, which validates that the values calculated on the basis of individual well decline curve analysis are fairly accurate.

Recovery factor was then calculated for each of the regions by dividing the total ultimate recoverable reserves by in place hydrocarbons.

The recovery factors are shown in table 23. 
Table 23. Gas and oil recovery factors for different regions

\begin{tabular}{lcc}
\hline \multicolumn{1}{c}{ Region } & $\begin{array}{c}\text { Recovery Factor } \\
\text { (Oil) }\end{array}$ & $\begin{array}{c}\text { Recovery Factor } \\
\text { (Gas) }\end{array}$ \\
\hline Central West & 0.0260 & 0.3500 \\
Central East & 0.0880 & 0.4213 \\
East & 0.0410 & 0.7100 \\
West & 0.0060 & 0.2436 \\
Seminole & 0.0004 & 0.0150 \\
Chandler & 0.0033 & 0.0040 \\
Alabama & 0.0214 & 0.0270 \\
\hline
\end{tabular}

From table 23 it can be seen that Central East shows a greater oil recovery than Central West. The recovery factors of hydrocarbons for Seminole and Chandler area is the least which can be due to low well density. It is also worth pointing out that gas recovery factor is greater than oil recovery factor. This is consistent with the idea that gas tends to be more mobile than oil phase.

Although the recovery factor correlates with the well density, the correlation between the well production and surrounding oil and gas in place is still poor. To understand the relationship between reserves and the oil (or gas) in place, each well is assumed to drain a surrounding 160 acres. We calculated the gas in place within that area and plotted the reserves from individual wells as a function of gas in place. This is shown in figure 86. Clearly, from this figure, it can be shown that the relationship between the two is very poor. This, as well as other evaluations from this section, indicates that it is difficult to predict the recovery of oil and gas based on the well log data. We will need to examine factors other than petro-physical data to understand the dynamic behavior of producing wells. We discuss this in the next section. 


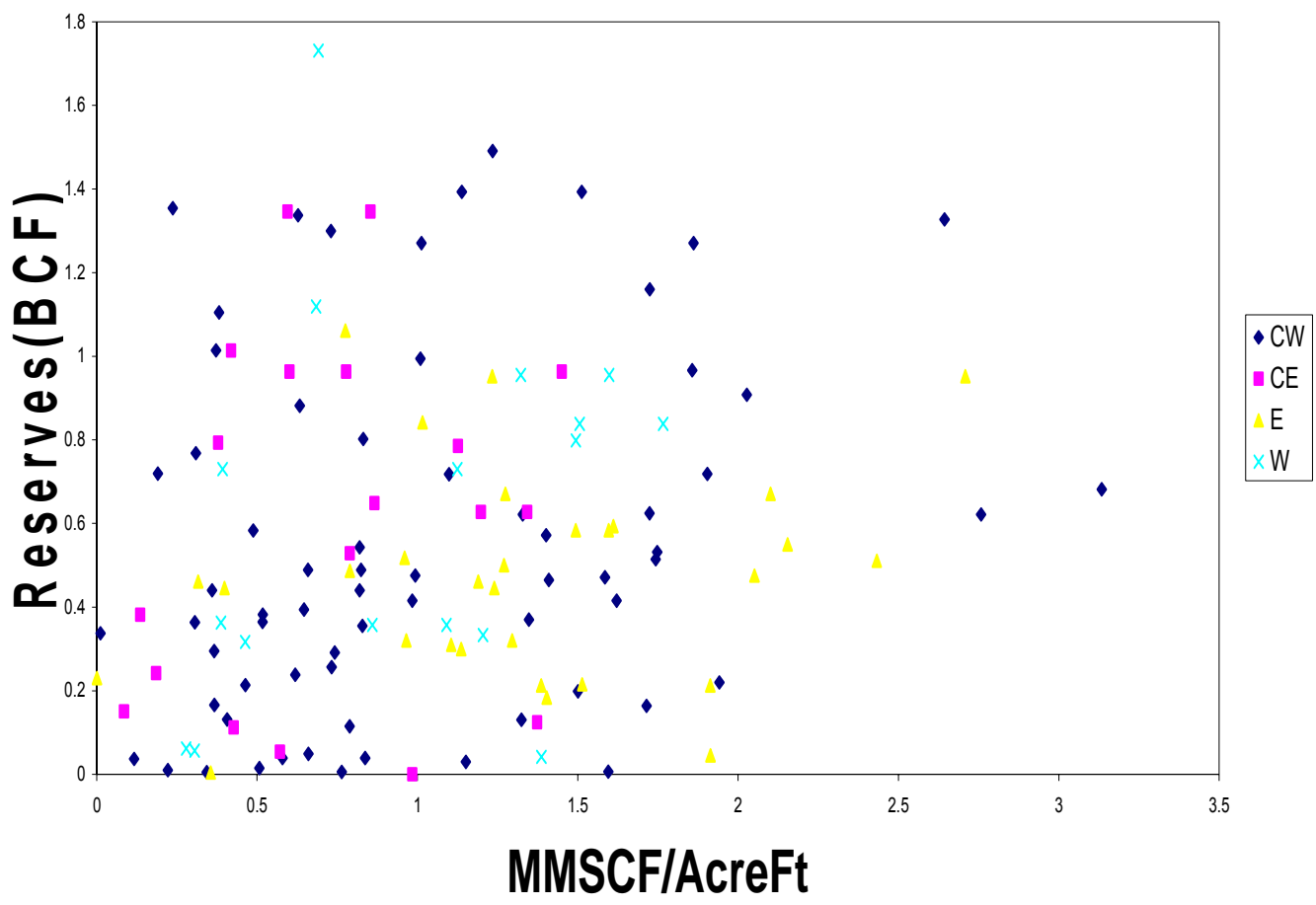

Figure 86: Reserves versus gas in place 


\section{Material Balance Analysis}

\section{Introduction}

Material balance technique is important to determine the oil and gas in place in the reservoir. To consider the material balance analysis for Hunton reservoir, we considered many different ways. They all provide reasonable representation of the reservoir characteristics, and provide different insight about how this particular reservoir is produced. We used the techniques which are based on an assumption that the reservoir is either producing from volatile oil reservoir, or a black oil reservoir. Irrespective of how we represented the reservoir in terms of hydrocarbons, we always assumed that the main energy mechanism for this reservoir is the solution gas. The problem is complicated by the fact that significant energy associated with the dissolved gas is wasted in producing water; hence, the recovery is not very efficient. Here, we describe different approaches we used in material balance evaluation.

Material Balance Equation for Volatile Oil. In the Fluid Properties Analysis section, we already established that the hydrocarbons present can be represented by volatile oil. In this section, we present the material balance technique used for such system. The material balance procedure is used to estimate the amount of hydrocarbon in place using the field cumulative production data. This is important since it helps in calculating the field recoveries and also helps in identification of potential locations for infill wells. In this section, we present a modified

method of $\frac{p}{Z}$ plots for volatile oil systems. A synthetic case was used for validating the applicability of this method to volatile oils and then the procedure was applied to field data. It can be seen that the material balance predicts the in place reserves that are mostly consistent with the results from decline curve analysis. We also compare material balance method with volumetric analysis to understand the difference between total oil volume versus connected oil volume. The equation used in this case is the standard gas material balance given by the following equation. 


$$
\frac{\bar{p}}{\bar{Z}}=\frac{p_{i}}{Z_{i}}\left(1-\frac{G_{p}}{G_{i}}\right)
$$

(Equation 1)

The same equation can also be used to evaluate volatile oil reservoirs with some modifications. In the above equation $p_{i}, Z_{i}$ are the initial field pressure and single-phase $\mathrm{Z}$ factor respectively. $G_{i}$ is the initial fluid in place that is to be estimated. $\bar{p}$ is the average field pressure at given time and $G_{p}$ is the equivalent cumulative gas production at pressure $\bar{p}$. $\bar{Z}$ is the two-phase $\mathrm{Z}$ factor at pressure $\bar{p} \cdot \bar{Z}$ is calculated using the following expression:

$$
\bar{Z}=L Z_{L}+V Z_{V}
$$

(Equation 2)

where $L, V$ are the mole fractions of liquid and vapor respectively and $Z_{L}, Z_{V}$ are the $\mathrm{Z}$ factors of liquid and vapor respectively. We need to use two-phase $\mathrm{Z}$ factor to account for the presence of both gas and liquid in the reservoir. This method has been successfully used for condensate reservoirs in the past, but has not yet been applied for volatile oil reservoirs.

Development of Representative Two-Phase Z factors. In calculating two-phase Z factor, we can consider two possibilities: constant volume depletion (CVD) experiment and constant composition expansion (CCE). In the CVD experiment, we assume that liquid dropping out of the two phases is immobile and only the free gas is produced. The overall composition in the cell will change over time, getting richer as more and more liquid is dropped. For the CCE experiment, we assume that the composition is constant through out the depletion phase. Therefore, the proportion of liquid and gas would be different in CCE experiments compared to CVD experiments. Traditionally, in simulating gas condensate reservoirs, we assume that CVD experiments mimic a gas condensate reservoir. We assume that gas is always mobile and liquid has to reach high critical saturation before it becomes mobile. The question is, can we use the CVD experiment to mimic the volatile oil reservoir? The reason the answer to this question is important is because the reservoir originally contains oil. Therefore, we have to assume that, 
originally, oil is a mobile phase. However, as the pressure depletes, a large amount of gas is released from volatile oil making gas the dominant mobile phase. It is possible that the behavior of volatile oil could fall somewhere between CVD and CCE experiments.

We can mimic both CVD and CCE experiments using the PVTI module in the Eclipse Office Suite. By knowing $L, V, Z_{L}$ and $Z_{V}$ at different pressures, we can calculate two-phase $\mathrm{Z}$ factor as a function of pressure using either the CVD or CCE experiment.

It is observed, however, that the CVD test assumes a constant volume and removes only the expanded gas from the cell. This process correctly represents the behavior of a gas condensate reservoir where only gas is produced. The drop-out liquid is usually immobile. However, in the case of a volatile oil reservoir, both oil and gas are produced and the CVD, therefore, does not exactly reproduce the reservoir depletion process. The two-phase $Z$ factor calculated from the CVD test is not an accurate estimation of actual value. A way of calculating the two-phase $Z$ factor is to run a synthetic case and back calculate the two-phase $Z$ factors from the number of moles produced using equation 1 . The density of the initial reservoir fluid can be obtained as an output from the simulator. A slight rearrangement of equation 1 gives the twophase $Z$ factor as:

$$
Z_{2 p}=\frac{\bar{p}}{\beta_{i} R T\left(1-\frac{G_{p}}{G_{i}}\right)}
$$

(Equation 3)

The initial gas in place $G_{i}$ and the initial reservoir fluid density $\beta_{i}$ are obtained from the simulator. Knowing these and the other constants, two-phase $Z$ factors can be calculated for each average reservoir pressure value. In most cases, however, it is not feasible to run a synthetic model of the reservoir process and back calculate the two-phase $Z$ factors. Almost all of the compositional reservoir depletion processes can be assumed to lie somewhere between those simulated by the CVD and those simulated by the CCE. While the CVD represents depletion of a gas condensate in which the drop-out liquid is immobile, the CCE represents a two-phase solution gas drive process. The two-phase $Z$ factors for any reservoir depletion process can then 
be represented by some kind of pressure averaging of the two-phase values obtained by the two tests.

An important aspect of generating the representative two-phase $Z$ factors is the determination of averaging method for the CCE and CVD obtained values. The averaging method depends on the reservoir depletion process especially the relative permeability curves and the critical saturation of oil and gas phases. For the cases with high critical oil saturation, more amount of gas is depleted from the reservoir and the two-phase $Z$ factors match closely with those obtained from the CVD data. Pressure averaging is more representative for reservoir depletion processes where more gas and less oil is removed from the reservoir.

Validation with Synthetic Data. The material balance procedure was first verified with synthetic data. The reservoir model used is the history-matched model described in the previous chapter. The in place oil at initial conditions was 950,300 rbbl. This oil is flashed at surface conditions to yield 977,000 STB of oil and 773.94 million SCF of gas. Using the following equation, the oil at surface conditions was converted to equivalent gas $G_{e q}$,

$G_{e q}=G_{s c}+V_{0} N_{s c}$

(Equation 4)

where $G_{s c}, N_{s c}$ are the gas and oil produced at surface from flashing the reservoir oil and $V_{0}$ is given by:

$V_{0}=133316 \frac{\gamma_{o}}{M_{o}}$

(Equation 5)

where $\gamma_{o}$ and $M_{o}$ are the specific gravity and molecular weight of the oil. The value of $V_{o}$ is obtained as $300 \mathrm{SCF} / \mathrm{STB}$ and the equivalent gas at surface is calculated as 803.26 million SCF. This data is obtained from initial reservoir conditions and from the generated fluid model. The simulation was run for two years and field pressure, cumulative oil and gas produced is recorded. 
A CVD test is simulated using the PVTI module at recorded field pressures and the two-phase $Z$ factors are calculated at the corresponding pressures using equation 2.

In this case, the back-calculated two-phase $\mathrm{Z}$ factors are used to develop a correlation between average field pressure and two-phase $\mathrm{Z}$ factors. Table 24 shows the back-calculated values obtained by running a synthetic case. Figure 87 shows the material balance plot comparison of back-calculated two-phase Z factors and those calculated by the CVD test. Figure 88 shows the plot of correlation between pressure and back-calculated two-phase $\mathrm{Z}$ factor values.

Table 24. Back-calculated two-phase $\mathrm{Z}$ factors

\begin{tabular}{|c|c|c|}
\hline Pressure (psi) & Cumm Moles Produced(MM) & P/z2p back calculated \\
\hline 1839 & 0 & 2458.99645 \\
\hline 1627.5 & 0.081715 & 2364.187169 \\
\hline 1438.7 & 0.228342 & 2194.064174 \\
\hline 1231.4 & 0.435062 & 1954.218679 \\
\hline 1038.4 & 0.646009 & 1709.468835 \\
\hline 879.46 & 0.82639 & 1500.182988 \\
\hline 754.21 & 0.971373 & 1331.967433 \\
\hline 656.58 & 1.086019 & 1198.950179 \\
\hline 580.16 & 1.176826109 & 1093.591839 \\
\hline 519.73 & 1.249415769 & 1009.370172 \\
\hline 471.35 & 1.30814111 & 941.2344889 \\
\hline
\end{tabular}




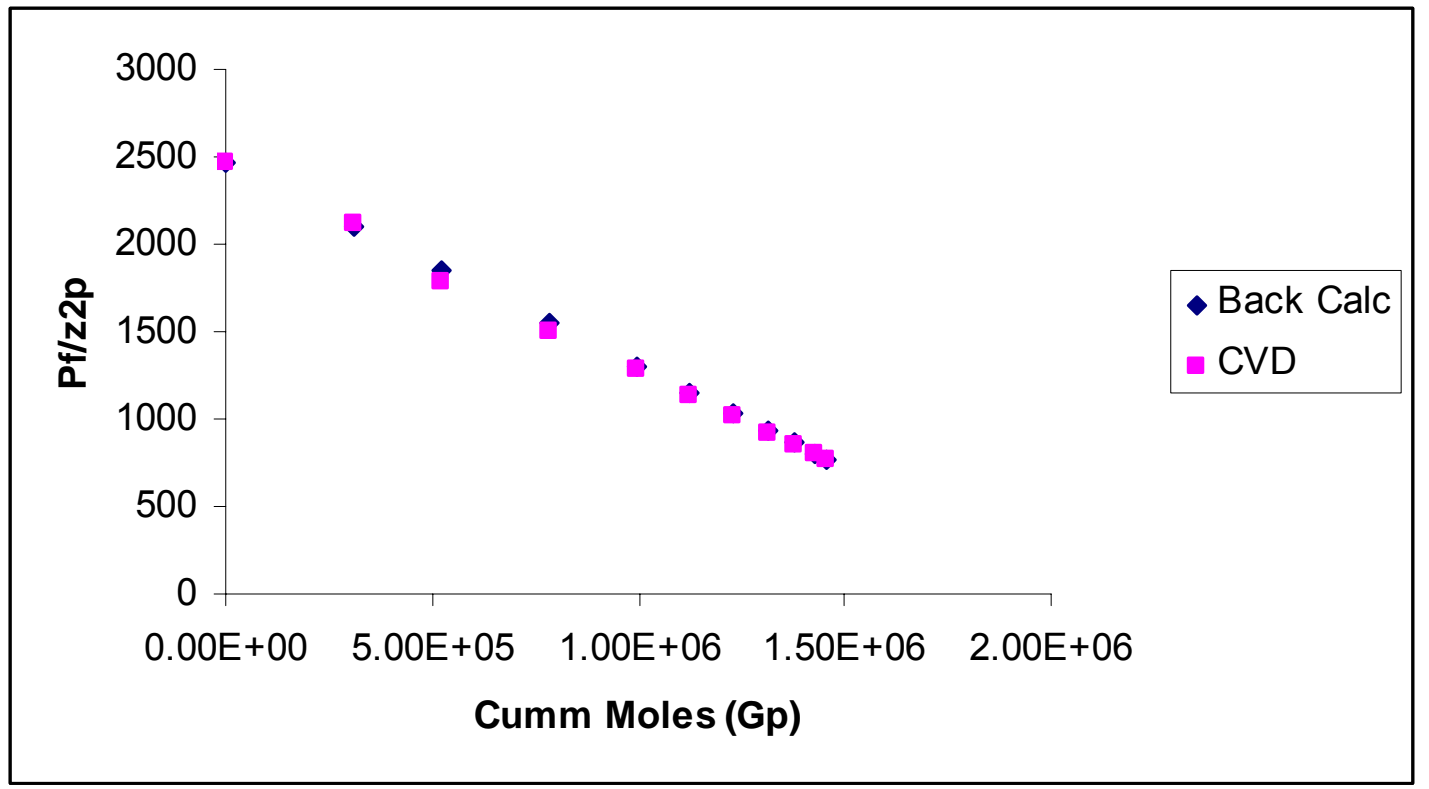

Figure 87: Z-factors using tank model

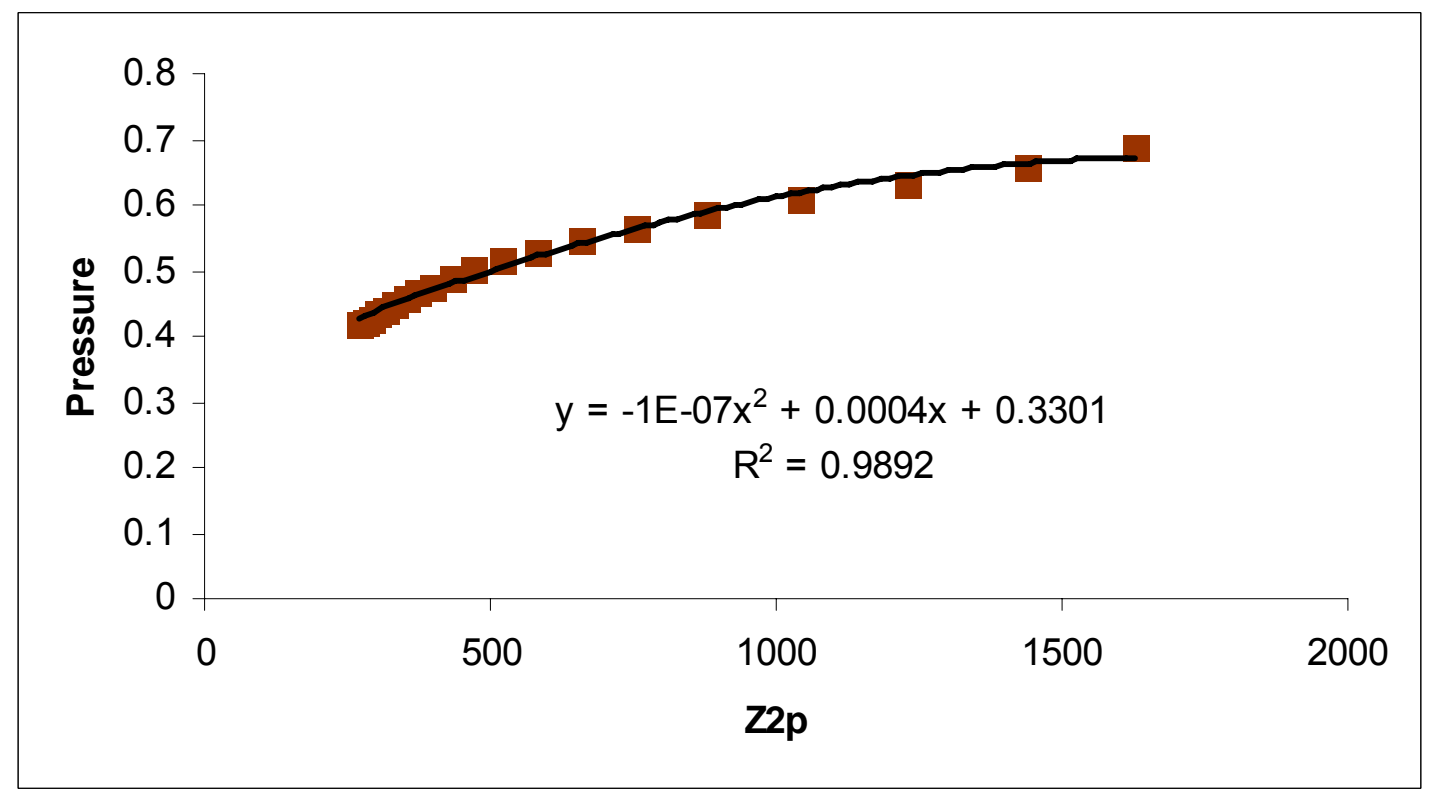

Figure 88: Plot of 2-phase $\mathrm{Z}$ factor

Application to Field Data. The material balance procedure was applied to field data after validating with the synthetic case. The field data is divided in four regions due to different 
local geologies and different initial pressures. Material balance was performed separately for each region and recovery for each region is calculated based on the quantity of initial oil in place as calculated by log data and the total recoverable amount based on estimates from material balance. Figure 89 shows the map of the area divided in four distinct regions. The orange color indicates the West Carney region, green indicates Central West, purple indicates Central East, and violet shows East Carney. West and East Carney regions consist of dolomite lithology, whereas, the central region is made up of limestone lithology. The central region is divided in two by a fault that passes through it. The initial pressure in the Central East region is less than initial pressure in the Central West. The pressure data are collected from initial pressures observed in newly drilled wells in individual region. The production data were collected from the public domain database (NRIS). A table of all pressures in drilled wells and cumulative oil and gas production in each region of the field is provided in Appendix C. Figures 90 through 93 show the material balance plots for each region with estimated gas in place. Table 25 shows the summary of results obtained from three different methods. The two decline curve methods are slightly different from each other. One is based on regional decline curve while other is based on individual well declines. It can be seen that material balance results agree well with those of decline curve analysis but usually predict higher values than predicted by decline curve analysis. There is some discrepancy in the values for the east region, but it is due to the fact that production is still occurring from that region and new wells are being drilled. All this causes the decline curve analysis to under-predict the reserves. Table 26 shows the recovery factors obtained from material balance. 


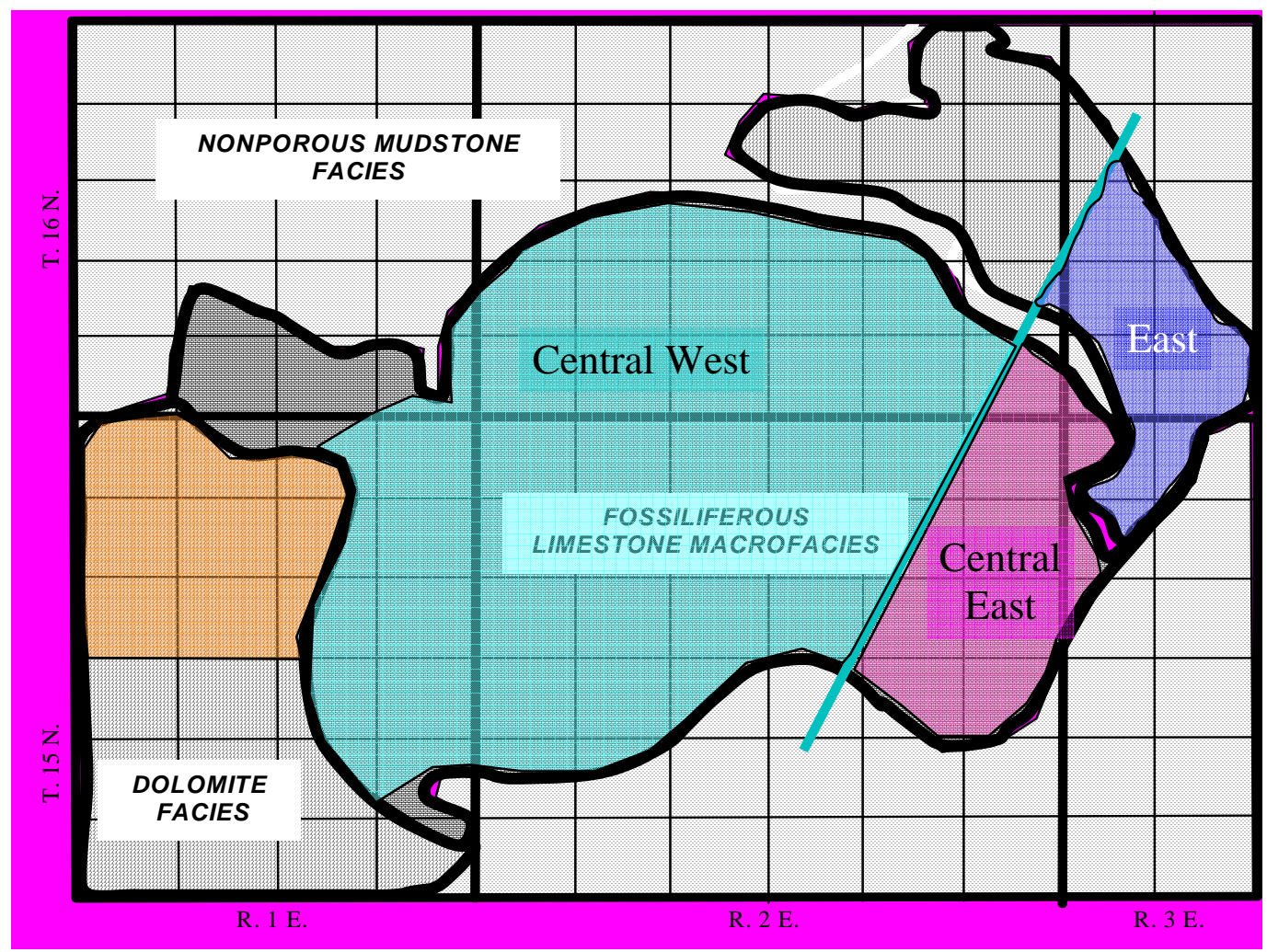

Figure 89: Map of West Carney field regions

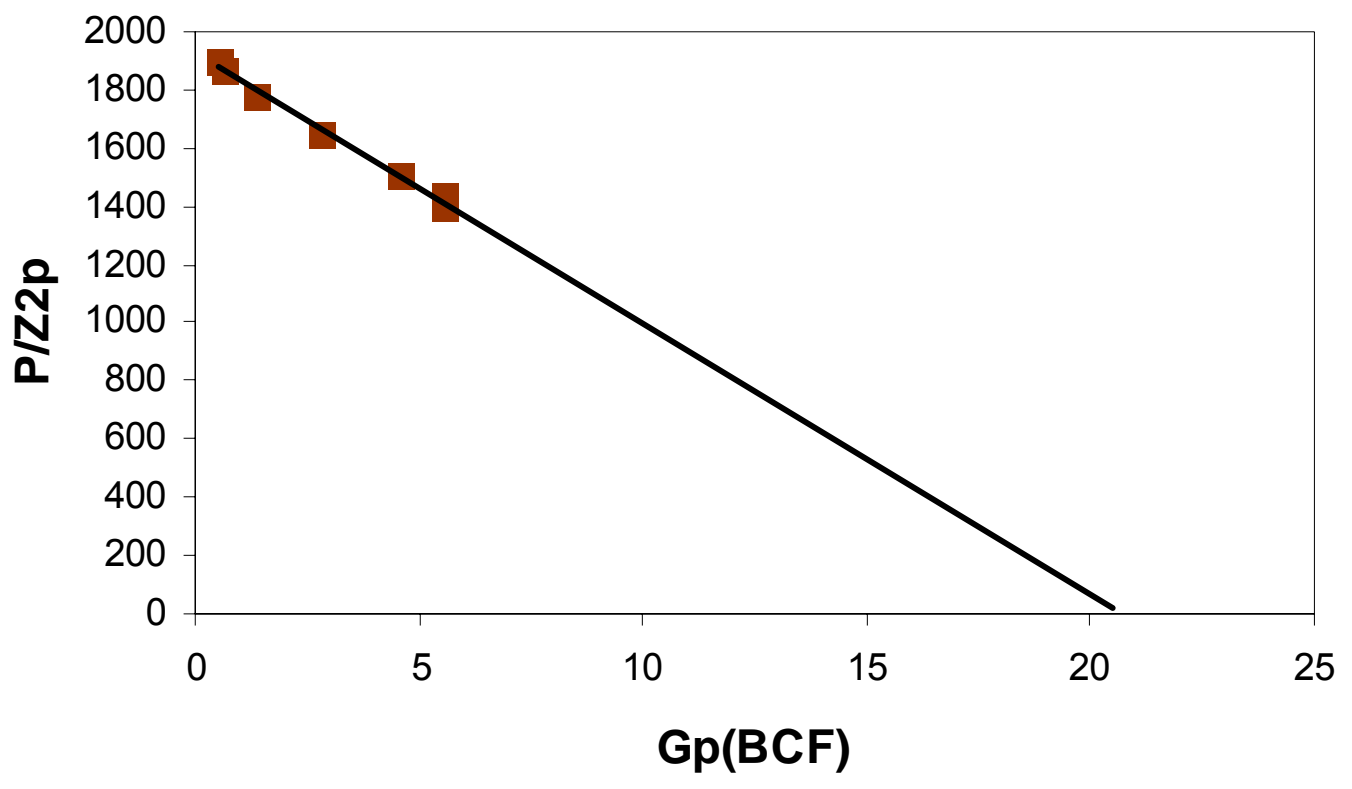

Figure 90: Material balance West Carney region 


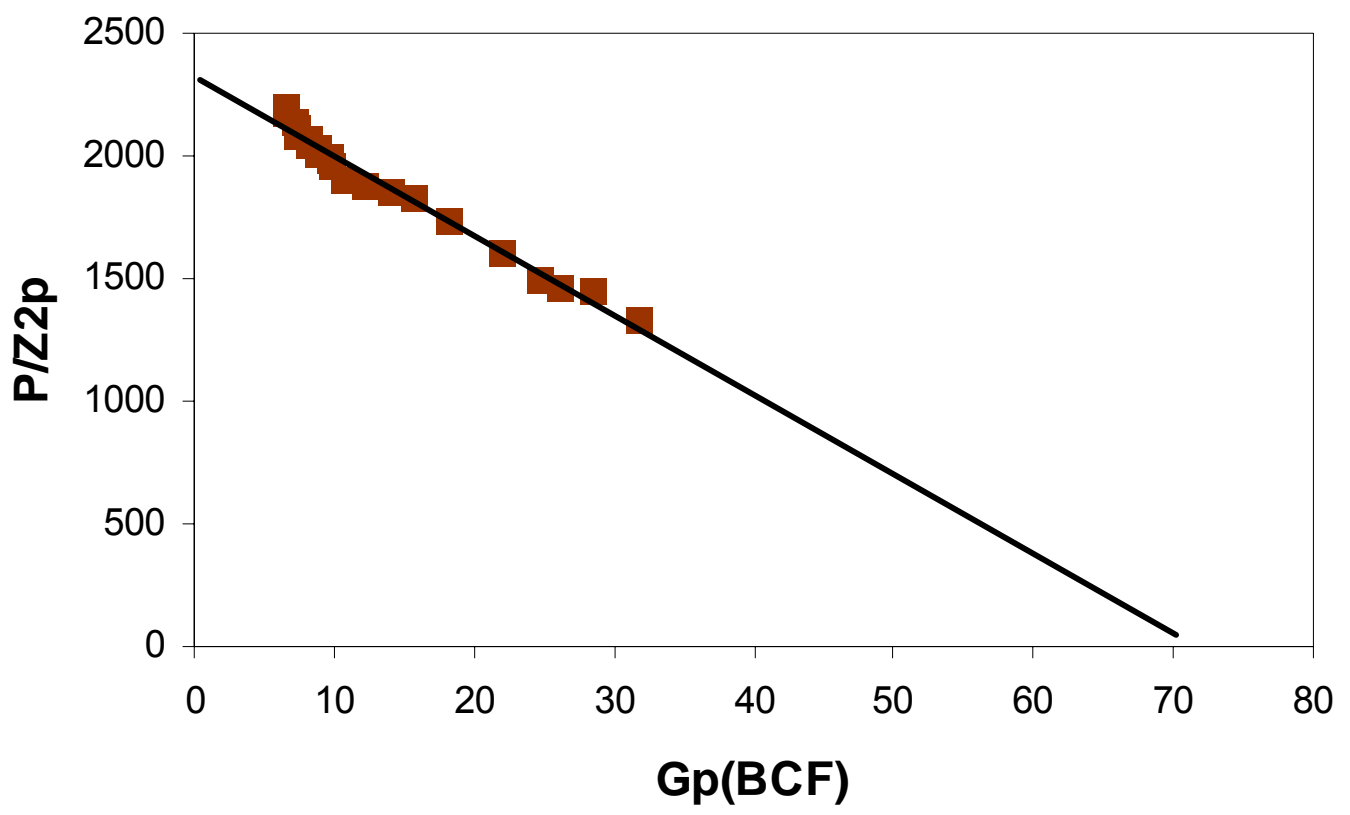

Figure 91: Material balance Central West Carney region

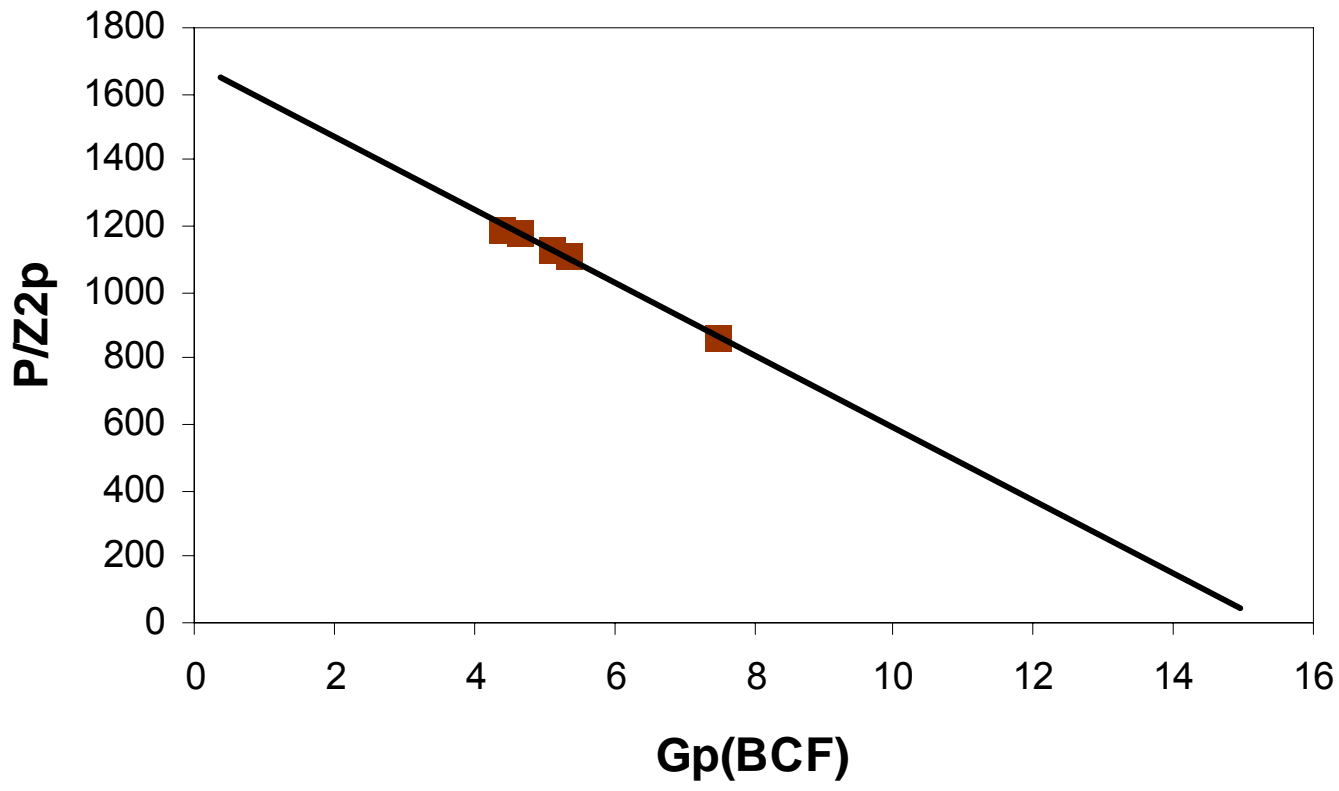

Figure 92: Material balance Central East Carney region 


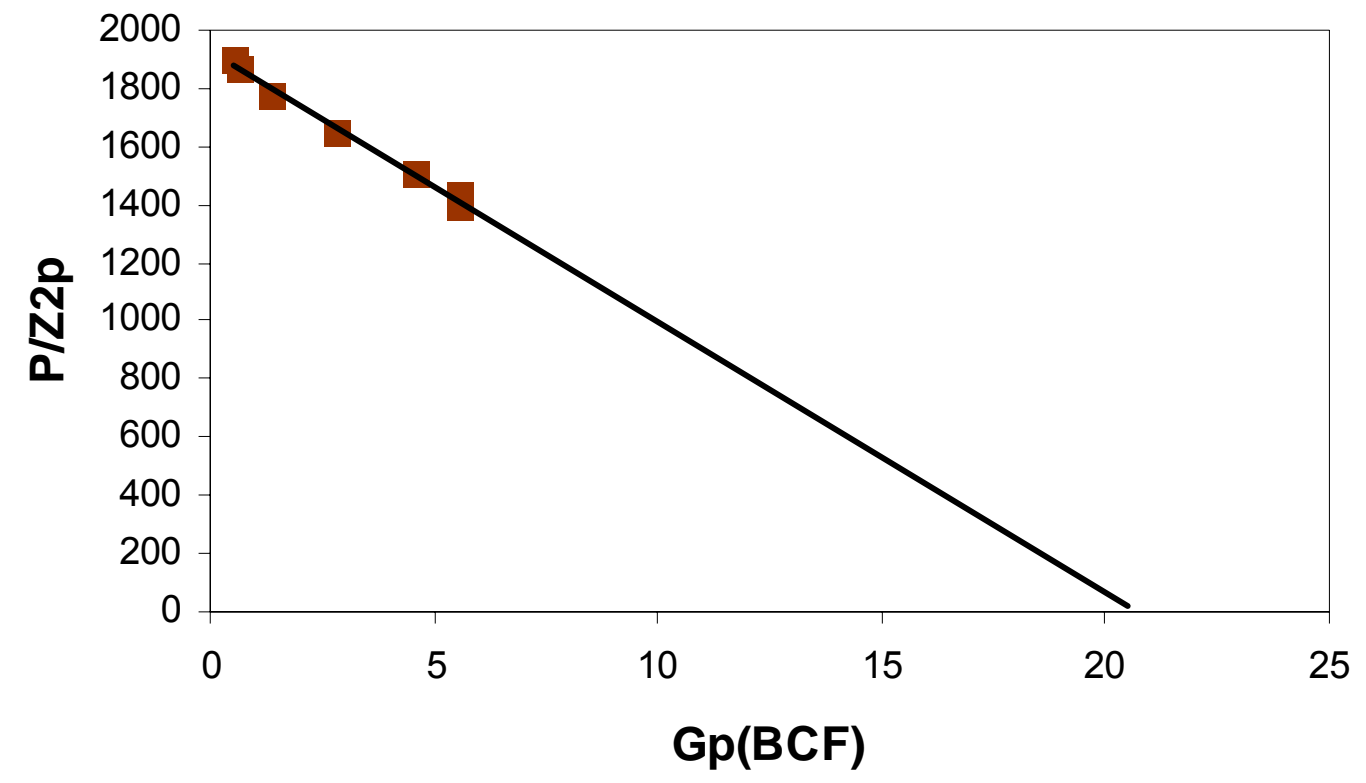

Figure 93: Material balance East Carney region

Table 25. Comparison of equivalent gas in place values

\begin{tabular}{|c|c|c|c|c|}
\hline Area & Log Data(BCF) & Material Balance (BCF) & Well Decline Curve (BCF) & Regional Decline Curve(BCF) \\
\hline West Carney & 57 & & & \\
& & 20 & 15 & 11 \\
Central West & 192 & 71 & 61 & 57 \\
\hline & & & & 10 \\
Central East & 45 & 15 & 11 & 20 \\
\hline
\end{tabular}


Table 26. Comparison of recovery factors

\begin{tabular}{|c|c|c|c|}
\hline Area & Log Data (BCF) & Material Balance (BCF) & RF\% (Material Balance) \\
\hline West Carney & 57 & 20 & 35 \\
\hline Central West & 192 & 71 & 37 \\
\hline Central East & 45 & 15 & 33 \\
\hline East Carney & 51 & 31 & 61 \\
\hline
\end{tabular}

Summary. As discussed in this chapter, there is consistency in estimating the oil in place values obtained from material balance and decline curve analysis. Material balance gas-in place always predicts higher values than those predicted by decline curve analysis. This is consistent since the difference indicates access to the regional oil-in-place. The Larger the discrepancy, the larger is the potential for infill wells. The potential for infill wells is greater in the east region as can be seen by the difference in the values calculated by material balance and decline curves. The plots also indicate high recovery values for the east and west regions, due to the presence of more homogeneous dolomite. The study also shows that material balance is a simple and effective tool in estimating the oil in place when only the field pressure and cumulative hydrocarbon production are available.

Black Oil Model. In the previous section, we applied the material balance technique based on volatile oil model. Although our results appear reasonable, one of the drawbacks of the proposed method was that we did not include the water production in the analysis. In a typical depletion type of volatile oil (or condensate) reservoir, we make an implicit assumption that the expansion of gas would cause the fluid to be produced. However, the fluid produced includes not only hydrocarbons, but also water. Some of the expansion energy is used to produce water, which was not explicitly accounted for in the calculations above. Therefore, to account for it, we decided to use a black oil model and tried to explicitly account for the production of water. 
Simplified Black Oil Approach. This section discusses a simplified approach we used to investigate the four regions discussed in figure 87. The method described here uses material balance and is applied individually to each of the four regions in West Carney. Final water saturation is calculated using gas recovery factor and compared with that obtained from cumulative water production. The comparison helps in validation of the material balance method. We first define the nomenclature:

$$
\begin{aligned}
& A=\text { Section Area, acres } \\
& h=\text { Thickness, ft } \\
& \phi=\text { Porosity } \\
& S_{w i}=\text { Initial water saturation } \\
& S_{w f}=\text { Final water saturation } \\
& S_{o f}=\text { Final oil saturation } \\
& R_{s i}=\text { Initial gas-oil ratio, SCF/STB } \\
& B_{o i}=\text { Initial oil formation volume factor, bbl/STB } \\
& P_{a}=\text { Abandonment Pressure, psia } \\
& R_{s a}=\text { Abandonment gas-oil ratio, SCF/STB } \\
& B_{o a}=\text { Abandonment oil formation volume factor, bbl/STB } \\
& B_{g a}=\text { Abandonment gas formation volume factor, bbl/SCF }
\end{aligned}
$$

where subscript $i$ represents the initial condition and subscript a represents the abandonment condition.

It is assumed that initially there is no free gas present in the reservoir. Using the above nomenclature,

Initial oil in place $=\frac{7758 A h \phi\left(1-S_{w i}\right)}{B_{o i}}$ STB

(Equation 6) 
Initial gas in place $=\frac{\frac{7758 A h \phi\left(1-S_{w i}\right)}{B_{o i}}}{s i} \mathrm{SCF}$

(Equation 7)

$\frac{7758 A h \phi S_{o f}}{B_{o a}}$

Remaining oil at abandonment $=\quad$ STB

(Equation 8)

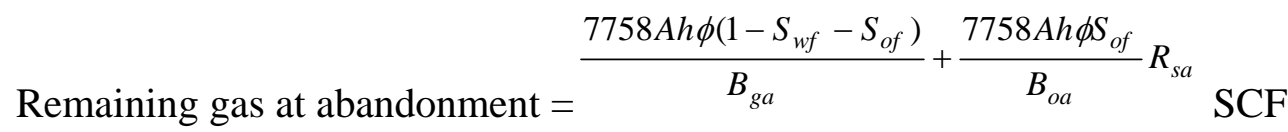

(Equation 9)

Ultimate oil recovery $=7758 A h \phi\left(\frac{1-S_{w i}}{B_{o i}}-\frac{S_{o f}}{B_{o a}}\right)$ STB

(Equation 10)

Recovery factor for oil $=\left(1-\frac{S_{o f} B_{o i}}{\left(1-S_{w i}\right) B_{o a}}\right)$

(Equation 11)

Ultimate gas recovery $=7758 A h \phi\left(\frac{\left(1-S_{w i}\right)}{B_{o i}} R_{s i}-\frac{\left(1-S_{w f}-S_{o f}\right)}{B_{g a}}-\frac{S_{o f} R_{s a}}{B_{o a}}\right)$ SCF

(Equation 12)

Recover factor for gas $=1-\frac{B_{o i}}{\left(1-S_{w i}\right) R_{s i}}\left(\frac{\left(1-S_{w f}-S_{o f}\right)}{B_{g a}}-\frac{S_{o f} R_{s a}}{B_{o a}}\right)$

(Equation 13)

The initial oil in place is obtained from the geologic/petrophysical model of each region. This is described in an earlier petrophysical analysis section. The cumulative oil and gas production is obtained from decline curve analysis. Recovery factors for oil and gas are obtained by dividing the cumulative production by the in place amount. The final oil saturation $S_{\text {of }}$ is obtained by substituting the oil recovery factor in equation 11 . The final water saturation $S_{w f}$ is obtained by substituting the gas recovery factor in equation 13. Table 27 shows the oil and gas recovery factors with final oil and water saturations at abandonment. The following values are used to perform the calculations: Notice that the results of gas recovery factors, although slightly different from table 26, are quite consistent. The difference is partly caused by the fact that in table 26, we assumed volatile oil and a compositional model, whereas, in this analysis, we are assuming black oil model. Another difference is that in table 26, we calculated the final recovery based on material balance, whereas, in table 27, we calculated the ultimate recovery based on decline curve analysis. In addition, in table 27, we also included oil recovery factors explicitly. 
Those numbers are small indicating that very small amount of initial oil is produced at the time of abandonment. The following properties are used for the calculations provided in table 27:

$$
\begin{aligned}
& P_{a}=300 \mathrm{psia} \\
& R_{s i}=650 \mathrm{SCF} / \mathrm{STB} \\
& B_{o i}=1.316 \mathrm{bbl} / \mathrm{STB} \\
& B_{o a}=1.076 \mathrm{bbl} / \mathrm{STB} \\
& B_{g a}=0.009037 \mathrm{bbl} / \mathrm{STB} \\
& R_{s a}=70.33 \mathrm{SCF} / \mathrm{STB}
\end{aligned}
$$

These values are based on an evaluation of oil properties based on the sample. The oil API gravity is observed to be 42 and the gas gravity is measured to be 0.72 . The abandonment pressure can be varied; however, we assumed it to be 300 psia. 
Table 27. Final oil and water saturation from oil and gas recovery factor

\begin{tabular}{lcccc}
\hline \multicolumn{1}{c}{ Region } & CE & $\mathbf{C W}$ & $\mathbf{E}$ & $\mathbf{W}$ \\
\hline Initial Oil Saturation & $\mathbf{0 . 4 8 7}$ & $\mathbf{0 . 4 8 0}$ & $\mathbf{0 . 3 8 2}$ & $\mathbf{0 . 2 7 9}$ \\
Initial Water Saturation & $\mathbf{0 . 5 1 3}$ & $\mathbf{0 . 5 2 0}$ & $\mathbf{0 . 6 1 8}$ & $\mathbf{0 . 7 2 1}$ \\
Porosity & 0.045 & 0.045 & 0.068 & 0.080 \\
Oil in Place(MSTB) & 25400 & 174380 & 53900 & 70630 \\
Gas in Place(BCF) & 16.520 & 113 & 35.035 & 46 \\
Total Oil & 2233 & 4534 & 2210 & 416 \\
Production(MSTB) & & & & \\
Total gas & 6.960 & 39.550 & 24.875 & 11.206 \\
Production(BCF) & & & & \\
OilRF & 0.088 & 0.026 & 0.041 & 0.006 \\
GasRF & 0.421 & 0.350 & 0.710 & 0.244 \\
Final Oil Saturation & $\mathbf{0 . 3 6 5}$ & $\mathbf{0 . 3 8 4}$ & $\mathbf{0 . 3 0 1}$ & $\mathbf{0 . 2 2 8}$ \\
Final Water Saturation & $\mathbf{0 . 4 1 6}$ & $\mathbf{0 . 3 8 5}$ & $\mathbf{0 . 5 1 9}$ & $\mathbf{0 . 6 3 2}$ \\
\hline
\end{tabular}

The recovery factor for water is also given by the following equation:

$\mathrm{RF}$ (water) $=\left(1-\frac{S_{w f}}{S_{w i}}\right)$

(Equation 14)

Cumulative water production for each region was obtained by prorating the water production of Marjo wells by using the oil production values of Marjo wells only and the cumulative oil production of the entire region (production from all operators). Unfortunately, we did not have water production data available from all the wells. We had data from Marjo Production Company only. The initial water in place is obtained from the geologic model of the region. The recovery factor is calculated by dividing the cumulative water production by original 
water in place. Using equation 14 the final water saturation $S_{w f}$ is calculated. Table 28 provides the $S_{w f}$ values obtained by using water recovery factors.

Table 28. Final water saturation from prorated water production

\begin{tabular}{lcccc}
\hline \multicolumn{1}{c}{ Region } & CE & CW & E & W \\
\hline Water in place (MSTB) & 35093 & 247474 & 114062 & 238869 \\
Total Water Production (MSTB) & 17665 & 54961 & 4868 & 27223 \\
Water RF & 0.503 & 0.222 & 0.043 & 0.114 \\
Final Water Saturation & $\mathbf{0 . 2 5 5}$ & $\mathbf{0 . 4 0 5}$ & $\mathbf{0 . 5 9 1}$ & $\mathbf{0 . 6 3 9}$ \\
\hline
\end{tabular}

It can be seen that for the Central East Region the difference between the $S_{w f}$ values obtained by the two methods (equations 13 versus 14) is very large. The values for the remaining regions are in a close agreement. The close agreement between the two water saturation further validates our simplified material balance approach. One reason for the discrepancy in the values of the Central East region could be the uncertainty in prorated water production. This is the region where we had the least amount of water production data available.

To reconcile the difference between the two water saturation values, an iterative procedure was used so that the water production was adjusted so that the water saturations from both methods would match with each other. The new water production values for the Central East, Central West and East regions were calculated by using the $S_{w f}$ from gas recovery factors. By doing this, the final water saturation for each region at abandonment calculated by using the gas recovery factors is made to match the final water saturation calculated by water recovery factors. Table 29 shows the results of calculated water production from each of the four regions to match the water saturation results. 
Table 29. New water production to match final water saturation from gas RF

\begin{tabular}{lcccc}
\hline \multicolumn{1}{c}{ Region } & CE & CW & E & W \\
\hline Initial Oil Saturation & 0.487 & 0.480 & 0.382 & 0.279 \\
OOIP (MSTB) & 25400 & 174380 & 53900 & 70630 \\
OGIP (BCF) & 16.510 & 113.347 & 35.035 & 45.909 \\
Oil Production (MSTB) & 2177 & 4430 & 2418 & 395 \\
Gas Production (BCF) & 6.953 & 42.548 & 19.500 & 12.493 \\
Oil RF & 0.086 & 0.025 & 0.045 & 0.006 \\
Final Oil Saturation & 0.365 & 0.384 & 0.300 & 0.228 \\
Gas RF & 0.421 & 0.375 & 0.557 & 0.272 \\
Final Water Sat using Gas RF & $\mathbf{0 . 4 1 5}$ & $\mathbf{0 . 3 8 4}$ & $\mathbf{0 . 5 2 0}$ & $\mathbf{0 . 6 3 2}$ \\
OWIP (MSTB) & 35093 & 247474 & 114062 & 238869 \\
New Water Production (MSTB) & $\mathbf{6 7 4 7}$ & $\mathbf{6 4 4 9 5}$ & $\mathbf{1 8 0 7 2}$ & $\mathbf{2 7 2 2 3}$ \\
Water RF & 0.192 & 0.261 & 0.158 & 0.114 \\
Final Water using Water RF & $\mathbf{0 . 4 1 5}$ & $\mathbf{0 . 3 8 4}$ & $\mathbf{0 . 5 2 0}$ & $\mathbf{0 . 6 3 9}$ \\
\hline
\end{tabular}

The interesting information from table 28 and table 29 are the differences in cumulative water production. For the Central West Region, we had the most water production data. No adjustment is needed in that production to match water saturations using the two methods. For the other three regions, we only had water production data from 7 - 8 wells. We extrapolated the data to all the producing wells by assuming that average cumulative WOR from the Marjo wells is similar to other wells. This assumption may not be true and, hence, it is quite possible that our extrapolated values are not accurate. In general, the data from this simplified material balance exercise indicates that a simplified material balance is valid to understand the recovery from these types of reservoirs. The results of water saturation validate the methodology. 
Dynamic Material Balance Approach. To validate the methodology further and to account for loss of energy due to water production, we extended the material balance analysis to account for the dynamic behavior of the reservoir. In this effort, we coupled the material balance analysis with dynamic behavior of the reservoir. By knowing the gas, oil, and water production rates, we tried to optimize the initial oil and gas in place, as well as to obtain oil-water and gaswater relative permeability curves. This model requires the geological data, relative permeability, and PVT data obtained from different correlations. The method is iterative and requires using the relationship between instantaneous gas-water ratio, gas-oil ratio, and gas saturation. This relationship results in a plot known as the reservoir performance curve which is an important tool of the developed model.

The equations used for evaluating the reservoirs are similar to the one used in the simplified approach. Some of the additional equations are shown below: The overall material balance equation is given by:

$$
\begin{aligned}
& N_{p}\left[B_{o}\left(R_{p}-R_{s}\right) B_{g}\right]+W_{p} B_{w}=N\left[\left(B_{o}-B_{o i}\right)+\left(R_{s i}-R_{s}\right) B_{g}\right]+m N B_{o i}\left(\frac{B_{g}}{B_{g i}}-1\right) \\
& +\frac{(1+m) N B_{o i}\left(S_{w c} C_{w}+c_{f}\right) \Delta p}{1-S_{w c}}+W_{e} B_{w}
\end{aligned}
$$

(Equation 15)

The oil, water and gas at a particular time step is calculated by:

$$
\begin{aligned}
& N_{p}=N_{p 1}+\Delta N_{p} \\
& W_{p}=W_{p 1}+\Delta W_{p} \\
& G_{p}=G_{p 1}+\Delta G_{p}
\end{aligned}
$$

(Equation 18)

Instantaneous gas-water ratio (and similarly, gas-oil ratio) is calculated as:

$$
(G W R)_{a v g} \cong \frac{\Delta G_{p}}{\Delta W_{p}}
$$

(Equation 19)

One of the difficulties in applying the methodology is lack of knowledge in water production. Oil and gas production data are readily available from public resources but operators 
do not report water production. We considered the data from four fields (same as shown in figure 87) West Carney, East Carney, Central West Carney and Central East Carney. The cumulative water production from the four fields is obtained by extrapolating the water production data from wells operated by Marjo Operating Company. We multiplied the water-oil ratio from the Marjo wells to the cumulative oil production for the entire field. The assumption is that the Marjo wells have the same water-oil ratio as the other wells producing from the same field. This might not be true, but this is the only way we can obtain cumulative water production data. The data are illustrated in figures 94 through 97.

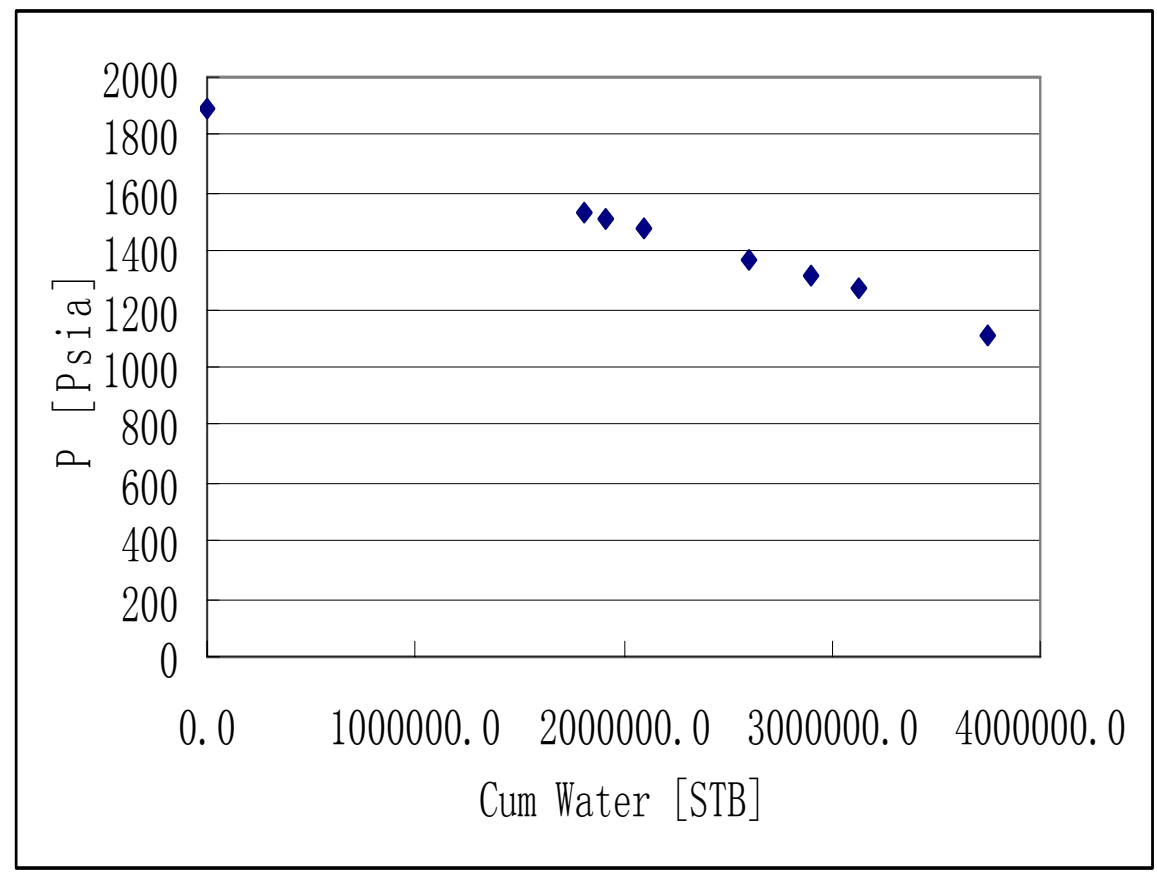

Figure 94: Cumulative production from East Carney field 


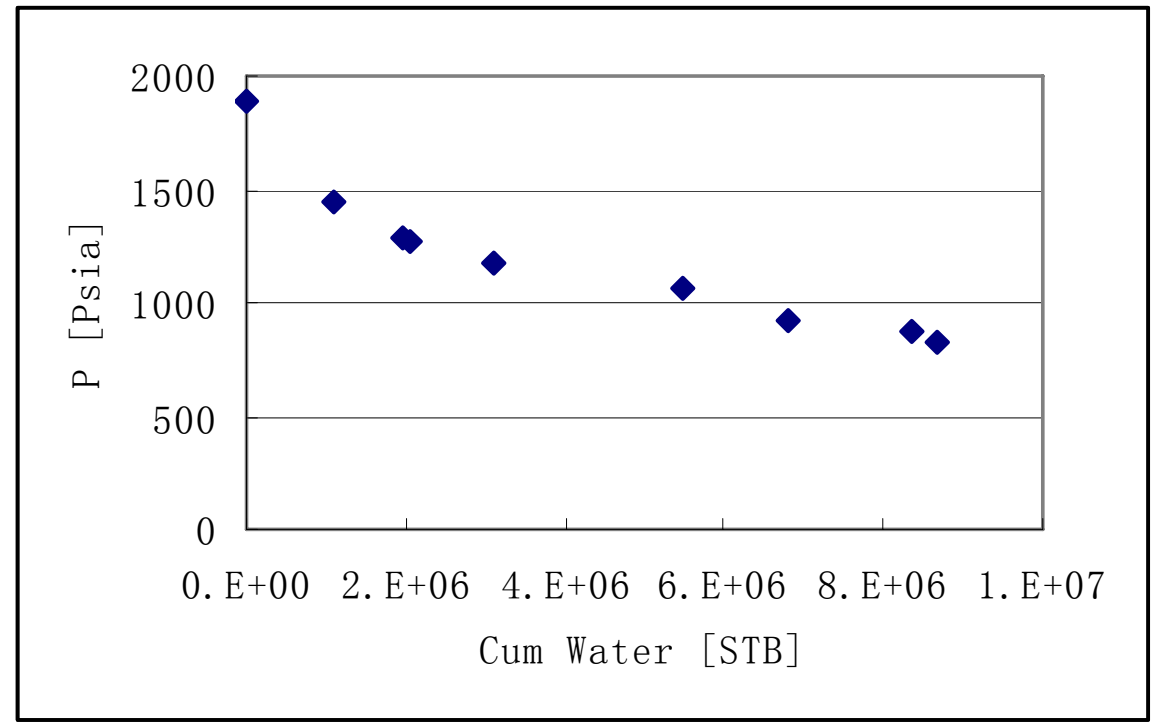

Figure 95: Cumulative water production from West Carney field

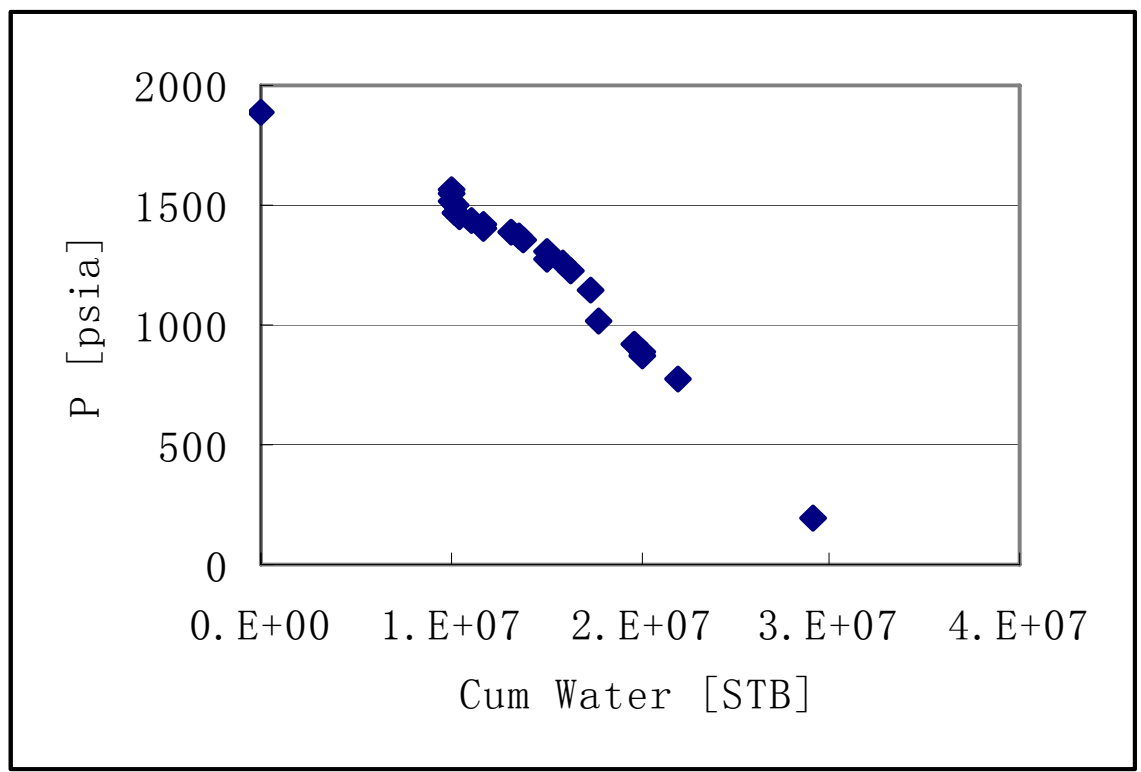

Figure 96: Cumulative water production from Central West Carney 


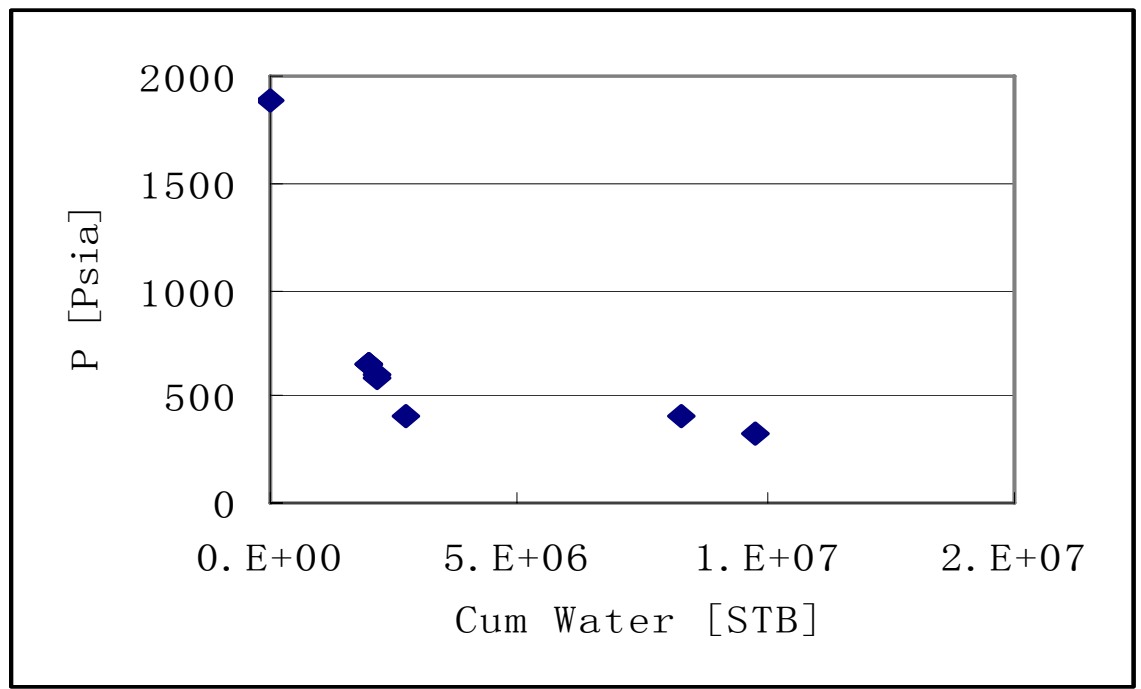

Figure 97: Cumulative water production from Central East Carney

Using the material balance method, there is a lot of uncertainty with respect to various parameters. To understand the importance of uncertainties, the uncertainty analysis is performed to validate the material balance. This is performed by altering the solution gas-oil ratio correlations, initial water saturation, area of the field, and initial average reservoir pressure to identify the least average error and standard deviation obtained between the water saturation from equation 13 and 14. The comparison helps in validation of the material balance and also in understanding the dewatering process. Based on the minimization of error, we determined the best parameters for the four fields and the results are shown in table 30. The final parameters obtained during the iterative process are within the realm of uncertainty for various parameters. As a result, they are reasonable. However, if these numbers are compared with the numbers obtained in table 29, one would notice that the oil in place values are smaller in table 30. Part of the reason is that table 30 is created based on additional oil, gas and water production data. Part of the reason is that we optimized many parameters simultaneously to minimize the error rather than just assuming that geologically based oil and place is the correct value. Most likely, the values presented in table 30 are more reasonable. 
Table 30. Optimal parameters for four fields

\begin{tabular}{lcccc}
\hline & East Carney & West Carney & Central West & Central East \\
\hline Swi & 0.71 & 0.72 & 0.72 & 0.74 \\
Area(Acres) & 12000 & 8000 & 45000 & 12167 \\
OIIP(STB) & $41,246,968$ & $31,589,041$ & $104,854,068$ & $27,511,980$ \\
WIIP(STB) & $132,354,975$ & $105,571,138$ & $341,495,443$ & $94,708,823$ \\
GIIP(MSCF) & $25,901,418$ & $18,407,831$ & $54,438,164$ & $11,407,453$ \\
$\bar{P}_{i}$ (Psia) & 1890 & 1600 & 1800 & 1200 \\
Std (\%) & 0.228 & 0.956 & 0.14 & 1.34 \\
Correlation & Standing & Standing & Glaso & Standing \\
Rsi (scf/stb) & 628 & 583 & 519 & 415 \\
Boi (bbl/stb) & 1.316 & 1.304 & 1.270 & 1.215 \\
\hline
\end{tabular}

Once the material balance equation is used to determine the optimal parameters, the next step is to determine the relative permeability ratios. The instantaneous GOR is the ratio of total gas flow rate (free gas and solution gas) to the oil flow rate. Inserting the gas and oil flow rates for Darcy's law equations, the instantaneous gas-oil ratio is demonstrated in the equations below.

$$
\begin{aligned}
& G O R=R_{s}+\frac{k_{r g}}{k_{r o}} \frac{B_{o}}{B_{g}} \frac{\mu_{o}}{\mu_{g}} \\
& \frac{k_{r g}}{k_{r o}}=\left(G O R-R_{s}\right)\left(\frac{\mu_{g} B_{g}}{\mu_{o} B_{o}}\right)
\end{aligned}
$$

(Equation 20)

(Equation 21)

The instantaneous gas-water ratio is computed by the ratio of gas flow rate to the water flow rate using Darcy's law for radial flow. The result of this derivation is illustrated in the equations below. 
$G W R=\frac{k_{r g}}{k_{r w}} \frac{B_{w}}{B_{g}} \frac{\mu_{w}}{\mu_{g}}$

(Equation 22)

$$
\frac{k_{r g}}{k_{r w}}=(G W R)\left(\frac{\mu_{g} B_{g}}{\mu_{w} B_{w}}\right)
$$

(Equation 23)

Similarly, the instantaneous water-oil ratio is computed by the ratio of water flow rate to the oil flow rate using Darcy's law for radial flow as shown in the equations below.

$W O R=\frac{k_{r w}}{k_{r o}} \frac{B_{o}}{B_{w}} \frac{\mu_{o}}{\mu_{w}}$

(Equation 24)

$$
\frac{k_{r w}}{k_{r o}}=W O R \frac{B_{w}}{B_{o}} \frac{\mu_{w}}{\mu_{o}}
$$

(Equation 25)

Predicting future reservoir production can be done as a function of declining reservoir pressure or time production phase. In this report the prediction is performed by declining reservoir pressure using Tracy's approach. The prediction of production in the reservoir using the material balance technique is highly influenced by the reservoir performance curves. As an example of relative permeability ratios, we illustrate the two curves below for the East Carney field.

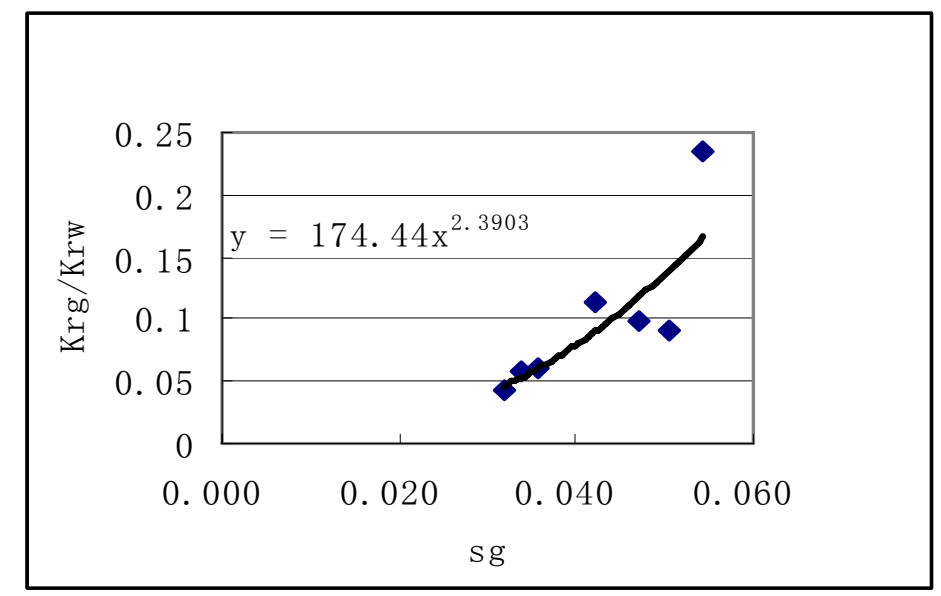

Figure 98: Gas to water relative permeability ratios for East Carney field 


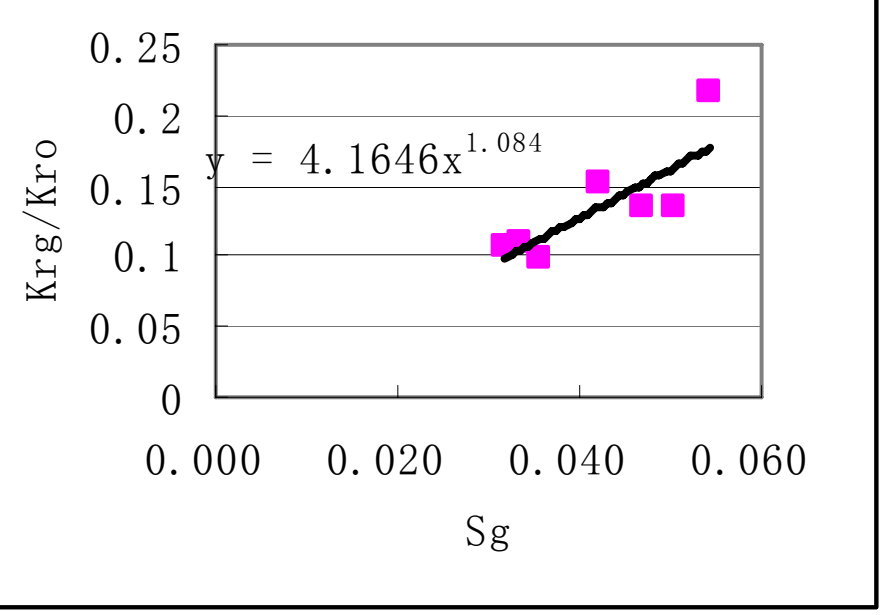

\section{Figure 99: Gas to oil relative permeability ratios for East Carney field}

The values obtained are fitted with a semi-log equation. The better the fit of the data, the better the predicted result compared to the actual performance. Similar curves are obtained for the other three fields. Since this is a three phase problem, the prediction is performed by combining the GWR and GOR using the gas saturation equation. Recall that the water-oil ratio (WOR) as one of the unknowns is determined by the ratio of GOR to GWR.

A simplified model is developed in VBA to predict the future production of the reservoir. There are three unknowns; incremental oil production, GOR, and WOR. These are computed by an interactive method where the reservoir permeability ratios are used to extrapolate the flow data to higher gas saturation. The general correlations for the hydrocarbon system are used to determine the basic fluid properties. The reservoir temperature, porosity, and thickness are assumed to be constant and the average reservoir pressure is assumed to be at bubble point pressure. The procedure of the model is summarized in figure 100 and the results are illustrated in figures 101 through 103 for East Carney field. 


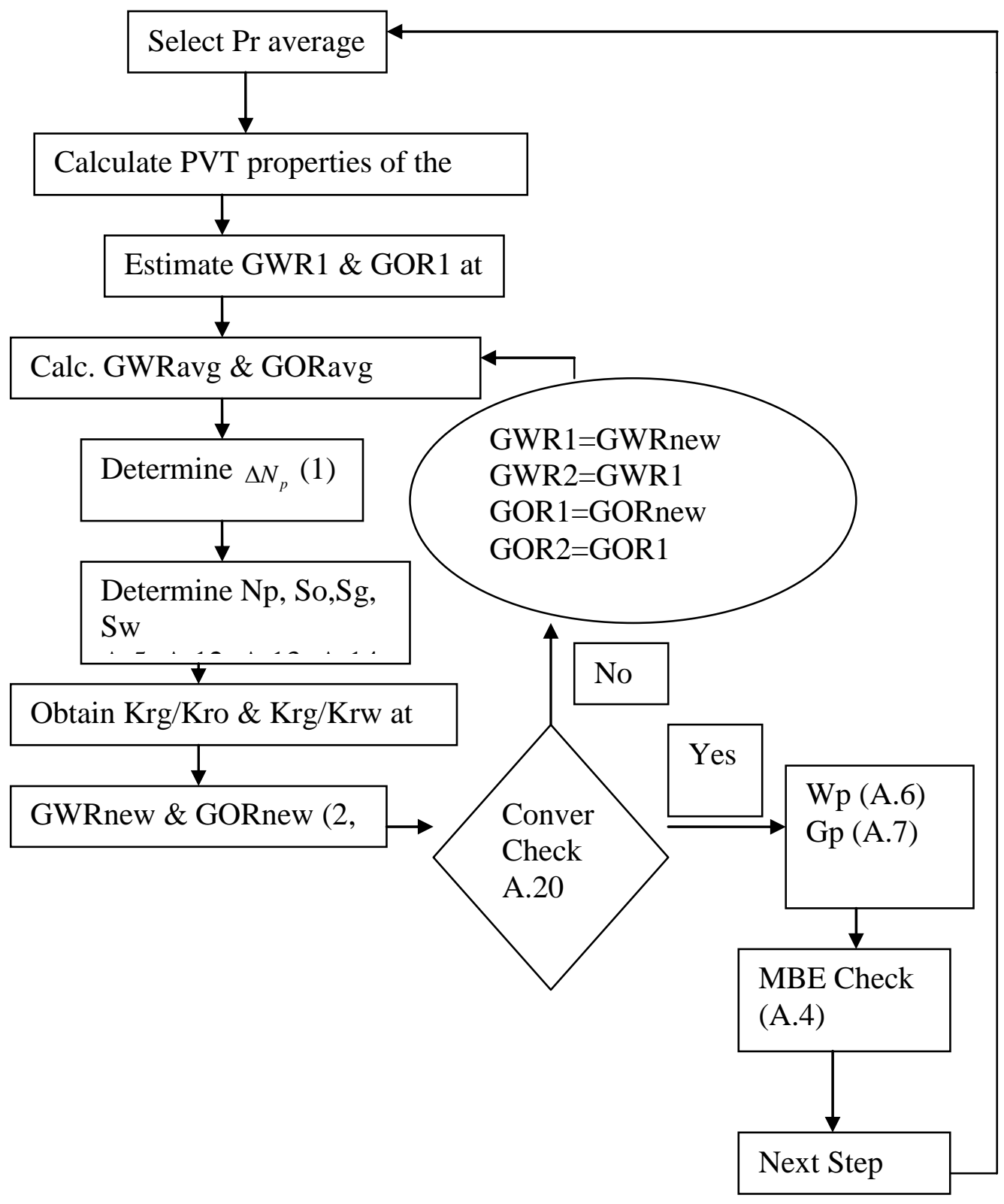

Figure 100: Flow diagram for predicting future performance 


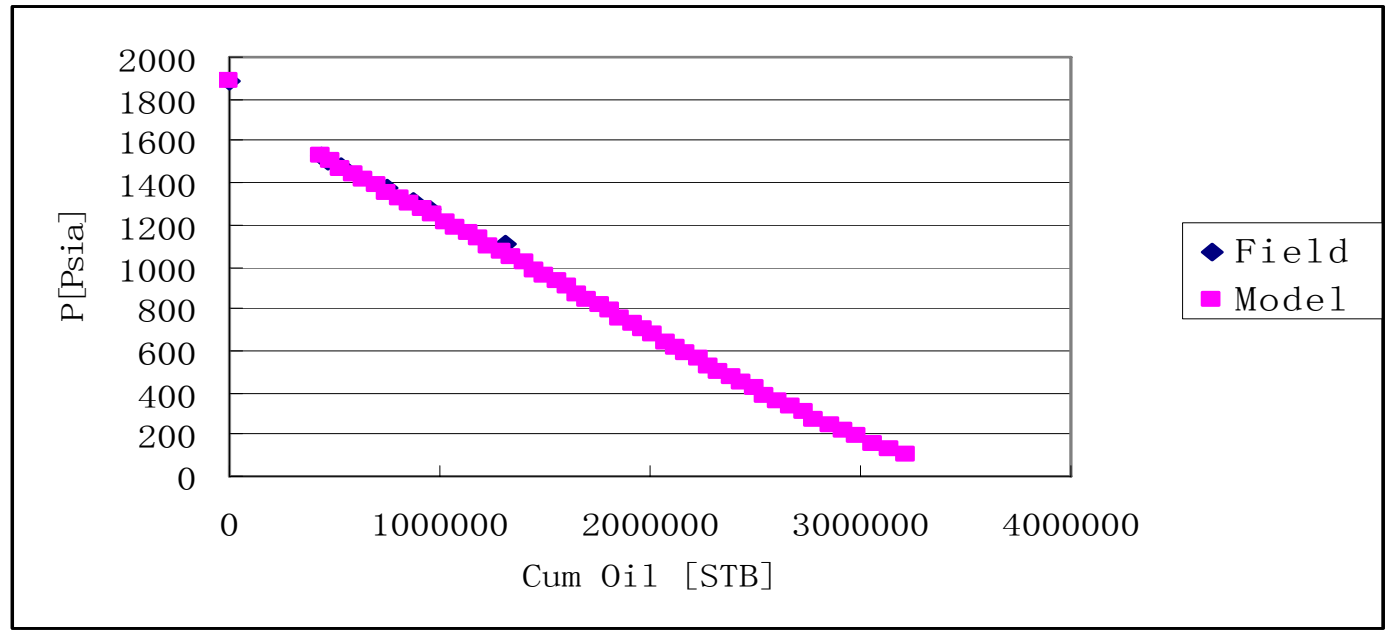

Figure 101: Comparison of predicted versus observed oil production for East Carney field

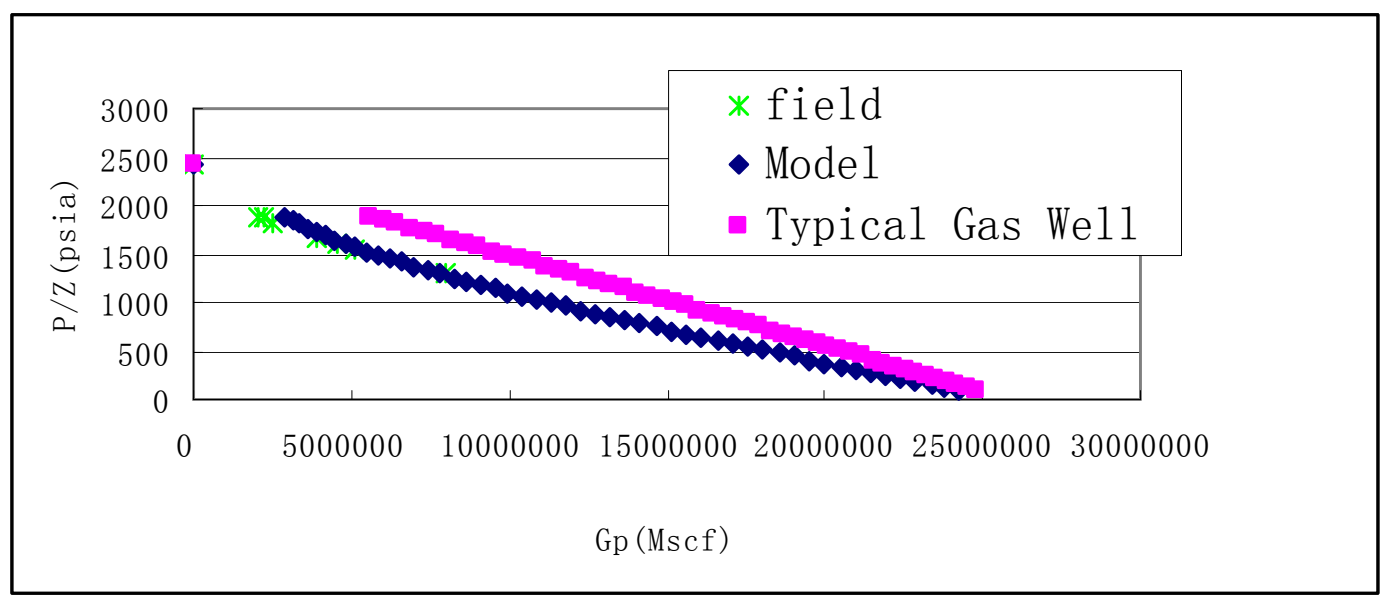

Figure 102: Cumulative gas production for East Carney - predicted versus observed 


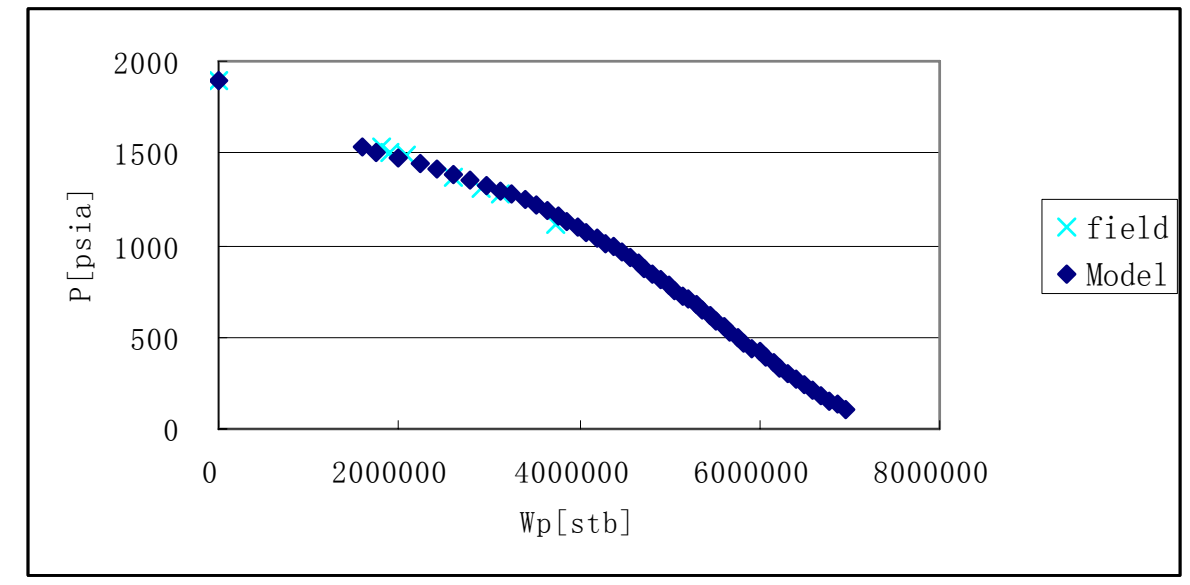

Figure 103: Cumulative water production of East Carney - predicted versus observed

In figure 102, for comparison purposes, we also illustrate how the graph of $\mathrm{p} / \mathrm{z}$ would look if we have no water production. As shown, with the presence of water, the curve has a concave nature illustrating the inefficient recovery of gas from the field. We observed that matches between the predicted and observed data were comparable for other fields as well.

The results from this study demonstrate that to increase the recoverable hydrocarbon (gas and oil) in these fields, the pressure must be decreased. This can be explained by the typical plot in figure 102. The results show the impact of excessive water production is clearly illustrated by the diminished gas production in this reservoir compared to a typical gas field. 


\section{Dynamic Data Analysis}

Once we realized that the relationship between the production data and log data is weak, we wanted to determine if the production data are related to any other parameters. This section explores our approach in evaluating the production data.

\section{Pressure depletion over time}

Bottom hole pressure data was collected for wells in the West Carney region. BHP (figure 104) was then plotted as a function of time to see the pressure behavior for these regions. For the Central West region it can be seen that the pressure for township 15N2E has decreased considerably. This is due to the high well density in this region and good connectivity in the reservoir. Also for $16 \mathrm{~N} 2 \mathrm{E}$ there is a general decline in pressure; although some wells are showing high BHP. The decrease in reservoir pressure can further be corroborated by plotting water production with time. Figure 105 shows that the water production has decreased considerably with time which further proves that the reservoir pressure has reduced considerably. Thus, the reservoir is served by a limited aquifer and the primary production mechanism is through solution gas drive. Due to limited water compressibility, water cannot provide sufficient energy to produce liquids and gas to the surface. However, the dissolved gas in oil, through expansion, can provide sufficient energy to produce water, as well as hydrocarbons, to the surface.

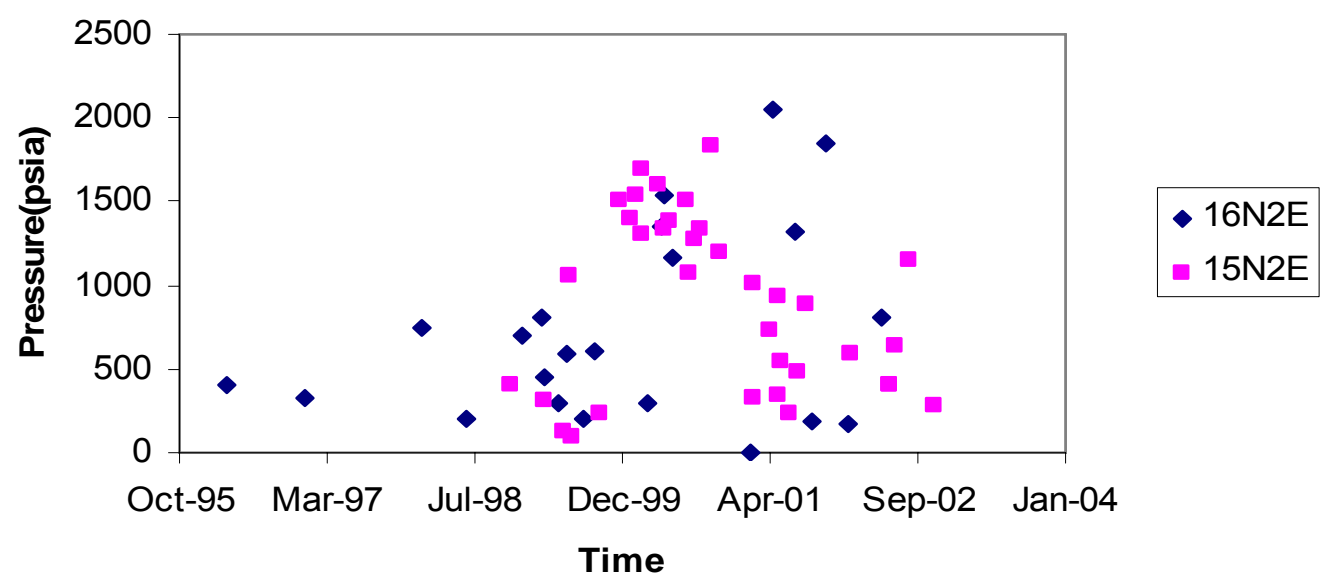

Figure 104: BHP versus time for Central West region 


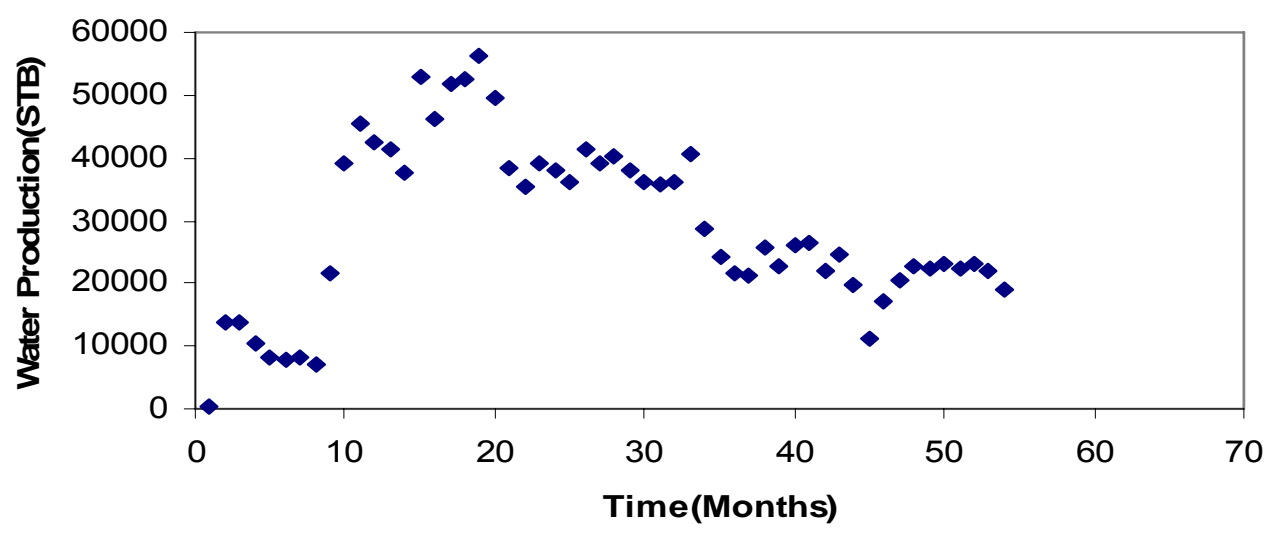

Figure 105: Water production versus time for Central East region

As reservoir pressure has decreased with time, the recoverable reserves have also decreased considerably. This can be seen in figures 106 and 107 which show plots of recoverable reserves of gas and oil respectively for each well and the time at which these wells were put to production. It can be seen that the oil recoverable reserves have decreased considerably with time. Also the gas reserves have decreased with time but it shows better reserves than oil. Some of the wells put into production after April 2001 show less oil recovery, but they still show good gas recovery. This is due to better mobility of gas and its ability to migrate toward the well bore more easily than oil. As a result, even at low pressures, gas still has sufficient mobility to be produced, whereas, oil recovery is reduced substantially at lower pressures. 


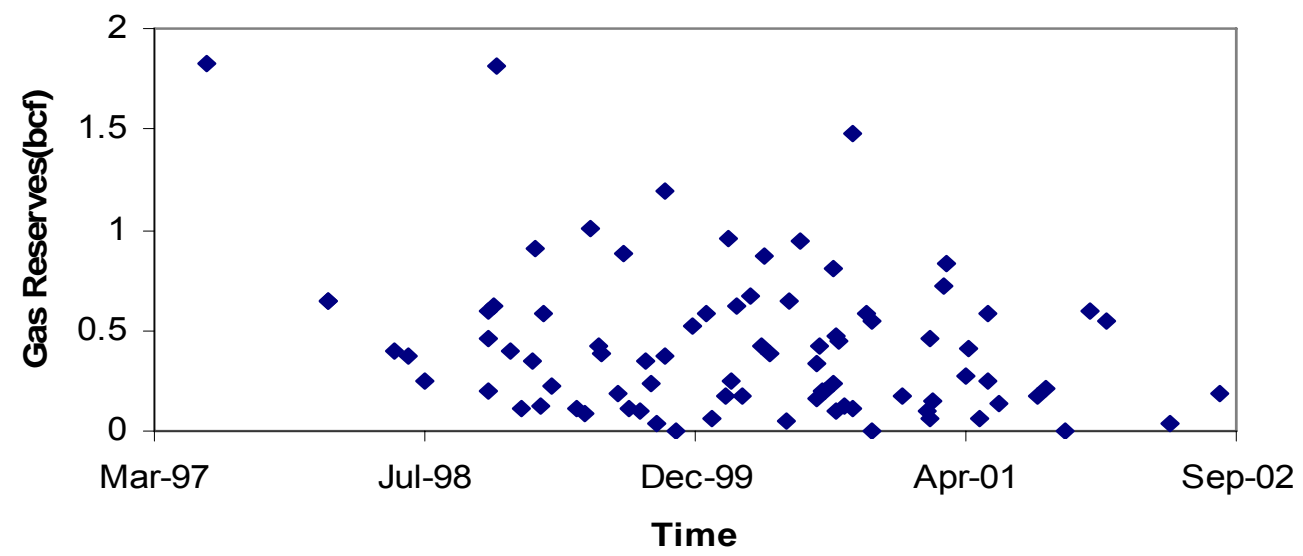

Figure 106: Gas reserves versus time for Central West region

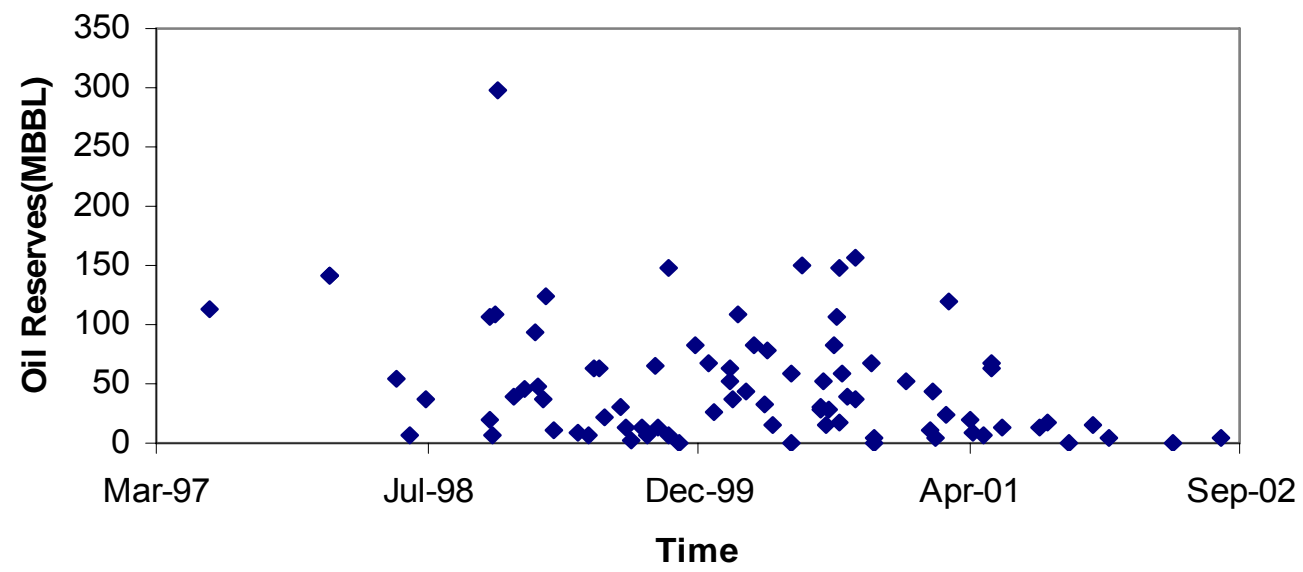

Figure 107: Oil reserves versus time for Central West region

\section{Recovery Factor}

Since the recovery of oil and gas is not related to petrophysical properties, we tried to relate it to other factors. One factor we considered was the IP (initial potential) of a well. To develop a better understanding of the relation between recovery and IP, plots of gas recovery versus IP and oil recovery versus IP were generated. We determined the recovery for individual 
wells using decline curve analysis. Dividing the recovery by the oil and gas in place in nearby area, we determined the individual recovery factors.

Gas recovery and oil recovery factors were determined for a grid block size of 160 acres, considering that the drainage area of each well is 160 acres. Gas or oil in place depends on the drainage area.

Figure 108 shows that the values of gas recovery factor for the four regions is more than 1 for some grid blocks, which shows that the wells are draining from an area that is greater than 160 acres. Thus, it is not really possible to accurately determine the drainage area of each well and calculate recovery factors correctly. This observation is consistent with the theory that hydrodynamic continuity is very strong in the reservoir. It is not inconceivable that a well with a strong IP can drain hydrocarbons from a region far away from the well. Figure 109 shows that the value of oil recovery factor at some wells is also high for the four regions, which is due to the well draining from an area more than 160 acres. However, due to lower mobility of oil, the recovery factor for oil is much lower than that for gas.

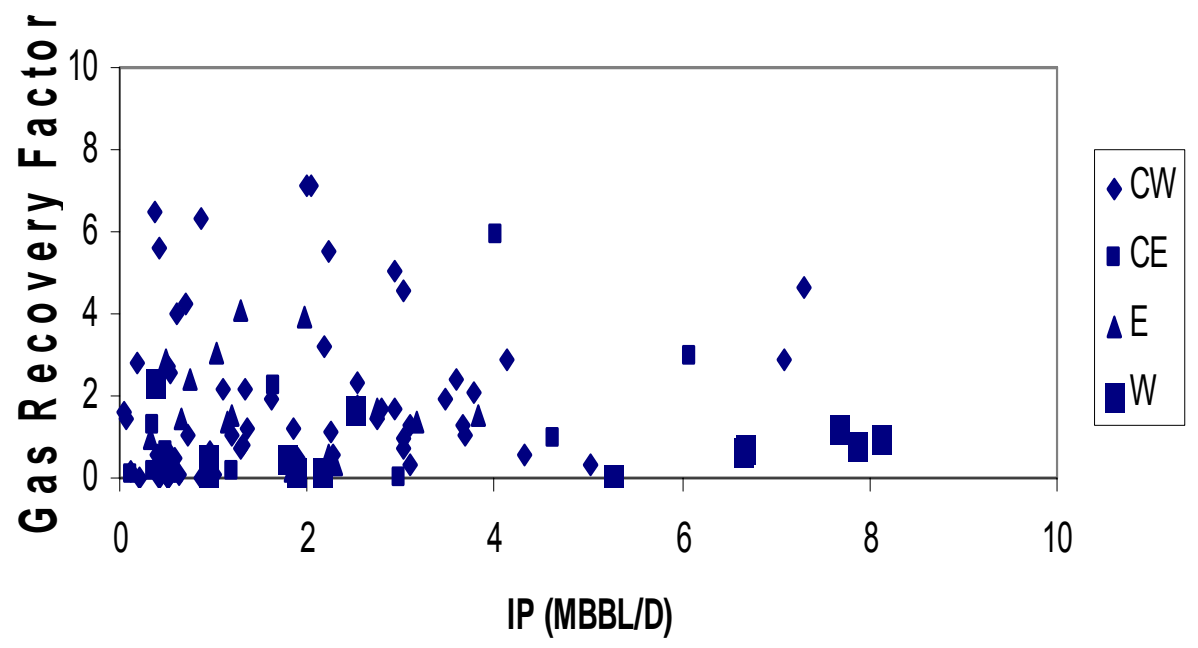

Figure 108: Gas recovery factor versus IP 


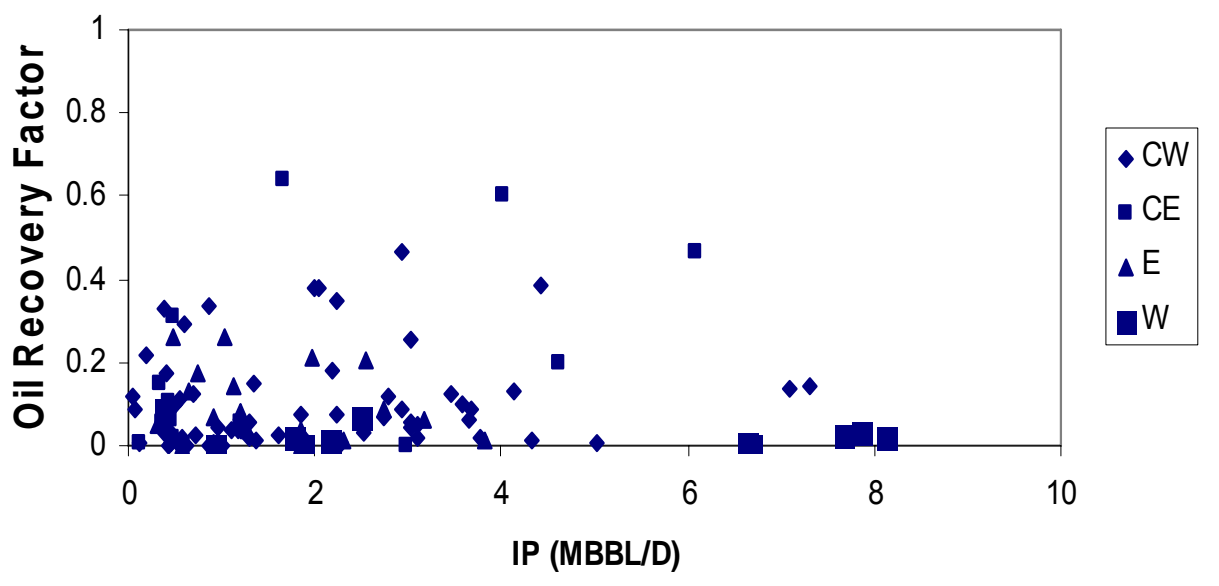

Figure 109: Oil recovery factor versus IP

Preferential flow of oil or gas through certain parts of the reservoir plays an important role in determining the reserves from individual wells. As a result, it is very difficult to determine the drainage area of the well, as it will depend on the connectivity in surrounding areas. Thus, IP can play a very important role in determining the reserves potential of a well. Higher IP may indicate preferential flow of fluids toward that well bore resulting in higher reserves. Also, high reserves will result in higher recovery. To delve into the effect of IP on reserves, a plot of total reserves (oil + gas) versus IP was generated. This plot (figure 110) was made on an individual well basis. This plot clearly shows that there is a strong relation between IP and reserves. High value of IP for a particular well results in higher reserves for that well. Plots were also developed in Petrel software for grid block sizes of 160 acres and they also show that reserves depend on IP. Thus, IP plays a crucial role in influencing the reserves of a well. See figures 111 and 112, which compare spatial distributions of IP data with reserves. 


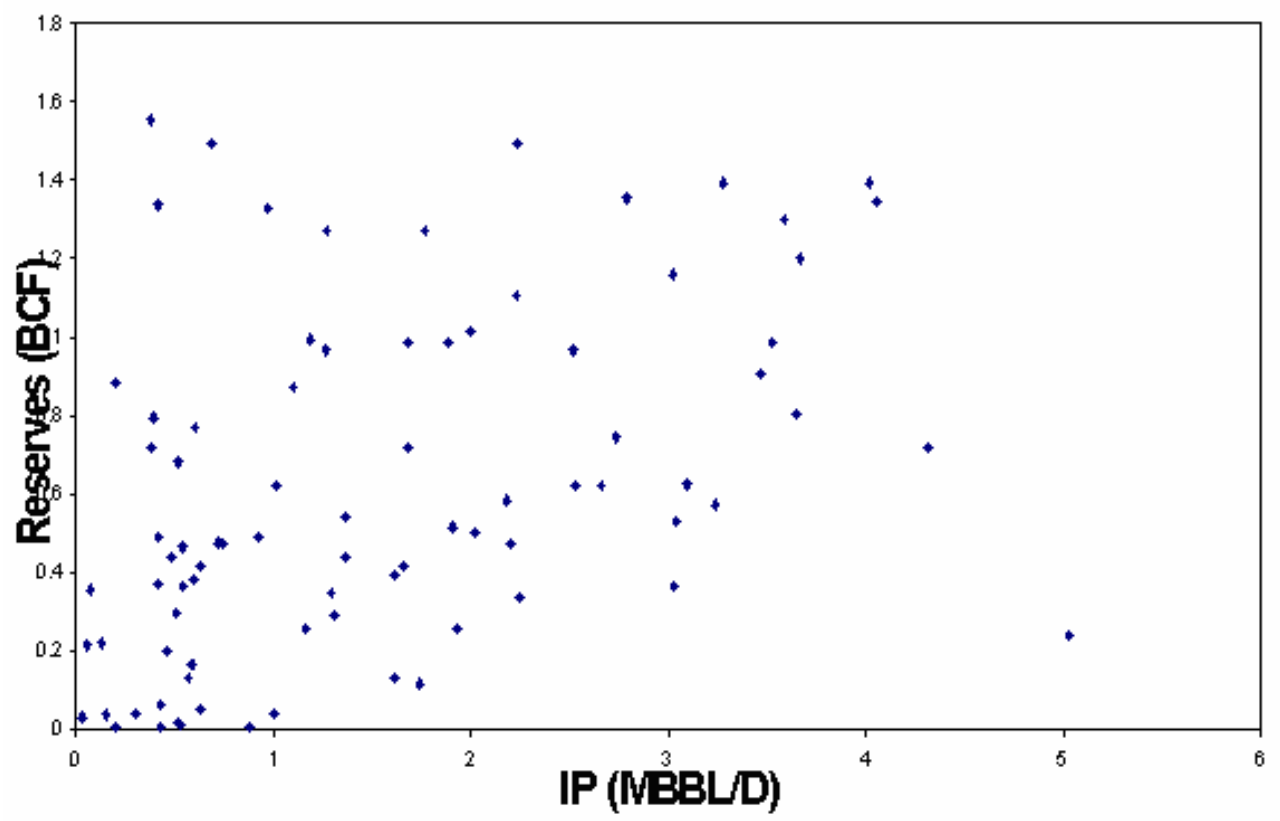

Figure 110: Equivalent gas reserves versus IP for Central West

IP and reserves were also compared for different operators. Average IP and average reserves were calculated for the wells drilled by different operators. Table 31 shows that operators which had high value of average IP for wells drilled by them also had high values of reserves. Thus, when observed on operator basis, it can be seen that IP does play an important role in increasing the reserves.

Table 31. Average oil and gas reserves compared with average IP for different operators

\begin{tabular}{lcccc}
\hline \multicolumn{1}{c}{ Company } & Oil (mbbl)/Well & Gas (bcf)/Well & IP/Well & No. of Wells \\
\hline Access Energy & 0.35 & 0.006 & 0.765 & 2 \\
Altex & 78.6 & 0.376 & 1.411 & 9 \\
Marjo & 14.78 & 0.338 & 0.806 & 8 \\
Special & 27.78 & 0.396 & 1.751 & 10 \\
New Dominion & 31.5 & 0.463 & 1.607 & 13 \\
\hline
\end{tabular}




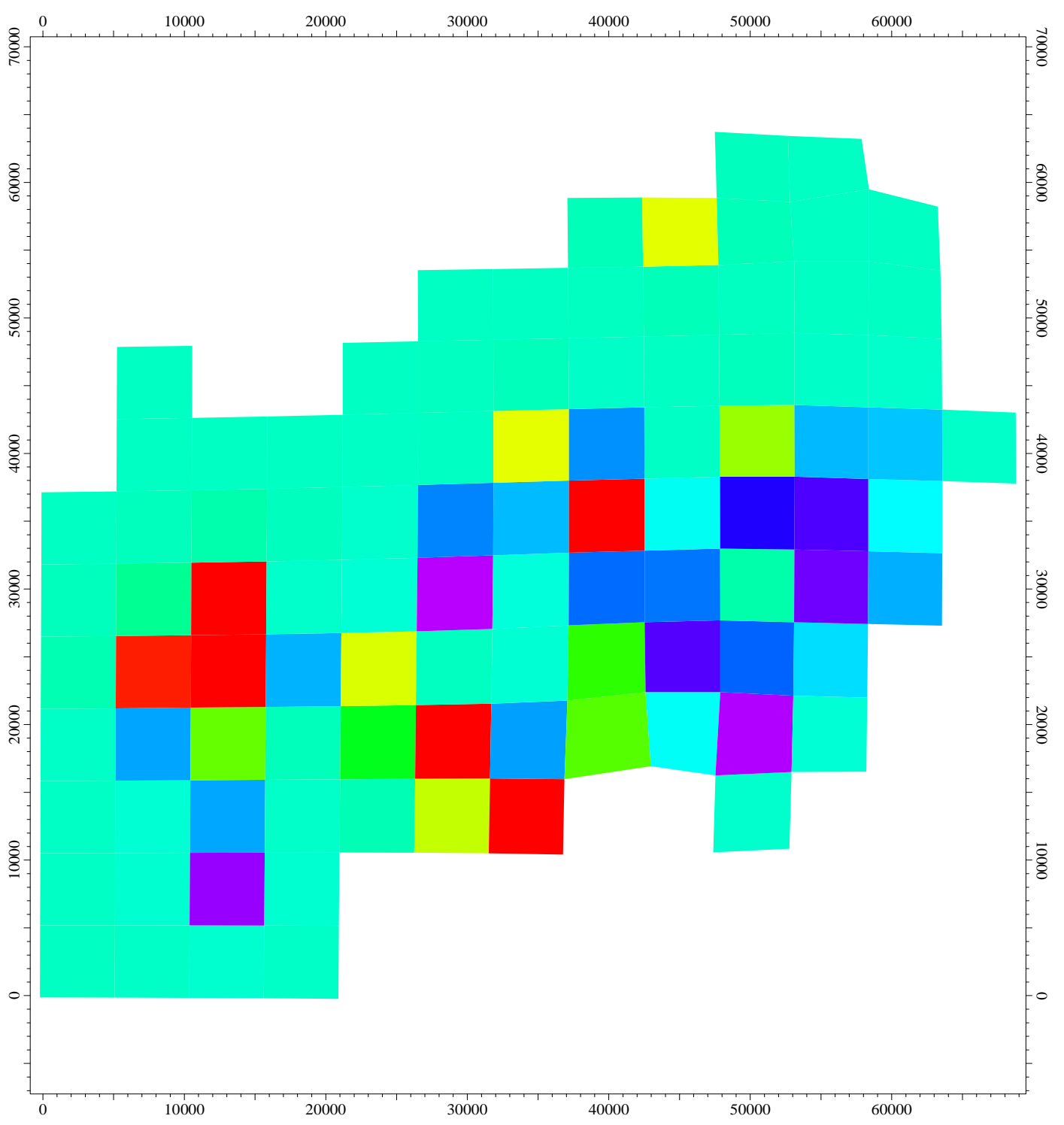

\begin{tabular}{|l|}
\hline MAP \\
\hline University of Tulsa \\
\hline Hunton \\
\hline $\begin{array}{l}\text { Oil Prod. } \\
\text { IP1 }\end{array}$ \\
\hline DOE \\
\hline
\end{tabular}

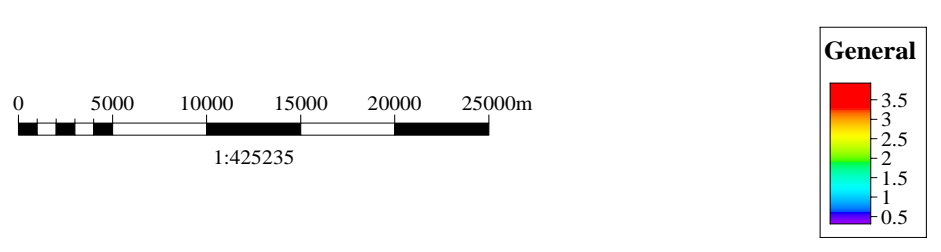

Figure 111: Initial potential 


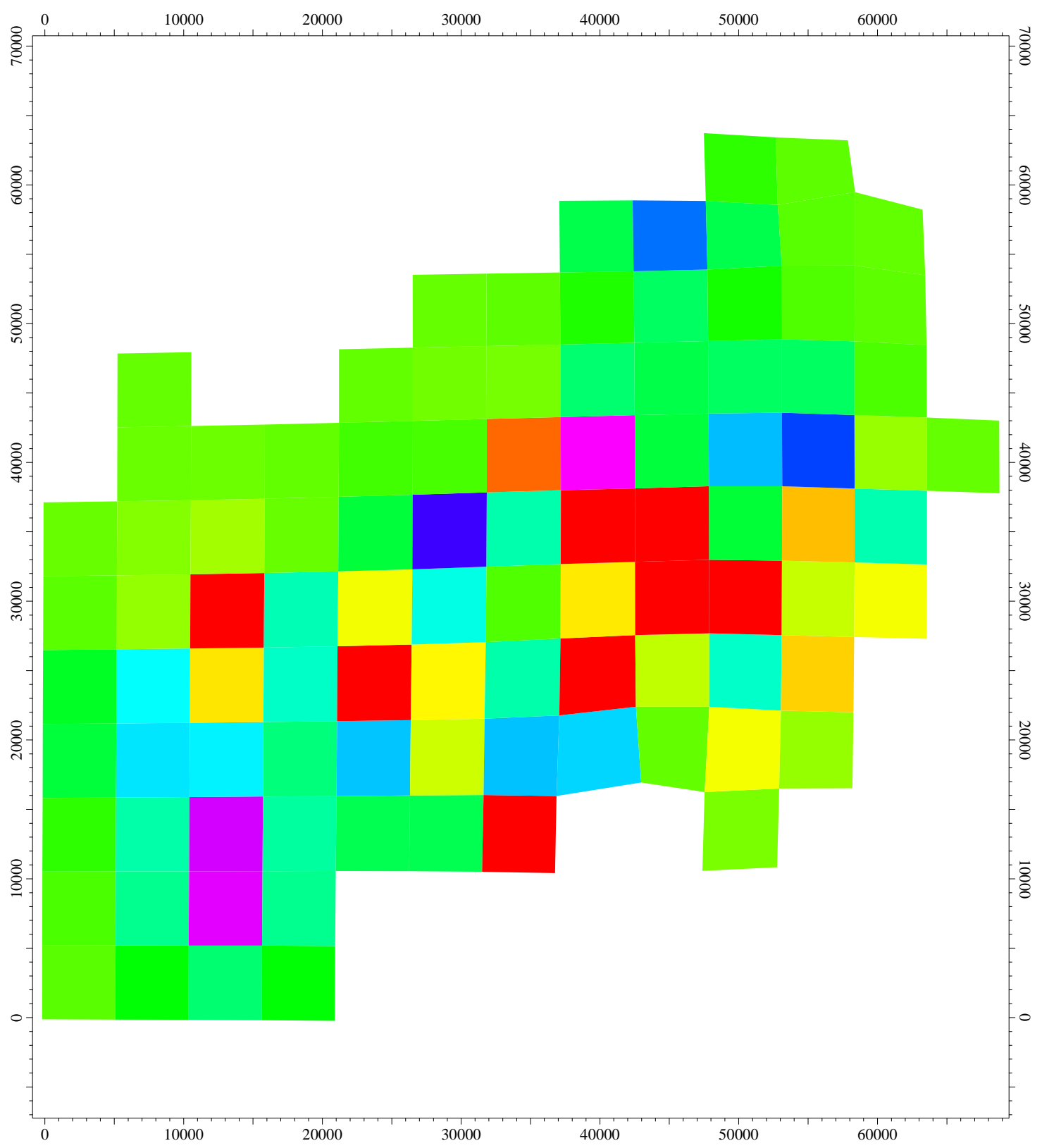

\begin{tabular}{|l|}
\hline MAP \\
\hline University of Tulsa \\
\hline Hunton \\
\hline $\begin{array}{l}\text { Oil Prod. } \\
\text { Reserves }\end{array}$ \\
\hline DOE \\
\hline
\end{tabular}

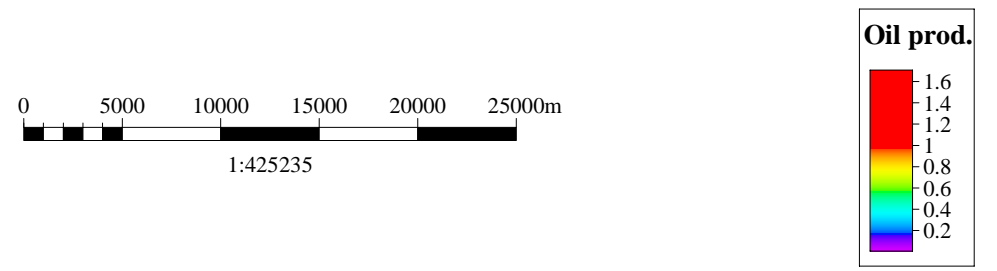

Figure 112: Reserves 


\section{Well Density}

Once we established the dynamic continuity in the reservoir as well as the importance of IP on the flow behavior, we wanted to examine the effect of optimal well density on the reservoir performance. To investigate the effect of well density or the number of wells on the recovery of hydrocarbons or on the recovery factor, a geological model for the West Carney area was constructed in Petrel for a grid size of 640 acres. The total recovery of oil and gas for a particular 640 acre grid block was calculated as the sum of the recovery of all the wells in that grid block. This was done for all the grid blocks in a region and also the number of wells in each grid block was determined. Plots were then generated between recovery and the number of wells for each region in the West Carney field to determine the relation between well density and recovery. In these plots, we show the total recovery as a function of the number of wells as well as the recovery per well as a function of the number of wells. Please note that the data points in these plots represent the average of many 640 acre sections in each region. For example, in the West Carney area, if there are twenty 640 acre sections, where the number of wells drilled is equal to 4 , then the total recovery from all the twenty sections is averaged and plotted on the graph. The same is done for the recovery per well. The figures below show the total recovery and recovery per well of oil and gas for regions in West Carney.

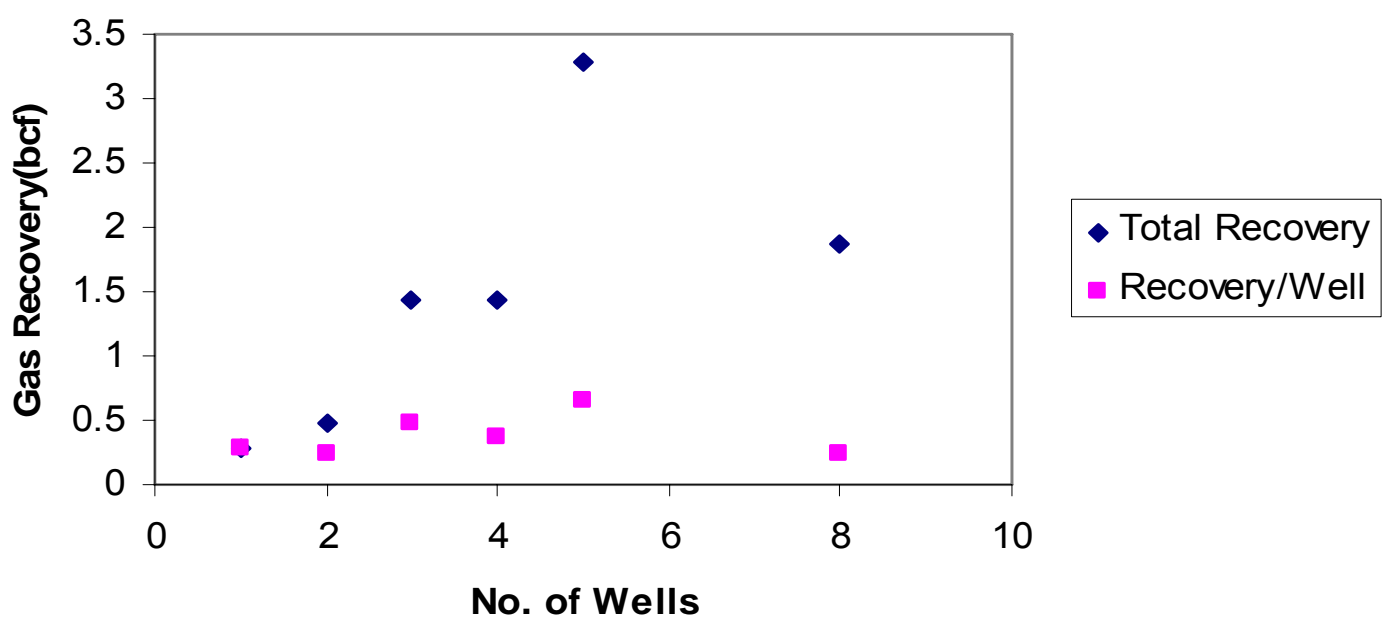

Figure 113: Gas recovery versus no. of wells for Central West region 


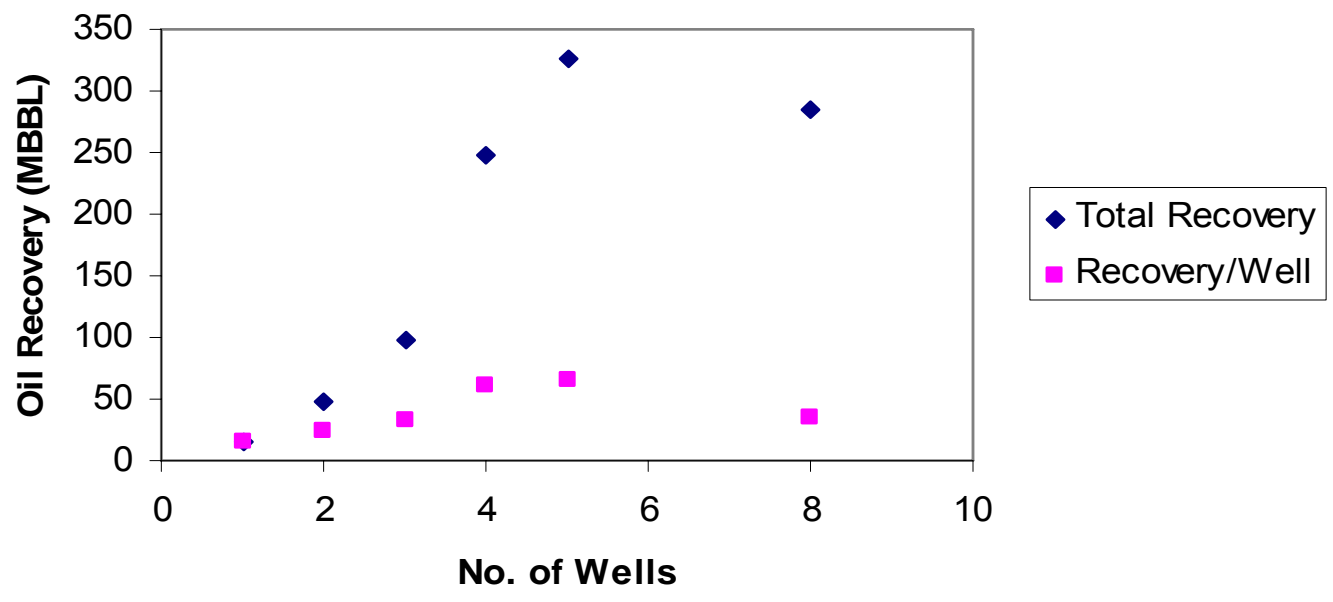

Figure 114: Oil recovery versus no. of wells for Central West region

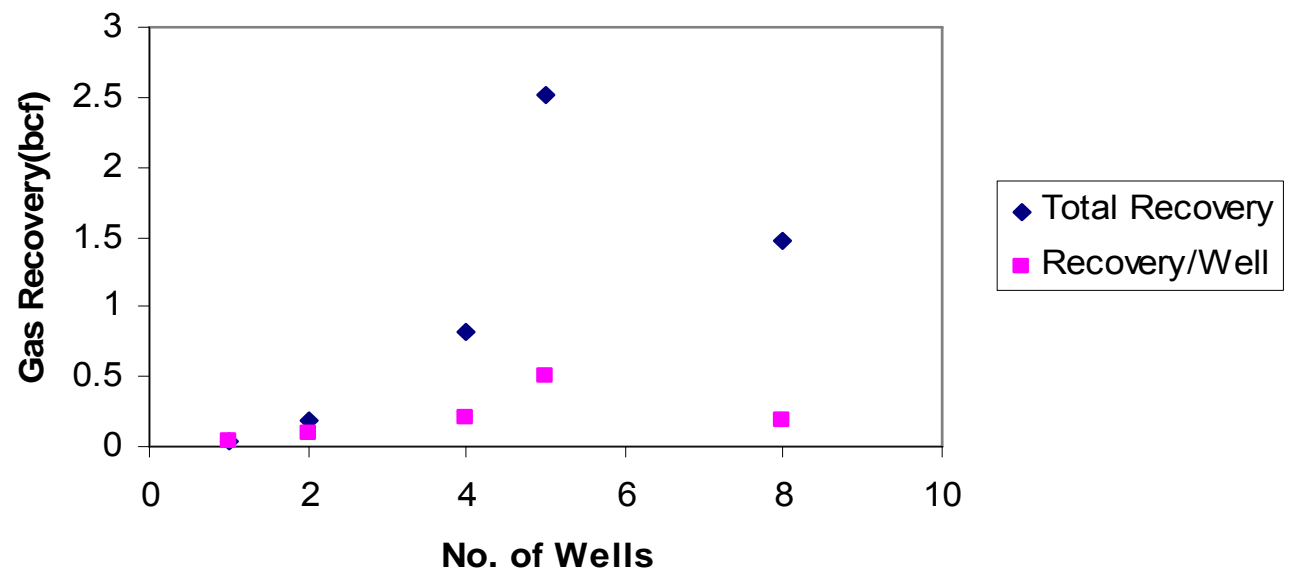

Figure 115: Gas recovery versus no. of wells for Central East region 


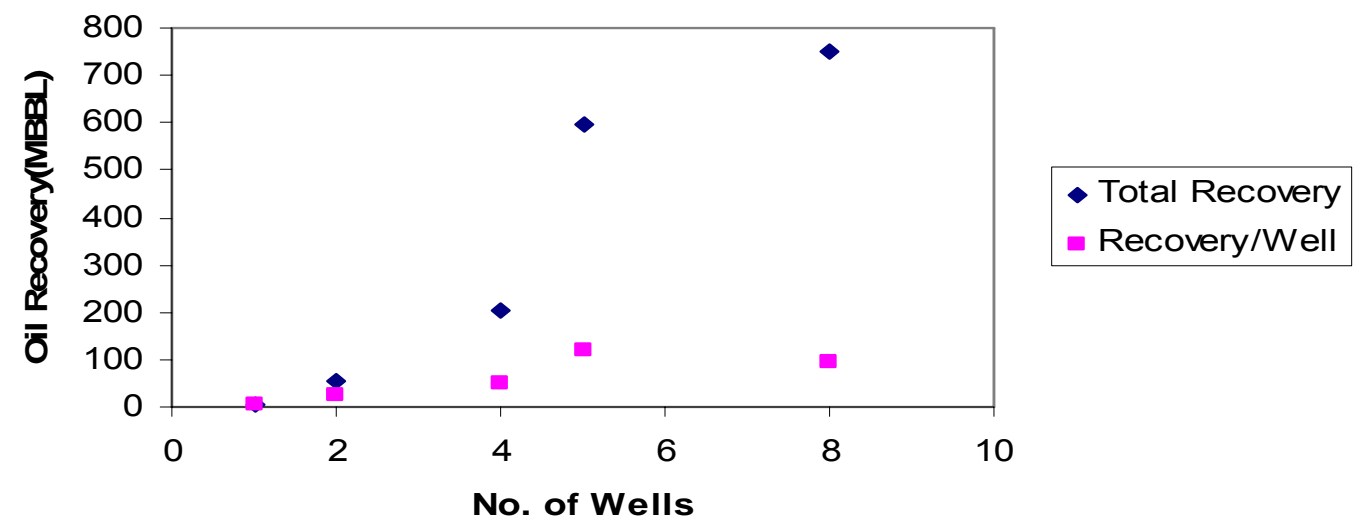

Figure 116: Oil recovery versus no. of wells for Central East region

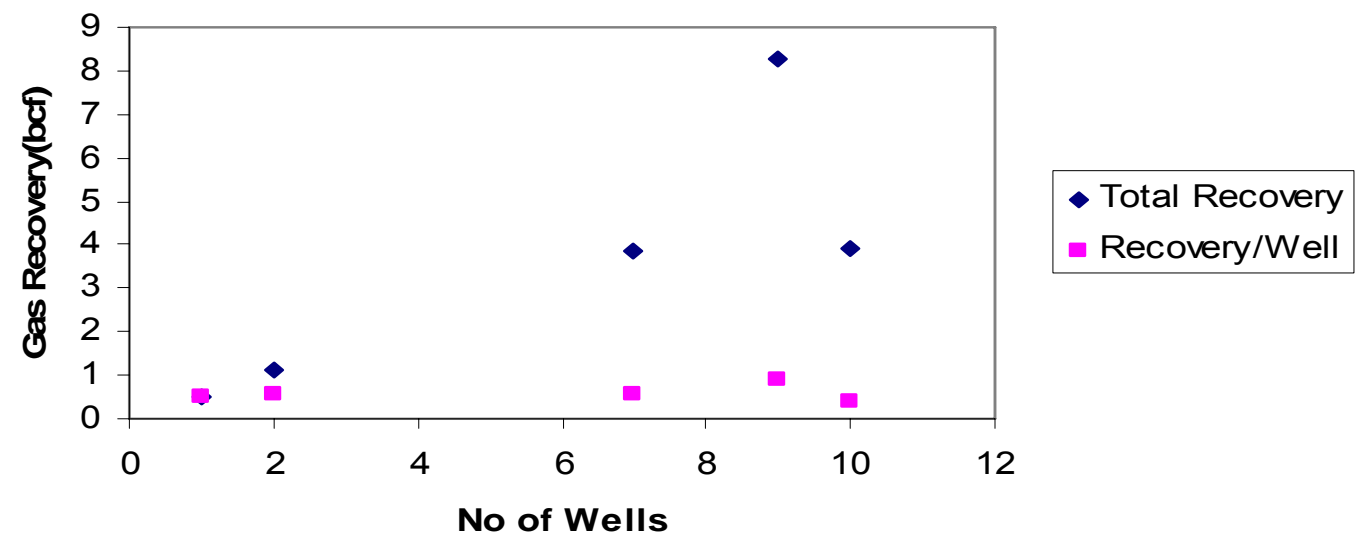

Figure 117: Gas recovery versus no. of wells for East region 


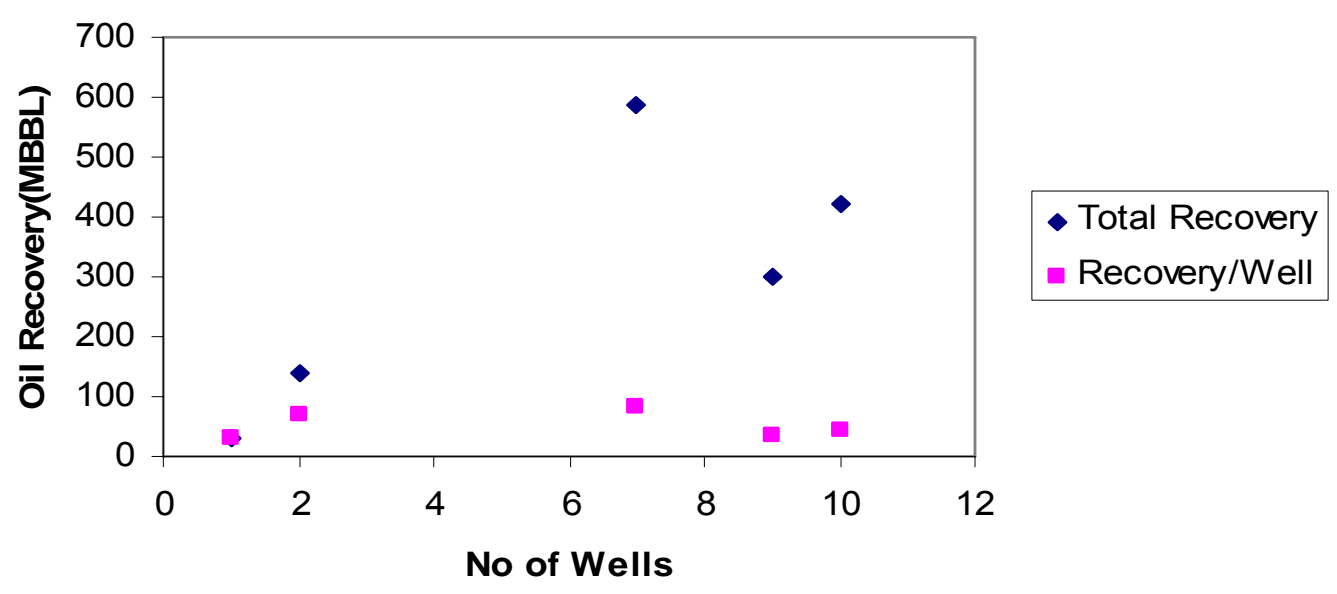

Figure 118: Oil recovery versus no. of wells for East region

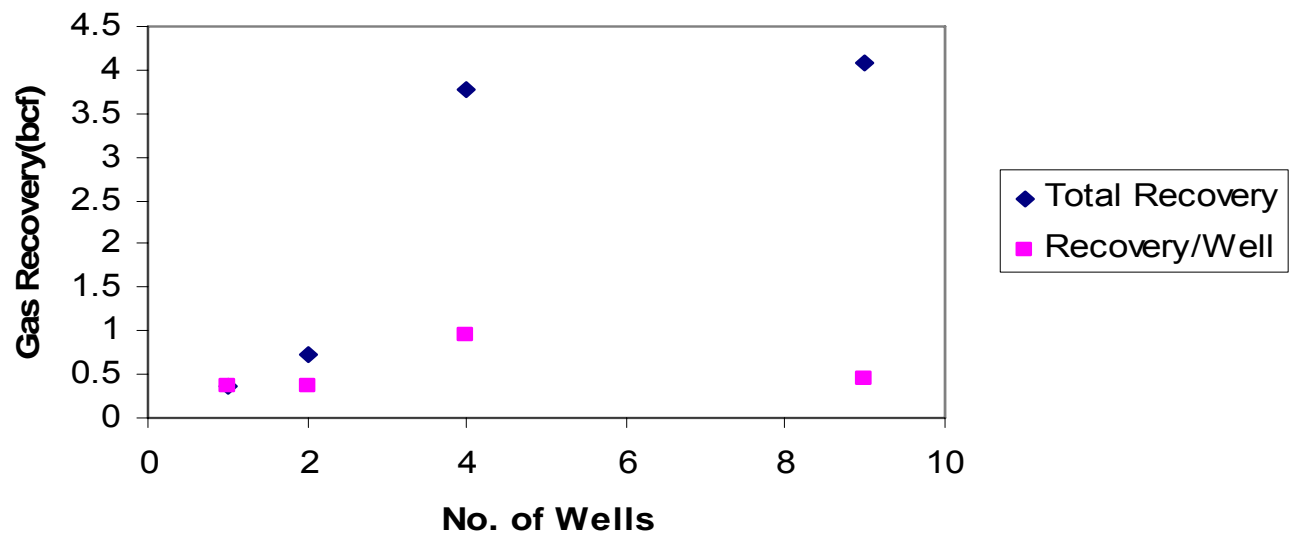

Figure 119: Gas recovery versus no. of wells for West region 


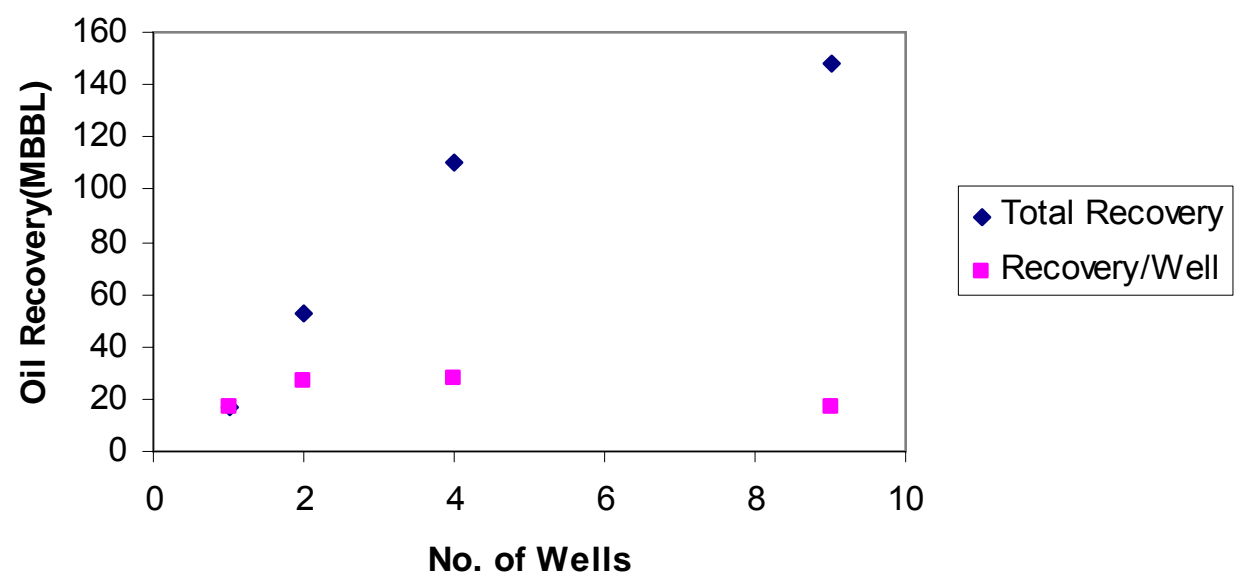

Figure 120: Oil recovery versus no. of wells for West region

These plots show that there is an optimal number of wells which can be drilled in a section to maximize recovery per well. Economically it would not be feasible to have wells more than the optimum value as the recovery per well will decrease and capital spent on drilling an extra well will not be justified. Also, the gas recovery per well for a section tends to be relatively flat as compared to oil recovery per well which can be explained by understanding that oil tends to be less mobile compared to gas. Thus, we need more drilled wells to increase the oil production.

In areas like Seminole, which show high value of mobile oil saturation, high value of oil in place, and low well density, more wells need to be drilled to optimize recovery. The number of wells drilled per section needs to be increased to 4 or 5 wells in order to enhance the recovery. Thus, areas like Seminole show good promise and are a good prospect for further development.

\section{Flow Simulation}

To understand the mechanism by which oil and gas is produced, we built a simple simulation model and history matched the performance of a typical well. As explained before, the typical oil recovery is very low. We examined different methodologies of improving the oil recovery through miscible displacement processes. 
Reservoir Simulation Evaluation - Primary Mechanism. One of the objectives of this study is to reproduce some of the important characteristics observed in the field. An Eclipse 300 simulator was used to simulate the reservoir. We considered the Schwake \#1 well to be a representative of reservoir behavior. Many unique characteristics typical of this reservoir are observed in the well performance of the Schwake well. These include large water production at initial conditions followed by delayed breakthrough of gas followed by breakthrough of oil, jump in GOR after shut-in, and decrease in WOR over time.

A single well radial model was considered to explain the primary production mechanism. The drainage area for one well is about 160 acres. The radius of the model is about 1,500 ft., divided into 12 grids increasing geometrically in size. There is only one grid in the angular direction. This was done because increasing the number of grids in the angular (6-12) causes extremely small size of the grids near the wellbore and results in stability problems while running the simulation. The model consists of two layers in the vertical direction, consistent with the geology. That is, we assume that most of the water is stored in large vug/high permeability regions and most of the oil is stored in low quality rock. The top layer is matrix with a low permeability, which stores all the oil. The bottom layer is the high permeability layer, which is responsible for production. The high permeability layer is connected to the wellbore, whereas the matrix layer is isolated. One reason for isolating the matrix layer is that oil cut is observed only after 5-6 days after the well is put on production. This indicates that oil does not exist in the immediate vicinity of the wellbore and has to travel some distance before it reaches the wellbore. This is also consistent with the idea that the properties near well bore may not influence the ultimate production. Figure 121 shows the schematic of the conceptual reservoir model. The initial reservoir pressure is 1,869 psia at a temperature of 117 F. As discussed in Fluid Properties section, this is approximately the bubble point of the reservoir fluid. As the well is put on production, water is produced from the high perm layer and there is a reduction in the reservoir pressure. This causes oil from the matrix layer to flow down into the high perm layer. This pressure reduction causes the reservoir pressure to drop below the bubble point causing gas to be released from oil. Water, oil and gas flow through the fracture and are produced at the wellbore. 


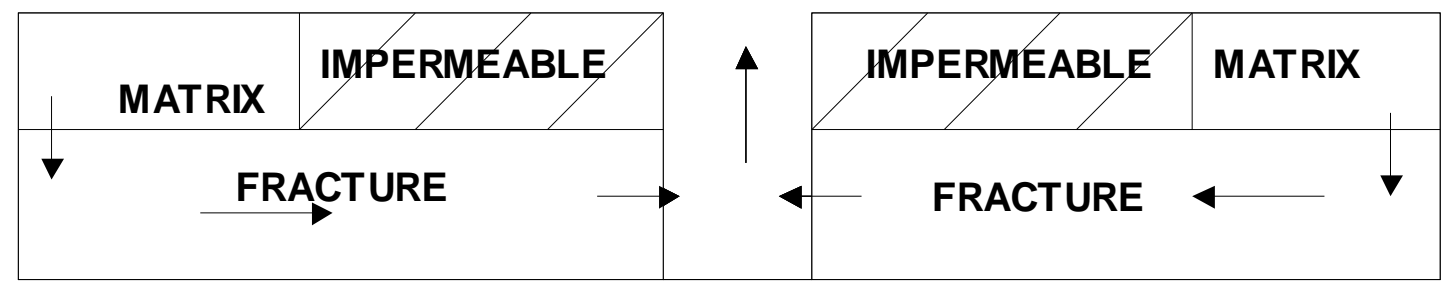

Figure 121: Conceptual reservoir model

The relative permeabilities are linear with no residual saturations. It is assumed that oil, water, and gas flow independent of each other. Once the model is defined, the input parameters are adjusted so that results from simulation can match the field production values and field production behavior.

History matching for the data was done by manually changing the input parameters until the desired field output was observed. The objective of the exercise as defined in the previous section was to match the normalized (rates divided by pressure drop) oil, gas, and water production rates and also the gas-oil ratio (GOR). The field data was obtained from Schwake 110 as it showed all the unique field characteristics. The rates were normalized because the field bottom-hole pressure (BHP) is not constant and decreases gradually with time. For simulation purposes, the BHP is kept constant at 100 psi. To account for this difference, normalized rates are used to match production history. A satisfactory oil rate and GOR match was obtained using the following parameters. Figures 122 through 124 show the oil rates and GOR plots obtained by history matching. It can be seen from the plots that the normalized oil rate matches well with the field rate through 100 days after which it starts to decline faster than the field value. The GOR in actual field data indicate a flattening trend, whereas, in the field data, the GOR starts increasing rapidly. Part of the reason for this difference is the rapid drop in oil rate in the model, whereas, the gas rate is matched reasonably well. Due to excellent dynamic continuity in the reservoir, it is possible that aquifer is connected over larger distance than indicated by 160 acre spacing. This will allow oil to be brought to the well from distances farther than 160 acre spacing. This is also consistent with the idea that the recovery factors in some wells exceed one indicating the recovery of hydrocarbons from a distance significantly farther away from the well bore. Our single well model did not account for such possibility. However, conceptually, it was able to 
reproduce the behavior of the reservoir. Table 32 shows parameter values of the reservoir model obtained by history matching.

Table 32. Parameter values from history match

\begin{tabular}{|c|c|}
\hline Parameter & Value \\
\hline Matrix Thickness (d1) & $30 \mathrm{ft}$ \\
\hline Fracture Thickness (d2) & $20 \mathrm{ft}$ \\
\hline Matrix Horizontal Permeability (kh1) & 0 \\
\hline Vertical Permeability (kv) & $20 \mathrm{md}$ \\
\hline Fracture Horizontal Permeability (kh2) & $20 \mathrm{md}$ \\
\hline Matrix Residual Oil Saturation (Sor1) & 0.3 \\
\hline Fracture Residual Oil Saturatio (Sor2) & 0 \\
\hline Matrix Residual Gas Saturation (Sgr1) & 0 \\
\hline Fracture Residual Gas Saturatio (Sgr2) & 0 \\
\hline Distance form Wellbore (D) & $636 \mathrm{ft}$ \\
\hline Connate Water Saturation (Swc) & 0.2 \\
\hline Water Relative Permeability & Linear \\
\hline Oil Relative Permeability & Linear \\
\hline Gas Relative Permeability & Linear \\
\hline \multicolumn{2}{|c}{} \\
\hline
\end{tabular}




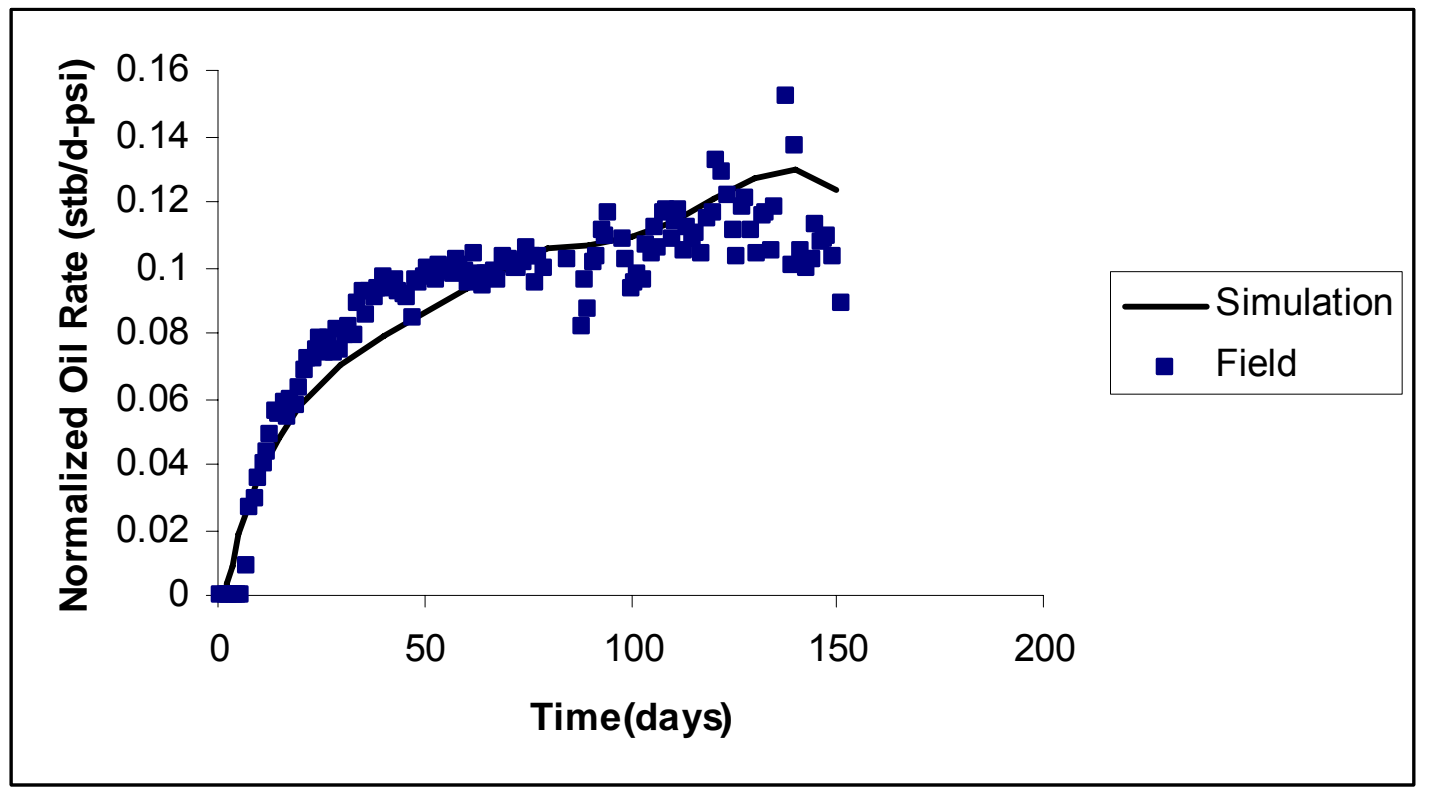

Figure 122: Oil rate match for Schwake 1-10

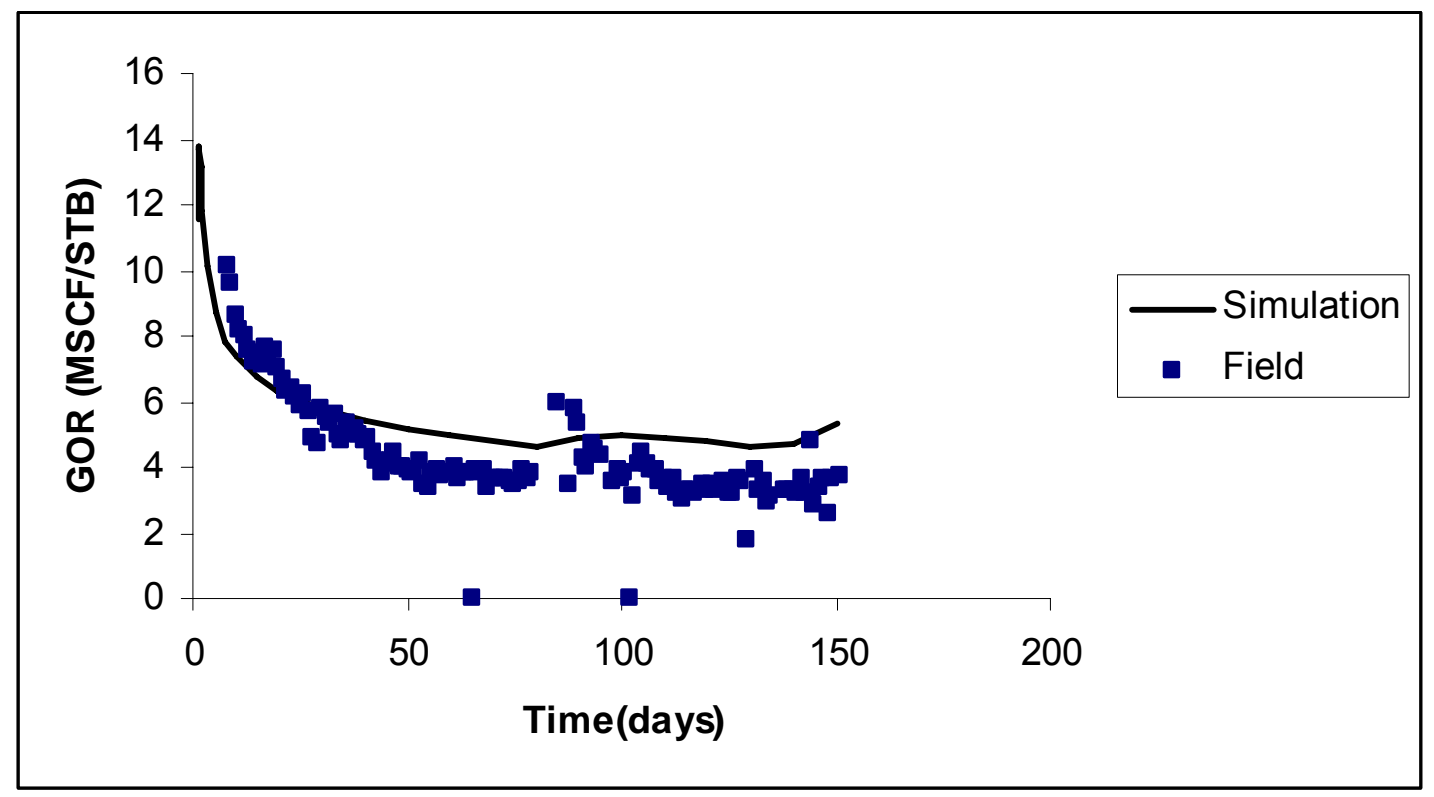

Figure 123: GOR match for Schwake 1-10 


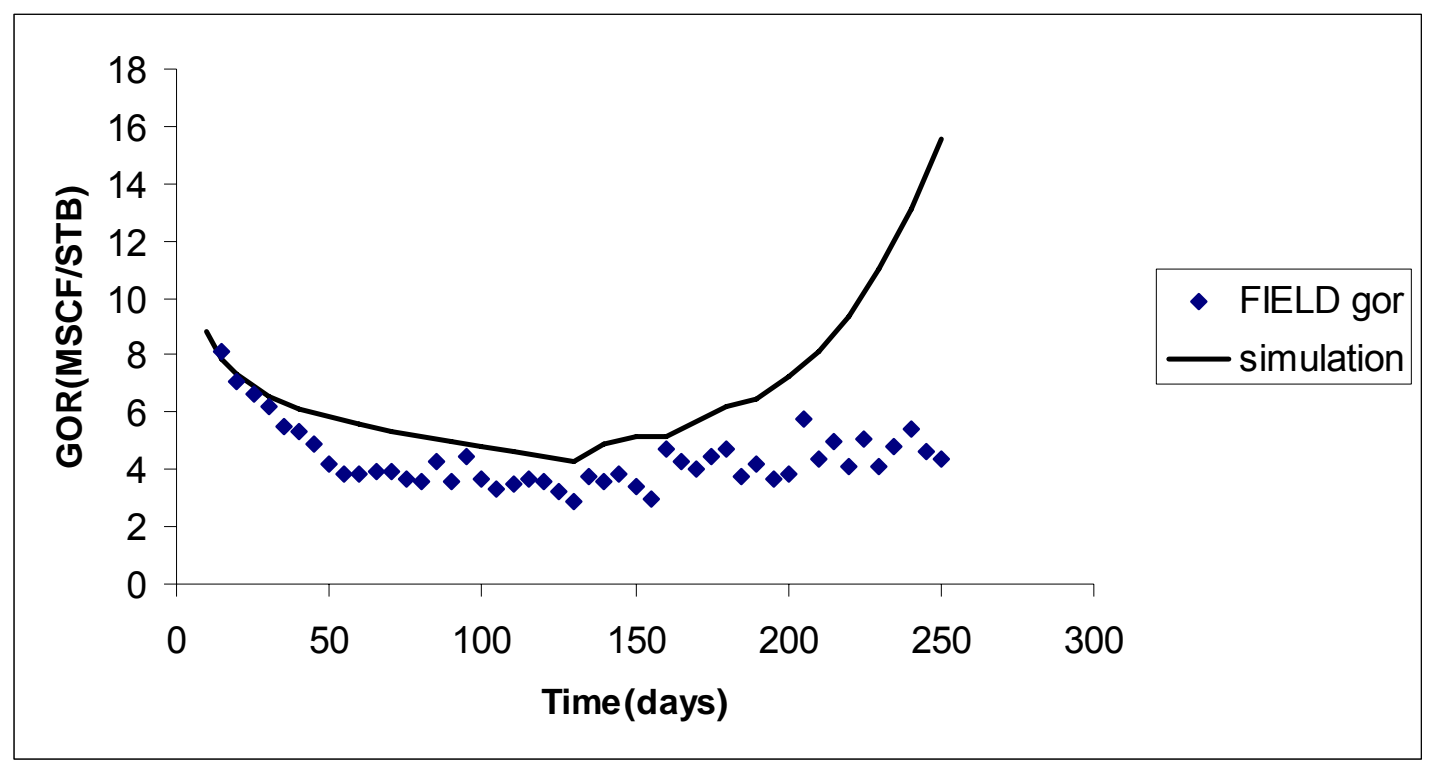

Figure 124: GOR match for Schwake (300 days)

Certain wells in the region of study exhibit an interesting behavior. These wells produce large quantities of water in early stages, followed by slow breakthrough of rich gas. Even after producing for several months, these wells never produce any oil, only rich gas. Since our hypothesis requires that the trapped hydrocarbons are represented by volatile oil, we wanted to examine the possibility of wells producing only gas. The model can reproduce the behavior of these wells by making small changes to its input parameters. The changes include reducing the proportionate depth of matrix layer to about $20 \%$ of the total formation depth (consistent with $\log$ data), increasing porosity in both layers to $10 \%$ (consistent with dolomite region in the reservoir) and introducing residual oil saturation in the high permeability layer. Figure 125 shows the production profile of such a well. It can be seen that the well produces only water and gas and no oil. In general the model is able reproduce the behavior of only gas production, although the reservoir initially contains volatile oil. 


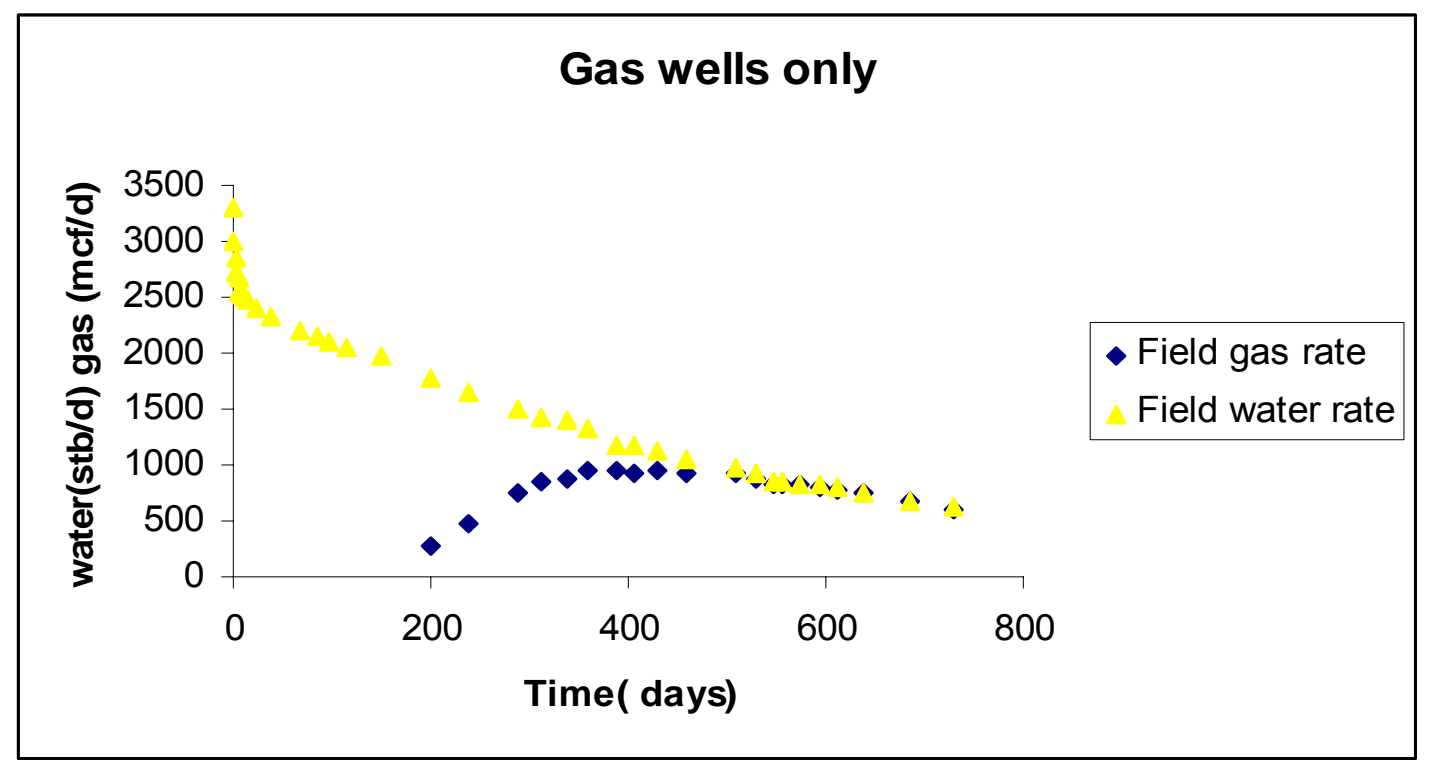

Figure 125: Production profile of gas wells

To summarize these simulation results, the Hunton reservoir exhibits several unique characteristics. Using compositional simulator and geologically consistent, reservoir model, we were able to re-produce most of the characteristics of the well production. These characteristics include: increasing oil/water ratio, decreasing GOR followed by increase, delayed production of oil and gas, spike in GOR after shut-in, and only gas production in some wells from reservoir containing volatile oil.

Secondary Recovery Mechanism. The West Carney field is declining very rapidly. Part of the reason for such a rapid decline is relatively low compressibility of water, and limited aquifer. As water is produced, the reservoir pressure declines. Since the primary mechanism of oil and gas production is solution gas drive, as the reservoir pressure declines, the ability of expanded gas to carry oil, water and gas also decreases rapidly. The overall recovery process is even less efficient than a typical solution gas drive since the expanded gas also has to produce formation water. The average decline in many wells is close to $50 \%$ indicating that the wells will become uneconomical to produce within three to five years. 
We cannot use water flooding to increase the production since water will only increase the pressure in the reservoir resulting in further reduction in oil and gas production. Conventional $\mathrm{CO}_{2}$ flooding is also not feasible since injected $\mathrm{CO}_{2}$ will move through the high permeability system resulting in quick breakthrough. In this section, we evaluate the feasibility of huff-n-puff methods. These include injection of gases including carbon-dioxide $\left(\mathrm{CO}_{2}\right)$, flue gas (88\% Nitrogen, $\left.12 \% \mathrm{CO}_{2}\right)$ and methane. The aim of an enhanced recovery process is to revitalize the depleted wells and produce maximum recoverable oil. The important factor in determining the feasibility of the process is the economics of the recovery project. Although this study does not deal with the economics of secondary recovery process, it provides a vital insight into the engineering aspects of the recovery process.

Enhanced recovery methods are used to produce the residual oil in the reservoir. Methane, flue gas and $\mathrm{CO}_{2}$ injection is studied and the results are discussed. The procedure for enhanced recovery is simulated (using Eclipse 300) in following steps:

- $\quad$ Primary Depletion: Primary depletion is carried out for a period of two years during which the reservoir pressure is depleted to a low value (500 psi). The composition of reservoir fluid changes with depletion and heavier components remain in the reservoir during the end of the primary depletion process.

- $\quad$ Calculation of Minimum Miscibility Pressure (MMP): Once primary depletion is carried out, the composition of the remaining reservoir fluid is used to determine the MMP for the injection gas. The MMP test is carried out using the GeoQuest PVTI module.

- Gas Injection: Gas is injected in the reservoir at the constrained bottom hole pressure until the reservoir attains the MMP. The injection period depends on injection pressure, MMP and the nature of injection gas.

- $\quad$ Shut in Period: After the gas has been injected, the reservoir is shut in for a 30day period, which allows the reservoir to re-pressurize and achieve MMP throughout the reservoir. This is also the period during which the vaporizing-gas drive is achieved.

- $\quad$ Production Period: The well is reopened and produced for a period that is economical or until a certain reservoir pressure is reached. For continuing cycles of enhanced recovery the production period and depleted reservoir pressure may need to be optimized. 
$\mathrm{CO}_{2}$ Injection Study. A $\mathrm{CO}_{2}$ injection study was performed to estimate the oil and gas production from the secondary process. Figure 126 shows the production cycle. It can be seen from the plot that the maximum oil production rate decreases with each cycle. The reservoir was depleted for a period of 2 years. Depleted reservoir pressure was about 520 psi. The MMP test was conducted using PVTI and the MMP was calculated to be 1,490 psi. $\mathrm{CO}_{2}$ was injected at an injection pressure of 2,500 psi for 70 days until the reservoir pressure was equal to the MMP. The well was put back on production after a 30-day shut in period. The well was produced for 400 days during which a maximum oil rate of $70 \mathrm{STB} / \mathrm{D}$ was recorded. A second $\mathrm{CO}_{2}$ injection cycle was carried out. The MMP was calculated to be 1,295 psi. $\mathrm{CO}_{2}$ was injected at a pressure of 2,500 psi for 60 days until the reservoir reached the MMP. The well was produced for 400 days after a 30-day shut in period. Maximum oil production during this cycle was 15 STB/D. A third injection cycle was performed but it showed very low oil production rates (less than 5 $\mathrm{STB} / \mathrm{D}$ ) and is not discussed here.

The gas produced consisted of $73 \% \mathrm{CO}_{2}$ indicating that it was not saleable without separation. Although an economic analysis of $\mathrm{CO}_{2}$ injection was not performed in this study, it can still be concluded based on these results that $\mathrm{CO}_{2}$ injection in its current state may not a viable unless it can be secured at low price (about \$0.5/MSCF). 


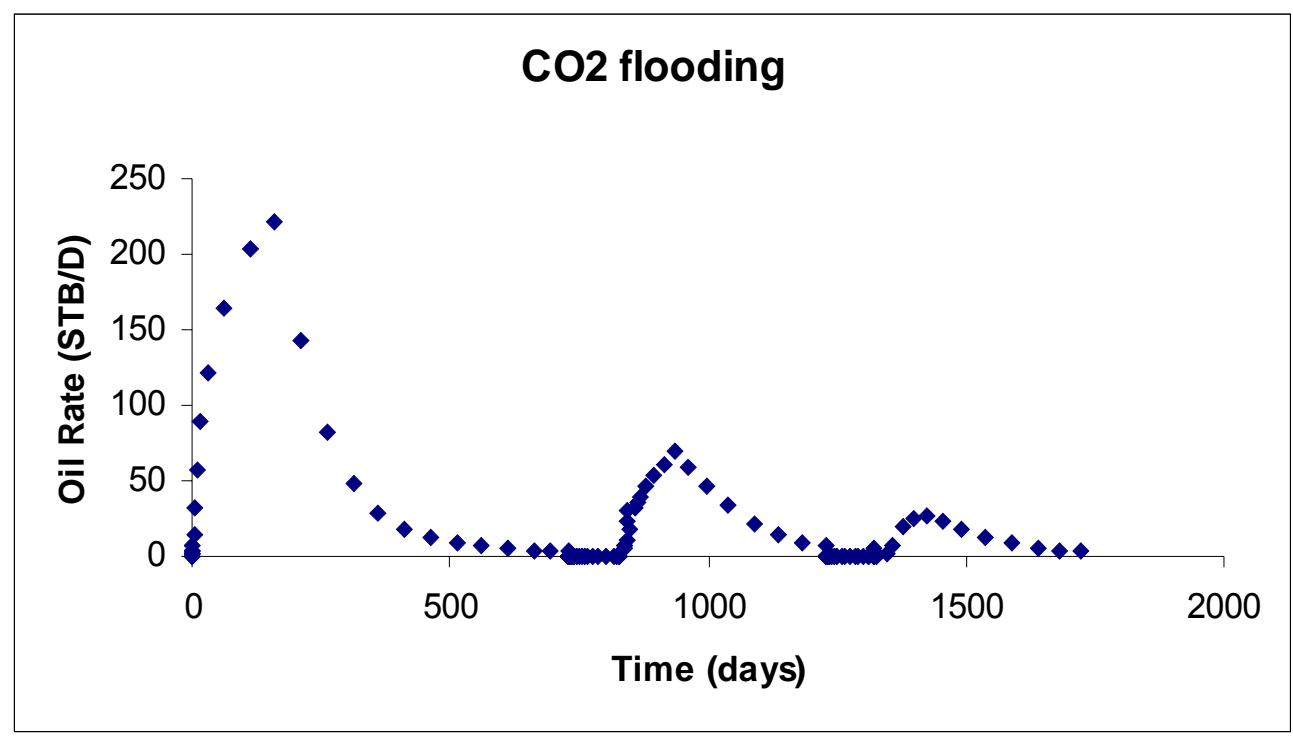

Figure 126: $\mathrm{CO}_{2}$ injection study

Flue Gas Injection Study. Apart from $\mathrm{CO}_{2}$, flue gas and methane injection studies were also carried out. Flue gas ( $\left.88 \% \mathrm{~N} 2,12 \% \mathrm{CO}_{2}\right)$ has a higher MMP than $\mathrm{CO}_{2}$. This was confirmed by simulating a MMP test for the depleted reservoir fluid composition. The MMP was obtained as 2,152 psi, which is considerably higher than the MMP for $\mathrm{CO}_{2}$. Flue gas was injected at a pressure of 2,500 psi for 115 days. Production was resumed from the well after a 30-day shut in period. Oil production was very low when compared to $\mathrm{CO}_{2}$ injection. The produced gas consisted of $63 \%$ nitrogen and $16 \% \mathrm{CO}_{2}$. Figure 127 shows the plot of flue gas injection study. As can be seen from the plot, only one injection cycle is performed and the oil rates are very low (5 STB/D). Further injection cycles were not performed, as the oil rate in the first cycle itself was very low. 


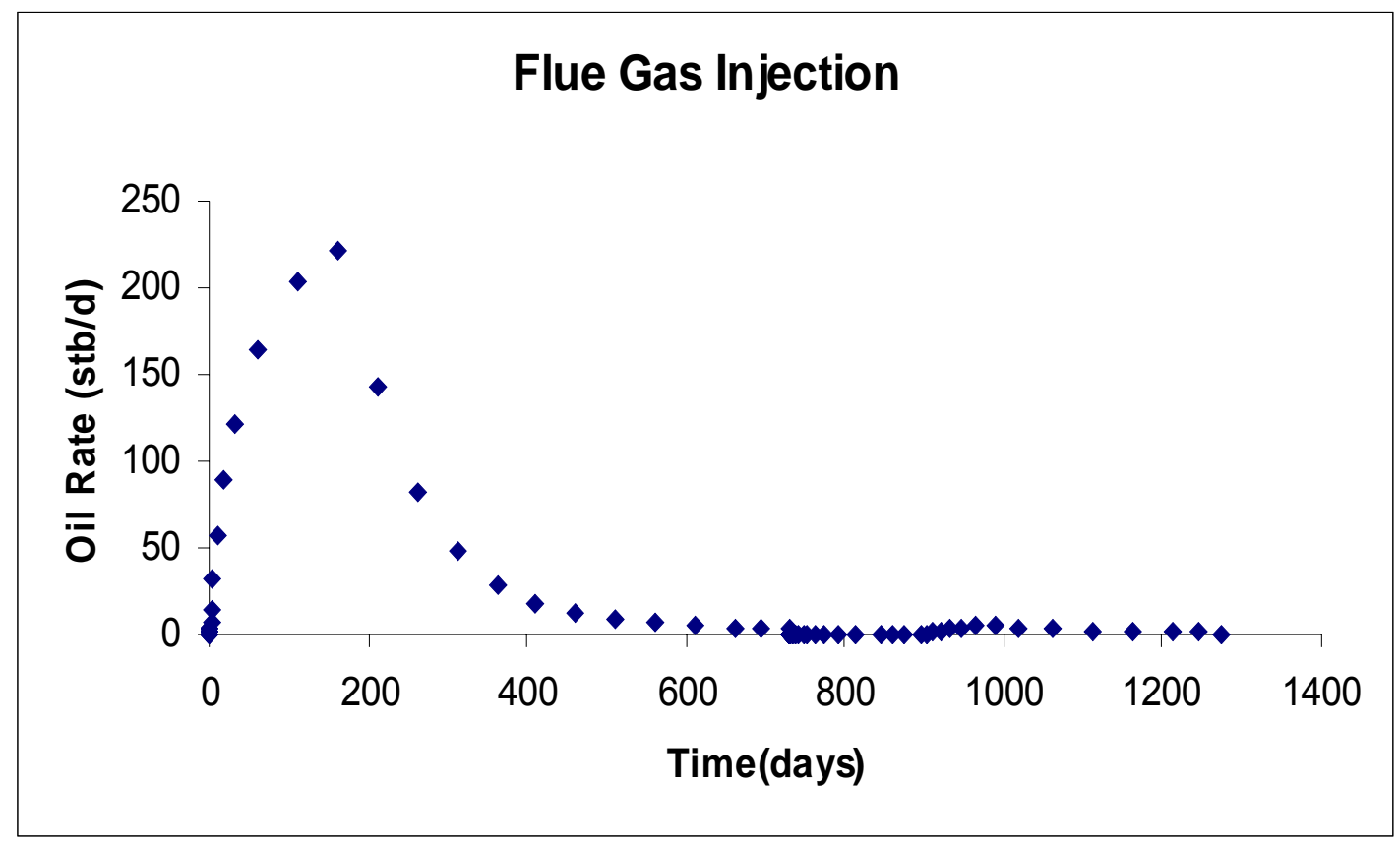

Figure 127: Flue gas injection study

Methane Injection Study. A methane injection study was carried to see if higher oil production could be obtained as compared to flue gas. The MMP for methane was obtained at 2,126 psi, same as that for flue gas. Methane was injected at a pressure of 2,500 psi for 80 days until the reservoir attained the MMP. The well was shut in for 30 days and put on production for 400 days. Production data indicated very low oil rates. Due to low oil recoveries in the first injection cycle, subsequent recovery cycles were not performed. Figure 128 shows methane injection study results. 


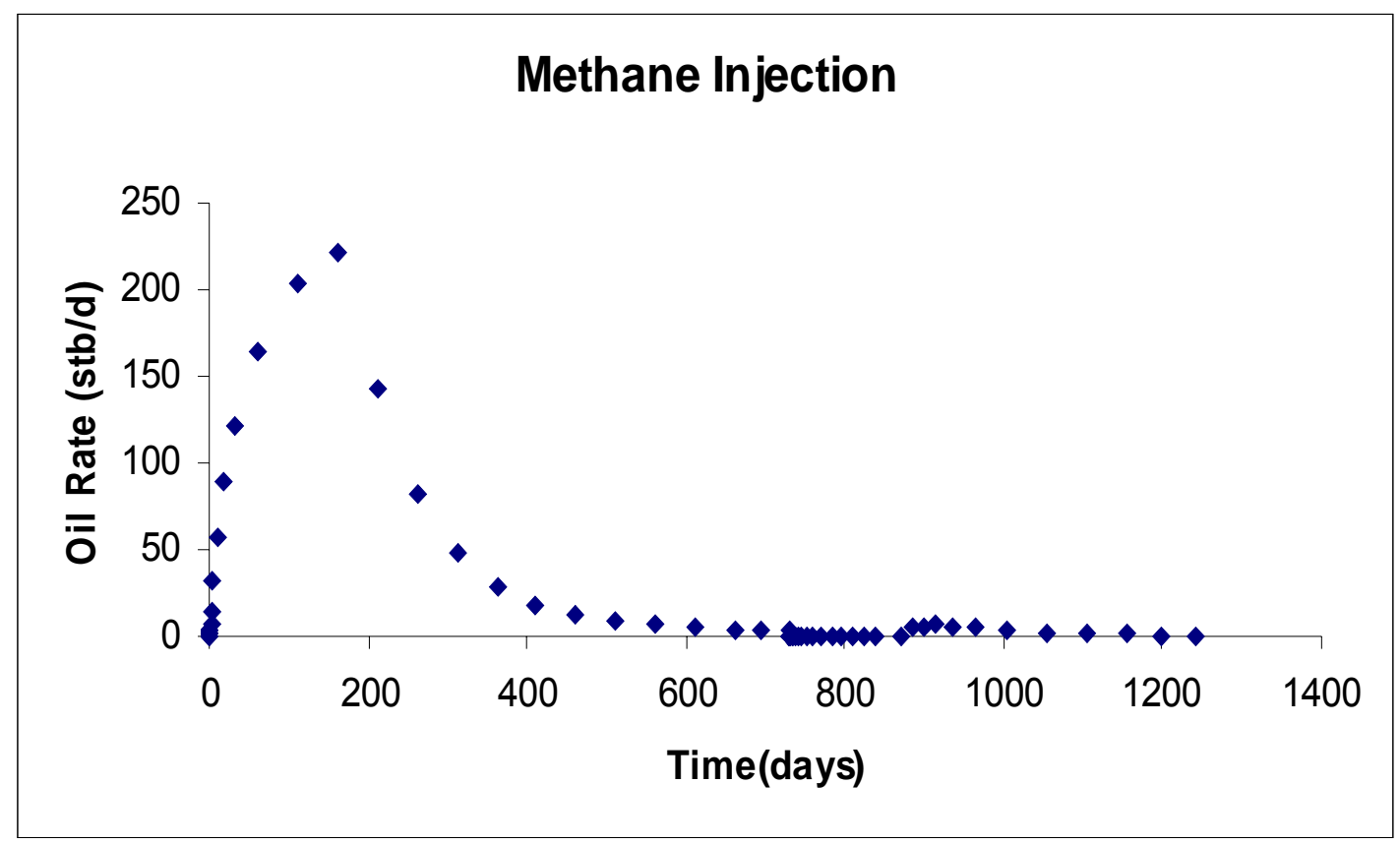

Figure 128: Methane injection study

To summarize the effect of enhanced recovery processes on the oil recovery in the Hunton field, we observed that only $\mathrm{CO}_{2}$ injection can increase oil recovery, although the produced gas contained $73 \% \mathrm{CO}_{2}$, which makes the recovery process economically difficult to justify. Enhanced recovery using $\mathrm{CO}_{2}$ is only possible if the price of $\mathrm{CO}_{2}$ is reasonable. Methane and flue gases do not show good oil recovery and, hence, are not suitable as enhanced recovery agents for this reservoir. 


\section{Economic Evaluation}

The economic evaluation is divided into two sections. The first part discusses the feasibility of drilling horizontal versus vertical wells in the field. The second part discusses the feasibility of using a different completion technique to improve the production from either vertical or horizontal wells.

\section{Vertical versus Horizontal Well}

The early development of the Hunton reservoir was mostly accomplished through vertical wells. However, in the last three to four years, new wells drilled are mostly horizontal wells. It is believed that horizontal wells have better probability of success and better productivity. Horizontal wells also have an added advantage of bigger spacing as compared to vertical wells, but horizontal wells cost more to drill. Thus, the efficacy of horizontal wells as against the vertical wells was investigated.

Economic Assumptions. The assumptions made in this study are as follows:

1) This study is a pre-tax analysis, so it does not involve any tax implications.

2) For the predictions of the well's revenues, income from the sale of oil was estimated using an oil price of $\$ 24.50$ for the first year, $\$ 24.03$ for the second year, and then escalated at a rate of $4 \%$ per year to a constant value of $\$ 30.00$.

3) Income from the sale of gas was estimated using a gas price of $\$ 5.35 / \mathrm{Mcf}$ for the first year, $\$ 4.73$ for the second year, and then held constant at $\$ 4.00 /$ Mcf.

4) For the years in which values of gross revenues and operating expenses were available for a few months, a pro-rated value was assumed for the remaining months and a summation of these pro-rated values was considered at the end of the year.

5) The after completion costs (ACP) and before completion costs (BCP) are combined with equipment costs to determine the total drilling costs. It was assumed that these costs were expended in year 0 .

6) The Central West and the Central East regions have been grouped under one central category. 
7) We assume an average Net Revenue Interest of $80 \%$ and severance tax of $7 \%$.

8) If the actual drilling and completion costs were unavailable, we assume a drilling cost $\$ 1,100,000$ for a horizontal well and $\$ 650,000$ for vertical well. For Marjo operated wells, we had the actual costs available. Using those numbers, we calculated reasonable average values for other wells.

9) If operating expenses are not available, they are assumed at the rate of average yearly expenses for wells from the same region.

10) For the years in which production data are not available, we use decline curve analysis to predict the future performance.

11) We use cumulative operation and completion expenses for group of wells, if only cumulative production data is available. That is, if we only have leasehold production, we use cumulative expenses from all the wells operating in that region.

East Carney Region. The number of wells studied in the East Carney region is twentyfive. Ten out of these twenty-five wells are horizontal. Table 33 gives the names of the wells studied in the east Carney region. The horizontal wells are denoted in red. 
Table 33. Wells studied in East Carney region.

\begin{tabular}{|l|}
\hline \multicolumn{1}{|c|}{ Well Name } \\
\hline Alex \#1-23 \\
\hline Bailey \#1-6 \\
\hline Bailey \#2-6 \\
\hline Betow \#1-24H \\
\hline Chachi \#1-25H \\
\hline Carney \#2 \\
\hline Carney \#3 \\
\hline Carney Townsite \#1 \\
\hline Cedol \#1-H \\
\hline Denney \#1-31 \\
\hline Dirks \#1 \\
\hline Dirks \#3 \\
\hline Geneva \#1-32 \\
\hline Hadaway \#1 \\
\hline Hadaway \#2-H \\
\hline Harrison \#2 \\
\hline Howerton \#1-30 \\
\hline Mary \#1-30H \\
\hline Patsy \#1-6 \\
\hline Patsy \#2-6 \\
\hline Patsy \#3-6 \\
\hline Potter \#1-19H \\
\hline Shull \#1 \\
\hline Wilson \#1-6 \\
\hline Wilson \#1 \\
\hline
\end{tabular}

It can be seen from figure 129 that the wells in the East Carney region are much better as compared to the West and the Central regions. 


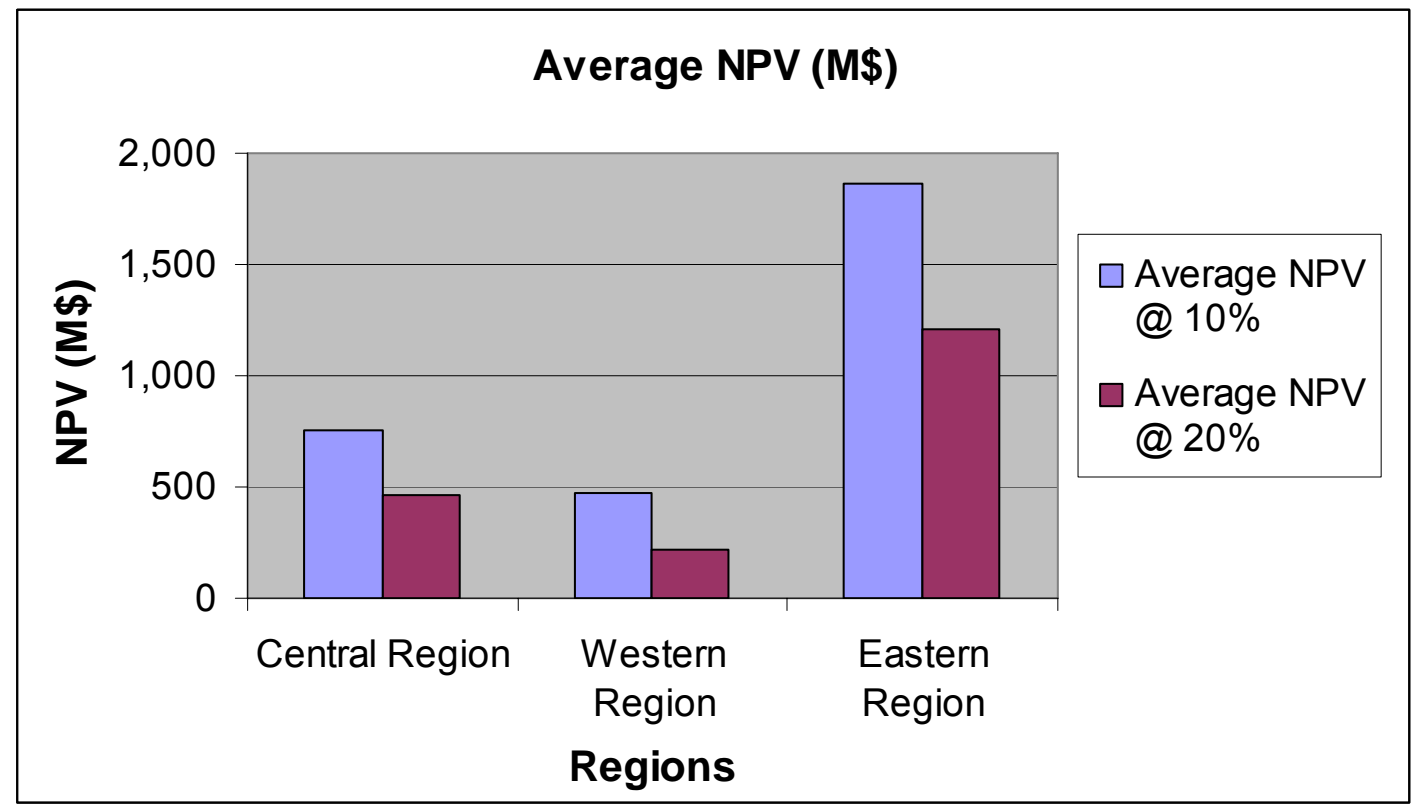

Figure 129: Average NPV for vertical wells in East Carney

The average net present value (NPV) of the vertical wells in the East region, at an annual rate of return of $10 \%$ is $\$ 2,340,921$, whereas the average NPV at a $20 \%$ annual rate of return is $\$ 1,589,434$.

No vertical well in the East Region is proved to be uneconomical; whereas, five out of ten horizontal wells are uneconomical. This makes the probability of success for horizontal wells only $50 \%$. The average NPV of the horizontal wells at an annual rate of return of $10 \%$ is $\$ 868,386$, whereas the value at $20 \%$ is $\$ 416,391$. It can be seen from figure 130 that the vertical wells outperform the horizontal wells in the East region. 


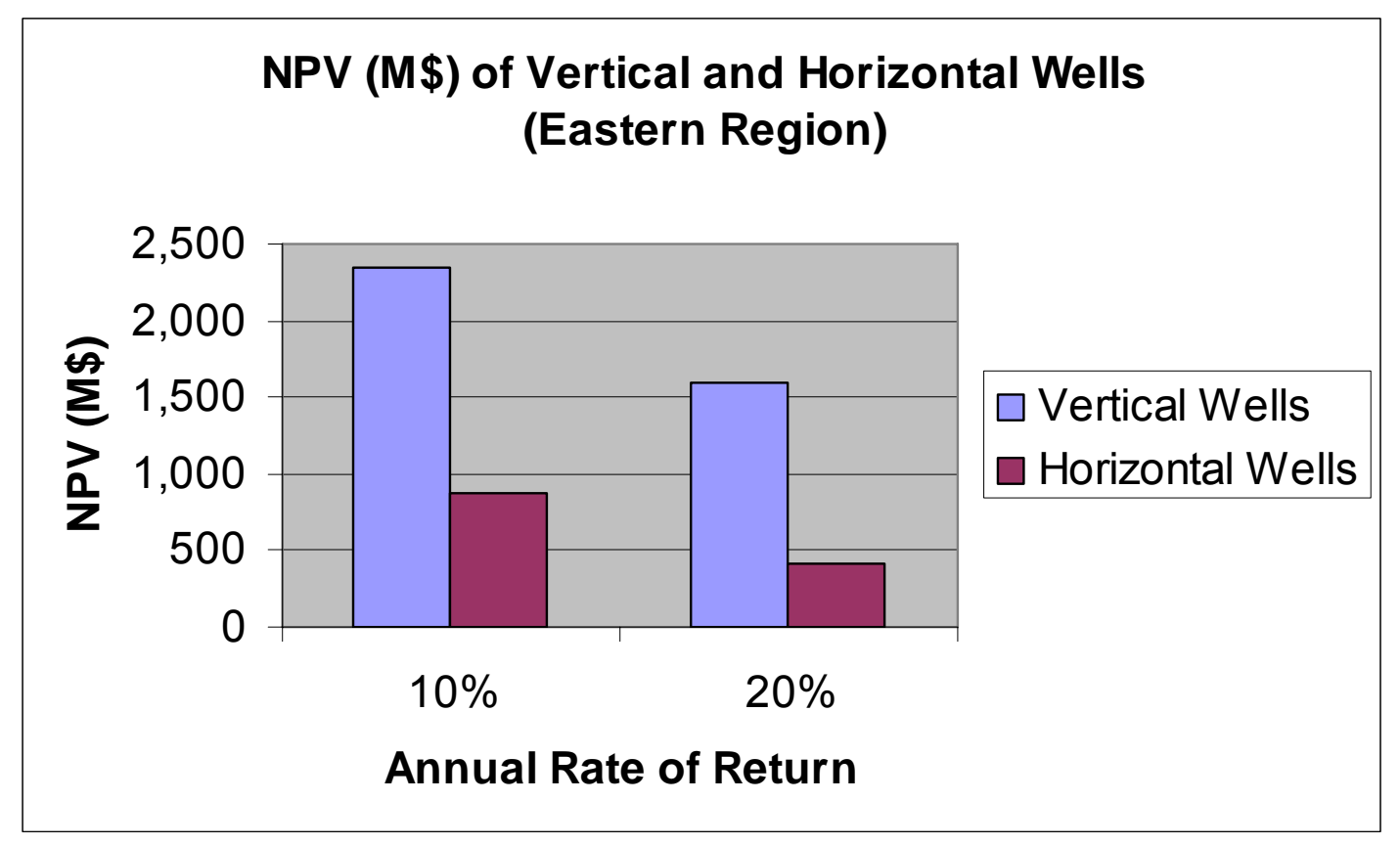

Figure 130: Average NPV (M\$) for Eastern Carney region

The internal rate of return (IRR) for the vertical wells in the East Carney region is 91.46\%, confirming that the vertical wells are performing efficiently. In contrast to this high return on vertical wells, the rate of return on horizontal wells is computed as $33.79 \%$, indicating that the performance is not as good as that of vertical wells. What is also surprising is that the reserves recovered from vertical wells exceed the reserves recovered by drilling horizontal wells. Part of the reason for this surprising behavior is the relatively late entry of horizontal wells compared to vertical wells. It is possible that vertical wells drained portion of the reserves from the regions where horizontal wells were drilled. Moreover, the difference in the number of studied horizontal and vertical wells can also impact on recovered resources.

Central Carney Region. The number of wells studied in this region is twenty-seven. Eight out of these twenty-seven wells are horizontal. Table 34 gives the names of the wells in the Central Carney region. The horizontal wells are denoted in red. 
Table 34: Wells studied in Central Carney region

\begin{tabular}{|l|}
\hline \multicolumn{1}{|c|}{ Well Name } \\
\hline Ables \#1-34 \\
\hline Chiaf \#1 \\
\hline Chiaf \#2 \\
\hline Boone \#1-4 \\
\hline Christie \#1-15 \\
\hline Danny \#1-34 \\
\hline Danny \#2-34 \\
\hline Doctor \#1 \\
\hline Garrett \#1-11 \\
\hline Gilmore \#1 \\
\hline Gilmore \#2 \\
\hline Henry \#1-3 \\
\hline Joe Givens \#1-15 \\
\hline Kathryn \#2-14 \\
\hline Mintoria milas \#1 \\
\hline McBride North \#1-10 \\
\hline McBride South \#1-10 \\
\hline Parkview \#1-3 \\
\hline Points \#1-13 \\
\hline Rollins \#1-13 \\
\hline Sandra \#1 \\
\hline Schwake \#1-10 \\
\hline Toles \#1-10 \\
\hline Townsend \#1-13 \\
\hline Wilkerson \#1-3 \\
\hline Wilkerson \#2-3 \\
\hline Williams \#1-3 \\
\hline
\end{tabular}


The average NPV of the vertical wells in the Central region at an annual rate of return of $10 \%$ is $\$ 755,675$; whereas, the average $\mathrm{NPV}$ at a $20 \%$ annual rate of return is $\$ 465,059$.

Four out of the nineteen vertical wells have a negative NPV, making $21 \%$ of the vertical wells uneconomical. Out of the eight horizontal wells, three wells are uneconomical, making $38 \%$ of the horizontal wells uneconomical. The average NPV of the horizontal wells at an annual rate of return of $10 \%$ is $\$ 349,426$ whereas the value at $20 \%$ is $\$ 14,635$. It can be seen from figure 131 that the vertical wells outperform the horizontal wells in the Central region.

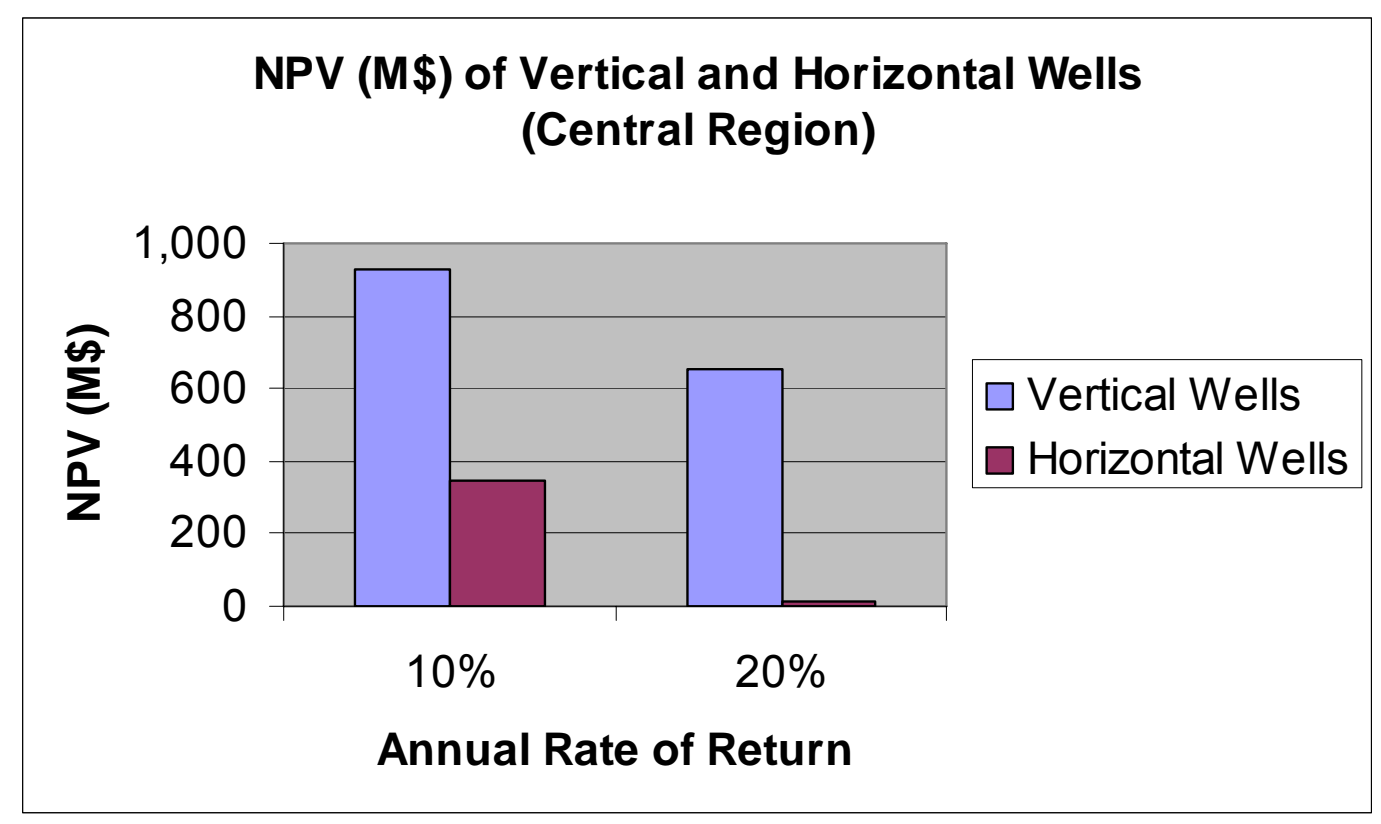

Figure 131: Average NPV (M\$) for Central Carney region

Similar to the East region, the IRR for vertical wells is greater than that of horizontal wells. In addition, the reserves drained by vertical wells are also greater than horizontal wells.

West Carney Region. The number of wells studied in this region is twenty-six. Out of these twenty-six wells studied, thirteen are horizontal wells. Table 35 gives the names of the wells studied in the Western Carney region. 


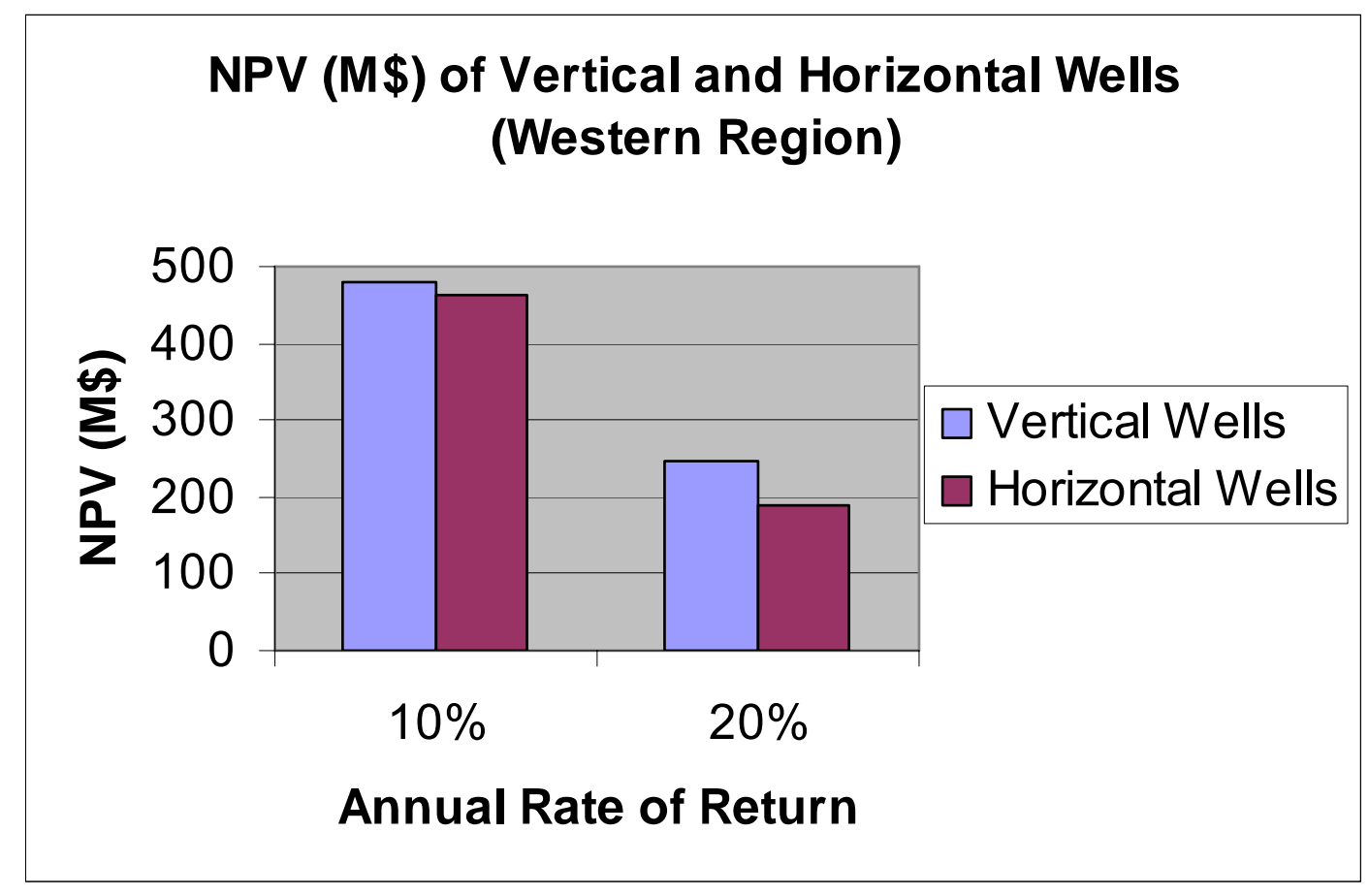

Figure 132: Average NPV (M\$) for West Carney region

Among the vertical wells, it was observed that almost $46 \%$ (i.e., six of the wells) are uneconomical. The average NPV at an annual rate of return of $10 \%$ is computed as $\$ 481,170$, with the value dropping down by $49 \%$ to $\$ 246,128$ at $20 \%$.

If compared to the Central Carney region, it can be said that the horizontal wells in the West region are performing slightly better in terms of probability of success. Only $31 \%$ of the wells studied (i.e., only 4 out of 13 wells) are uneconomical. The average NPV for the horizontal wells, at an annual interest rate of $10 \%$, is calculated as $\$ 464,219$; whereas, at an interest rate of $20 \%$, it is calculated as $\$ 187,611$ respectively. Figure 53 shows the NPV of vertical as well as horizontal wells at an annual rate of return of $10 \%$, as well as $20 \%$. 
Table 35. Wells studied in Western Carney region

\begin{tabular}{|l|}
\hline \multicolumn{1}{|c|}{ Well Name } \\
\hline Adams \#1 \\
\hline Blackstuff \#1 \\
\hline Cal \#1-11 \\
\hline DMS \#1-H \\
\hline Griffin \#1 \\
\hline N. Habben \#1 \\
\hline N. Habben \#2 \\
\hline S. Habben Unit \#1 \\
\hline S. Habben Unit \#2 \\
\hline Iconium Townsite \#1-H \\
\hline Jenkins \#1-10 \\
\hline Jennifer \#1-10 \\
\hline Jordan \#1-8 \\
\hline Kightlinger \\
\hline Mark Houser \#1-11A \\
\hline Meridian State \#1 \\
\hline Mr. B \\
\hline Reardon \#1-8H \\
\hline Robert \#1-10 HE \\
\hline Rosemary \#1-10 \\
\hline Roxana \#1-H \\
\hline Smith Co \#1 \\
\hline Stevenson \#1-14 \\
\hline Susie \#1 \\
\hline
\end{tabular}


In contrast to Central Carney region, the rate of return observed on vertical wells is not significantly different from horizontal wells: $33.42 \%$ for vertical wells, compared to $33.20 \%$ for horizontal wells. Based on economic evaluation parameters, the West region is the worst of the three regions. This is consistent with oil saturations observed in each of the three regions. It is also interesting to note that with lower oil saturation, horizontal wells are economically performing closer to vertical wells.

Effect of Length. The respective lengths of the horizontal wells were considered and an attempt was made to check the correlation between the length of a well and the NPV. This should indirectly check whether the performance of a well is correlated to its length or not.

Table 36 gives the names of the horizontal wells, and its respective lengths in feet. 
Table 36: Lengths of horizontal wells

\begin{tabular}{|l|c|}
\hline \multicolumn{1}{|c|}{ Horizontal Wells } & Length (Ft.) \\
\hline Blackstuff \#1 & 1126 \\
\hline Cedol \#1-H & 1979 \\
\hline Chiaf \#2 & 1734 \\
\hline Gilmore \#1 & 153 \\
\hline Gilmore \#2 & 1235 \\
\hline Iconium Townsite \#1-H & 3727 \\
\hline Jennifer \#1-10 & 2517 \\
\hline Mark Houser \#1-11A & 680 \\
\hline Mintoria Milas \#1 & 2200 \\
\hline Mr. B & 1728 \\
\hline Rollins \#1-13 & 1553 \\
\hline Sandra \#1 & 108 \\
\hline Shull \#1 & 1521 \\
\hline Smith Co \#1 & 2172 \\
\hline Wilkerson \#2-3 & 3432 \\
\hline Wilson \#1 & \\
\hline
\end{tabular}

An attempt to correlate the NPV with the lengths of the wells showed that no correlation exists between them. Figure 133 confirms the result. 


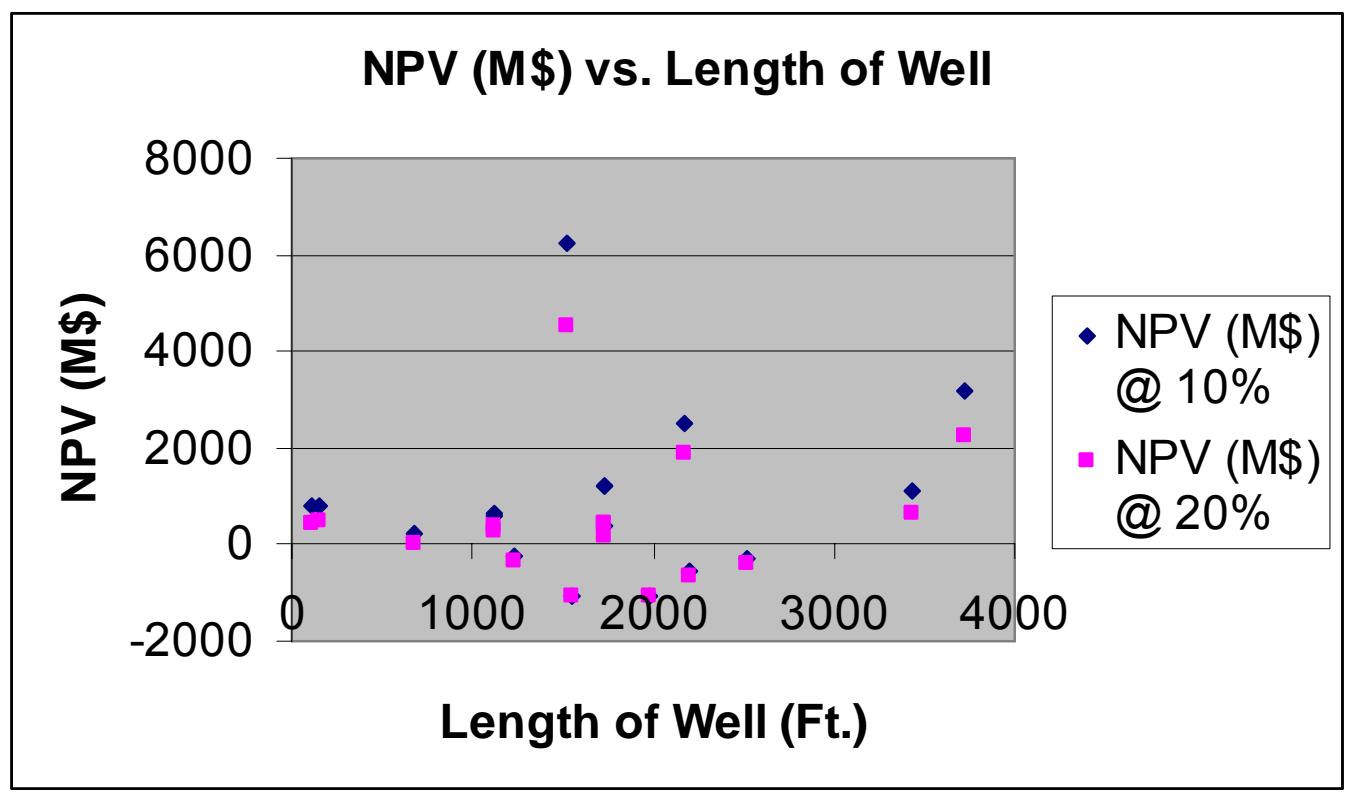

Figure 133: NPV versus length of well

Estimated Reserves Comparisons. The estimated reserves for each well are assumed to be closely related to gross revenue from each well. We computed the gross revenue from each of the vertical and horizontal wells till the point of abandonment. A comparison of these revenues is given in figure 134.

It can be seen from figure 134 that for the Central and West regions, revenues generated from horizontal wells are not substantially less than those generated by the vertical wells. In contrast, in the East Region, vertical wells significantly outperform horizontal wells in terms of recovery of reserves. 


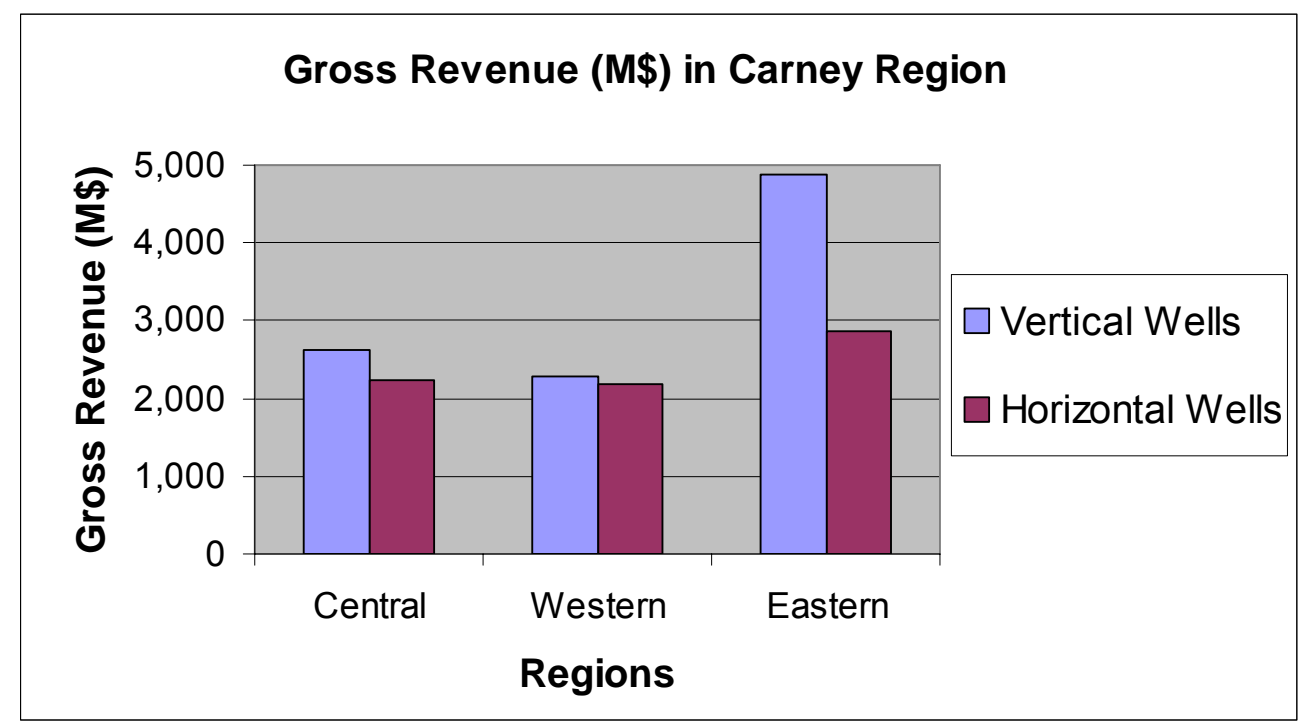

Figure 134: Gross revenue comparisons

To summarize the findings of this work, we have not seen the evidence of better performance by drilling horizontal wells compared to vertical wells. It is argued that by drilling horizontal wells, there is a better probability of connecting to high permeability streaks. However, the data indicates that vertical wells can be also prolific if they are connected into high permeability streaks. Further, the probability of success for vertical wells is not significantly different than horizontal wells.

\section{In-Situ Disposal of Produced Water}

The conventional completion technique for de-watering of Hunton involves co-producing both gas and water, and disposing water in a disposal well after a surface separation. This requires installation of large submersible pump at the beginning. As the gas-water ratio increases over time and water production declines, this submersible pump may be replaced by a rod pump to lift the liquid. This procedure requires an extra expense of disposal well. Further, because of presence of water in the tubing, back pressure on the formation is exerted; this can result in lower production of gas and water. In addition, if we cannot reduce the back pressure on the formation, we will not be able to reduce the abandonment pressure and, hence, this will affect the ultimate recovery of the gas. 
As an alternative to this conventional approach, we investigated the possibility of installing a downhole gas/water separation (DGWS) system. The idea of the system is separation of water from gas by gravity and then pumping the water produced to the disposal zone below to the production zone by using the electrical submersible pump. The gas is produced to the surface through the casing and tubing annulus. The service company which manufactures this equipment is Baker Hughes Centrilift. The schematic of the method is shown in figure 135.

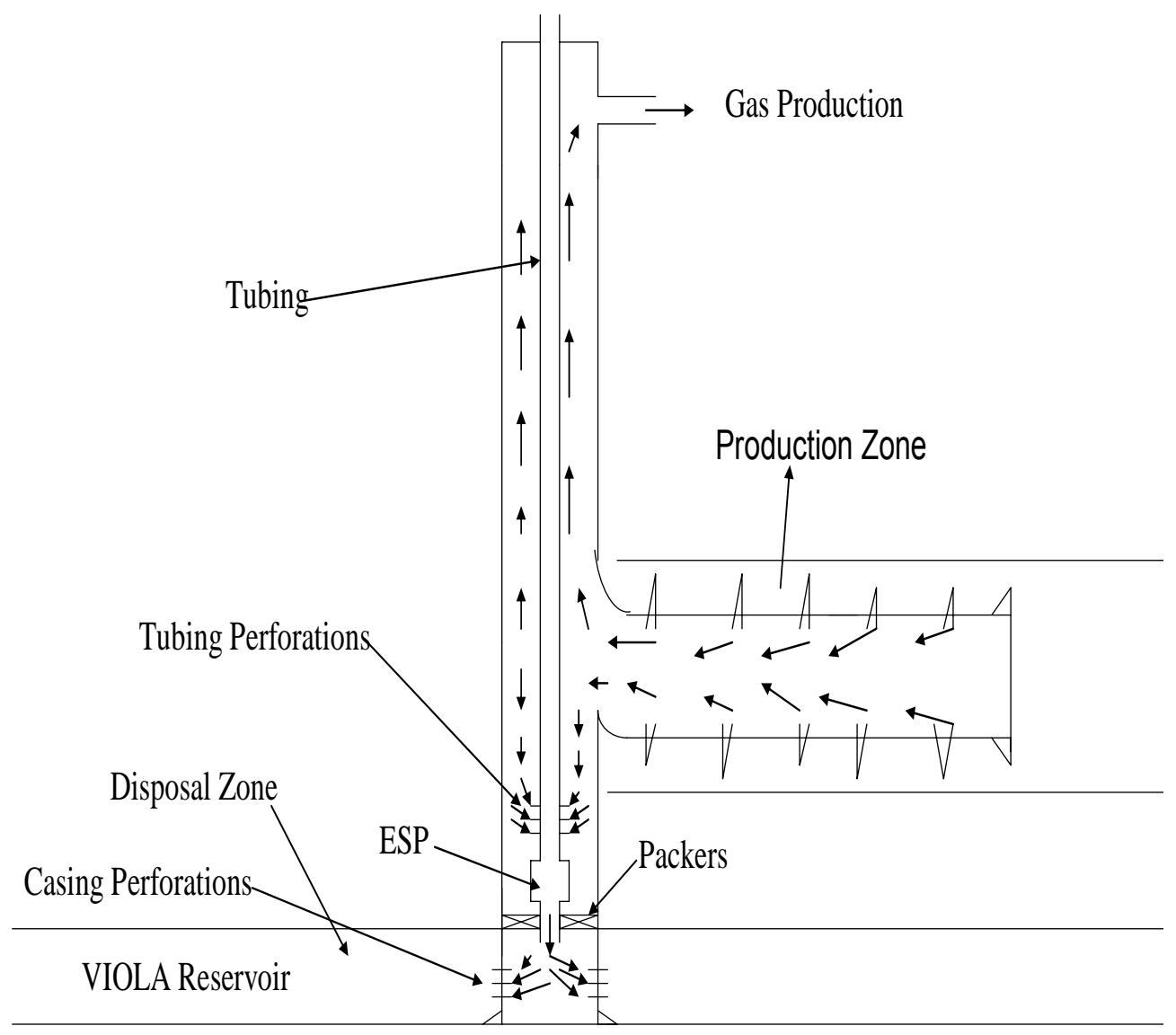

Figure 135: DGWS system

As shown in figure 135, water and gas is co-produced from the Hunton formation. Due to gravity, gas and water are separated in annular space, and gas moves to the top and water is injected in Viola formation below Hunton formation through the use of submersible pump. The advantage of this process is that no disposal well is needed since water is disposed in-situ. 
Secondly, because water is separated at the bottom hole, the only back pressure on the formation is the gas column. This is lot smaller than the back pressure created by gas and water mixture column.

The total measured depth of the horizontal well is approximately to 8,500 ft with TVD equal to 5,000ft. This is a shallow well with kick off point approximately at 3,200ft. The disposal zone is located down to $7,000 \mathrm{ft}, 2,000 \mathrm{ft}$ below to the TVD of the original well as illustrated in figure 136. Sidetracking operation is needed for drilling and completion of the additional section down to Viola reservoir at the depth of 7,000ft.

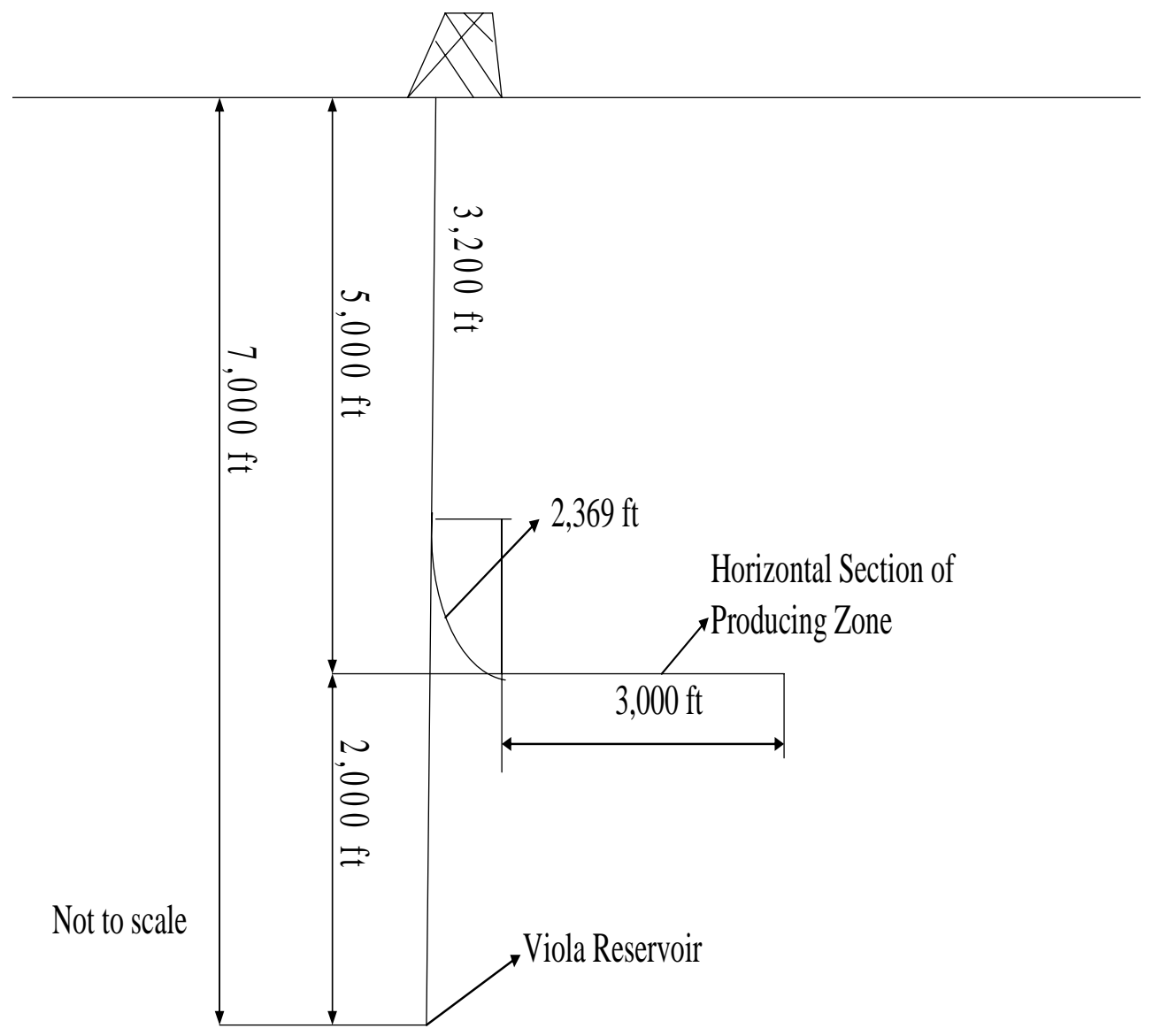

Figure 136: Dimensions of overall configuration 
The ESP is set below the production zone. The gas separates from water by gravity and then an ESP is used to pump water produced down to the Viola reservoir (disposal zone). The gas is produced to the surface through the casing and tubing annulus while water enters in the tubing through the perforated tubing region and is then pumped down by the ESP.

The ESP is installed in an unconventional manner. Two options can be used in installing an ESP:

1) Run an electric submersible pump (ESP) backward

2) Turn an electric submersible pump (ESP) upside-down

The second option is the preferred option. The ESP is installed with pump below the motor rather than the motor on bottom as conventional design system. Figure 137 illustrates the complete DGWS with inverted ESP. 


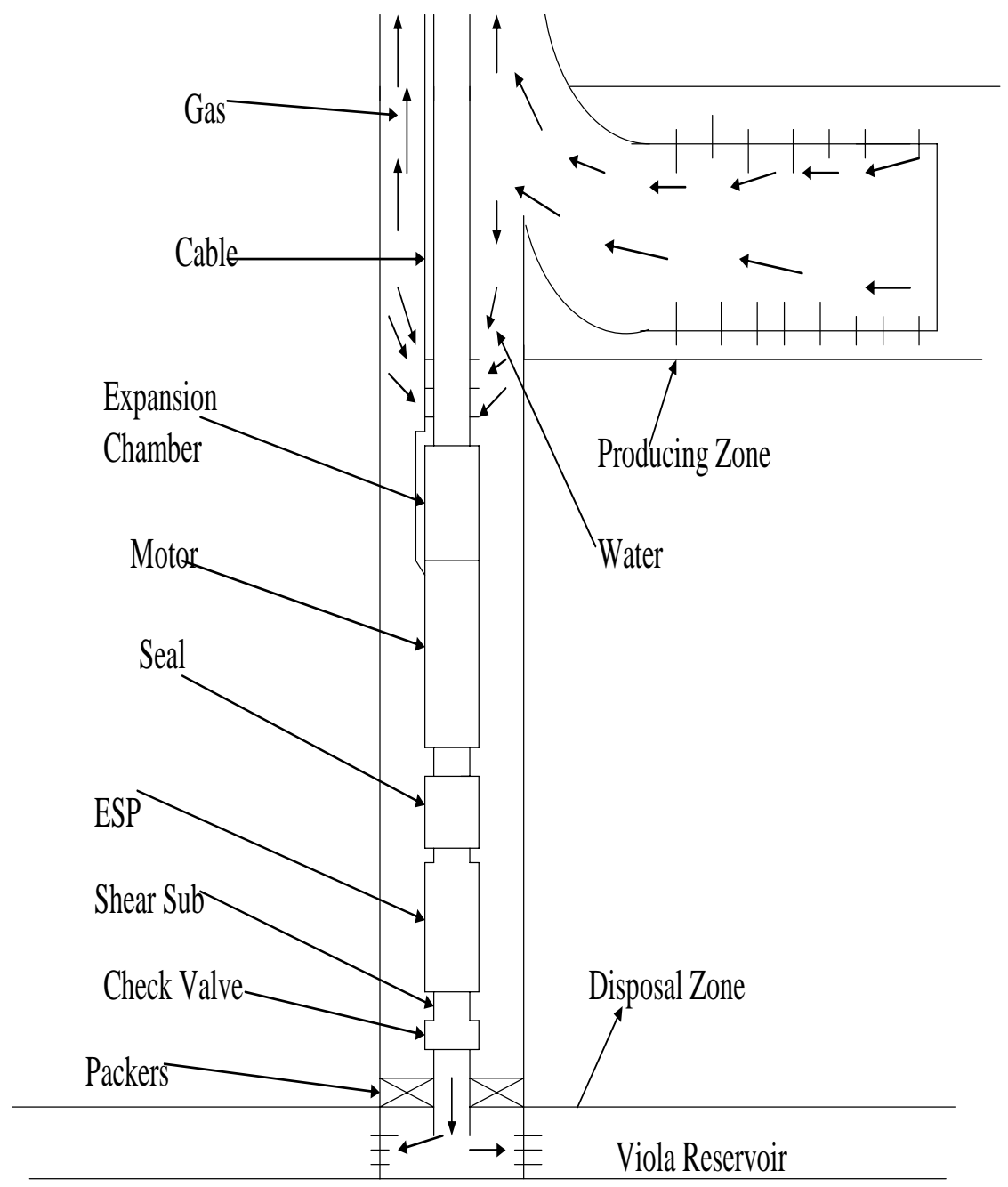

Figure 137: Inverted ESP in DGWS System

According to the GTI (Gas Technology Institute), the success of the system depends on if the casing is well cemented, minimal sand production, soft water (little scaling), low pressure, and high injectivity disposal zone below the producing region.

Two packers are used to separate water from disposal zone from flowing back to the casing and tubing annulus. One check valve is installed and it opens when water is injected to the disposal zone and closes when it is not running. So, the main function of the check valve is to limit backflow of water when the pump is off. The expansion chamber, seal, shear sub are all part of the seal or protector. The main function of the seal or protector is to keep the thrust from the pump off the motor. It also seals the motor from external fluid; see figure 137. The cost of 
installation is estimated as shown in table 37. This is the initial cost of using a new method compared to the old method.

Table 37: Installation cost of new method

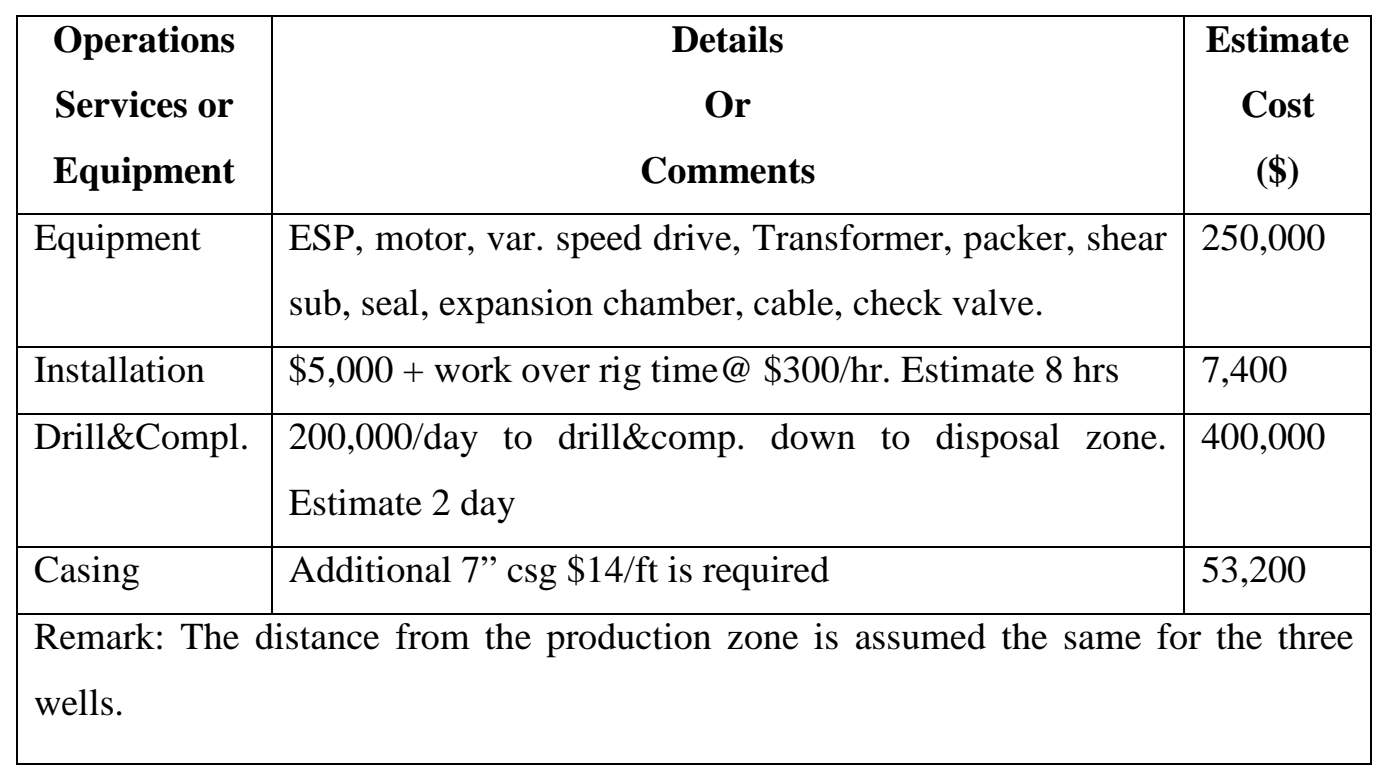

In contrast to this, the old method requires an additional disposal well for every four producing wells at a cost of $\$ 800,000$. In addition, it costs about $\$ 500 /$ month to operate a disposal well. The standard electrical submersible pump in a conventional well will cost about $\$ 90,000$.

To compare the results of an old method versus new method, we selected three wells in the Vinco Project in Lincoln County. We have production data available from these three wells which includes both gas and water production data. We also have a reasonable information about the bottom hole pressure in the well. The gas flow rate is estimated using an effective well bore radius approach using Darcy's equation. Since all the 3 wells are horizontal, an effective well bore radius is calculated and the following equation is used to calculate the gas flow rate.

$$
q_{g}=\frac{K K_{r g} h\left(\bar{P}_{r}^{2}-P_{w f}^{2}\right)}{1422 T\left(\mu_{g} Z\right)_{a v g}\left[\operatorname{Ln}\left(r_{e h} / r_{w}^{\prime}\right)-0.75+S\right]}
$$

(Equation 26) 
The values of viscosity and gas compressibility factor are evaluated at the average pressure.

The initial reservoir pressure is 1200 psia and decreases to 200 psia which is considered an abandonment reservoir pressure. The bottom hole pressure for old case (without DGWS) is 600 psia and decreases linearly down to 150 psia after 2 years, whereas the new case (with DGWS) the bottom hole pressure is assumed to be constant and is equal to 100 psia. The drainage area for each well is assumed to be 320 acres and is readjusted during the history matching. The length of horizontal section of the well is assumed equal to 3,000 ft. The initial guess for absolute permeability is obtained by using equation 26 by assuming that initial rate is 100 MSCFD after 1 month. This value is $41 \mathrm{mD}$. This is adjusted during the history matching process. Since majority of the flow is expected to occur through high permeability regions, we initially assume the gas relative permeability to be a linear function of gas saturation. This exponent of gas saturation is also adjusted as part of the history matching process.

The water flow rate is also calculated using a similar approach as shown below.

$$
q_{w}=\frac{K K_{r w} h\left(P_{r}-P_{w f}\right)}{141.2 \mu_{w} B_{w}\left(\ln \left(r_{e h} / r_{w}^{\prime}\right)-0.75+S\right)}
$$

(Equation 27)

With the exception of relative permeability of water, all the other values are same as gas. We also assumed a linear relationship for water relative permeability which was eventually adjusted to get a history match. .

The time required to produce gas during a given interval is computed by:

$$
\Delta t=\frac{\Delta G_{p}}{\bar{q}_{g}}
$$

(Equation 28)

The increment in gas produced is obtained from material balance equation and the average gas flow rate is obtained by averaging the gas produced at a given interval using the logarithmic average The same approach is used to compute the water produced at a given interval as illustrated in equation 29; 


$$
\Delta t=\frac{\Delta W_{P}}{\bar{q}_{w}}
$$

(Equation 29)

After obtaining the increment in time, the cumulative time is given by;

time $=$ time $_{1}+\Delta t$

where time1 is initial time equal to zero.

Using these equations, history matching of the actual production data was done by adjusting drainage area, relative permeability exponents and absolute permeability of the formation. We assumed that it is possible that drainage areas for gas and water could be different since water is coming mostly from connected volumes whereas gas is coming from disconnected pockets which are produced through connected water conduits.

The results for history match for the Kelly well are shown below.

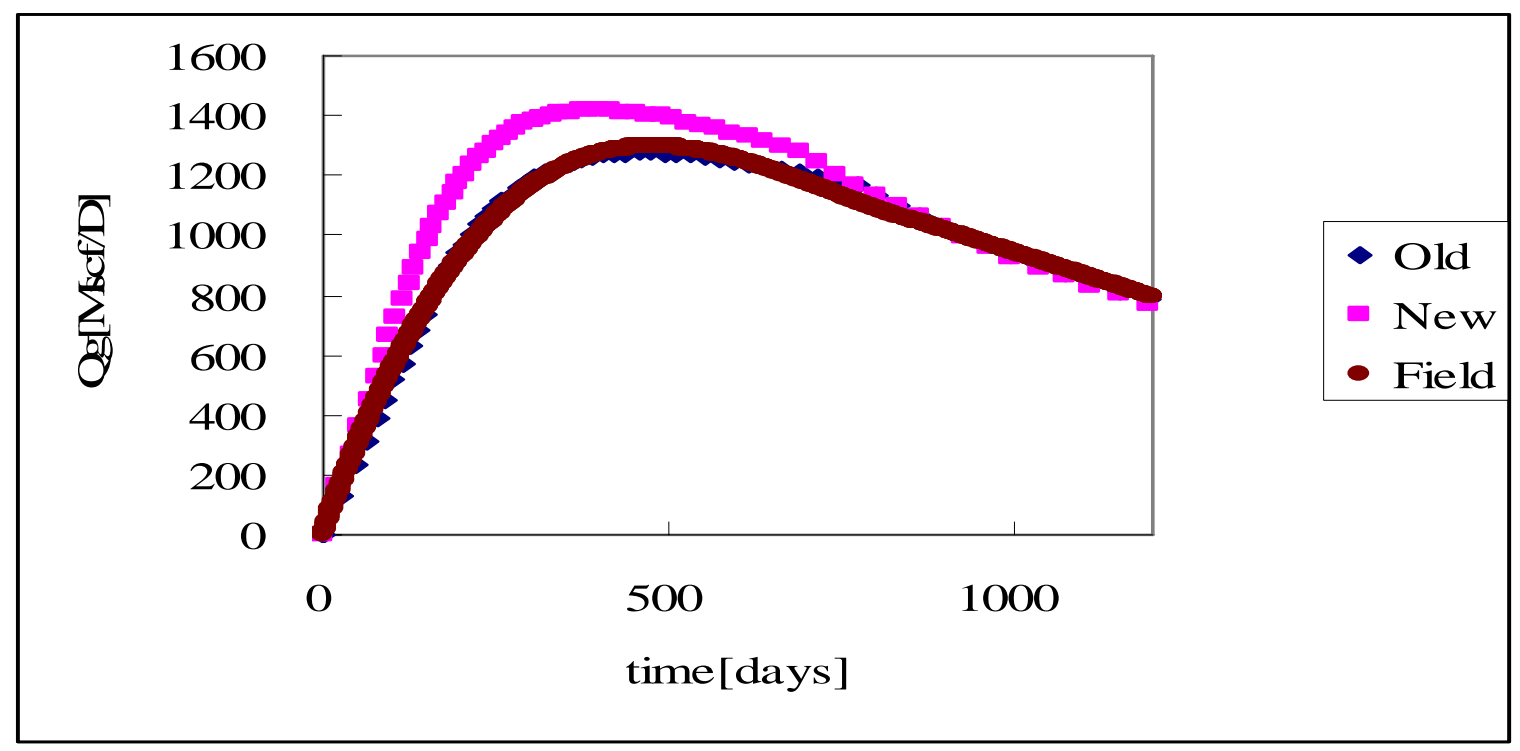

Figure 138: Kelly well - gas rate history match 


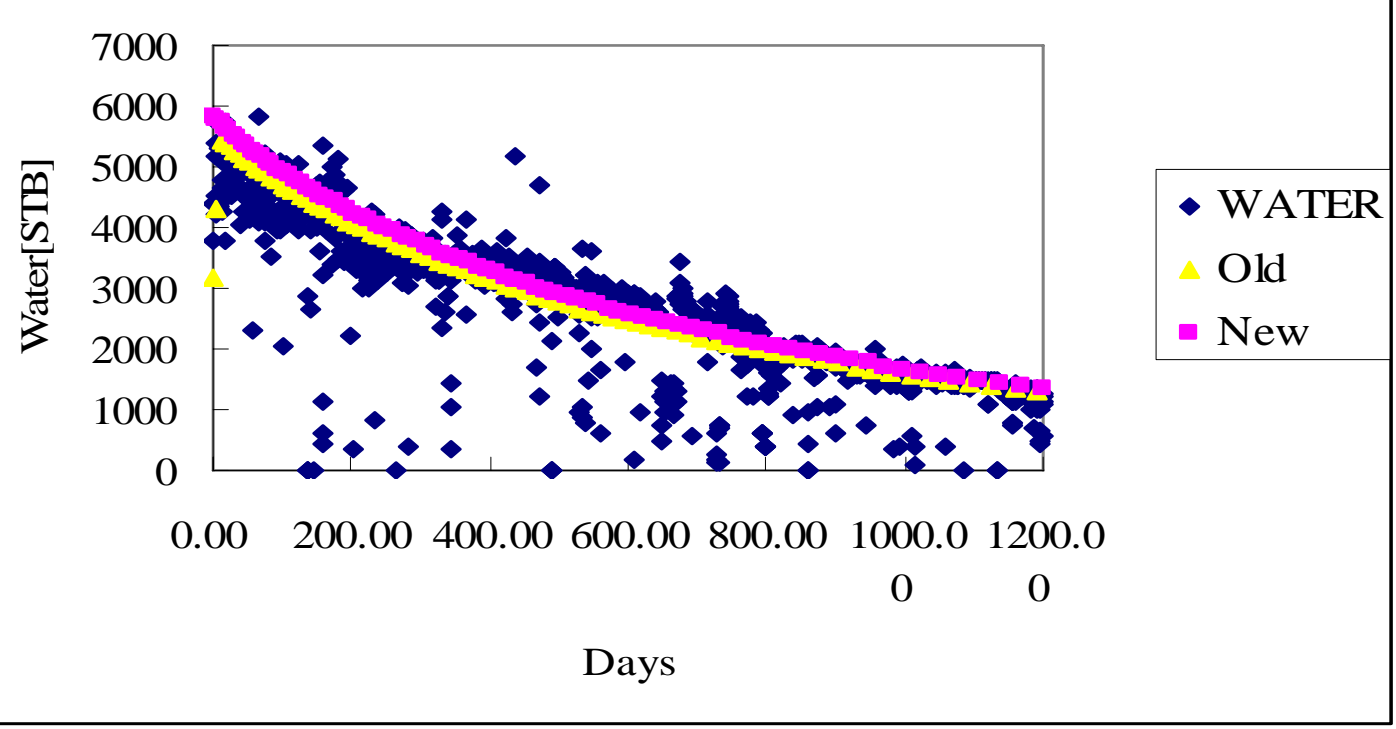

Figure 139: Water rate history match - Kelly well

In addition to the history match of the current production data, the figures also show the new production profile with the new method. Recall that new method allows for the disposal of water in the lower zone and, hence, lower bottom hole pressure from the beginning. That allows higher production and lower abandonment pressure compared to the old method. History matches for the other two wells are obtained in a similar fashion. The matches for all the wells were reasonable. The history matched parameters are shown in table 38. 
Table 38: Matched parameters for 3 wells

\begin{tabular}{|l|c|c|c|c|}
\hline \multicolumn{2}{|c|}{ Kelly } & \multicolumn{2}{c|}{ Water } \\
\hline & Initial Guess & Convergence & Initial Guess & Convergence \\
\hline Area (Acres) & 320 & 780 & 320 & 450 \\
\hline $\begin{array}{l}\text { Absolute } \\
\text { Permeability }\end{array}$ & $41 \mathrm{mD}$ & $20 \mathrm{mD}$ & $41 \mathrm{mD}$ & $20 \mathrm{mD}$ \\
\hline $\begin{array}{l}\text { Relative } \\
\text { Permeability }\end{array}$ & $k_{r g}=S_{g}$ & $k_{r g}=0.35 S_{g}$ & $k_{r w}=S_{w}$ & $k_{r w}=S_{w}$ \\
\hline
\end{tabular}

Sumner

\begin{tabular}{|l|c|c|c|c|}
\hline & \multicolumn{2}{|c|}{ Gas } & \multicolumn{2}{c|}{ Water } \\
\hline & Initial Guess & Convergence & Initial Guess & Convergence \\
\hline Area (Acres) & 320 & 450 & 320 & 520 \\
\hline $\begin{array}{l}\text { Absolute } \\
\text { Permeability }\end{array}$ & $41 \mathrm{mD}$ & $26 \mathrm{mD}$ & $41 \mathrm{mD}$ & $26 \mathrm{mD}$ \\
\hline $\begin{array}{l}\text { Relative } \\
\text { Permeability }\end{array}$ & $k_{r g}=S_{g}$ & $k_{r g}=0.15 S_{g}$ & $k_{r w}=S_{w}$ & $k_{r w}=S_{w}$ \\
\hline
\end{tabular}

\section{Wall 1-9}

\begin{tabular}{|l|c|c|c|c|}
\hline & \multicolumn{2}{|c|}{ Gas } & \multicolumn{2}{c|}{ Water } \\
\hline & Initial Guess & Convergence & Initial Guess & Convergence \\
\hline Area (Acres) & 320 & 820 & 320 & 820 \\
\hline $\begin{array}{l}\text { Absolute } \\
\text { Permeability }\end{array}$ & $41 \mathrm{mD}$ & $30 \mathrm{mD}$ & $41 \mathrm{mD}$ & $30 \mathrm{mD}$ \\
\hline $\begin{array}{l}\text { Relative } \\
\text { Permeability }\end{array}$ & $k_{r g}=S_{g}$ & $k_{r g}=0.13 S_{g}$ & $k_{r w}=S_{w}$ & $k_{r w}=S_{w}$ \\
\hline
\end{tabular}

Although the results are different, there are some commonalities observed in all three history matches. For example, the drainage areas for both phases are different; however, in all cases, the drainage area exceeds 320 acre spacing. This illustrates that the wells are draining much bigger area than well spacing. This is further illustrated by the fact that the new wells drilled in the Vinco field have not been as productive as these three wells, indicating that some of the gas from the new wells is already drained by the old wells. It is also true that the relative permeability of the gas is lower than the relative permeability of water. This is consistent with the idea that water is in a continuous phase to start with and, as gas is released, it is probably flowing as a secondary phase. It is also true that we can model the relative permeability for both gas and water as linear relationships. As a cross-check, we compared the relative permeabilities based on the individual wells with the relative permeabilities we obtained from the field data. 
We have two figures. Figure 140 represents the relative permeability ratio based on the Wall 1-9 data and figure 141 represents the relative permeability ratio based on the Sumner data. As can be seen from both figures, although some variation exists between the field and the individual well data, the match is close to each other and the differences are negligible. This further validates our approach to history matching the individual well data to evaluate the new method of disposing water.

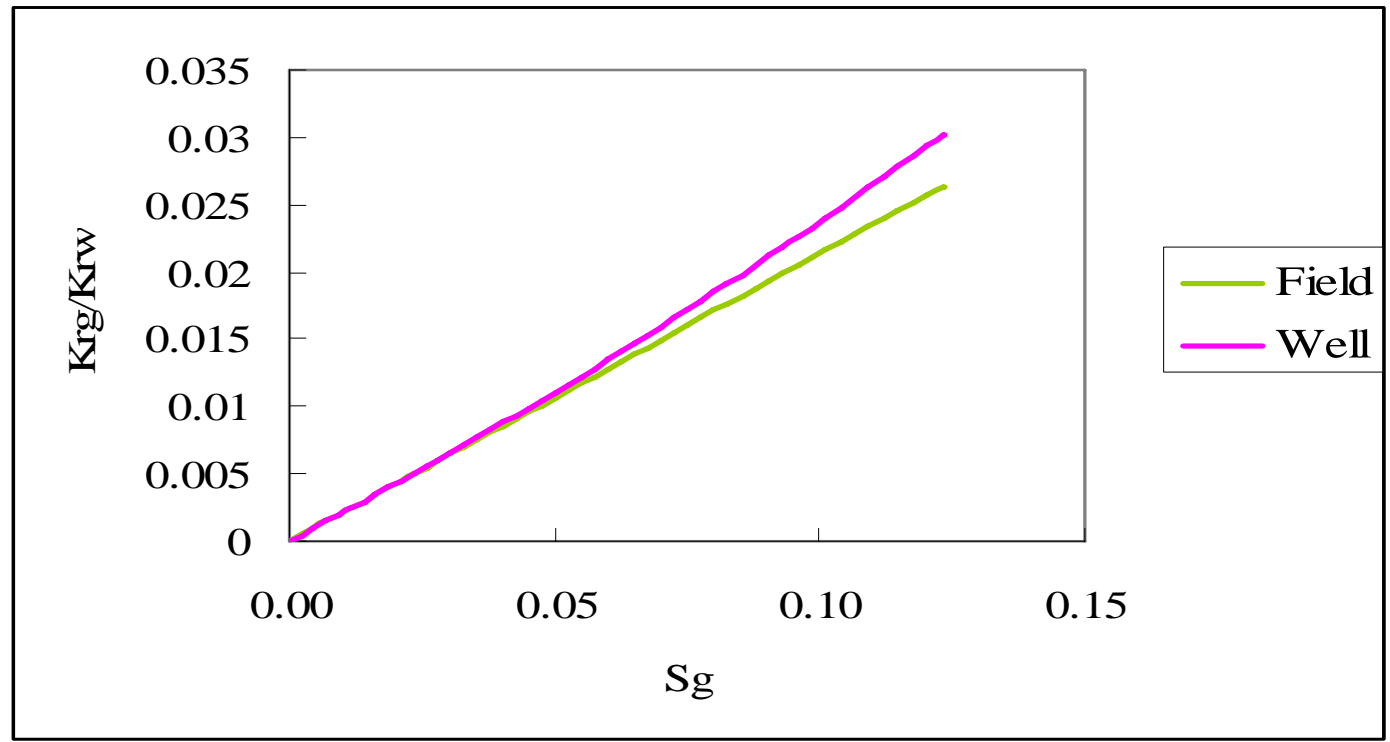

Figure 140: Gas/water relative permeability ratio for Wall 1-9 


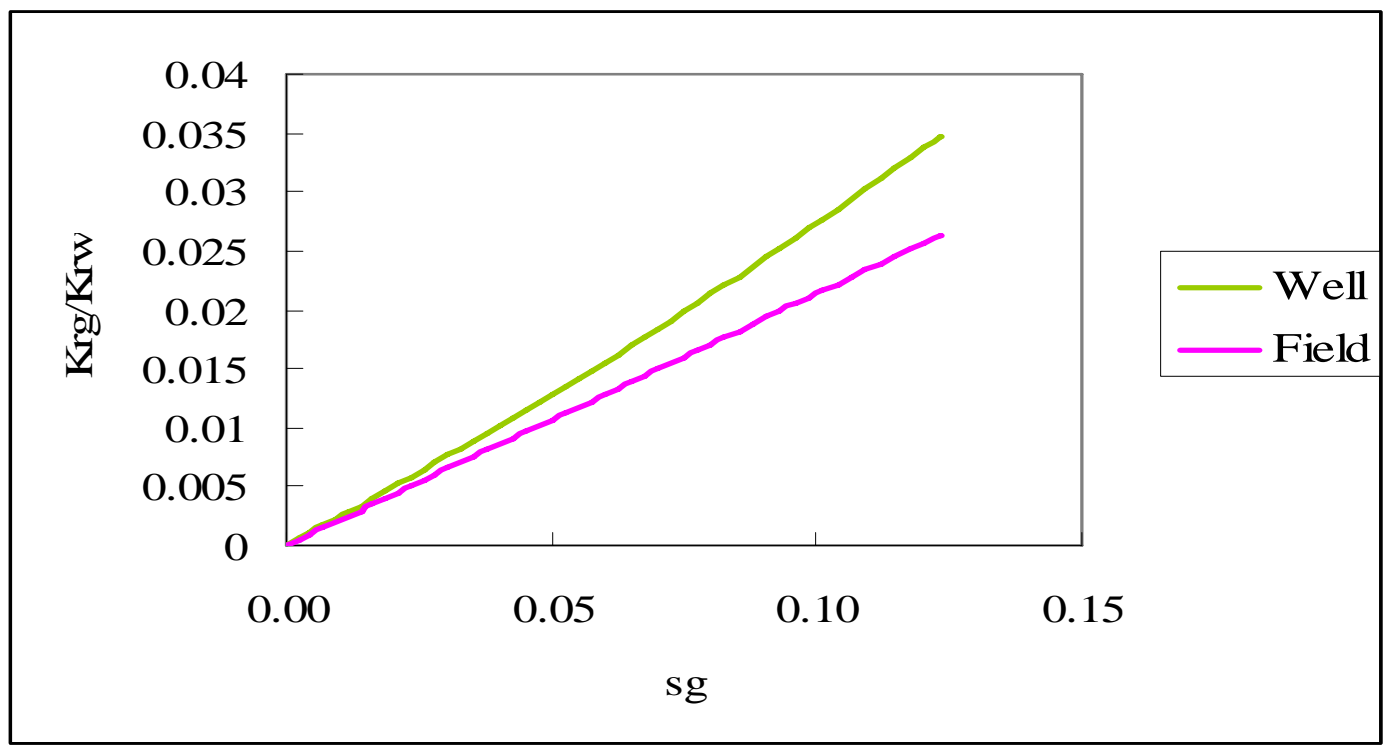

Figure 141: Gas/water relative permeability ratio for Sumner 1-13

Using the relative permeability data obtained from history matching, we predicted the new rate at which the well will produce based on the new method. We have already shown the results in figure 138. By assuming the gas price of \$5/MSCF, we calculated the payback period using the new versus the old method. The results are shown in table 39. As can be seen, the old method appears to be better than the new method. Although the new method is capable of producing at a higher rate, the additional cost of installation $(\$ 250,000$ versus $\$ 90,000)$ cannot be recovered quickly using the new method, making the new method more expensive. If we can reduce the costs of new pump, the new method would be clearly superior to the old method.

Table 39: Payback period for each well using two methods

\begin{tabular}{|c|c|c|}
\hline & \multicolumn{2}{|c|}{ Payback Period (Days) } \\
\hline Well & Old Method & New Method \\
\hline Kelly 1-18 & 127.45 & 191.69 \\
\hline Wall 1-9 & 240.56 & 360.76 \\
\hline Sumner 1-13 & 138.41 & 213.40 \\
\hline
\end{tabular}


To summarize this work, we have observed that it may not be feasible to dispose of water directly in the formation below using the down hole motor. Although the technique provides a better production profile, the cost does not justify the additional production. 


\section{Technology Transfer}

An important aspect of this project is effective communication and technology transfer. We have explored several avenues to effectively transfer the technology. These include field trips, presentations and publications, workshops, a newsletter, and web page.

In order to explain the details of the project, we have taken several teams on field trips. These trips allowed students and various industry and government professionals to visit the field and appreciate its rapid development.

Project findings were published and presented at quarterly project team meetings and various public meetings as noted below.

\section{Publications and Presentations}

1. Derby, J., Podpechan, J., and Andrews, J.: "U.S. Department of Energy Sponsored Study of West Carney Hunton Field, Lincoln and Logan County, Oklahoma: A Preliminary Report”, presented at the Tulsa Geological Society Meeting on November 13, 2001 and at the Oklahoma City Geological Society Meeting on January 23, 2002.

2. Kelkar, M.: “Production from Hunton Formation: Engineering Perspective”, presented at New Mexico Institute of Technology, September 12, 2000, and at Texas A\&M University, October 18, 2001.

3. Marwah, V., Kelkar, M., and Keefer, B.: "Reservoir Mechanism for Hunton Formation Production”, SPE 75127 paper to be presented at the SPE/DOE Thirteenth Symposium on Improved Oil Recovery, Tulsa, Oklahoma, April 13-17, 2002.

4. Frederick, J., Kelkar, M., and Keefer, B.: "Production Type Curves for the Hunton Formation”, SPE 75248 paper to be presented at the SPE/DOE Thirteenth Symposium on Improved Oil Recovery, Tulsa, Oklahoma, April 13-17, 2002.

5. Kho, T. and Kelkar, M.: “History Matching Using Triple Loop Procedure”, SPE 75220 paper to be presented at the SPE/DOE Thirteenth Symposium on Improved Oil Recovery, Tulsa, Oklahoma, April 13-17, 2002. 
6. Derby, J. R., Podpechan, F. J., Andrews, J., and Ramakrishna, S.: "U.S. DOE-Sponsored Study of West Carney Hunton Field, Lincoln \& Logan Co., OK: A Preliminary Report,” Shale Shaker Journal of the Oklahoma City Geological Society, vol. 53, no. 1, pages 919, and vol. 53, no. 2, pages 39-48 (2002).

7. Derby, J. R., Podpechan, F. J., Andrews, J., and Ramakrishna, S.: "Development Case Study of a Karsted Carbonate "Island" Hydrocarbon Reservoir: West Carney Hunton Field, Oklahoma," American Association of Petroleum Geologists, Electronic Publication: Search and Discovery, Article \#20008 (2002).

8. Derby*, J. R., Podpechan*, F. J., Andrews, J., and Ramakrishna, S.: “U.S. DOESponsored Study of West Carney Hunton Field, Lincoln \& Logan Co., OK: A Preliminary Report,” presented at meetings of the Tulsa Geological Society (November 13, 2001) and the Oklahoma City Geological Society (January 23, 2002). *Speakers

9. Derby*, J. R., Podpechan, F. J., Andrews, J., and Ramakrishna, S.: “Development Case Study of a Karsted Carbonate "Island" Hydrocarbon Reservoir: West Carney Hunton Field, Oklahoma,” presented at the International Symposium on the 21st Century Petroleum Exploration (May 16, 2002) and the 2nd Forum on Marine Carbonate Reservoirs in China, Hangzhou, China (May 14-17, 2002). *Speaker

10. Derby*, J. R., Podpechan, F. J., Andrews, J., and Ramakrishna, S.: “Development Case Study of a Karsted Carbonate "Island" Hydrocarbon Reservoir: West Carney Hunton Field, Oklahoma,” presented at the invitation of the Tulsa Geological Study Group (May 21, 2002). *Speaker

11. Derby*, J. R., Podpechan, F. J., Andrews, J., and Ramakrishna, S.: "Development Case Study of a Karsted Carbonate "Island" Hydrocarbon Reservoir: West Carney Hunton Field, Oklahoma," presented at the Noon Seminar Series of the University of Tulsa's Department of Geosciences (October 30, 2002). *Speaker

12. Derby*, J. R., Podpechan, F. J., Andrews, J., and Ramakrishna, S.: "Development Case Study of a Karsted Carbonate "Island" Hydrocarbon Reservoir: West Carney Hunton Field, Oklahoma,” presented to the Tulsa Geological Society, , in conjunction with a talk 
by David Chernicky and Scott Schad of New Dominion on the discovery and development of West Carney Hunton Field (November 5, 2002). *Speaker

13. Kelkar, Mohan: "Exploitation and Optimization of Reservoir Performance in Hunton Formation, Oklahoma,” presented at the U.S. DOE Class II Shallow Shelf Carbonate Review at The University of Texas, Permian Basin, Odessa, TX (December 12, 2002).

14. Keefer, B.: “Hunton Dewatering Project: Mystery Solved?" presented at $15^{\text {th }}$ Oil Recovery Conference, TORP, University of Kansas, Wichita, KS (March 17, 2003).

15. Joshi, R.: "Exploitation and Optimization of Reservoir Performance in Hunton Formation, Oklahoma,” first place paper, Masters division, SPE Student Paper Contest, Mid-Continent Division, presented at the University of Missouri - Rolla (April 5, 2003)

16. "Dewatering of the Hunton Reservoir in West Carney Field - Mystery Solved?" Technical Workshops with presentations by Mohan Kelkar, Joe Podpechan, Brian Keefer, Sandeep Ramakrishna, Rahul Joshi, and Jeff Frederick at the DoubleTree Hotel, Tulsa, OK (April 16, 2003) and the Metro Technology Center, Oklahoma City, OK (April 21, 2003).

17. Ramakrishna, S., Keefer, B., and Kelkar, M.: "Correlating Static Data to Dynamic Characteristics: Hunton Reservoir," paper submitted for publication by the University of Kansas (May, 2003).

18. Podpechan, J., Derby, J. R., and Andrews, J.: "Limestone and Dolomite Cores from the Hunton Formation, West Carney Field, Oklahoma,” presented at the Poster/Core Sessions, 2003 Mid-Continent Section Meeting, American Association of Petroleum Geologists (October 13-14, 2003).

19. Podpechan, J., Derby, J. R., Andrews, J., and Ramakrishna, S.: "Dewatering as a Production Technique in a Dual Permeability Reservoir: West Carney Hunton Field, Lincoln and Logan Counties, Oklahoma,” presented at the 2003 Mid-Continent Section Meeting, American Association of Petroleum Geologists (October 13-14, 2003).

20. Joshi, R. and Kelkar, M.: "Production Performance Study of West Carney Field, Lincoln County, Oklahoma,” SPE 89461 paper presented at the SPE/DOE Fourteenth Symposium on Improved Oil Recovery, Tulsa, Oklahoma (April 17-21, 2004). 
21. Patwardhan, S., Kelkar, M. and Keefer, B.: "Dewatering in Hunton Reservoir - Drill Vertical or Horizontal Well?” SPE 89462 paper presented at the SPE/DOE Fourteenth Symposium on Improved Oil Recovery, Tulsa, Oklahoma (April 17-21, 2004).

22. Kelkar, M.: "Hunton Formation: Production Performance and Solutions," presented at Graduate Seminar at the University of Missouri, Rolla, MO (December 2, 2004)

23. Kelkar, M.: "Dewatering of Hunton Reservoir - What Makes It Work?" presented at SPE Mid-Continent Section Luncheon and Workshop (March 3, 2005); also presented as SPE 94347, SPE Production Symposium, OK City, OK (April 17-19, 2005).

24. Seethepalli, A., Adibhatla, B., and Mohanty, K. K., "Physicochemical Interactions during Surfactant Flooding of Fractured Reservoirs,” SPE J., 9 (4), 411-418 (December, 2004).

25. Adibhatla, B., Sun, X., and Mohanty, K. K., "Numerical Studies of Oil Production from Initially Oil-Wet Fracture Blocks by Surfactant Brine Imbibition,” SPE 97687, SPE International Improved Oil Recovery Conference, Kuala Lumpur, Malaysia, 4-6 December, 2005.

26. Adibhatla, B., Mohanty, K. K., Berger, P. \& Lee, C. "Effect of Surfactants on Wettability of Near-Wellbore Regions of Gas Reservoirs,” J. Pet. Sci. Eng., 52, 227-236 (2006).

27. Adibhatla, B. \& Mohanty, K. K., “Oil Recovery from Fractured Carbonates by Surfactant-Aided Gravity Drainage: Laboratory Experiments and Mechanistic Simulation,” SPE 99773, Proceedings of SPE/DOE 15th Symposium on Improved Oil Recovery, Tulsa, April 22-26, 2006.

\section{Web Development}

- $\quad$ The project web software was converted to Dreamweaver MX due to technology issues between The University of Tulsa's servers and Microsoft FrontPage XP. With this conversion, cascading style sheet (CSS) technology was applied to provide a uniform appearance and allow for quick formatting changes in the future. (July, 2003)

- $\quad$ Geological data for the BPII Final Report was converted from its various original formats to PDF and added to the web site. This data includes core descriptions, core log plots, core photographs, thin sections, pore and facies codes, and conodont samples. (July 2007) 
http://www.tucrs.utulsa.edu/Hunton/Reports/15125R20_Geology/bp2_geology.stm 


\section{References}

1 Seethepalli, A., Adibhatla, B., and Mohanty, K. K., "Physicochemical Interactions during Surfactant Flooding of Fractured Reservoirs,” SPE Journal, 9 (4), 411-418 (December, 2004).

2 Adibhatla, B., Sun, X., and Mohanty, K. K., "Numerical Studies of Oil Production from Initially Oil-Wet Fracture Blocks by Surfactant Brine Imbibition,” SPE 97687, SPE International Improved Oil Recovery Conference, Kuala Lumpur, Malaysia, 4-6 December, 2005.

3 Adibhatla, B., Mohanty, K. K., Berger, P. \& Lee, C. "Effect of Surfactants on Wettability of Near-Wellbore Regions of Gas Reservoirs,” Journal of Petroleum Science Engineering, 52, 227-236 (2006).

4 Adibhatla, B. \& Mohanty, K. K., “Oil Recovery from Fractured Carbonates by SurfactantAided Gravity Drainage: Laboratory Experiments and Mechanistic Simulation,” SPE 99773, Proceedings of SPE/DOE 15th Symposium on Improved Oil Recovery, Tulsa, April 22-26, 2006.

5 Derby, J.R., F. Joe Podpechan, Jason Andrews, and Sandeep Ramakrishna, 2002, U.S. DOE-Sponsored Study of West Carney Hunton Field, Lincoln \& Logan Co., OK: A Preliminary Report:

6 Kelkar, M., 2002, Exploitation and Optimization of Reservoir Performance in Hunton Formation, Oklahoma: Final Report, Budget Period 1 on Work Performed Under Contract No. DE-FC26-00BC15125, prepared for the National Energy Technology Laboratory, National Petroleum Technology Office, U.S. Department of Energy, Tulsa, OK, pp. 305.

7 Shale Shaker (Journal of the Oklahoma City Geological Society, v. 53, no. 1, pages 9-19, and vol. 53, no. 2, pages 39-48, 2002.

8 Lucia, F. J.: "Rock Fabric/Petrophysical Classification of Carbonate Pore Space for Reservoir Characterization,” AAPG Bulletin, v. 79, no. 9, (1995) pp 1275-1300. 
9 Fritz, R. D., and Medlock, P.L.: Sequence Stratigraphy of the Hunton Group as Defined by Core, Outcrop, and Log Data,” in Johnson, K.S., ed., 1993, Hunton Group Core Workshop and Field Trip: Oklahoma Geological Survey Special Publication 93-4 (1993) pp 161-180.

10 Rottmann. Kurt, E.A. Beaumont, R.A. Northcutt, Zuhair Al-Shaieb, Jim Puckett, and Paul Blubaugh, 2000, Hunton Play in Oklahoma (including Northeast Texas Panhandle): Oklahoma Geological Survey Special Publication 2000-2, 131 p., 6 pls.

11 Stanley, T.M., 2001, Stratigraphy and Facies Relationships of the Hunton Group, Northern Arbuckle Mountains and Lawrence Uplift, Oklahoma: Oklahoma Geological Survey Guidebook 33, 73 p.

12 Johnson, M.E., 1996, Stable Cratonic Sequences and a Standard for Silurian Eustasy: Geological Society of America, Special Paper 306, p. 203-211.

13 Barrick, J. E., (in press), The Silurian stratigraphic succession in the southern Midcontinent region of North America, in E. Landing and M. E. Johnson, (eds.), Silurian Lands \& Seas, Part II: Laurentia, New York State Museum Bulletin

14 Amsden, T.W., and Rowland, T.L., 1965, Silurian stratigraphy of northeastern Oklahoma: Oklahoma Geological Survey Bulletin 105, 174 p.

15 Amsden, T. W., 1975, “Hunton Group (Late Ordovician, Silurian, and Early Devonian) in the Anadarko Basin of Oklahoma,” Oklahoma Geological Survey Bulletin, No. 121 (1975) 205 p.

17 Witzke, B.J., and Johnson, M.E., 1999, Silurian brachiopod and related benthic communities from carbonate platform and mound environments of Iowa and surrounding areas, p. 806-848, in Boucot, H.A., and Lawson, J.D., Paleocommunities: a case study from the Silurian and Lower Devonian: Cambridge Univ. Press, 895 p.

17 Johnson, M. E., 1987, Extent and Bathymetry of North American Platform Seas in the Early Silurian: Paleoceanography, v. 2, no. 2, p. 185-211 (April, 1987).

18 Ripley, B.D., Modern Applied Statistics with S-Plus, Springer-Verlag, New York, (1994) 301. 
19 Lee, S.H. and Datta-Gupta, A., "Electrofacies Characterization and Permeability Predictions in Carbonate Reservoirs: Role of Multivariate Analysis and Nonparametric Regression,” SPE 56658 paper presented at the 1999 SPE Annual Technical Conference and Exhibition, Houston, Texas, October 3-6.

20 Doveton, J., "Pfeffer: Petrofacies Evaluation of Formations for Engineering Reservoirs”, The University of Kansas. (July 2001).

21 Agarwal, R.G. et al., “Analyzing Well Production Data Using Combined-Type-Curve and Decline-Curve Analysis Concepts,” SPEREE (Oct. 1999) 478. 


\section{Appendix A - Geological Analysis}

Due to the quantity of data, only samples of each type (core descriptions, core-log plots, core photos, paleo conodont samples, pore and facies codes and analysis, and thin section descriptions) are provided in this report. To view this information in greater detail, go to:

http://www.tucrs.utulsa.edu/Hunton/Reports/15125R20_Geology/bp2_geology.stm 


\section{Core Descriptions}

http://www.tucrs.utulsa.edu/Hunton/Reports/15125R20_Geology/core_descriptions.stm

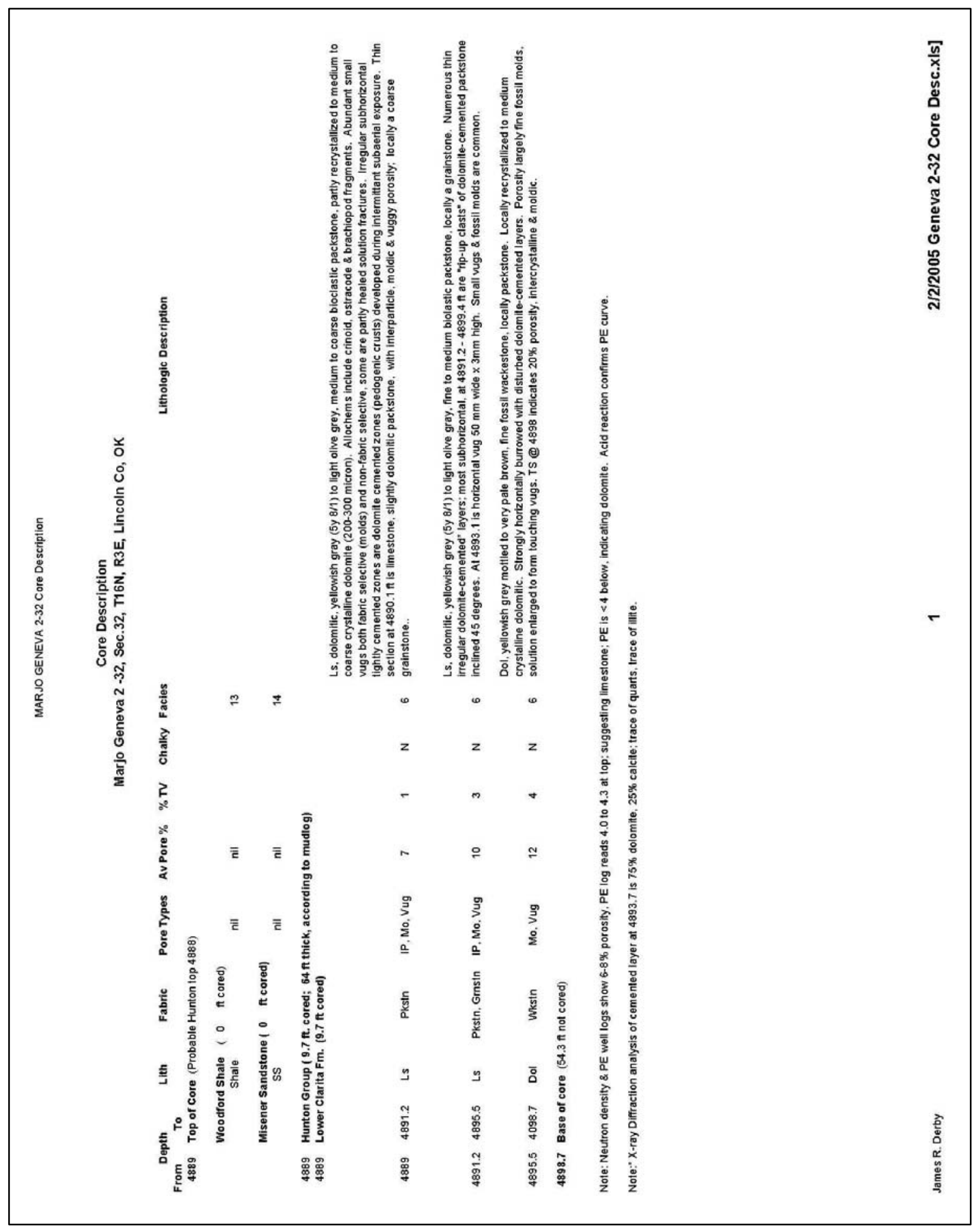

The University of Tulsa 


\section{Core Log Plots}

http://www.tucrs.utulsa.edu/Hunton/Reports/15125R20_Geology/core_log_plots.stm

Examples:

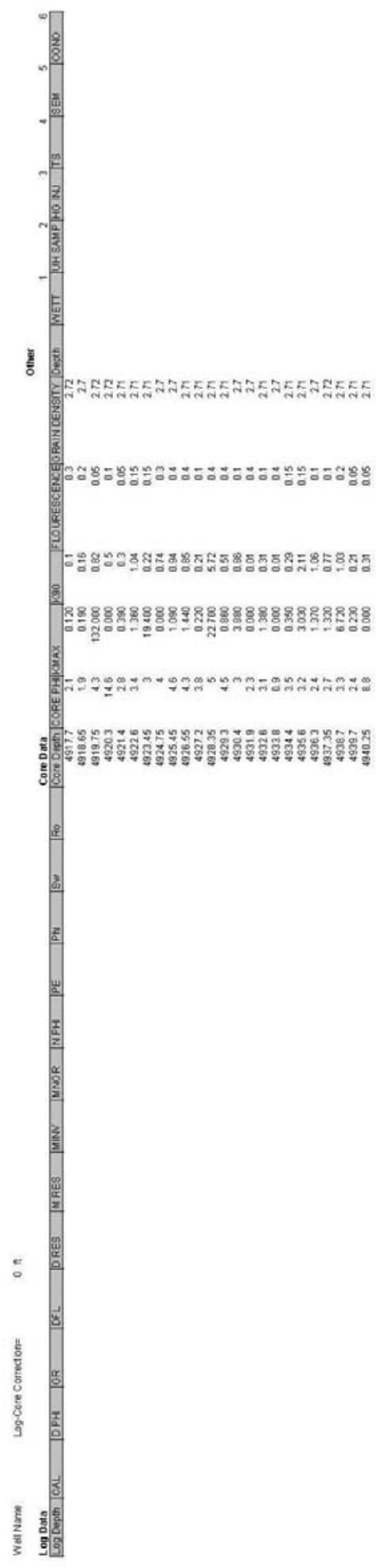


Saunders 1-13 Core-Log Plot
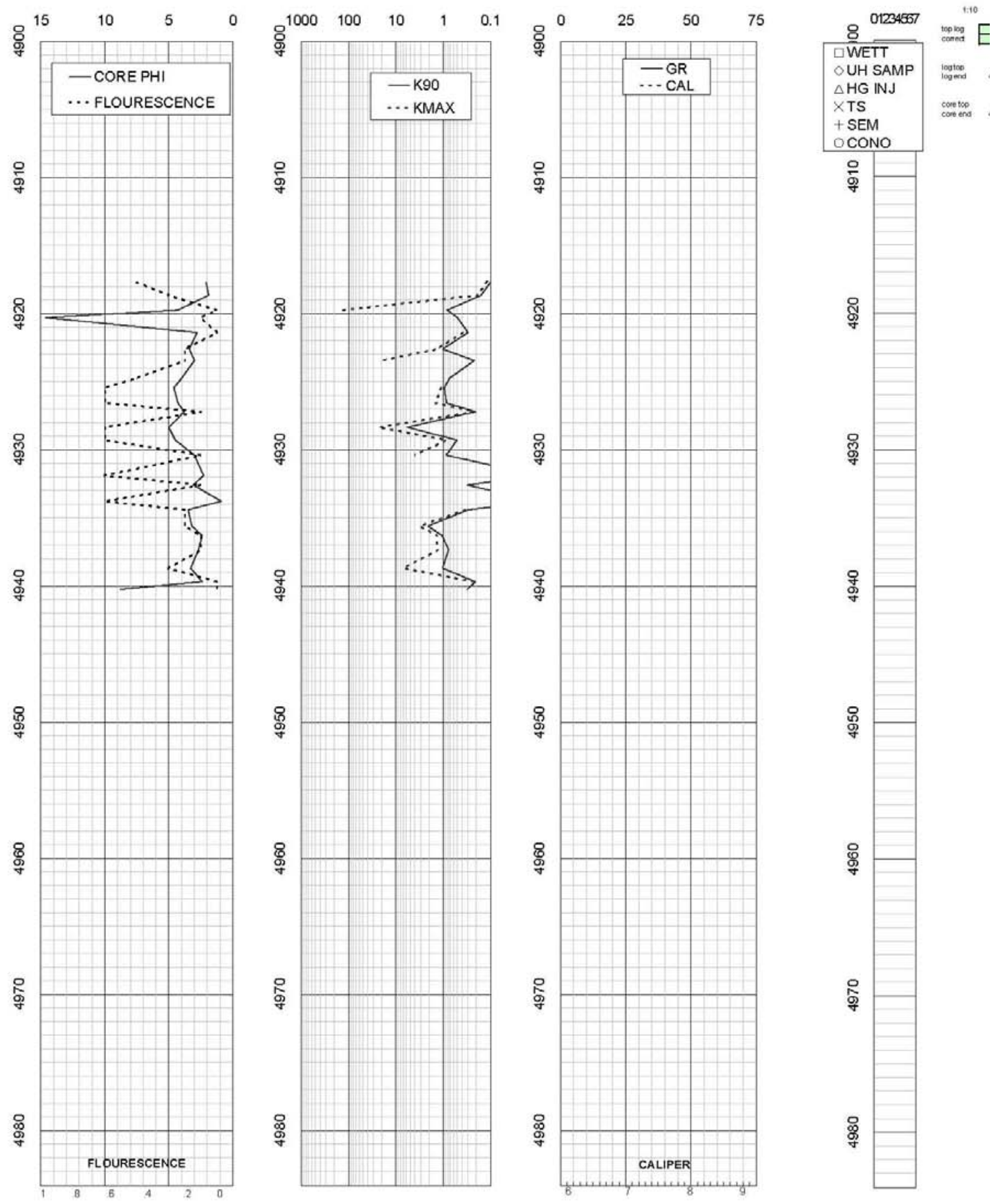

7/2012007 Saunders 1-13 Coretog Plot.xls 


\section{Core Photos}

http://www.tucrs.utulsa.edu/Hunton/Reports/15125R20_Geology/core_photos.stm

Example:

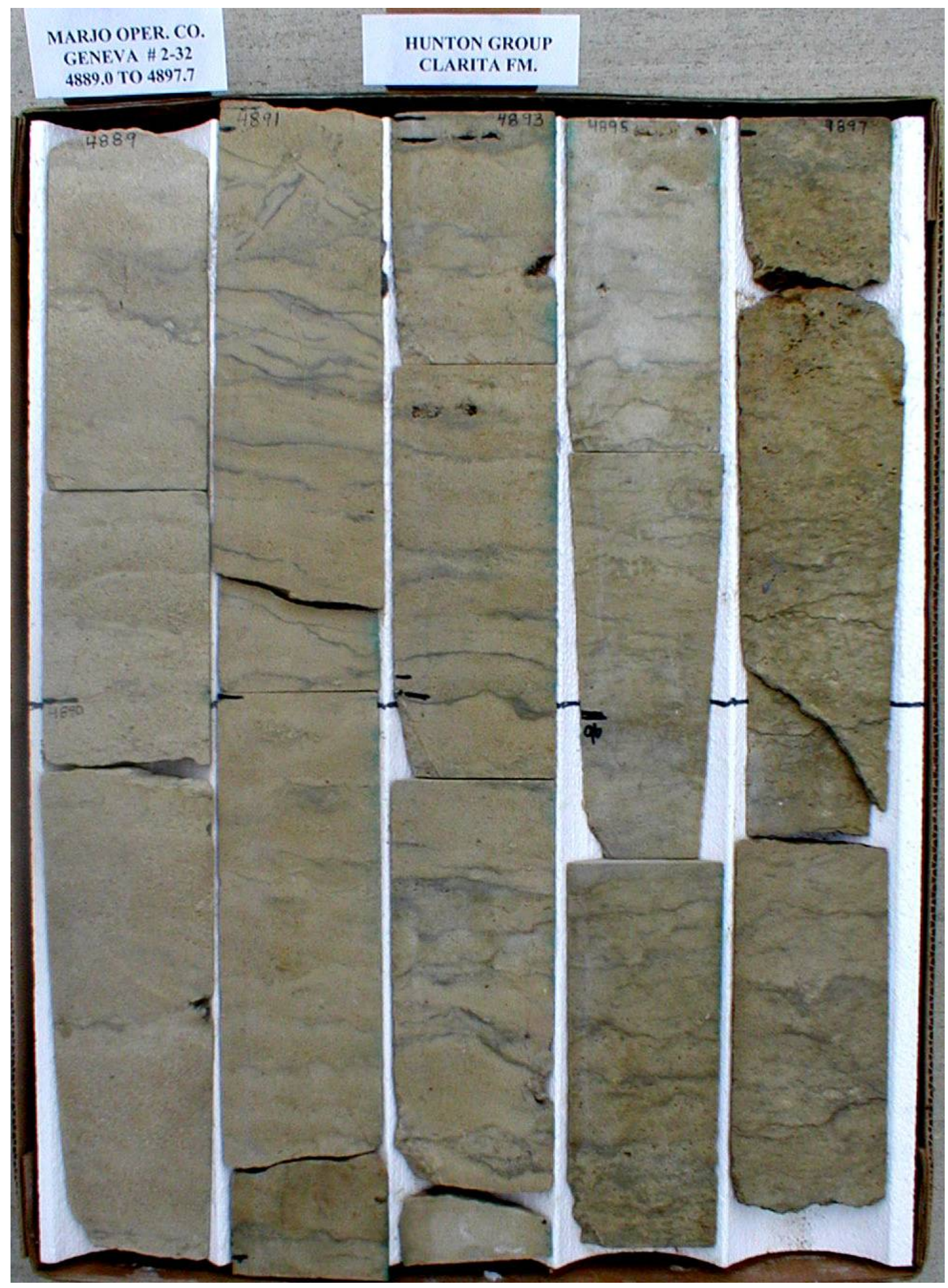

The University of Tulsa 


\section{Paleo Conodont Samples}

http://www.tucrs.utulsa.edu/Hunton/Reports/15125R20_Geology/paleo_cono_samples.stm Example:

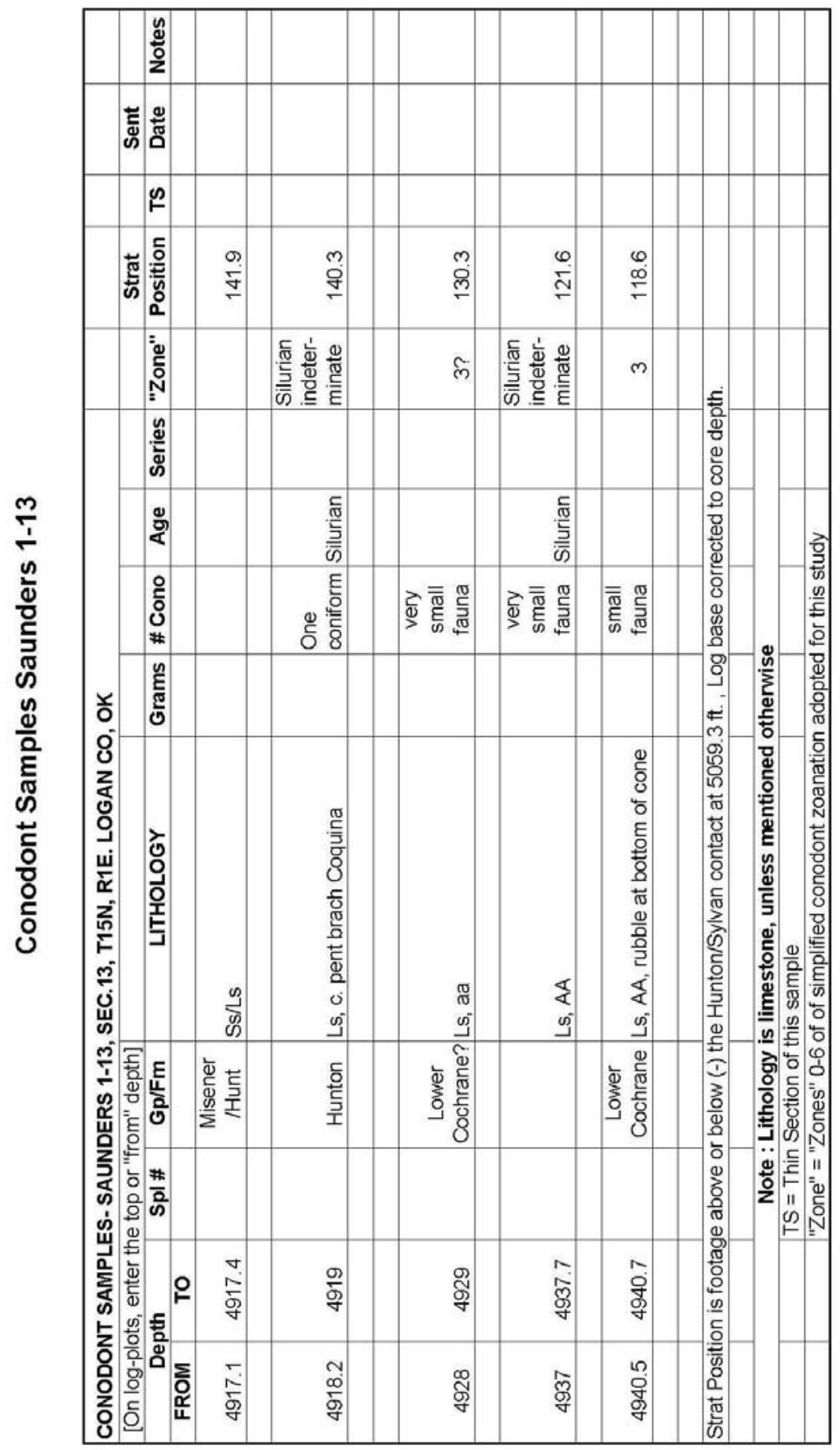

The University of Tulsa 


\section{Pore and Facies Codes and Analysis}

http://www.tucrs.utulsa.edu/Hunton/Reports/15125R20_Geology/pore_facies_codes_and_analysis.stm Example:

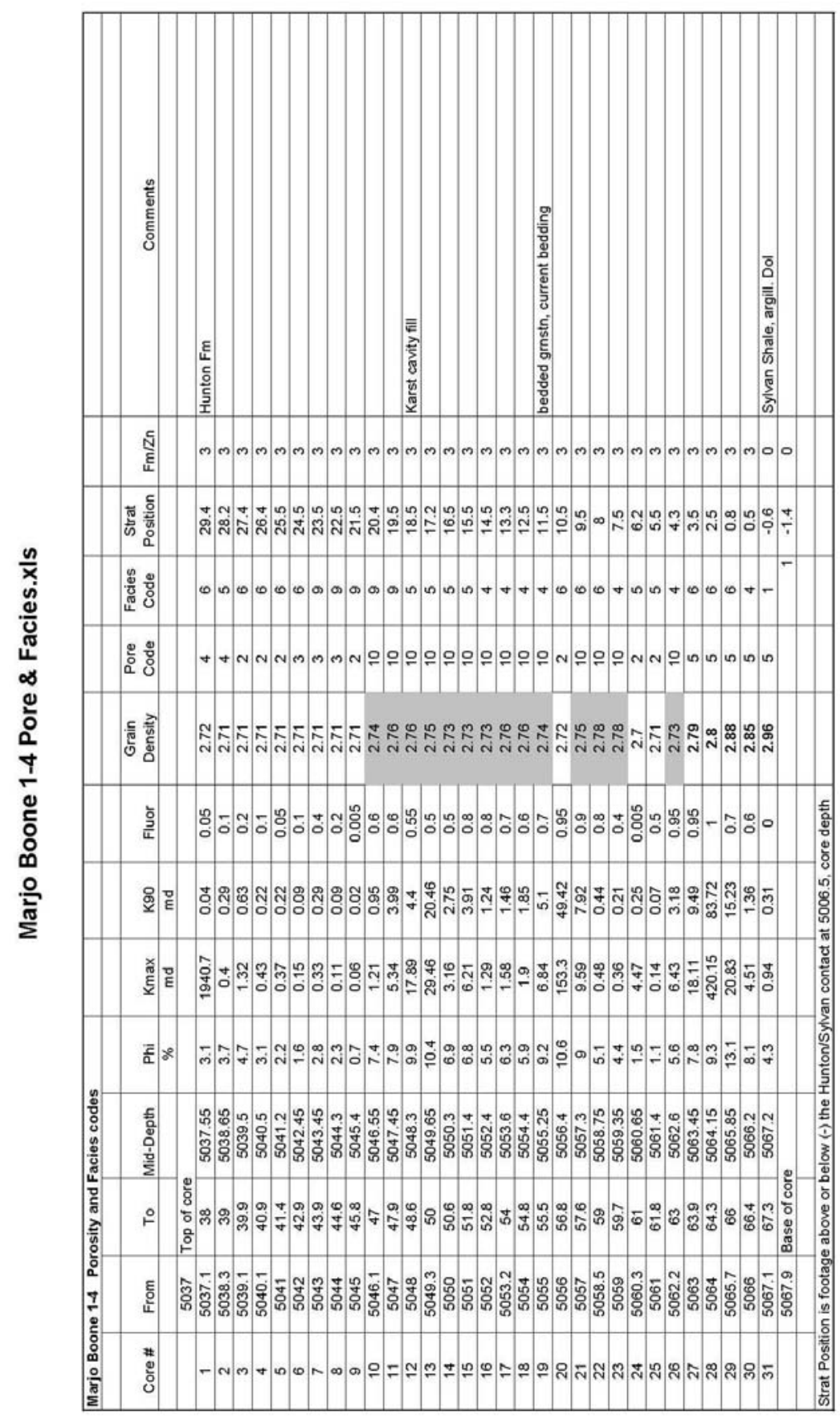

The University of Tulsa 


\section{Thin Section Descriptions}

http://www.tucrs.utulsa.edu/Hunton/Reports/15125R20_Geology/thin_section_descriptions.stm Example:

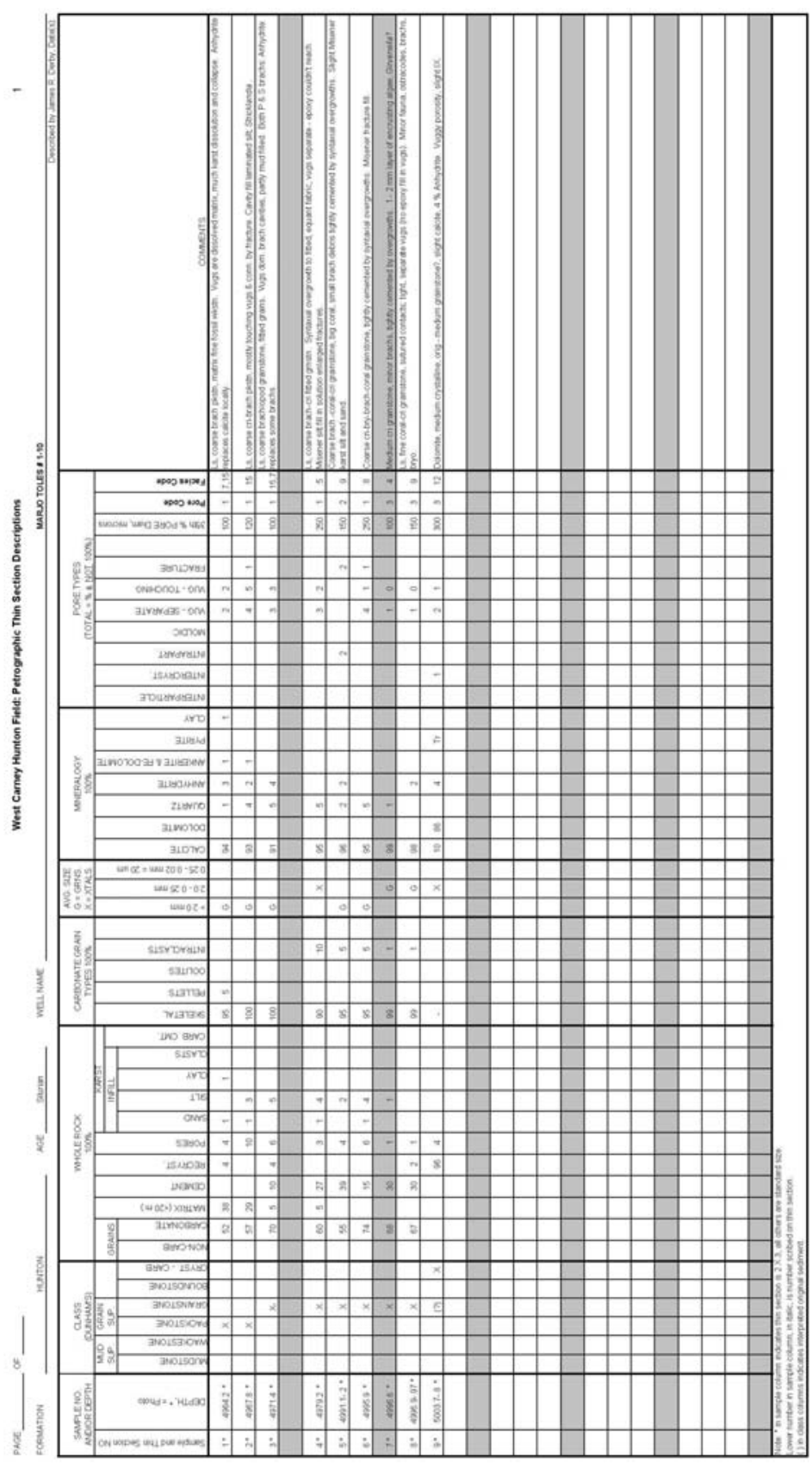




\section{Appendix B - Fluid Properties Analysis}

Table B1. Schwake wellstream composition

\begin{tabular}{|c|c|c|c|c|c|c|}
\hline \multicolumn{7}{|c|}{ Wellstream Fluid Composition } \\
\hline & $\begin{array}{r}\text { Basis of Recombination } \\
\text { Separator Gas Gravity } \\
\text { Separator Liquid Density }\end{array}$ & \multicolumn{5}{|c|}{$\begin{array}{l}4130 \text { scf separator gas at } 15.025 \mathrm{psia} \text { and } 60^{\circ} \mathrm{F} / \mathrm{bbl} \text { separator liquid } \\
0.8417 \text { (Air }=1.00 \text { ) } \\
0.7876 \mathrm{~g} / \mathrm{cc} \text { at } 43 \mathrm{psig} \text { and } 95^{\circ} \mathrm{F}\end{array}$} \\
\hline \multicolumn{2}{|r|}{$\begin{array}{c}\text { Component } \\
\text { (Symbol / Name) } \\
\end{array}$} & $\begin{array}{c}\text { Separator Gas } \\
(\mathrm{mole} \%)\end{array}$ & $\begin{array}{l}\text { Separator } \\
\text { Liquid } \\
\text { (mole\%) }\end{array}$ & $\begin{array}{c}\text { Molecular } \\
\text { Weight }\end{array}$ & $\begin{array}{c}\text { Specific } \\
\text { Gravity } \\
(\text { Water }=1.0)\end{array}$ & $\begin{array}{l}\text { Wellstream } \\
\text { Fluid } \\
(\text { mole \%) }\end{array}$ \\
\hline $\mathrm{N}_{2}$ & Nitrogen & 7.179 & 0.048 & 28.01 & 0.809 & 6.179 \\
\hline $\mathrm{CO}_{2}$ & Carbon Dioxide & 0.103 & 0.004 & 44.01 & 0.818 & 0.089 \\
\hline $\mathrm{H}_{2} \mathrm{~S}$ & Hydrogen Sulfide & 0.000 & 0.000 & 34.08 & 0.801 & 0.000 \\
\hline $\mathrm{C} 1$ & Methane & 67.363 & 1.244 & 16.04 & 0.232 & 58.093 \\
\hline $\mathrm{C} 2$ & Ethane & 10.305 & 0.917 & 30.07 & 0.405 & 8.989 \\
\hline C3 & Propane & 7.917 & 2.187 & 44.10 & 0.507 & 7.114 \\
\hline iC4 & i-Butane & 0.842 & 0.584 & 58.12 & 0.563 & 0.806 \\
\hline $\mathrm{nC} 4$ & n-Butane & 3.307 & 3.550 & 58.12 & 0.584 & 3.341 \\
\hline iC5 & i-Pentane & 0.681 & 1.902 & 72.15 & 0.624 & 0.852 \\
\hline nC5 & n-Pentane & 1.031 & 3.758 & 72.15 & 0.631 & 1.413 \\
\hline $\mathrm{C} 6$ & Hexanes & 0.783 & 9.276 & 85.78 & 0.673 & 1.974 \\
\hline $\mathrm{C} 7$ & Heptanes & 0.303 & 12.911 & 98.42 & 0.704 & 2.071 \\
\hline C8 & Octanes & 0.136 & 10.485 & 113.44 & 0.710 & 1.587 \\
\hline $\mathrm{Cg}$ & Nonanes & 0.017 & 8.831 & 126.32 & 0.731 & 1.253 \\
\hline C10 & Decanes & 0.033 & 44.302 & 241.88 & 0.876 & 6.239 \\
\hline \multicolumn{2}{|l|}{ Total } & 100.000 & 100.000 & & & 100.000 \\
\hline \multicolumn{2}{|c|}{$\begin{array}{l}\text { Molecular Weight } \\
\end{array}$} & 24.38 & 159.04 & & & 43.18 \\
\hline
\end{tabular}


Table B2. Schwake CCE test

\begin{tabular}{|c|c|c|c|c|c|c|}
\hline \multicolumn{7}{|c|}{$\begin{array}{c}\text { Constant Composition Expansion at } 110^{\circ} \mathrm{F} \\
\text { Pressure-Volume Relations }\end{array}$} \\
\hline $\begin{array}{c}\text { Pressure } \\
\text { (psia) }\end{array}$ & $\begin{array}{c}\text { Fluid } \\
\text { Condition }\end{array}$ & $\begin{array}{l}\text { Relative } \\
\text { Volume } \\
\left(V / V^{\text {sat }}\right)\end{array}$ & $\begin{array}{c}\text { Gas } \\
\text { Density } \\
\left(\mathrm{g} / \mathrm{cm}^{3}\right)\end{array}$ & $\begin{array}{l}\text { Absolute } \\
\text { Liquid } \\
\text { Volume } \\
(\%)\end{array}$ & $\begin{array}{c}\text { Deviation } \\
\text { Factor } \\
(z) \\
\end{array}$ & $\begin{array}{c}\text { Gas } \\
\text { Viscosity } \\
(c P) \\
\end{array}$ \\
\hline 962 & & 3.769 & & 11.82 & 0.718 & \\
\hline 1210 & Curr. Res. & 2.951 & & 13.26 & 0.708 & \\
\hline 1510 & Orig. Res. & 2.351 & & 16.41 & 0.704 & \\
\hline 2000 & & 1.793 & & 23.71 & 0.711 & \\
\hline 3000 & $\uparrow$ & 1.320 & & 40.52 & 0.785 & \\
\hline 4000 & & 1.150 & & 45.66 & 0.912 & \\
\hline 5000 & | & 1.072 & & 42.33 & 1.063 & \\
\hline 6000 & Two-Phase & 1.028 & & 23.16 & 1.222 & \\
\hline 6200 & & 1.021 & & 13.11 & 1.255 & \\
\hline 6400 & & 1.016 & & 7.12 & 1.288 & \\
\hline 6600 & & 1.010 & & 3.59 & 1.321 & \\
\hline 7000 & Dew Point & 1.000 & 0.571 & 0.00 & 1.387 & 0.168 \\
\hline 7500 & & 0.989 & 0.577 & & 1.471 & 0.175 \\
\hline 8000 & & 0.979 & 0.583 & & 1.553 & 0.183 \\
\hline 8500 & & 0.970 & 0.588 & & 1.635 & 0.190 \\
\hline 9000 & & 0.963 & 0.593 & & 1.717 & 0.196 \\
\hline 9500 & & 0.955 & 0.598 & & 1.799 & 0.203 \\
\hline 10000 & & 0.948 & 0.602 & & 1.879 & 0.209 \\
\hline
\end{tabular}


Table B3. Well stream composition for Morrow 1-27

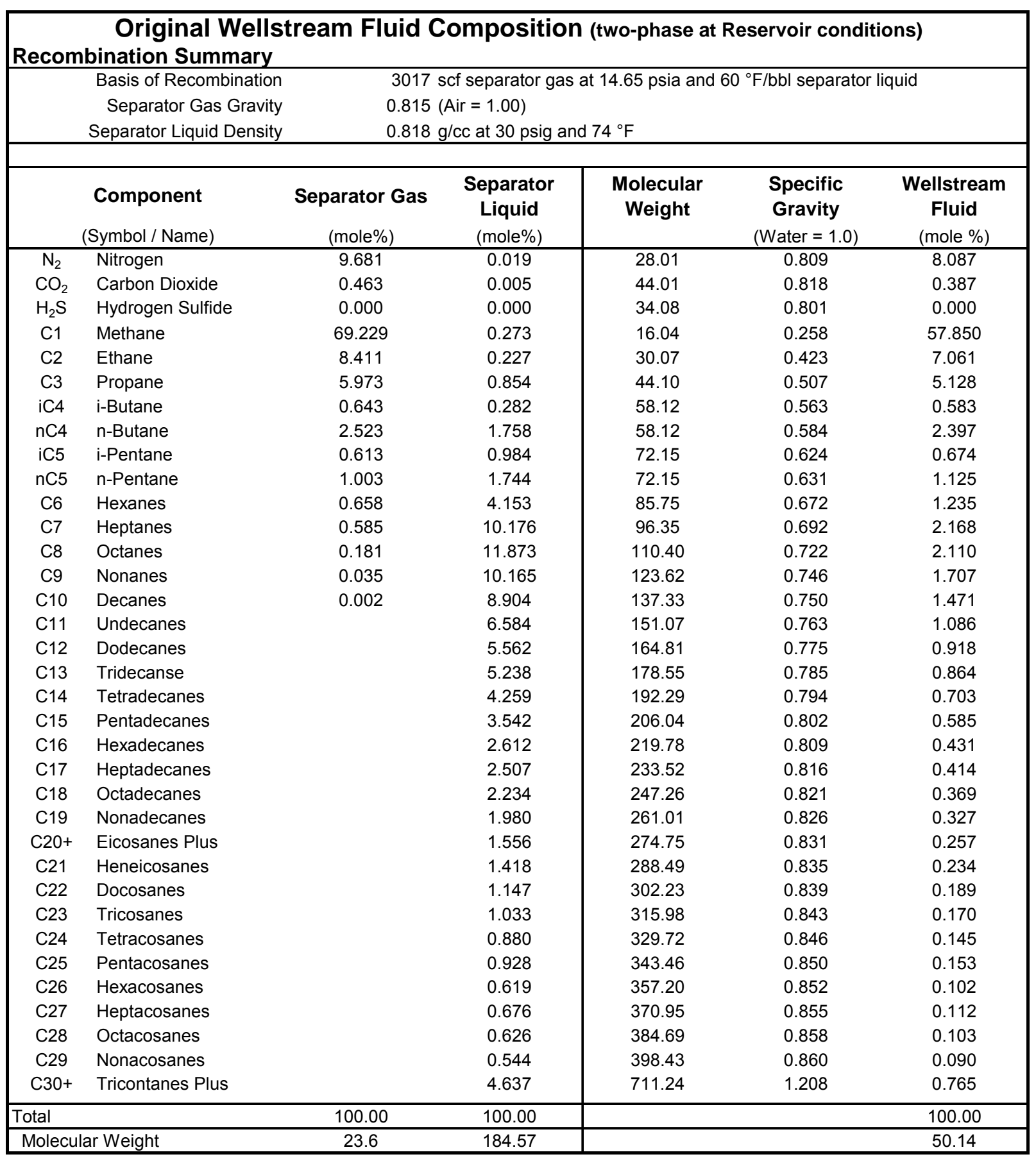


Table B4. CCE test for Morrow fluid

\begin{tabular}{|c|c|c|c|c|c|c|}
\hline $\begin{array}{c}\text { Pressure } \\
\text { (psia) }\end{array}$ & $\begin{array}{l}\text { Fluid } \\
\text { Condition }\end{array}$ & $\begin{array}{l}\text { Relative } \\
\text { Volume } \\
\left(\mathrm{V} / \mathrm{V}_{\text {sat }}\right) \\
\end{array}$ & $\begin{array}{c}\text { Gas } \\
\text { Density } \\
\left(\mathrm{g} / \mathrm{cm}^{3}\right)\end{array}$ & $\begin{array}{c}\text { Absolute } \\
\text { Liquid } \\
\text { Volume } \\
(\%) \\
\end{array}$ & $\begin{array}{c}\text { Deviation } \\
\text { Factor } \\
(\mathrm{z})\end{array}$ & $\begin{array}{c}\text { Gas } \\
\text { Viscosity } \\
\text { (cP) } \\
\end{array}$ \\
\hline 6000 & & 0.422 & 0.270 & & 1.173 & 0.032 \\
\hline 5000 & & 0.459 & 0.248 & & 1.063 & 0.029 \\
\hline 4000 & & 0.522 & 0.218 & & 0.968 & 0.025 \\
\hline 3000 & & 0.642 & 0.177 & & 0.892 & 0.020 \\
\hline 2000 & & 0.932 & 0.122 & & 0.864 & 0.016 \\
\hline 1869 & Reservoir & 1.000 & 0.114 & 0.000 & 0.866 & 0.016 \\
\hline 1600 & Two-Phase & 1.181 & & 0.028 & 0.876 & \\
\hline 1500 & $\downarrow$ & 1.268 & & 0.037 & 0.881 & \\
\hline 1400 & $\checkmark$ & 1.368 & & 0.044 & 0.887 & \\
\hline 1300 & & 1.486 & & 0.049 & 0.895 & \\
\hline 1200 & & 1.625 & & 0.053 & 0.903 & \\
\hline 900 & & 2.190 & & 0.059 & 0.921 & \\
\hline 800 & & 2.513 & & 0.060 & 0.927 & \\
\hline
\end{tabular}
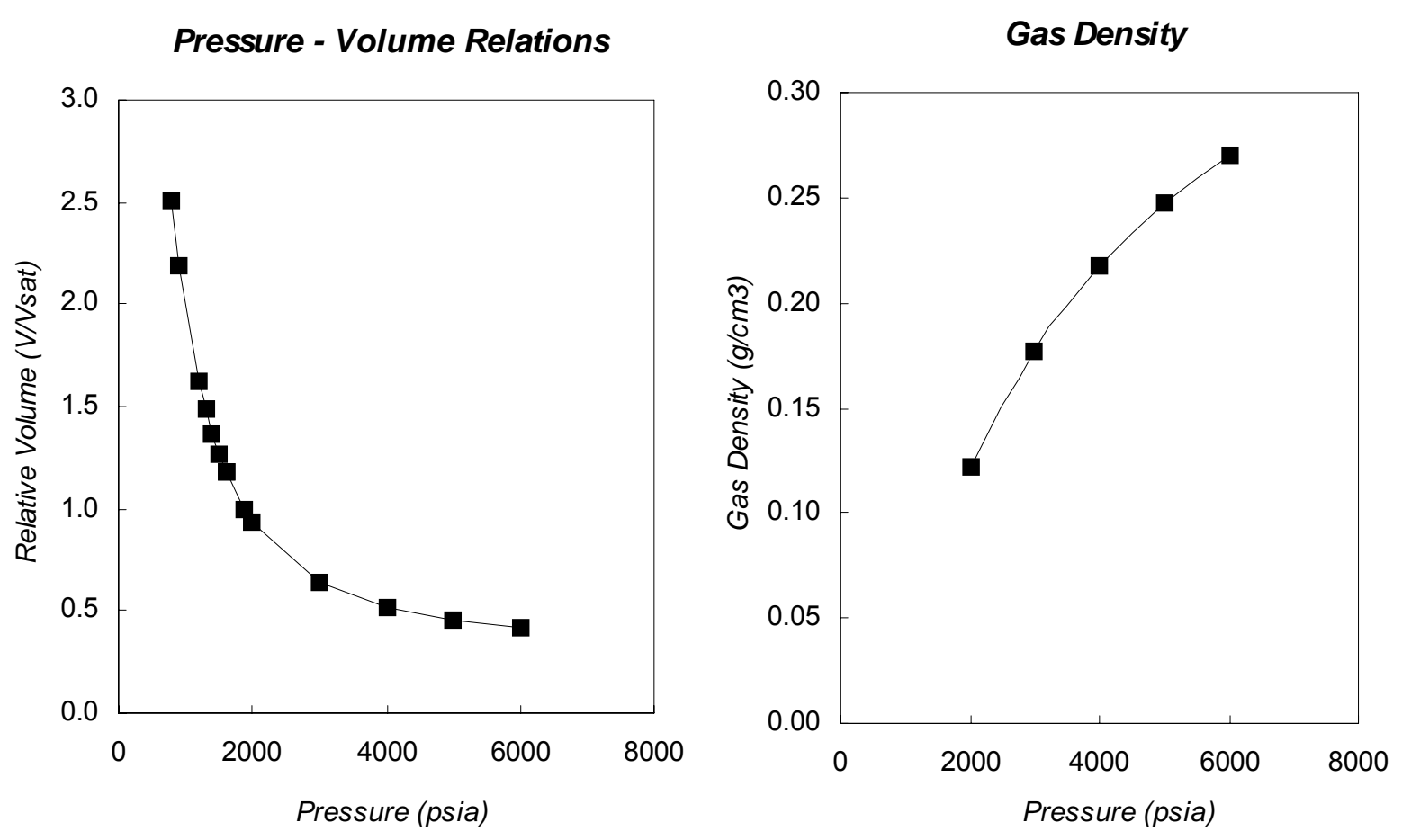

Figure B1: CCE test plots 


\section{Appendix C - Material Balance Analysis}

Table C1. CVD data for synthetic case

\begin{tabular}{|c|c|c|c|c|c|}
\hline Pressure & $\mathrm{v}$ & $\mathrm{I}$ & $\mathrm{zv}$ & $\mathrm{zl}$ & $\mathrm{z} 2 \mathrm{p}$ \\
\hline 1836 & 0 & 1 & 0.8486 & 0.746 & 0.746 \\
\hline 1627.5 & 0.3016 & 0.6984 & 0.8514 & 0.7007 & 0.74615112 \\
\hline 1438.7 & 0.3872 & 0.6128 & 0.8604 & 0.6566 & 0.73551136 \\
\hline 1231.4 & 0.4575 & 0.5425 & 0.8708 & 0.6024 & 0.725193 \\
\hline 1038.4 & 0.4929 & 0.5071 & 0.881 & 0.5449 & 0.71056369 \\
\hline 879.46 & 0.5034 & 0.4966 & 0.8897 & 0.4911 & 0.69175524 \\
\hline 754.21 & 0.5012 & 0.4988 & 0.8966 & 0.4439 & 0.67079324 \\
\hline 656.58 & 0.4931 & 0.5069 & 0.902 & 0.4036 & 0.64936104 \\
\hline 580.16 & 0.4823 & 0.5177 & 0.9062 & 0.3696 & 0.62840218 \\
\hline 519.73 & 0.4706 & 0.5294 & 0.9096 & 0.3412 & 0.60868904 \\
\hline 471.35 & 0.459 & 0.541 & 0.9122 & 0.3172 & 0.590305 \\
\hline
\end{tabular}

Table C2 Field data for East Carney region

\begin{tabular}{|c|c|c|c|c|}
\hline Well & BHP & Corrected BHP & Cumm Oil (STB) & Cumm Gas (MSCF) \\
\hline Wilson \# 1-6 & 1442.65 & 1528 & 433931 & 2080409 \\
\hline Geneva \#1-32 & 1562.26 & 1509.115 & 464794 & 2233471 \\
\hline Carney Townsite 1-5 & 1416.21 & 1482.0465 & 529877 & 2520854 \\
\hline Denney \#1-31 & 1527 & 1374.402 & 745808 & 3897744 \\
\hline Carney Townsite \#2-5 & 1435 & 1314.5995 & 869027 & 4591368 \\
\hline Geneva \#2-32 & 1115 & 1273.682 & 953516 & \\
\hline Denney \#2-31 & 1091 & 1106.8645 & 1314553 & \\
\hline
\end{tabular}


Table C3. Field data for Central East Carney region

\begin{tabular}{|c|c|c|c|c|}
\hline Well & BHP & Corrected BHP & Cumm Oil (STB) & Cumm Gas (MSCF) \\
\hline Alan Ross 1-11 & 769.4 & 655.27 & 1690477 & 388958 \\
\hline Franny 1-11 & 697.01 & 649.407 & 1736672 & 4096707 \\
\hline Pearl \#1-12 & 553.03 & 643.544 & 1736672 & 4096707 \\
\hline Lewis \#1-14 & 619.7 & 605.4345 & 1842686 & 4563392 \\
\hline Townsend \#1- & & & & 4783902 \\
\hline 13 & 516.34 & 587.8455 & 1892022 & 6795666 \\
\hline Carter \#1-14 & 298 & 412.5418 & 2233787 & \\
\hline Kathryn \#2-14 & 433.49 & 332.2187 & 2322586 & \\
\hline
\end{tabular}

Table C4. Field data for West Carney region

\begin{tabular}{|c|c|c|c|c|}
\hline Well & BHP & Corrected BHP & Cumm Oil (STB) & Cumm Gas (MSCF) \\
\hline Cal \#1-11 & 1193 & 1444.8 & 8491 & 109793 \\
\hline Griffin \#1-14 & 1598 & 1292.5908 & 15098 & 515849 \\
\hline Houser \#1-11 A & 1187 & 1265.2712 & 20768 & 658182 \\
\hline Stevenson \#1-14 & 1346.4 & 1176.4825 & 51938 & 1360511 \\
\hline Susie Q \#1-15 & 1008.76 & 1060.3742 & 118568 & 2780711 \\
\hline Steffanie \#1-15 & 1008 & 924.7519 & 197748 & 4542470 \\
\hline Jennifer \#1-10 & 656 & 865.2342 & 238724 & 5450843 \\
\hline Mr. B \#1-3 & 861 & 829.1333 & 238724 & 5450843 \\
\hline
\end{tabular}


Table C5. Field data for Central West region

\begin{tabular}{|c|c|c|c|c|}
\hline Well & BHP & Corrected BHP & Cumm Oil (STB) & Cumm Gas (MSCF) \\
\hline Schwake \#1-10 & 1509.62 & 1561.8 & 906417 & 6169676 \\
\hline Garrett 1-11 & 1385.02 & 1547.962 & 906417 & 6169676 \\
\hline Mary Marie \#1-11 & 1399.78 & 1511.48 & 988686 & 6748538 \\
\hline Wilkerson \#1-3 & 1535.75 & 1493.868 & 171141 & 7254694 \\
\hline Toles \#1-10 & 1307.1 & 1466.192 & 171141 & 7254694 \\
\hline Parkview \#1-3 & 1685.64 & 1462.418 & 171141 & 7254694 \\
\hline Christy 1-15 & 1475.75 & 1451.096 & 1189727 & 7812124 \\
\hline McBride North \#1-10 & 1607.09 & 1430.968 & 1189727 & 7812124 \\
\hline Danny 1-34 & 1344.04 & 1412.098 & 1306570 & 8481249 \\
\hline Ables 1-34 & 1532.51 & 1395.744 & 1306570 & 8481249 \\
\hline Henry \#1-3 & 1610.57 & 1389.454 & 1452336 & 9236998 \\
\hline Mary Marie \#2-11 & 1384 & 1368.068 & 1452336 & 9236998 \\
\hline Danny 2-34 & 1164 & 1356.746 & 1616943 & 9236998 \\
\hline Joe Givens \#1-15 & 1078 & 1301.394 & 1780124 & 10054662 \\
\hline Williams \#1-3 & 1510 & 1278.75 & 1780124 & 11628664 \\
\hline McBride South \#1-10 & 1277 & 1251.074 & 1959159 & 13310743 \\
\hline Boone \#1-4 & 1332 & 1228.43 & 2137428 & 15040818 \\
\hline Wilkerson \#2-3 & 1195 & 1139.112 & 2626538 & 17410895 \\
\hline Carter Ranch \#2-15 & 1007 & 1014.57 & 3230124 & 20891802 \\
\hline JB \#1-13 & 733 & 922.736 & 3789028 & 23568449 \\
\hline Saunders \#1-13 & 925 & 891.286 & 3947709 & 24864835 \\
\hline Points \#1-13 & 544 & 872.416 & 3947709 & 27149522 \\
\hline Gilmore Price Horizontal \#1-33 & 892 & 775.55 & 4211862 & 30521472 \\
\hline Rollins \#1-13 & 281 & 191.838 & 5142326 & 42114356 \\
\hline
\end{tabular}


Table C6. 2-Phase Z Factors CVD Data

\begin{tabular}{|c|c|c|c|c|c|}
\hline Pressure & $\mathbf{v}$ & I & $\overline{Z I}$ & Zv & Z2p \\
\hline 1838 & 0 & 1 & 0.746 & 0.8486 & 0.746 \\
\hline 1800 & 0.0825 & 0.9175 & 0.7378 & 0.8433 & 0.74650375 \\
\hline 1750 & 0.1444 & 0.8556 & 0.7272 & 0.8457 & 0.7443114 \\
\hline 1700 & 0.1909 & 0.8091 & 0.7165 & 0.848 & 0.74160335 \\
\hline 1650 & 0.2295 & 0.7705 & 0.7056 & 0.8503 & 0.73880865 \\
\hline 1600 & 0.2621 & 0.7379 & 0.6945 & 0.8526 & 0.73593801 \\
\hline 1550 & 0.29 & 0.71 & 0.6831 & 0.855 & 0.732951 \\
\hline 1500 & 0.3143 & 0.6857 & 0.6714 & 0.8573 & 0.72982837 \\
\hline 1450 & 0.3355 & 0.6645 & 0.6593 & 0.8597 & 0.7265342 \\
\hline 1400 & 0.3541 & 0.6459 & 0.6469 & 0.8622 & 0.72313773 \\
\hline 1350 & 0.3706 & 0.6294 & 0.6342 & 0.8646 & 0.71958624 \\
\hline 1300 & 0.3852 & 0.6148 & 0.621 & 0.8671 & 0.71579772 \\
\hline 1250 & 0.3982 & 0.6018 & 0.6075 & 0.8697 & 0.71190804 \\
\hline 1200 & 0.4098 & 0.5902 & 0.5934 & 0.8722 & 0.70765224 \\
\hline 1150 & 0.4201 & 0.5799 & 0.5789 & 0.8748 & 0.70320759 \\
\hline 1100 & 0.4292 & 0.5708 & 0.5639 & 0.8775 & 0.69849712 \\
\hline 1050 & 0.4372 & 0.5628 & 0.5483 & 0.8801 & 0.69336296 \\
\hline 1000 & 0.4441 & 0.5559 & 0.5322 & 0.8828 & 0.68790146 \\
\hline 950 & 0.4501 & 0.5499 & 0.5154 & 0.8854 & 0.681937 \\
\hline 900 & 0.4552 & 0.5448 & 0.4981 & 0.8881 & 0.675628 \\
\hline 850 & 0.4594 & 0.5406 & 0.48 & 0.8909 & 0.66876746 \\
\hline 800 & 0.4627 & 0.5373 & 0.4613 & 0.8936 & 0.66132521 \\
\hline 750 & 0.465 & 0.535 & 0.4417 & 0.8963 & 0.653089 \\
\hline 700 & 0.4665 & 0.5335 & 0.4214 & 0.8991 & 0.64424705 \\
\hline 650 & 0.467 & 0.533 & 0.4003 & 0.9018 & 0.6345005 \\
\hline 600 & 0.4665 & 0.5335 & 0.3782 & 0.9046 & 0.6237656 \\
\hline 550 & 0.465 & 0.535 & 0.3552 & 0.9074 & 0.611973 \\
\hline 500 & 0.4624 & 0.5376 & 0.3311 & 0.9101 & 0.5988296 \\
\hline 450 & 0.4586 & 0.5414 & 0.3059 & 0.9128 & 0.58422434 \\
\hline 400 & 0.4535 & 0.5465 & 0.2795 & 0.9155 & 0.567926 \\
\hline 350 & 0.447 & 0.553 & 0.2519 & 0.9182 & 0.5497361 \\
\hline 300 & 0.4391 & 0.5609 & 0.2228 & 0.9207 & 0.52924789 \\
\hline 250 & 0.4298 & 0.5702 & 0.1922 & 0.9232 & 0.5063838 \\
\hline 200 & 0.4197 & 0.5803 & 0.1599 & 0.9255 & 0.48122232 \\
\hline 150 & 0.411 & 0.589 & 0.1256 & 0.9278 & 0.4553042 \\
\hline 100 & 0.4115 & 0.5885 & 0.089 & 0.9307 & 0.43535955 \\
\hline
\end{tabular}

